\title{
Environmental Assessment of the Thermal Neutron Activation Explosive Detection System for Concourse Use at U.S. Airports
}

Manuscript Completed: February 1990

Date Published: August 1990

C. G. Jones

Division of Industrial and Medical Nuclear Safety Office of Nuclear Material Safety and Safeguards U.S. Nuclear Regulatory Commission

Washington, DC 20555

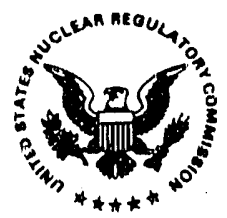




\begin{abstract}
This document is an environmental assessment of a system designed to detect the presence of explosives in checked airline baggage or cargo. The system is meant to be installed at the concourse or lobby ticketing areas of U.S. commercial airports and uses a sealed radioactive source of californium-252 to irradiate baggage items.

direct exposure of the public to scattered or leakage radiation from the source and to induced radioactivity in baggage items. Under normal operation and the most likely accident scenarios, the environmental impacts that would be created by the proposed licensing action would not be significant.
\end{abstract} The major impact of the use of this system arises from 


\section{Contents}

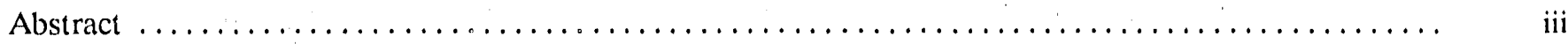

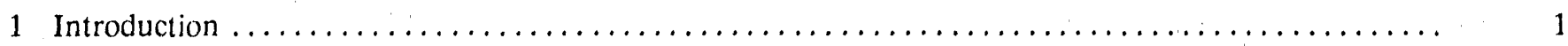

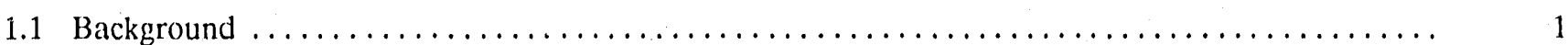

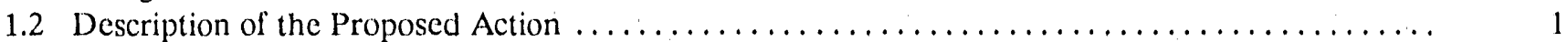

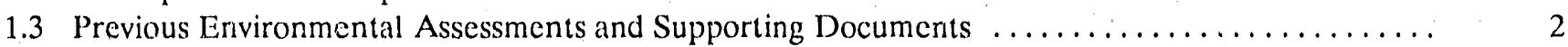

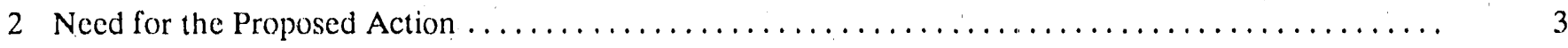

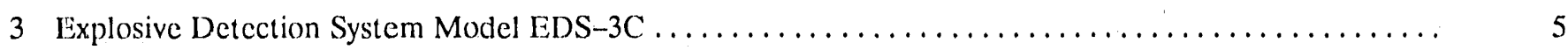

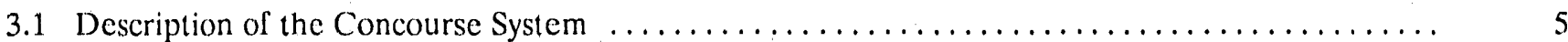

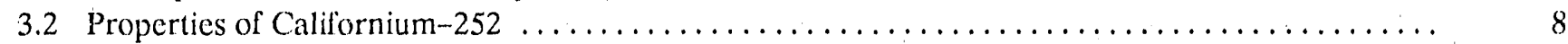

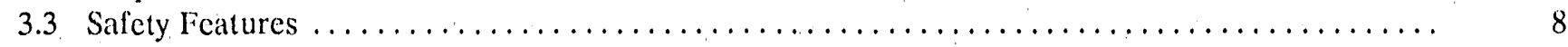

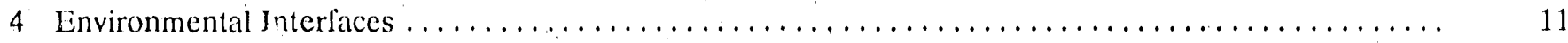

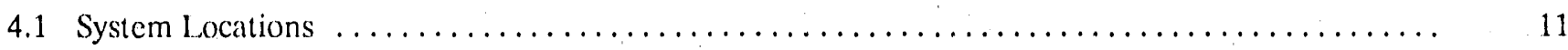

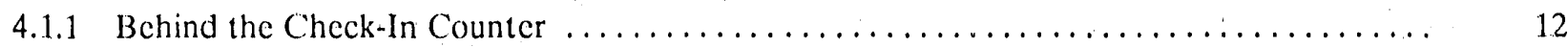

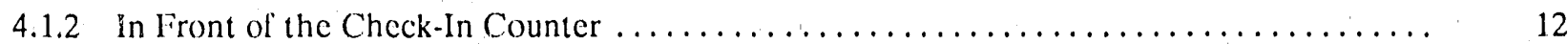

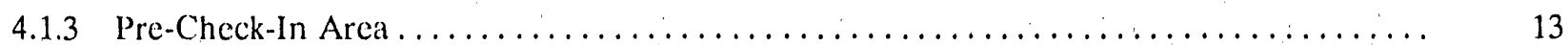

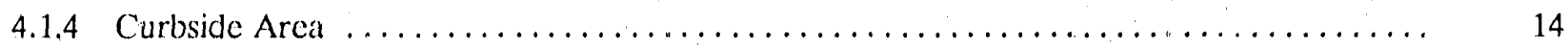

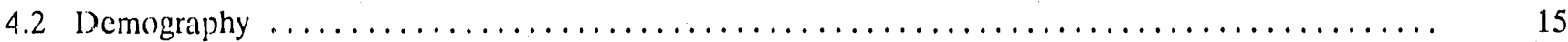

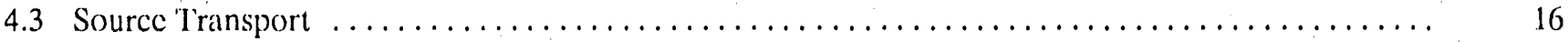

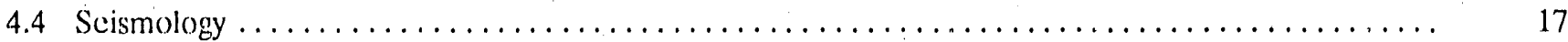

5 Environmental Impacts of the Proposed Action $\ldots \ldots \ldots \ldots \ldots \ldots \ldots \ldots \ldots \ldots \ldots \ldots \ldots \ldots \ldots \ldots \ldots$

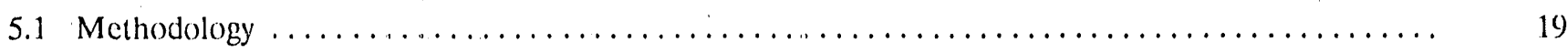

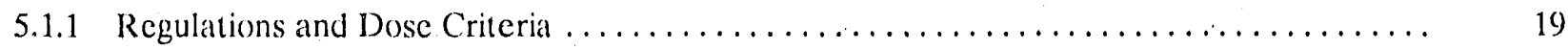

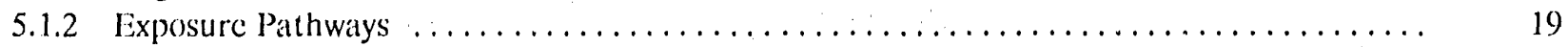

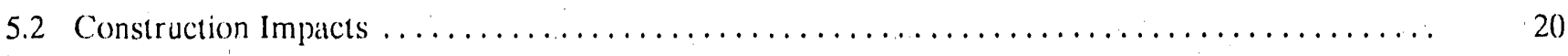

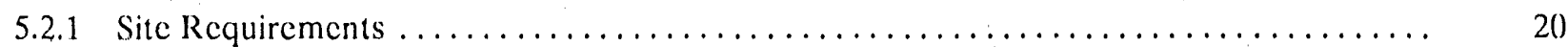

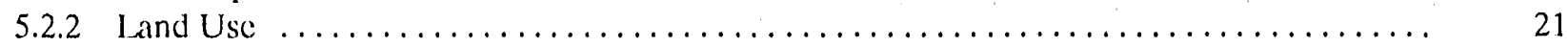

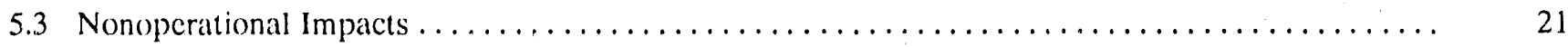

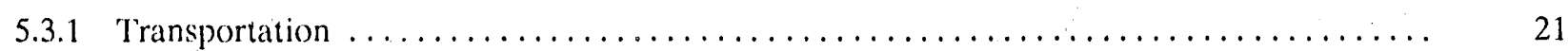

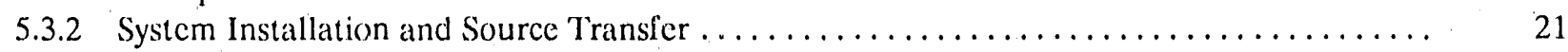

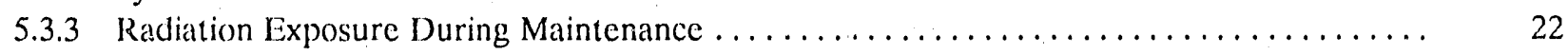

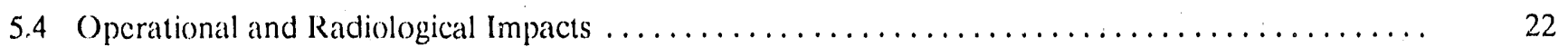

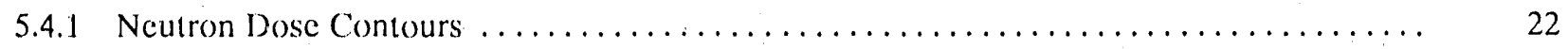

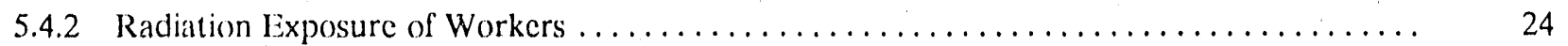

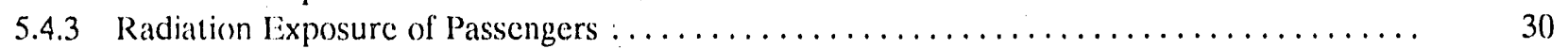

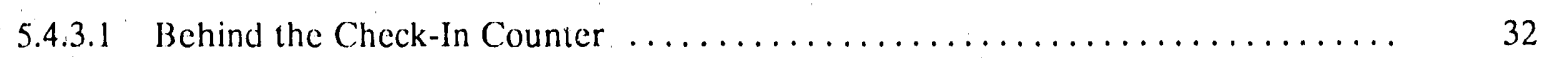

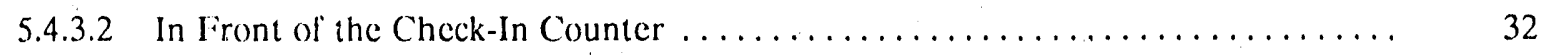

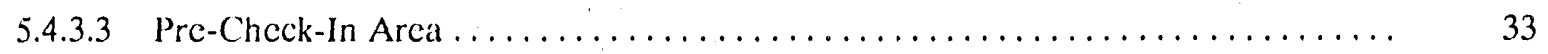

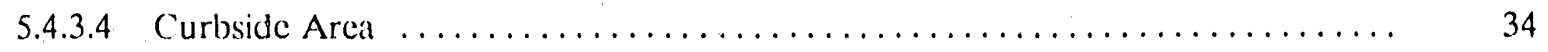

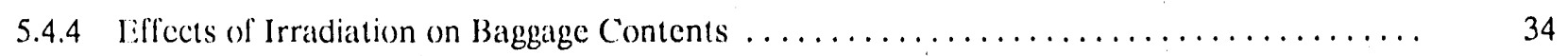

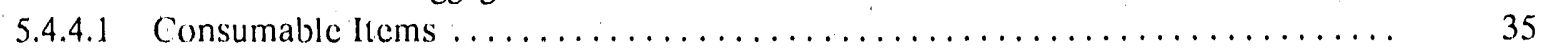

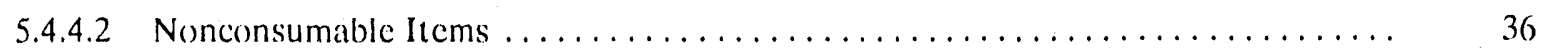




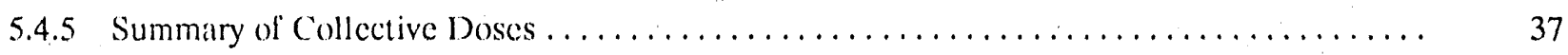

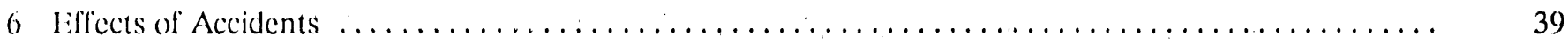

6.1 Source-Transter Accidents . . . . . . . . . . . . . . . . . . . . . . . . . . . . . . . . 39

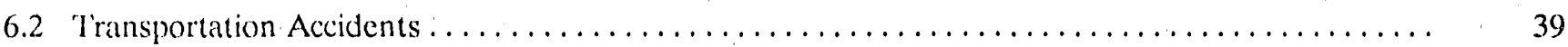

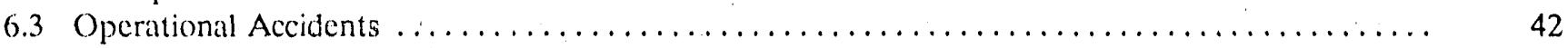

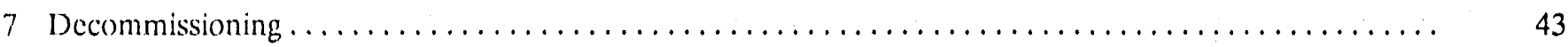

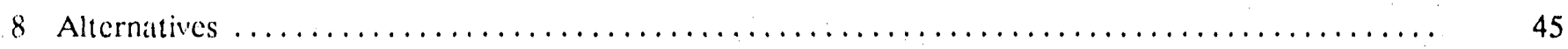

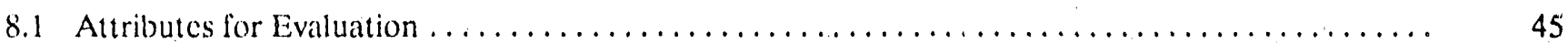

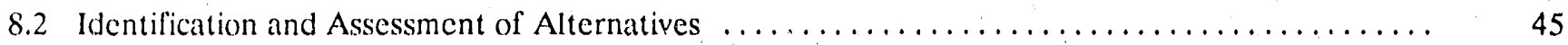

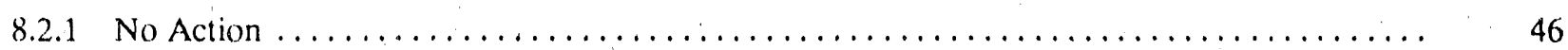

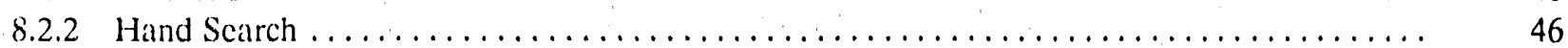

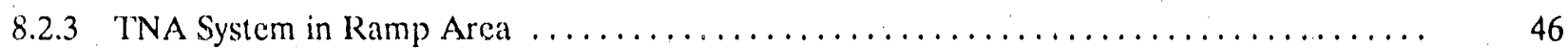

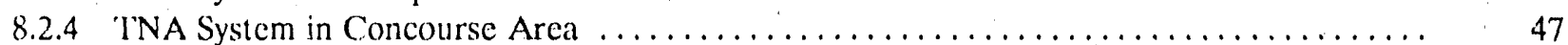

8.2 .5 INA System With Enhanced Radiation Protection ..................... 47

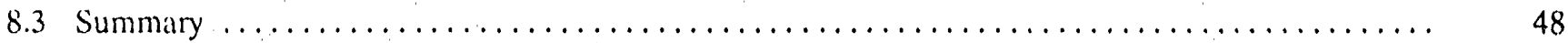

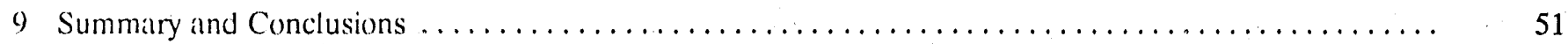

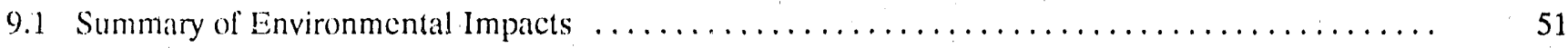

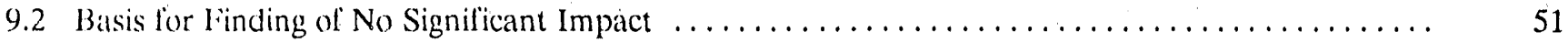

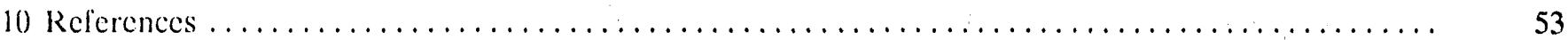

\section{Appendices}
A Installation and Radiation Safety Operating Procedures for EDS-3C
B Tables in English System of Units Corresponding to Tables in Sections 5 and 6
C. Dose Rate and Fluence Information for liDS-3C
1) National Institute of Standards and 'Technology Report on T'NA System

\section{Figures}

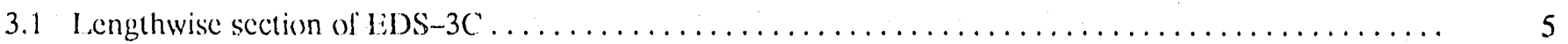

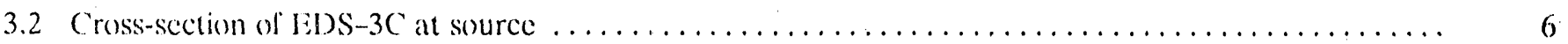

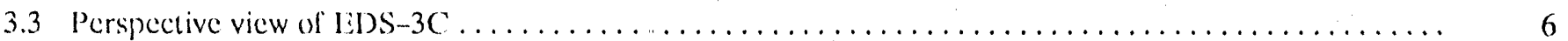

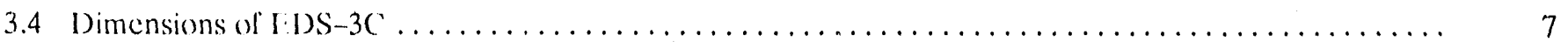

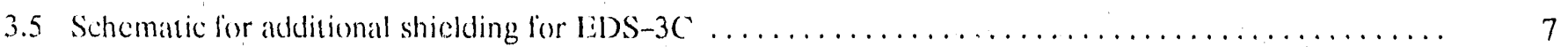

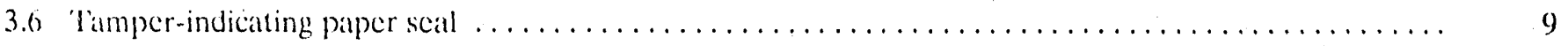

4.1 TNA explosive detection system with XIENIS and diverter $\ldots \ldots \ldots \ldots \ldots \ldots \ldots \ldots \ldots \ldots \ldots \ldots$

4.2 Behind the check-in counter--proposed setup for United Airlines at San lirancisco

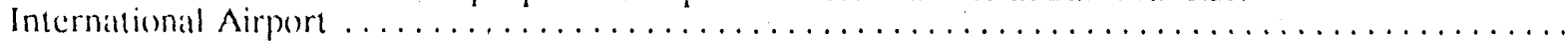




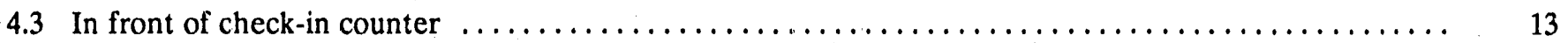

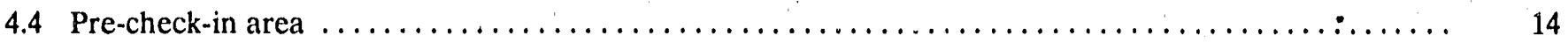

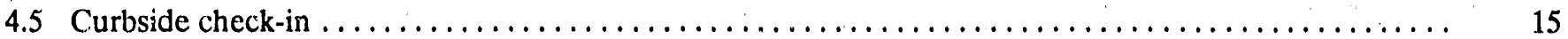

4.6 Barrier system to protect TNA operating personnel, passengers, and others from intrusion

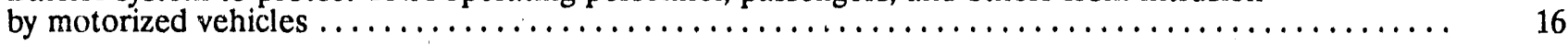

5.1 Proposed EDS-3C at Dulles International Airport $\ldots \ldots \ldots \ldots \ldots \ldots \ldots \ldots \ldots \ldots \ldots \ldots \ldots \ldots \ldots \ldots \ldots \ldots$

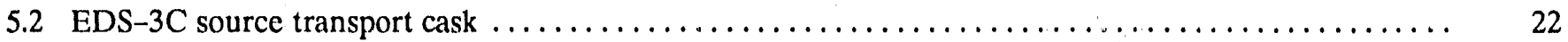

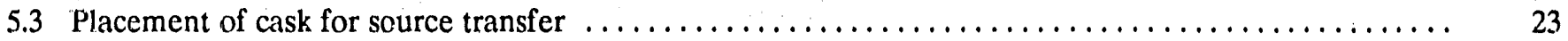

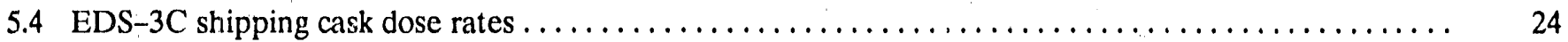

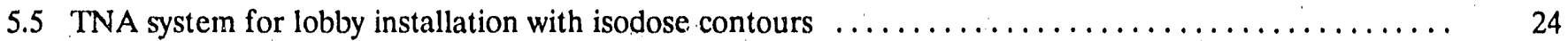

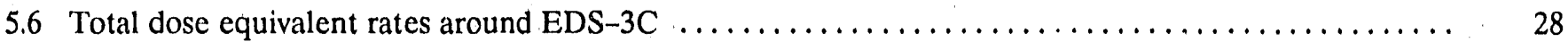

6.1 Isodose contours for source wedged at interface of cask and EDS-3C $\ldots \ldots \ldots \ldots \ldots \ldots \ldots \ldots$

\section{Tables}

5.1 Potential activation products (for slow neutrons) of baggage contents containing

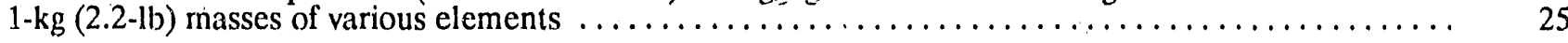

5.2 Potential activation products (for fast neutrons) of baggage contents containing

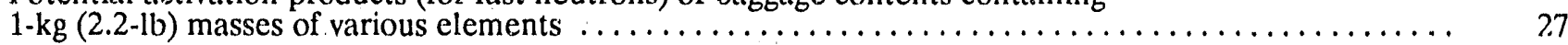

5.3 Major activation products of baggage contents containing 1-kg (2.2-1b) masses of

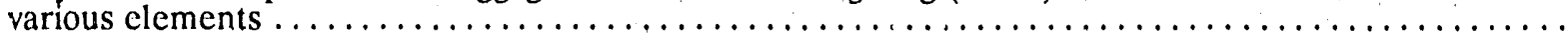

5.4 Calculated beta dose to the skin from a $3.7 \times 10^{4} \mathrm{~Bq} / \mathrm{cm}^{2}$ source $\ldots \ldots \ldots \ldots \ldots \ldots \ldots \ldots \ldots \ldots \ldots$

5.5 Elemental composition of the contents of an aluminum suitcase $\ldots \ldots \ldots \ldots \ldots \ldots \ldots \ldots \ldots \ldots \ldots$

5.6 Gamma dose rates from EDS-3C activation of the contents of an aluminum suitcase $\ldots \ldots \ldots \ldots \ldots . . .31$

5.7 Committed effective dose equivalent from daily intakes of elements 1 hour after

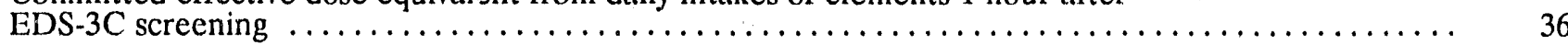

5.8 Age dependence of sodium intake and dose conversion factors (specific activity of

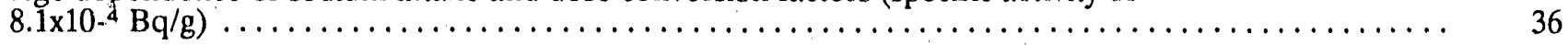

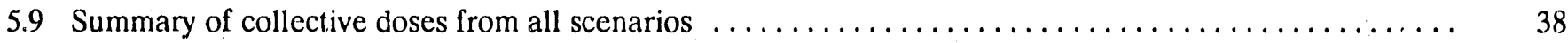

5.10 Summary of annual individual doses from all scenarios $\ldots \ldots \ldots \ldots \ldots \ldots \ldots \ldots \ldots \ldots \ldots \ldots \ldots$

6.1 Maximum potential dose equivalent rates from one $150-\mu \mathrm{g}$ Cf-252 source following a

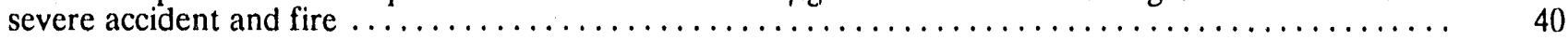

6.2 Offsite concentrations [at $50 \mathrm{~m}(54 \mathrm{yd})]$ of airborne releases for various fractions of $\mathrm{Cf}-252 \ldots \ldots \ldots \ldots$

6.3 Annual inhalation dose to the nearest individual $50 \mathrm{~m}$ ( $54 \mathrm{yd}$ ) away from postulated

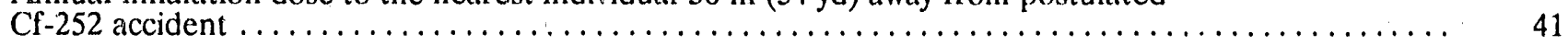

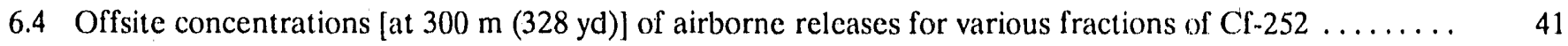

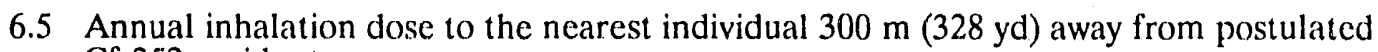

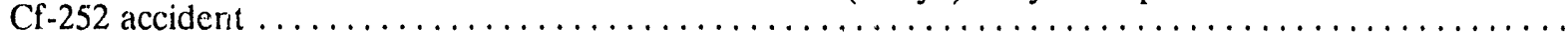


7.1 Major constituents of concrete and long-term activation products $\ldots \ldots \ldots \ldots \ldots \ldots \ldots \ldots \ldots .43$

8.1 Construction costs for curbside and indoor EDS-3C installations $\ldots \ldots \ldots \ldots \ldots \ldots \ldots \ldots \ldots . \ldots$

8.2 Value-impact summary for airline explosive detection alternatives $\ldots \ldots \ldots \ldots \ldots \ldots \ldots \ldots \ldots . \quad 49$ 


\section{INTRODUCTION}

\subsection{Background}

The Federal Aviation Administration (FAA) became involved in developing an efficient explosive detection system in the mid-1960s. Development efforts were initially based on various technologies including vapor detection by olfactory (e.g., canines) and instrumental (chromatography) means, $x$ ray radiography, and several nuclear methods. Although several of these technologies ap. peared promising, none of the early efforts yielded satisfactory results.

As a result of a rash of hijacking incidents in the early 1970s, Congress recognized the need to increase the overall security of the U.S. airspace and airport system. In the Anti-Hijacking Act of 1974, Public Law 93-366, FAA was assigned the responsibility for research and development in aviation sccurity. In the late 1970s and 1980s, FAA sponsored several programs to develop and demonstrate a prototype explosive detection system using thermal neutron activation (TNA) analysis. The initial attempts at developing prototype systems showed that explosive detection using TNA analysis was technically feasible, but scanning times were too long for practical applications.

In September 1985, FAA awarded Science Applications International Corporation (SAIC) a contract to develop a second-generation, improved TNA explosive detection system (EDS) that could screen a larger number of bags and, in general, was more suitable for the operational screening of baggage (SAIC, 1988). Since 1985, one demonstration prototype and six other smaller production models have been, or are in the process of being, built for FAA. To test the explosive detection capabilities of these models, simulated explosives whose elemental composition and shape and, therefore, system respense were similar to those of actual explosives specified by FAA were used. These simulated explosives have been valiunted by tests in the laboratory by comparing them with attual explosives (SAIC, 1988). Tests of the latest product ion model, EDS-3, showed that the system could clear all $t$ ut 3 to 5 percent of the bags that did not contain explosives.

In 1988, the U.S. Nuclear Regulatory Commission (Commission or NRC) began assessing the environmental effects of installing and operating the prototype TNA system (Model EDS-2) at the ramp level of an airport. This included assessing scenarios for possible internal exposure of both workers and passengers, possible exposure of passengers or other members of the public who may consume irradiated food items packed in luggage, anticipated radiation doses, possible exposure resulting from malfunctions of the 'INA system, and several types of plausible accidents. In lebruary 1989, the NRC issued a license to FAA to use the prototype on the ramp level of interna- tional airports. SAIC developed Model EDS-2, which was originally designed as a one-of-a-kind prototype, into the current production system (Model EDS-3), which optimizes radiation levels, cost, bulk, weight, and complexity. This system, licensed for ramp use in August 1989, uses less than half the amount of californium-252 (Cf -252$)$ and only one-quarter the radiation shiclding than did the original prototype.

The findings of the NRC environmental assessments associated with these two models were summarized and published in the Federal Register (54 FR 33636) on August 15, 1989 (NRC, 1989). The NRC concluded that the environmental effects of normal use of the TN.A system in baggage- or cargo-handling ramp areas would be insignificant.

\subsection{Description of the Proposed Action}

By letter dated August 22,1989, FAA (the licensce) submitted a proposed amendment to its existing NRC License No. 29-13141-05 to operate a TNA explosive detection system for routine screening of checked baggage in the lobby or concourse arcas of international airports. For concourse installations, additional shielding is added onto the sides of the EDS-3 near the source, underneath the outer pancls (see Section 3.1). This new TNA system has been designated as EDS-3C and has been issued Certificate of Registration CA-590-D-118-S (California Department of Health Services, 1990). It is estimated that these systems (or their equivalent) will be installed at more than 200 major airports in the next 5 years and will be used to screen luggage on international flights (U.S. Department of Transportation, 1989). The term "concourse area" refers to the area that is used in conjunction with passenger ticketing and baggage check-in operations and is usually located in the main icrminal area. The proposed action involves the following:

(1) Modification of existing concourse areas (or construction of new ones) to allow installation of an EDS-3C. If existing concourse space is insufficient, this could include additional construction of structural supports or the rebuilding of the ticketing arcas for operation of the system.

(2) Installation of one $\mathrm{Cl}-252$ source in an EDS-3C, containing 150 micrograms $(\mu \mathrm{g}) \mid 80$ millicuries (mCi)|. 'I'his includes transportation of the source within a shielded cask to the EDS-3C from outside the airport.

Since most systems will be placed in existing airport facilities, each site will differ in terms of site-specilic considerations, such as distanees from the ticket counters to the EDS-3C, occupancy statistics in the airport, number of 
passengers, waiting time for tickets and boarding passes, and vehicular traffic. For this assessment, actual design and construction information from six international airports in this country was used to crcate a "model airport" for calculating radiation dose and estimating the effect of possible accident scenarios.

\subsection{Previous Environmental Assessments and Supporting Documents}

Several environmental docluments have been prepared that are specific for the previous FAA license application for SAIC Modeis EDS-2 and EDS-3. FAA submitted an cnvironmental report in support of the first prototype device in February 1988 and a revised report for public release in June 1988. In September 1988, Idaho National
Engineering Laboratory (INEL) assessed for the NRC the environmental effects of the EDS-2 in the "Environmental Assessment for Explosive Detection Systems Using Thermal Neutron Activation for Airline Baggage Inspection" (INEL, 1988). On August 15, 1989, the NRC staff published a Finding of No Significant Impact in the Federal Register (54 FR 33636), which provided the evaluation and summary of the environmental effects of using the EDS-3 at the ramp levels of airports (NRC, 1989). Finally, SAIC submitted to the NRC an environmental report related to the proposed EDS-3C for concourse installation in October 1989 and a revised report in response to NRC questions in December 1989' (SAIC, 1989). For further technical details with respect to previous assessments, see the documents that are contained in Docket Number 030-30885 at NRC's Region I Public Document Room, 475 Allendale Road, King of Prussia, Pennsylvania 19406. 


\section{NEED FOR THE PROPOSED ACTION}

The need for improved baggage security persists. Since 1985 , more than 425 lives have been lost, several aircraft have been destroyed, and international commerce has been disrupted. The nature of the security threat today is far different from (and far more dangerous than) that in the early 1970s when screening of passengers and luggage first began. Previously, the primary threat was hijacking. Currently, it is sabotage by international terrorists seek. ing to influence the behavior of governments through acts of violence against commercial aviation (U.S. House of Representatives, 1989).

Although the first six TNA systems are owned and operated by FAA, the subsequent widespread use of these systems would be by the airline carriers rather than FAA. On September 5, 1989, FAA published a final rule that would require, by amendment under Section 108.25 of Title 14 of the Code of Federal Regulations (14 CFR), that each aitline carrier use an explosive detection system that has been approved by the FAA Administratc $r$ to screen checked baggage on international flights (ste U.S. Department of 'Transportation, 1989). So far, the only explosive detection systems that have been appruved are Science Applications International Corporation (SAIC) Models EDS-3 and EDS-3C. Once this r ule is enforced, an estimated 200 to 400 TNA system: will have to be licensed in both this country and abroad. FAA, in its continuing program to collect operating data in various airport environments, has requested the NRC to evaluate the TNA system in one of four possible areas on the concourse level of airports: (1) behind the check-in precounter, (2) in front of the check-in counter, (3) at a check-in area, and (4) at a curbside location near the concourse level.

Even though the EDS-3 is currently licensed for use at the ramp level of airports where baggage is sorted for loading aboard planes and has been shown to have a high sensitivity for detecting explosives in baggage, there has b'en some difficulty in resolving lalse positive ("nuisince" or "false") alarms on a small percentage of all bags inspected. These alarms are presumed to be real until they are proven to be false. Various methods are used for resolving the problem of false alarms, but the method currently used is to open and hand search the bag, which (under FAA regulations) must be done in the presence of the passenger. At John F. Kennedy (JIK ) International Airport, where the EDS-3 has been in operation since September 1989, the only way to do this is by paging and locating the passenger in the terminal, having the passenger come to the TNA area, and hand inspecting the luggage in question. At JFK Airport, it has taken up to 1 hour to locate a passenger and resolve the alarm problem At many proposed airport sites, the only practical way to screen luggage for explosives is to locate the system so that it is near the area where the baggage is checked in (at the concourse level) so that the passenger is immediately available to give his or her consent to open bags that cause an alarm. This environmental assessment addresses the expected environmental effects associated with the proposed operation of and the construction that might be necessary for SAIC Model EDS-3C at concourse locations of international airports in the United States. 


\section{EXPLOSIVE DETECTION SYSTEM MODEL EDS-3C}

\subsection{Description of the Concourse System}

Model EDS-3C is shown in Figures 3.1 and 3.2. Baggage is loaded onto a conveyor, passes over one source containing $150 \mu \mathrm{g}(80 \mathrm{mCi})$ of callifornium-252 (Cf-252), and then leaves the system at the opposite end. The Cf-252 doubly encapsulated scaled source is located inside a moderated assenibly containing heavy-metal panels to shield against the direct gamma rays from the source. The principle of operation is based on the property of nuclei of elements in baggage absorbing the moderated neutrons and emitting gamma rays with energies characteristic of a particular element, such as nitrogen, which is a major constituent of all common explosives. By using many detectors and acquiring data in short time slices, the system is able to generate an image of the nitrogen distribution. The highnitrogen density allows the system to distinguish explosives from benign high-nitrogen materials like wool or silk.

Figure 3.3 shows the EDS-3C completely assembled with the exterior panels. The merhanical structure is made of aluminum channels and beams welded together, with a welded-on outer shell of 5-mm (3/16-in.) aluminum. Aluminum was chosen because of its low interaction rate with neutrons and therefore minor production of activation gamma rays, as compared with other choices such as steel. The structure is filled with moderators of low atomic number (mainly paraflin loaded with boric acid) and is then cast into place. Sheet metal panels, not shown on the sertion drawings, cover the entire system for cosmetic purposes.

The TNA system consists of three major pieces of equipment: the diverter, the XENIS ( $x$ ray enhanced neutron inspection system), and the EDS-3C. 'The EDS-3C is the only piece that is too heavy to be placed directly on the floor without supplemental structural support. The overall area needed for the installation of the EDS-3C, the diverter, and the XENIS is approximately $41 \mathrm{~m}^{2}\left(438 \mathrm{ft}^{2}\right)$.

The TNA system consists of three modular sections with a gross weight of $12,700 \mathrm{~kg}(28,000 \mathrm{lb})$ to facilitate transportation. The end sections weigh $2,720 \mathrm{~kg}(6,000 \mathrm{lb})$ each, are supported on four legs, and impose a uniform load of 17 kilopascals ( $\mathrm{kPa}$ ) [353 pounds per square foot (psi)] on the floor area below the unit. The ecnter section weighs $7,260 \mathrm{~kg}(16,000 \mathrm{lb})$, is supported on eight legs, and imposes a uniform load of approximately $22.4 \mathrm{kPa}$ (467 pst) on the floor area below the system. These three sections are secured together at each installation site before the source is inserted. Figure 3.4 shows the dimensions of Model EDS-3C. For concourse installations, additional shiclding is added on the sides of the system near the source, underncath the outer panels (Figure 3.5). This model (EDS-3C) has additional shiclding consisting of plates of lead $[0.64-\mathrm{cm}(1 / 4-i n$.$) thick ]$ and polyethylene approximately $2.5-\mathrm{cm}(1-$ in.) thick]. These plates occupy hollow spaces in the outer panels, which are made of

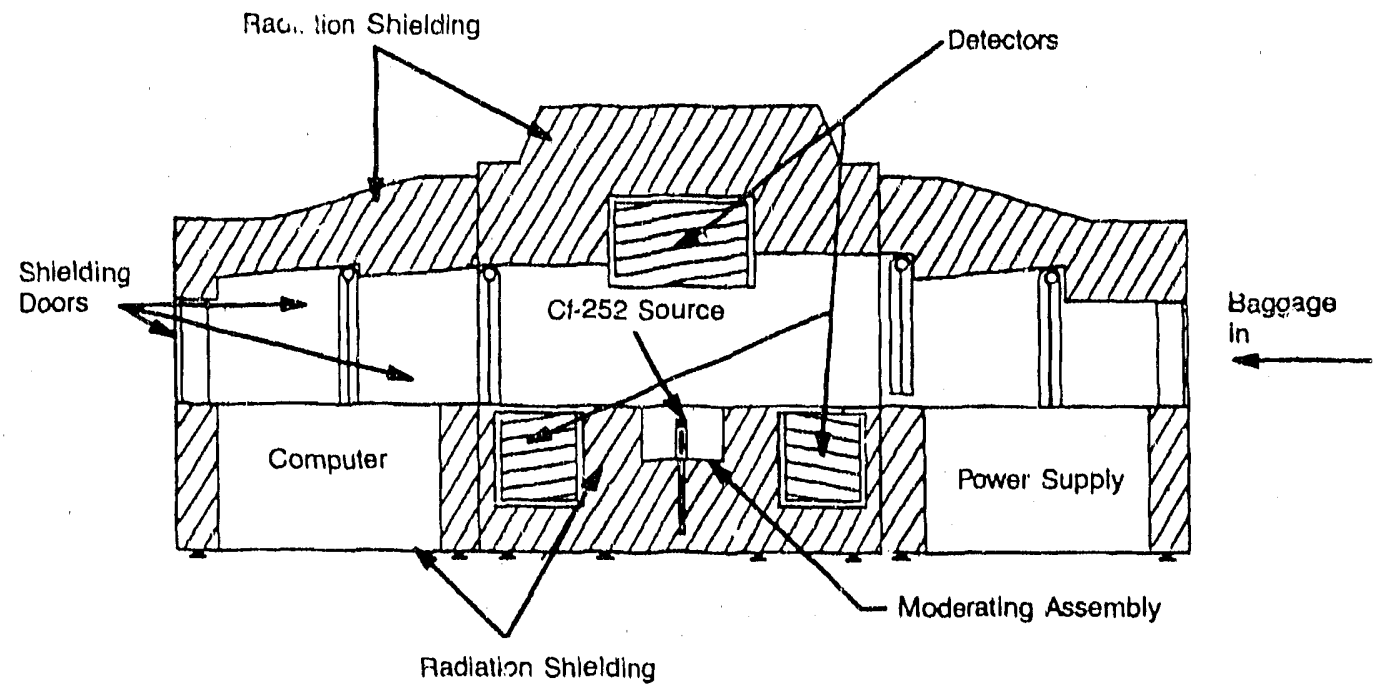

I ïgure 3.1 1 engthwise section of EDS-3C 


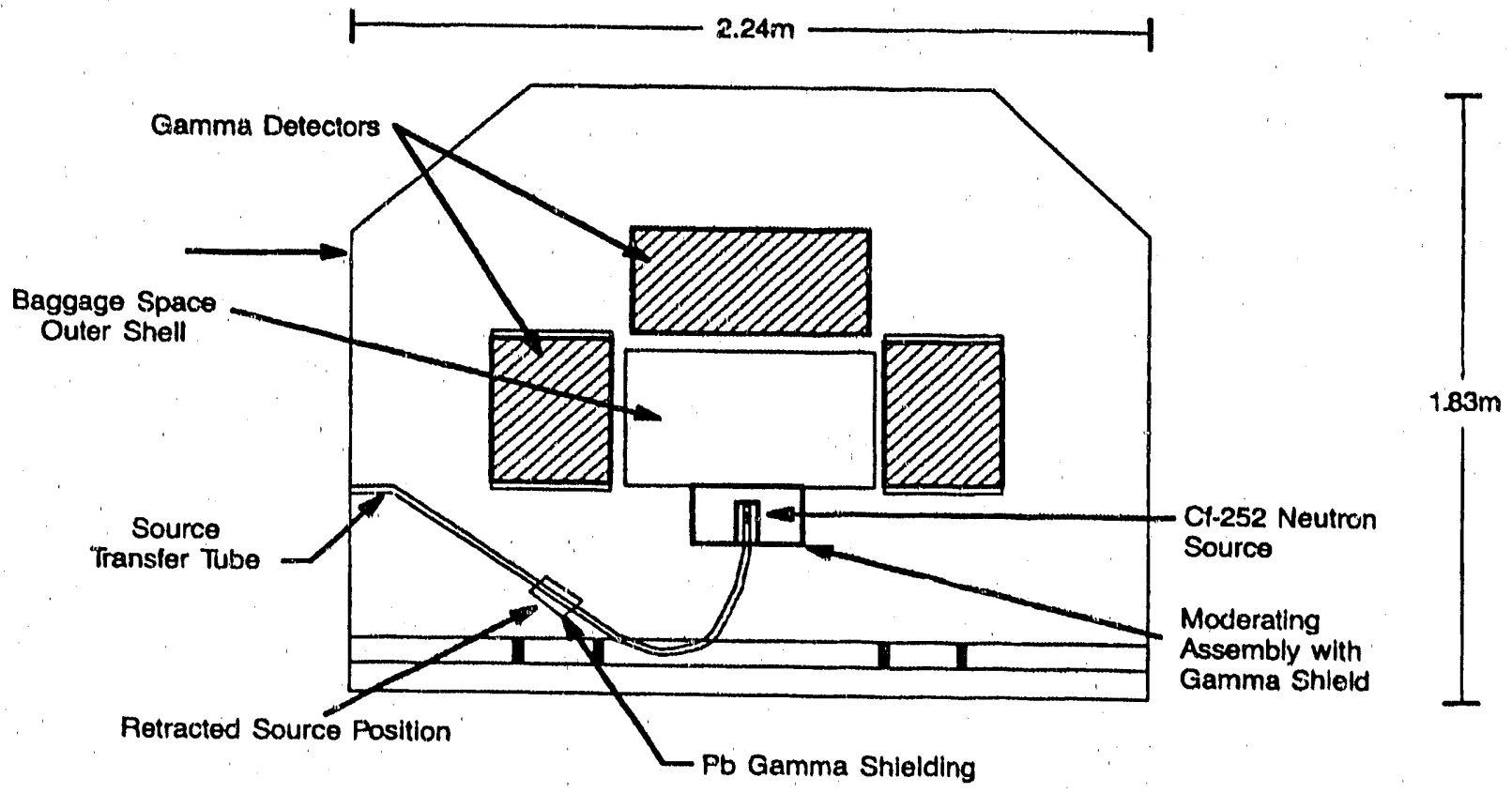

Figure 3.2 Cross-section of EDS-3C at source

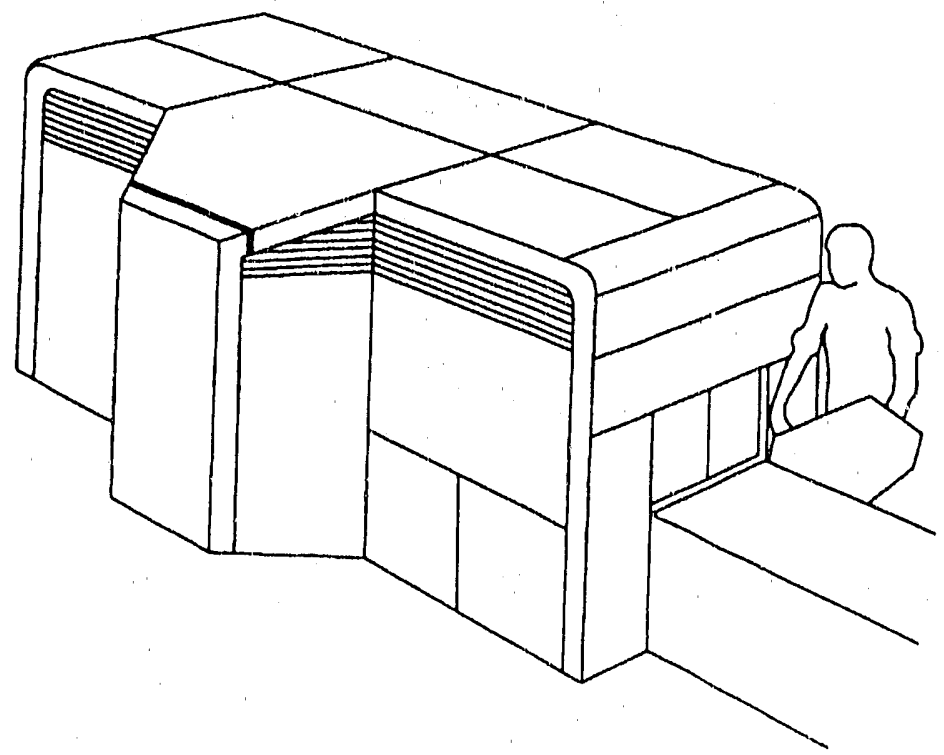

Figure 3.3 Perspective view of EDS-3C 


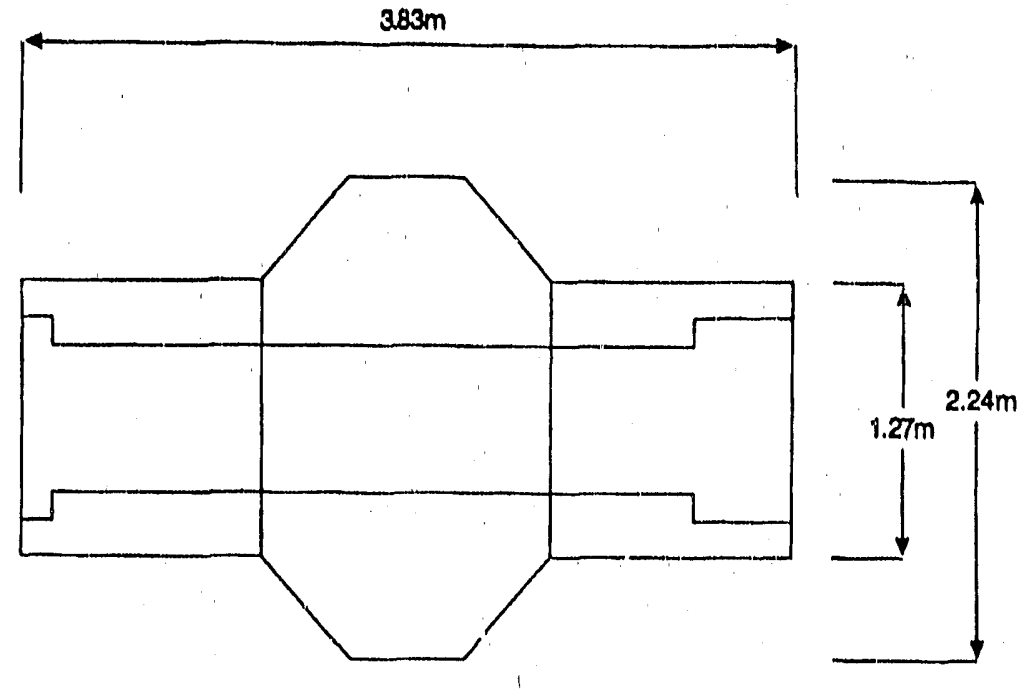

Plan Viow

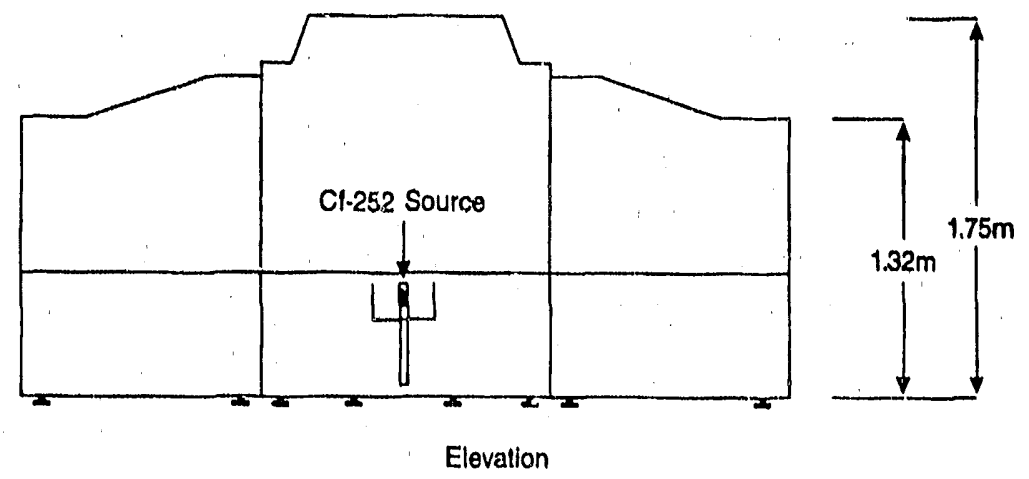

Figure 3.4 Dimensions of EDS-3C

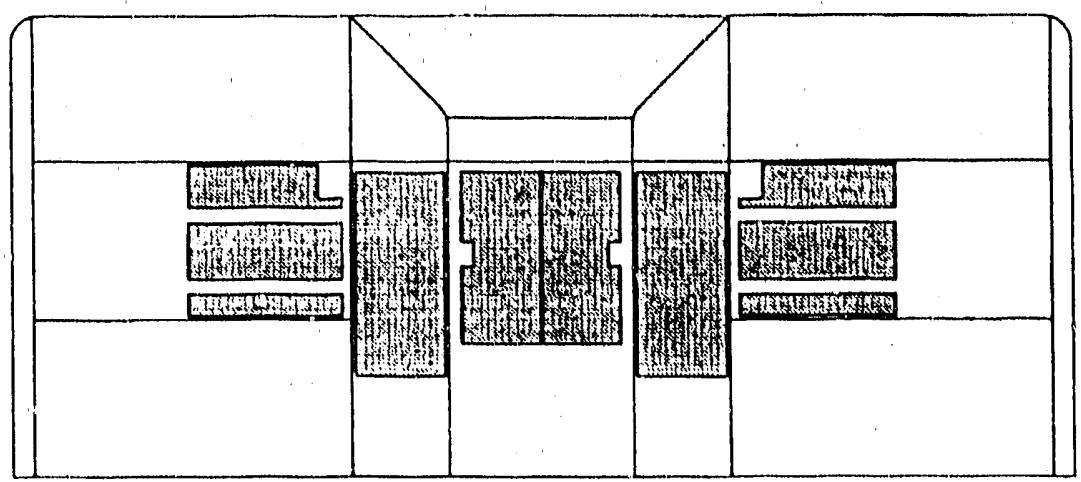

Figure 3.5 Schematic for additional shielding for EDS-3C

Shaded areas show location of added shielding. 
14-gauge steel. This shiclding significantly reduces the exterior dose rate. Llownward shielding has also been added in the moderating assembly. The spaces above and below the ends of the baggage cavity contain detector electronics, the system computer, electronics cooling equipment, electric distribution components, conveyor belt motors, and pulleys.

Three pivoted panels of borated polyethylene and lead at each end of the system attenuate the radiation emitted from either end of the EDS-3C (sce Figure 3.1). The end panels are $10 \mathrm{~cm}(4 \mathrm{in})$ thick and swing about vertical axes with return springs. "The four inner panels hang from a horizontal pivot point with a cam-spring arrangement that allows them to be pushed up easily by the baggage. If the spring mechanisin were to fail, it would fall in the closed position because of the weight of the panels. Individual position sensors for each panel are coupled to an indicator light on the main panel to show that the doors are closing when there is no baggage.

\subsection{Properties of Californium-252}

Californium-252 (Cf-252) decays by both alpha emission and spontaneous fission and has an effective half-life of 2.646 years. The dcminant decay mechanism is alpha decay, and the alpha emission rate is about 32 times that for spontaneous fission. A $1-\mu \mathrm{g}$ sample of $\mathrm{Cf}-252$ will emit $1.97 \times 10^{7}$ alpha particles and undergo $6.14 \times 10^{5}$ spontaneous fissions per secor d (Knoll, 1979). The neutron energy spectrum peaks at about 1.0 megaelectronvolt (MeV), although a significant number of neutrons have energies as high as 8 or $10 \mathrm{McV}$. Cf- 252 emits $2.34 \times 10^{12}$ neutrons per second per gram and $1.3 \times 10^{13}$ photons per second per gram of material, exidusive of internal conversion $x$ rays. No beta radiation has been reported from the decay process. The beta radiation associated with the equilibrium fission nroducts during spontaneous fission is easily absorbed and does not contribute significantly to dose rates (E.I. du Pont de Nemours and Comipany, 1971).

The neutron fluence rate at $1 \mathrm{~m}(3.3 \mathrm{ft})$ for $1 \mathrm{~g}$ of $\mathrm{Cf}-252$ is $1.9 \times 10^{7}$ neutrons/ $\mathrm{crr}^{2}-\mathrm{s}$, the absorbed dose rate in tissue is 2.84 grays (Gy)/hr (284 rad/hr), and the dose equilalent is 24 sieverts (Sv)/hr $(2400 \mathrm{rcm} / \mathrm{hr})$.

For the EDS-3C, a 50- $\mu \mathrm{g}$ doubly encapsulated, sealed neutron source (Frontier Technology Model 100 series or Amersham Model C' N.CY6) is used (California Departmerit of Health Services, 1989). The source is mechanically attached to the end of a Teleflex cable and is held by a locking compound. The cable is approximately $5 \mathrm{~mm}$ ( $3 / 16$ in.) in diamete:; and the source adapter is $9 \mathrm{~mm}$ ( $3 / 8$ in.) in diameter. The source can be withdrawn manually to a retracted po:ition, which lowers radiation levels in the baggage cavity to allow routine in-cavity maintenance or to release a baggage jam.

\subsection{Safety Features}

The following safety features have been incorporated in the concourse version of the EDS-3 (i.e., EDS-3C):

- The outer shield doors are key locked when the EDS-3C is unattended.

- The outer shield doors are interlocked so that if the system operator removes the computer system key before locking the shiclded doors, an alarm is sounded.

- In case of a baggage jam, the source can be withdrawn manually to a retracted position, allowing retrieval of luggage stuck in the cavity while the radiation ficlds are lower.

- The source is always confined within several layers of shielding, and a locked panel covers the Teleflex cable to which the source is mounted.

- A tamper-irdicating seal is used (see Figure 3.6) to show if tampering has been attempted.

- A baggage activation monitor checks all baggage passi:ig through the 'TNA system for excessive radiation levels. This monitor is equipped with both audible and visible indicators. 'The sensitivity is adjusted to a level that will ensure that any bag that has a surface dose rate of more than $5 \mu \mathrm{Sv} / \mathrm{hr}(0.5 \mathrm{mrem} / \mathrm{hr})$ will trigger the monitor.

- A permanent "Radioactive Matcrial" sign with isotope identification and dated source strength is located at the locked panels that cover the source cable.

- Caution signs indicating a high-radiation area are placed at the entrance and exit of the system. A "Caution-Radioactive Materials" sign is placed on top of the system.

- Additional shielding barriers are used in any insta!lation where the public might otherwise be exposed to the radiation field from the exit and entrance of the TNA system.

- A sign will be prominently displayed informing passengers that their luggage will be screened with a new type of detection system to detect the presence of plastic explosives. Passengers will be advised to remove needed items from their luggage belore EDS-3C screening. Passengers will not have access to luggage contents once the luggage has gone through the I:DS-3C and has been banded with 


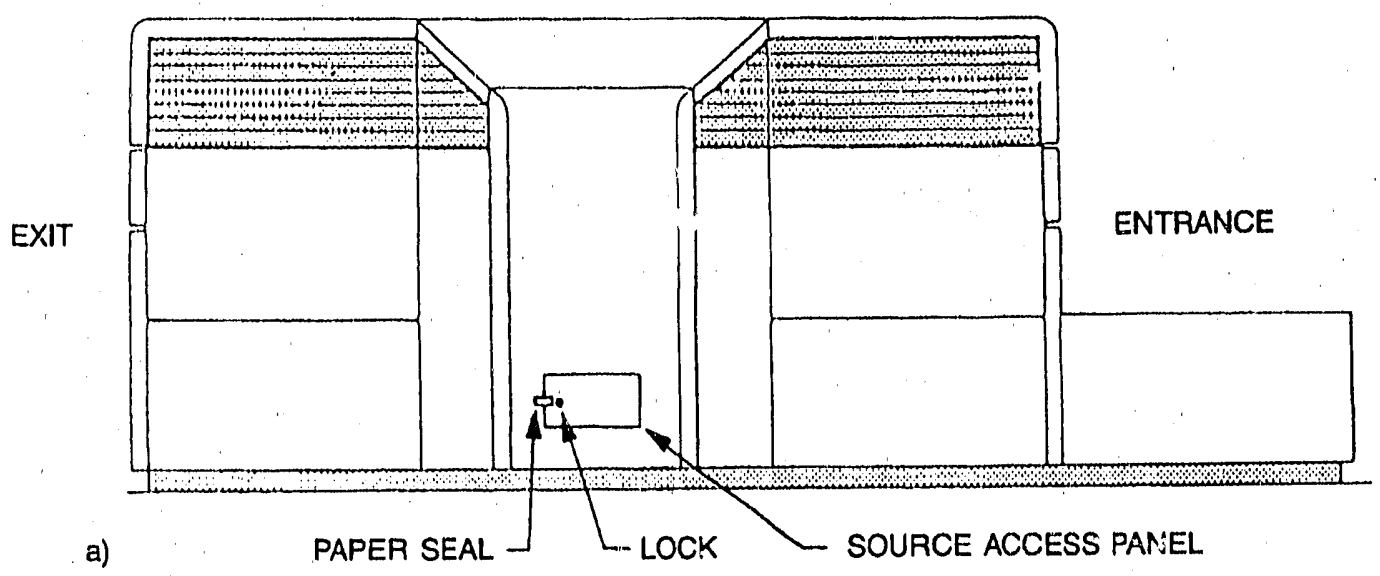

b)

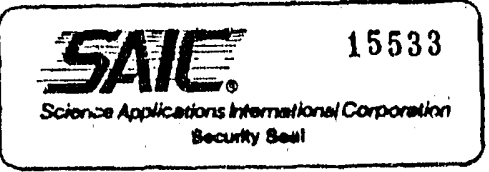

Figure 3.6 Tamper-indicating paper seal.

(a) Placement, (b) full-size sample

tamper-resistant security tape. In addition, handouts will be available for those members of the pidblic who request more information.

In addition, several internal safety features have been added:

- A log book is used to record all routine maintenance, transfer of the source, retraction of the source, opening of computer and high-voltage access doors, personnel entering the baggage passageway (including duration), baggage jams (including reasons for jams), inspections, emergencies, and breakage of tamper-indicating seal by the operator during handling of the source or by actual or attempted tampering.

- A special shielded cask designed to reduce external radiation fields during transfer is used to move the source to or from the EDS-3C.

- Environmental monitors are used to monitor possible radiation doses in the area.

- One ion chamber gamma ray survey meter and one neltron rem meter will be kept at each site for use by the TNA operators. 


\section{ENVIRONMENTAL INTERFACES}

\subsection{System Locations}

In lobby (concuurse) installations, the TNA system is proposed to be installed at or near the ticket counter of an international airline, or at a terminal's curbside check-in area. For each of the scenarios, an airline baggage handler will feed the baggage into the system. As each bag leaves the system, the computer will identify each bag with a "clear" or "alarm" signal from the TNA system. In case of an alarm, the bag will be passed through the EDS-3C again. If the bag still alarms, the bag will be removed to a secure area and will be opened by the security attendant with the consent of the passenger. If the passenger does not consent, he or she will not be allowed to board the airplane.

The desirability of lobby installation stems from the FAA requirement to have the passenger present when his or her luggage is hand searched. In the ramp installation, as explained earlier, there is no convenient way to contact the passenger when a piece of luggage causes the TNA system to alarm, perhaps 30 minutes or more after initial check-in. Current methods used to locate these passengers at JFK International Airport have taken on the aver. age approximately 1 hour.
Figure 4.1 shows the TNA system attached to an $x$ ray inspection system labeled "XENIS" ( $x$ ray enhanced neu tron inspection system). The TNA system consists of a standard commercial baggage and cargo inspection system coupled to an image processing computer. $X$ ray image information is combined with the nitrogen distribution image information from the EDS-3C in a separate computer, which correlates the information so that a decision can be made regarding the presence or absence of a bomb (FAIC, 1989). This combination of technology has cut the false-positive rate in approximately half. XENIS also produces a combined image that can assist a trained security operator in resolving many of the remaining alarms, thus further reducing the number of passengers whose bags must be opened. The use of XENIS adds about $\$ 150,000$ to the total cost of the installation, as wcll as requires additional space.

The following four locations for lobby installations are evaluated in this assessment:

(1) Behind the check-in counter

(2) In front of the check-in counter

(3) Pre-check-in area

(4) Curbside area
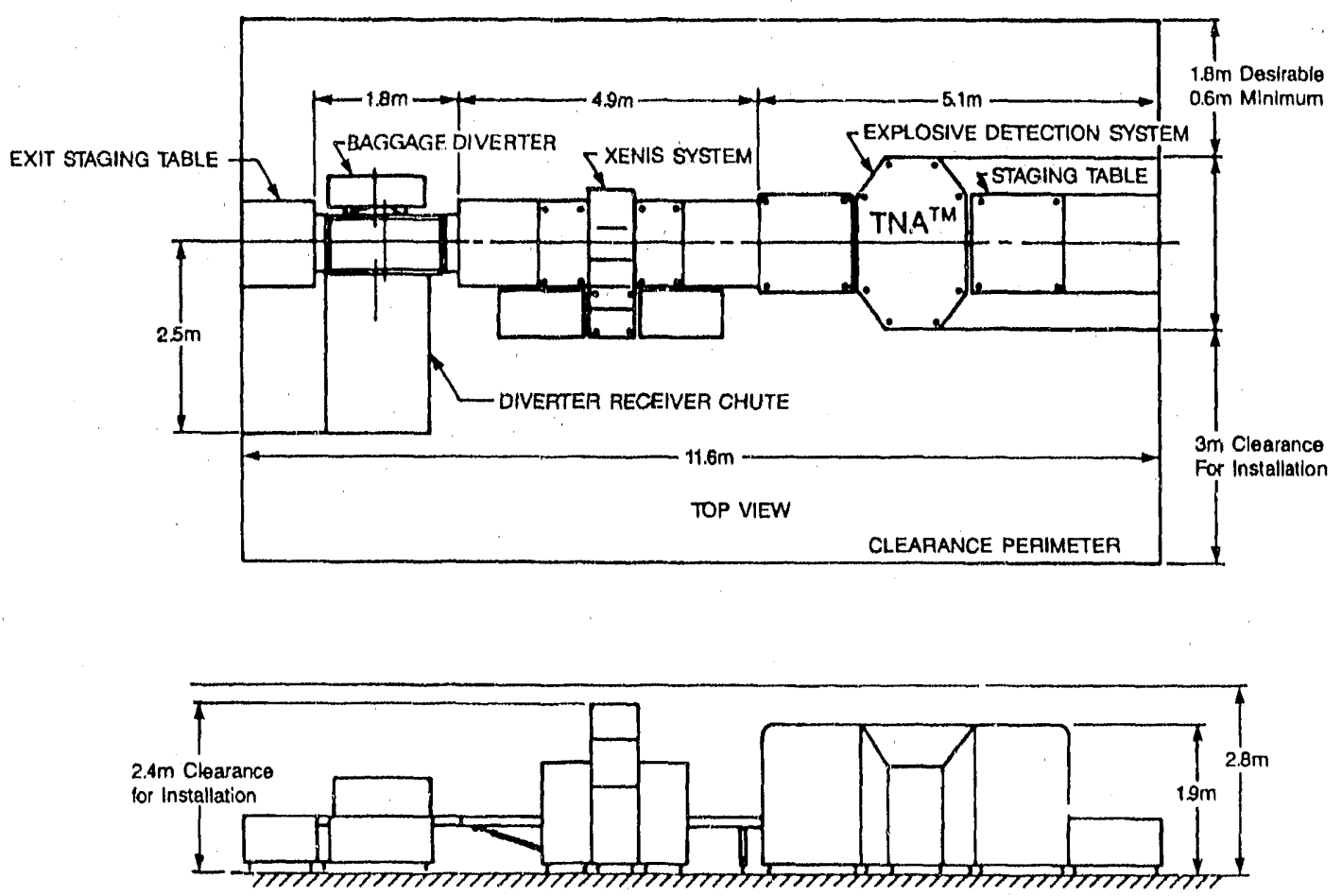

SIDE VIEW

Figure 4.1 TNA explosive detection system with XIENIS and diverter 


\subsubsection{Behind the Check-In Counter}

In this secnario, the 'TNA system would be placed behind the counter (probably behind airline personnel) where the passengers check their baggage and get their airline tickets. Figure 4.2 shows one proposed setup for United Airlines at San Franciseo International Airport. While the passenger's passport, ticket, and scat assignment were being checked, the baggage would be placed on a conveyor belt, which has two $90^{\circ}$ turns, and enter the TNA system. If the TNA system alarmed, the passenger would be asked to step to the end of the counter where the inspection station is located to have the baggage opened. The passenger would not receive a boarding pass until the baggage had been elcared. For international check-in, which takes approximately 5 minutes per person at the counter, one TNA system could service abot:t 20) check-in positions.

This secnario, in some respects, is similar to that for the ramp EDS-3, which has been in operation at JIK International Airport since September 1989. Passengers would still not be permitted to be next to the machine, but would, however, be able to view the EDS-3C from the ticket counter.

\subsubsection{In Front of the Check-In Counter}

This scenario is similar to the one described in Section 4.1.1, except that the entrance to the EDS-3C would be in the public area in front of the check-in counter (Figure 4.3), while the exit of the EDS-3C would be behind the ticket counter. Passengers would hand their luggage to a TNA airline attendant who would place it on the conveyor belt entering the TNA system. The passengers would then wait in line at the check-in counter, check to make sure that their bags had passed the TNA check, and be issued boarding passes. If a piece of luggage did not clear the TNA system, the passenger would be available to witness a hand inspection at a nearby inspection counter.

Members of the public could stand immediately next to the INA system unless a barricr was crected, which would increase the TNA system's already considerable size. A variation of this approach would be to have the body of the TNA system behind the counter with only the entrance in front of the counter; this probably would be more difficult and expensive to integrate into an existing airport.

An advantage of this scenario over the one described in Section 4.1.1 would be that two airlines with adjacent ticket counters could both use th ? TNA system to screen

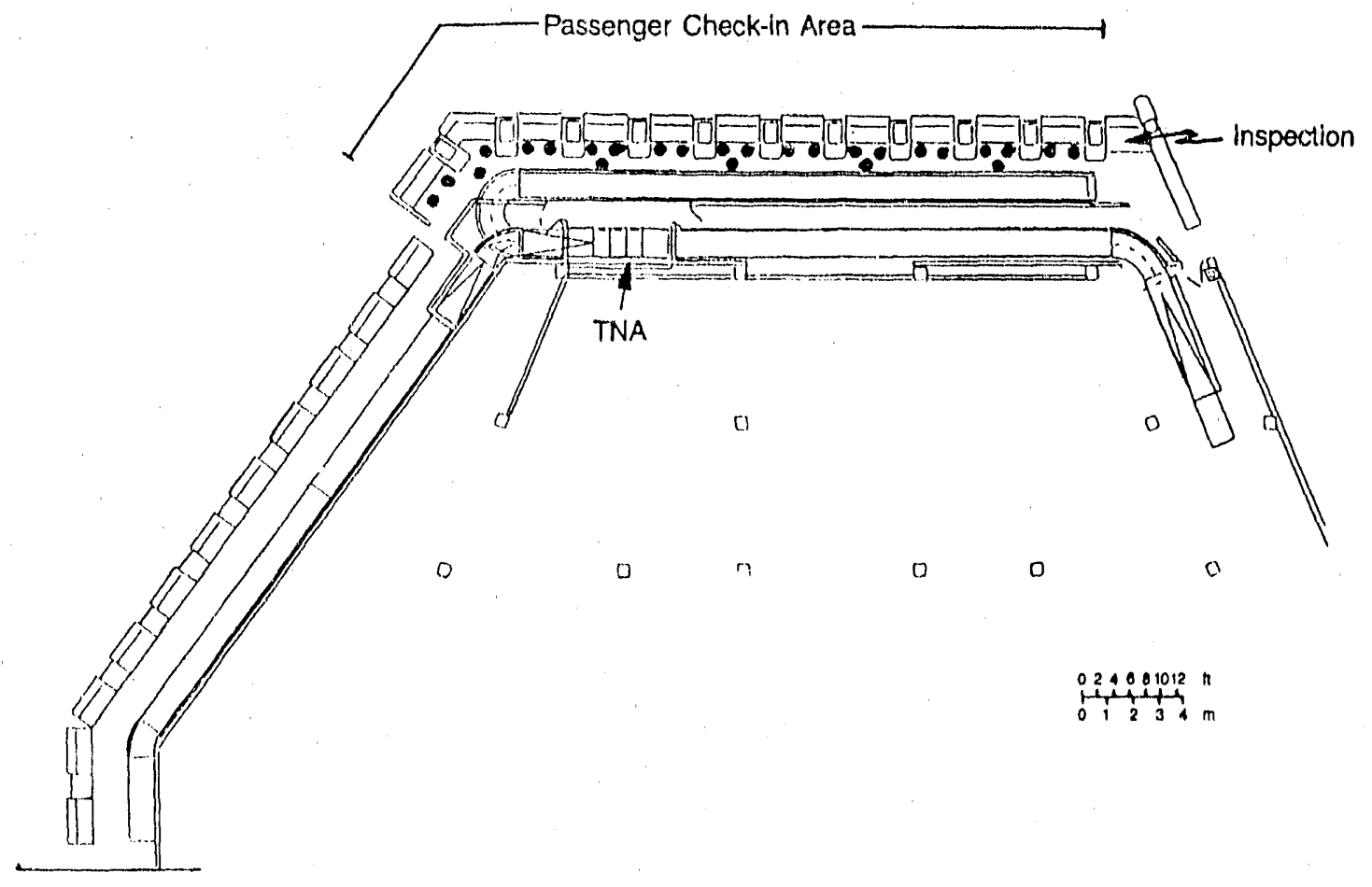

ligure 4.2 Behind the check-in counter-proposed setup for United Airlines at San J tancisco International Airport (indicates location of an agent) 


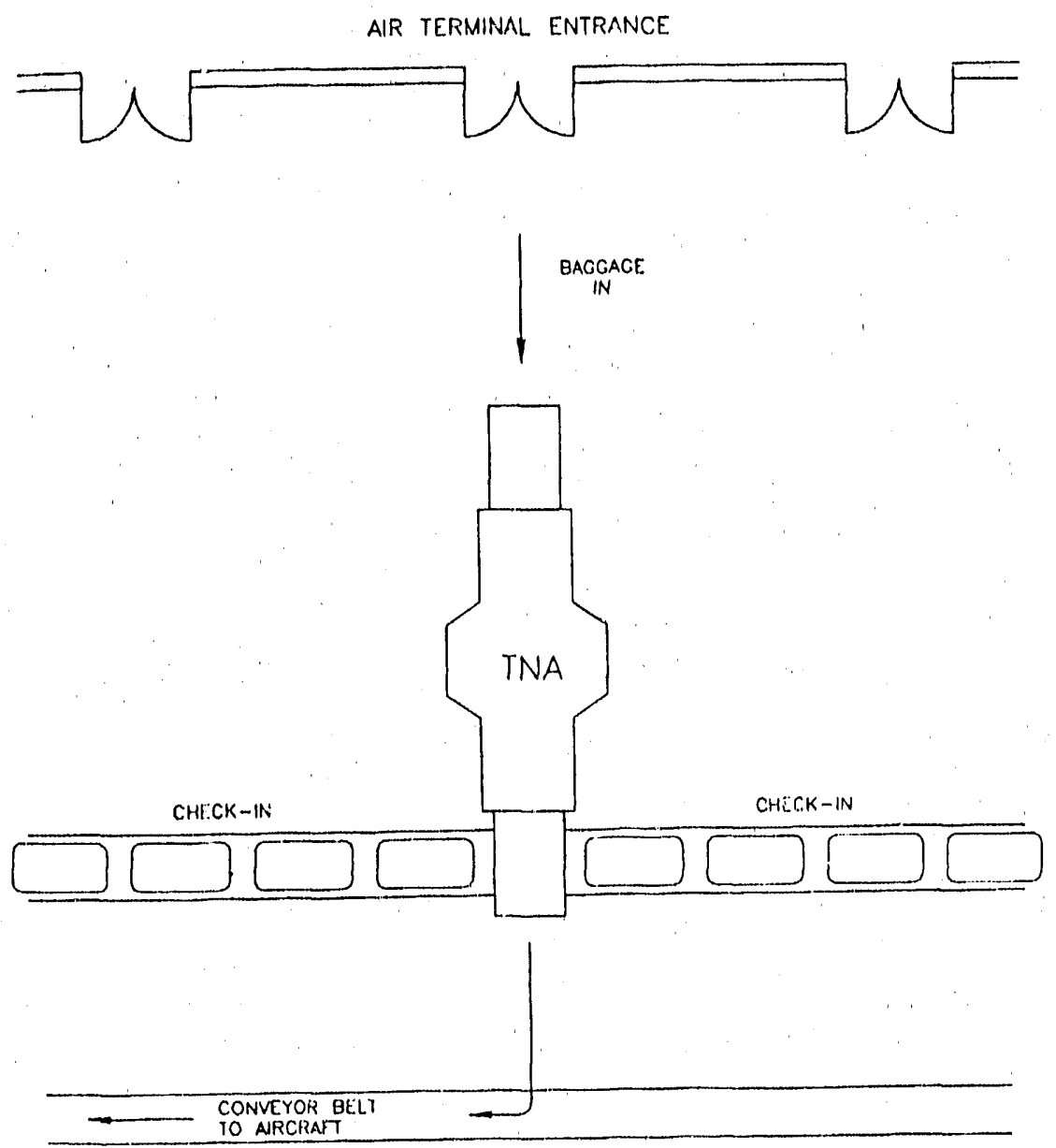

Figure 4.3 In front of check-in counter

luggage. In this case, two airlines could share the responsibility and cost of operating the TNA system. Although two airlines could also share the TNA system as illustrated in ligure 4.2 , it would be much more difficult.

\subsubsection{Pre-Check-In Area}

In this scenario, the EIDS-3C would be placed in an open area near the terminal entrance and check-in locations (Figure 4.4). When the luggage was cleared by the INA system, the attendant at the exit would band it with tamper-resistant security tape and return it to the passenger. The passenger would then take it to the check-in counter of the appropriate airline, where it would be checked in for delivery to the aircraft.

Passengers whose bags were being inspected would come to the entrance of the 'l'NA system, walk alongside as the bags were going through, and wait at the exit of the system. Bags resulting in an alarm would be opened at a station near the exit, perhaps at a table placed there for that purpose. In addition, other members of the general public or airline employees might come close to the 'INA system as they walked about the terminal.

An advantage of this scenario is that many airlines could use this one system for screening international luggage. Passengers typically must arrive several hours before their scheduled flight is to depart, therefore allowing plenty of time to have their checked luggage screened. If passengers allowed enough time for this screening process at the beginning of their travel plans, there most probably would be no significant scheduling delays.

Several disadvantages are also foreseen in regard to this scenario. Since the passengers would have acess to their luggage immediately after'INA screening, they would be exposed to the potentially radioactive contents for a time depending on the scheduled departure. If a flight was cancelled after a passenger's luggage was scanned by a 


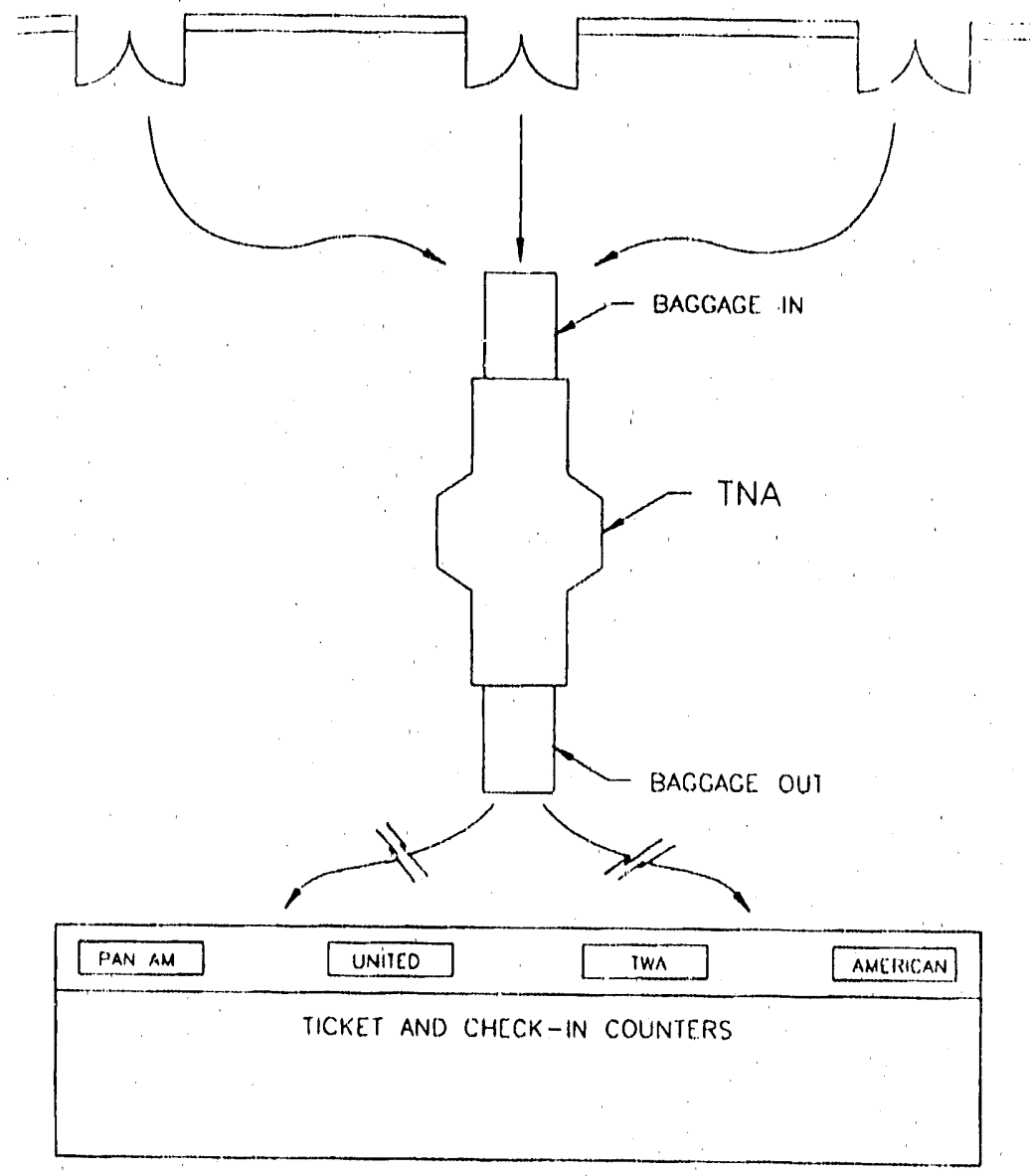

Figure 4.4 Pre-check-in area

TNA system, the passenger would have the slightly activated luggage for a longer period than during any of the other scenarios. This additional dose has been calculated and is assessed in Section 5.4.3.3.

\subsubsection{Curbside Area}

For this installation, the TNA system would be placed along the departure curb of an airport, similar to where curbside check-in for domestic flights is now permitted. Because the TNA system could be located in an area that would not be sheltered from the elements, it would have to be enclosed within a small building (as is currently down with the IODS-3 at JFK Intcrnational Airport). In addition, this enclosure would have to be protected from vehicular traffic in the area adjacent to the system. Figure 4.5 illustrates the type of barriers and setup that would be required for this option. Vehicle barriers and Jersey walls (concrete median barriers) similar to those used in high- way construction would be used in these installations (Figure 4.6). The passengers would still hand their luggage to an airline baggage handler ("sky-cap"), wait for the clear signal from the TNA computer, and then receive their claim checks after the luggage left the system. In case of an alarmed bag, the passenger would be available to witness a hand inspection, if necessary.

Passengers would come within several fect of the TNA systern when they delivered their bags and, depending on the design of the installation, might walk alongside the system (as discussed in Section 4.1.3) to the exit. Alternatively, they might wait for a clear signal near the inspection station. Other members of the public might also pass near the system, but probably fewer than those in the pre-check-in scenario.

The INA system is affected by temperature and humidity in much the same way as any other electronic equipment might be. Internal thermal design considerations have 


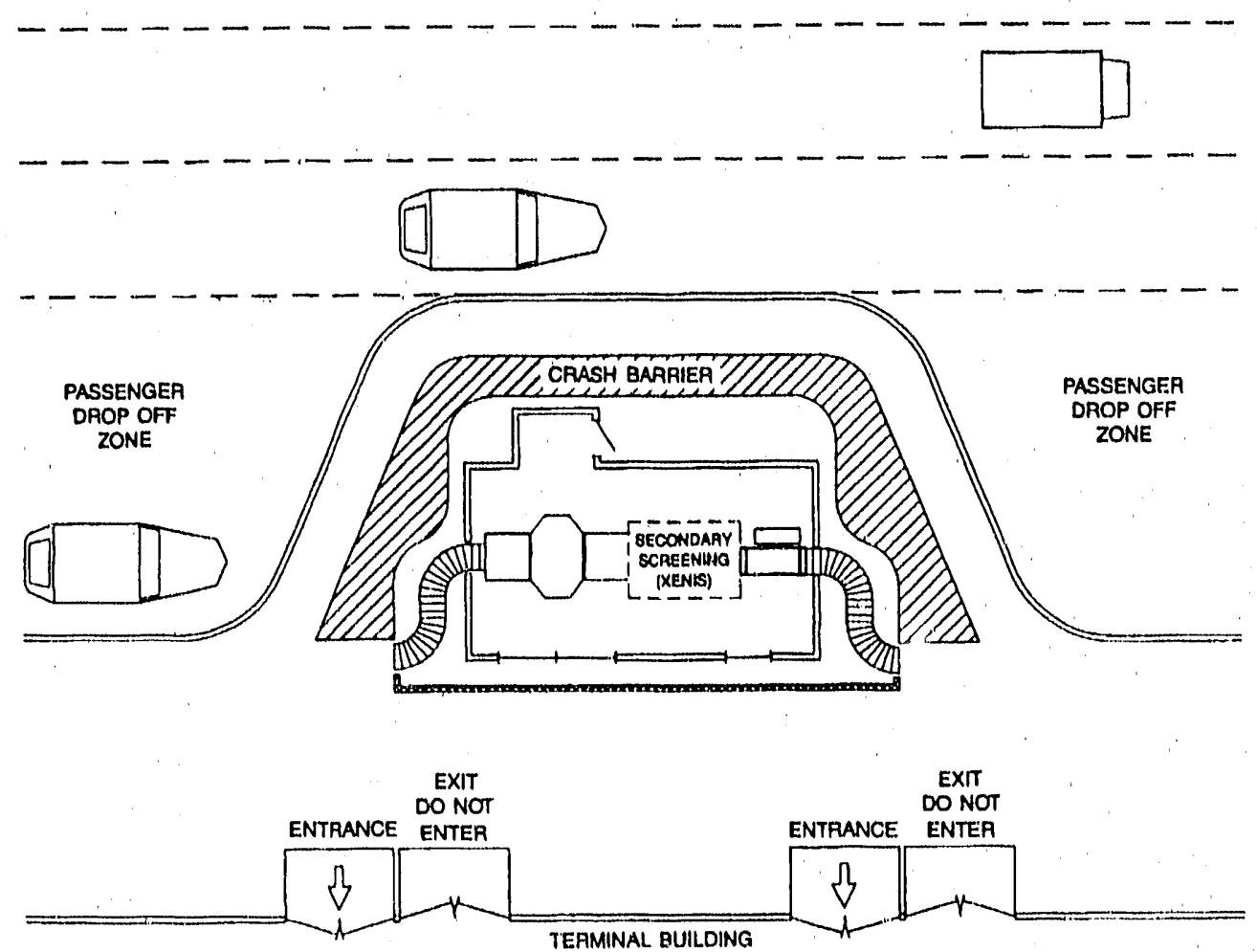

Figure 4.5 Curbside check-in

resulted in the specification of ac circuits, fans, clucting, and thermostatically controlled heaters (SAIC, 1989). Rapid changes in temperature (such as a stream of subzero air directly into the scanning chamber) could result in some damage of the detector or temporary malfunction of the computer equipment. A small building, such as the one built for the EDS-3 at JFK International Airport, would be suitable for protecting both the operating personnel and the EDS-3C from the elements. As in the case of any construction, builơings will have to be in compliance with local building codes and any other regulatory requirements.

\subsection{Demography}

There are two types of workers who could have contact with the EDS-3C: those who would work directly with the EDS-3C (such as the operators and baggage handlers) and those whose duties would bring them infrequently near the EDS-3C (such as airline ticketing agents, supervisory personncl, and baggage cart drivers).

For purposes of this document, the public is defined as all those who are not workers as defined above. This includes all passengers and those members of the general public who may be at the airport, as well as employees who work at the airport but who do not normally frequent the main ticketing arca of the airport.

The population density in the vicinity of the EDS-3C at concourse installations of airports will vary with location. However, the number of passengers whose baggage is screened by conventional $x$ ray equipment is known. The following list shows the number of people screened annually at eight major international airports in the United States (sec SAIC, 1988):

\begin{tabular}{lr}
\hline Airport & People screened \\
\hline San Francisco & 22.6 million \\
JFK & 14.9 million \\
Los Angeles & 89.7 million \\
Chicago-O'Hare & 69.8 million \\
Miami & 12.7 million \\
Detroit & 31.3 million \\
Dallas-Ft. Worth & 70.4 million \\
Dulles & 6.6 million
\end{tabular}




\section{Environmental Interfaces}

Barrier system to be two phased. Phase one would consist of a deflecting shield such as is used to separate opposed lanes of traffic.

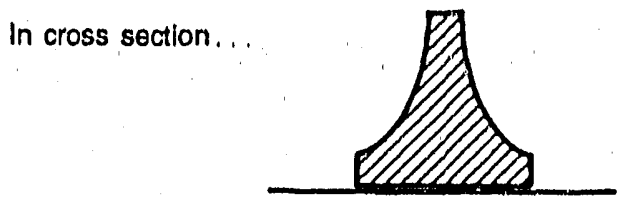

Phase two would be fluid-filled, collapsible barrels such as are used to absorb the impact of a motor vehicle. Both these systems are currently in common use on California highways.

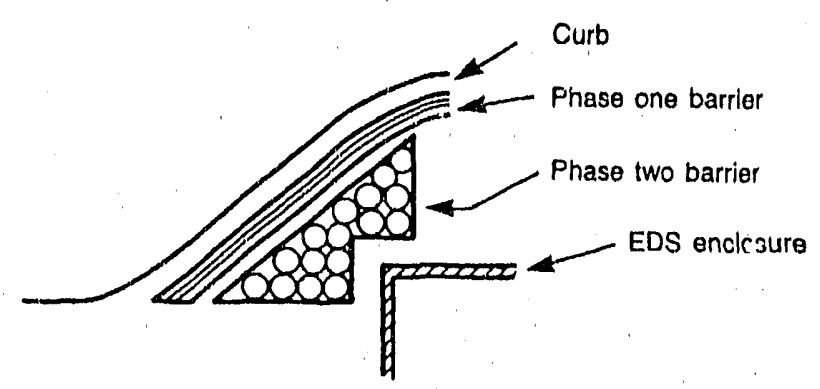

Figure 4.6 Barrier system to protect TNA operating personnel, passengers, and others from intrusion by motorized vehicles

The number of domestic and international passengers enplaning in the United States during the years 1985 through 1987 has continued to increase, as shown below (U.S. Burcau of the Census, 1989):

\begin{tabular}{lllll}
\hline & \multicolumn{3}{c}{ Number in millions } & \\
\cline { 2 - 4 } Passengers & $\mathbf{1 9 8 5}$ & $\mathbf{1 9 8 6}$ & $\mathbf{1 9 8 7}$ & $\begin{array}{l}\text { Percent } \\
\text { increase }\end{array}$ \\
\hline Domestic & 357 & 394 & 416 & 14.2 \\
International & 25 & 25 & 31 & 19.4 \\
\hline
\end{tabular}

If these trends continue at this rate, an estimated 38 million international passengers could travel in 1990.

The number of passengers traveling through each airport daily can be estimated by dividing the total number of passengers departing by the number of large airport "hubs." A large hub is one at which at least 1 percent of the total revenue passengers using all services and all operations of U.S. certified route air carriers enplane (U.S. Bureau of the Census, 1989). From 198; statistics, we can estimate the number of passengers in an average airport to be:

$$
\frac{448,913,700 \text { cleparting passengers }}{28 \text { large hubs }}
$$

The average number of passengers on a daily basis would be approximately $44,000(16,032,600 / 365)$. Although only a small fraction of these passengers would be going on international travel, many of these passengers could pass near the EDS-3C. The radiological impacts of the EDS-3C located on the concourse level of airports are discussed in Section 5.4.

\subsection{Source Transport}

The average distance from the supplier of Cf-252 sources (located in Ohio) to various airport locations is approximately $1900 \mathrm{~km}(1200 \mathrm{mi})$. Because ( $\mathrm{Cf}-252$ has an effective half-life of 2.646 years, periodic replacement of the source is necessary to maintain the desired neutron 
fluerice in the EDS-3C chamber cavity. On the basis of the estimated frequency oi: replacing one $C f-252$ source annually, one truck shipment per EDS-3C would be expected on local and interstate highways each year. Since local roadways going to and from each airport are currently heavily traveled by cargo and industrial traflic, an additional truck shipment per year duc to LIDS-..? C operation is not expected to be noticeable in existing traffic on local roads leading to the interstate highways. Since the estimated operaticnal lifetime of the TNA systems is 15 years, a total of 15 shipments is anticipated for each system. Fstimatcs of transportation accidents involving shipments of radionctive material are dis assed in Section 6 .

\subsection{Seंsmology}

Several of the airports that would be slated for a INA system are located in carthquake areas. The most likely effect of an earthquake on the EDS-3C would be the shifting of the three major sections of the 'INA system slightly apart, which could result in gaps in the system's shiclding. To prevent this, each joint is tied together by four joining plates attached by six large bolts. A TNA system was assembled and operating at SAIC"s Santa Clara, California, facility during the October 17, 1989, I.sma Pricta earthquake, which measured 7.1 on the Richter scale. No effects on the TNA system were observed, and the integrity of the souree was maintained. 


\section{ENVIRONMENTAL IMPACTS OF THE PROPOSED ACTION}

\subsection{Methodology}

\subsubsection{Regulations and Dose Criteria}

The NRC promulgates regulations and establishes standards for protection against radiation arising out of activities conducted under licenses issued by the Cor mission. These requirements as set forth in Title 10 of the Code of Federal Regulations (10 CFR), l'art 20, state:

Persons engaged in [licensed] activities...should, in addition to complying with the requirements set forth in this part, make every reasonalle effort to maintain radiation exposures, and relcases of radioactive, iluents to unrestricted areas, as low as is reasonably achicvible. The term "as low as is reasonably athicvible" moans as low as is reasonably achicevable taking into account the state of technology, and the cconomics of improvements in relation to bencfits to the public health and safety, and other societal and sorioceconomic considcrations, and in relation to the utilization of atomic energy in the public interest.

Currently, 10 CFR Part 20) is being revised and will incorporate the most recert gulidince from the International Commission on Radiolugeical Protection (ICRP). This new guidance incorporates derived limits for intakes of radionuclides that have hecen developed using updated metabolic and dosimetric meslels (ICRP Publications 23, 28 , and 30). Radiation deses calculated in this environmental assessment rellect the new ICRP guidance pertaining to external and internal (losimetry.

Maximum allowed values of radiation dose that may be received by workers in restricted areas (EDS-3C operators and assistants in this case) and those in unrestricted areas (other non-INA workers, passengers, and members of the public) are provided by the NRC' in the current 10) CFR Part 20:

\section{Restricted areas}

$\mathrm{mSv} / \mathrm{yr}(\mathrm{rem} / \mathrm{yr})$

Whole body; head and trunk; active

blood-forming organs; lens of

eycs; or gonads

Hands and forearms; feet and ankles

Skin of whole body

Unrestricted areas

Whole body (current regulations)

Whole body (proposed regulations)
The dose equivalent $(H)$ from external exposure from sources of ionizing radiation depends on the absorbed dose $(D)$, the effective quality factor $(Q)$, and other modifying factors $(N)$ that may be specificd:

$$
H=D \times Q \times N
$$

where

$H$ is in units of sievert (or rem)

$D$ is in units of gray (or rad)

$N$ is the product of any other modifying factors

The quality factor allows for the effect of higher energy deposition along particle tracks produced by various radiation types such as neutrons, alpha particles, $x$ rays, or gamma rays. In ICRP Publication 21, a value of 2.3 is given for $Q$ for thermal neutrons. In 1985, the ICRP, and in 1987, the National Council of Radiation Protection and Measurements (NCRP Report 91) recommended that the quality factor for ncutrons be increased by a factor of 2 as an interim measure pending full revicw. Report 40 of the International Commission on Radiological Units (ICRU) indicates that an increase by a factor of 2.5 is jurtificd for neutrons, but states that further review is appropriate.

Because the EDS-3C is expected to be deployed at U.S. carricrs at airport locations worldwide, several international regulatory agencies that have adopted a neutron quality factor of 20 will use this environmental assessment as a reference for licensing this system at airports. Consequently, although the current NRC policy is to use a neutron quality factor of 10 , in this assessment a quality factor of 20 is used for both international agreement and added consçrvatism.

\subsubsection{Exposure Pathways}

Individuals who may receive radiation exposures due to normal operations are divided into two major categories: EDS-3C workers and members of the general public. 'T'he personnel assigned to operate the IEDS-3C will be specifically trained for 'INA system operations. 'These personnel will consist of the operator and other technical assistants, such as baggage handlers and trained security specialists. Training for the 'INA operators will consist of lectures and courses in radiation physics, radiation safety, biological effects of radiation, instrumentation, radiation control, and operating procedures during normal and accident conditions. Lach 'I $N A$ operator will have to pass a radiation salfety examination covering all of these items. ()ther'INA workers will load and unload the bags on and off the lids-3C. 'These workers will be supervised by a 
I'NA enerater and will receive a more basic radiation salfety training course that is commensurale with their limited duties. This type ol training is consistent with the training specifled by lO CTR l'att 19, "Notices. Instructions, and Reports to Workers; Inspections." laach indlvidual who enters a restricted area under such circumstances that he or she receives, or is likely to receive, a dose in any calcondar cuaterter in exeess of 25 pereent of the values specilied in 10 (ClR 20.10)(a) will be recquired to wear personnel dosimeters. Because the only personnel that might receive a quarterly dose in exeess of 25 pereent will be the l:DS-3C (nperaters, they will be the only'l'NA employeces required to wear personnel dosimetry (neutron and famma). I'he 'INA operalor will be the only andhorized user who may manipulate the sourece, pertorm the passige maintenanee, and extract jammed baggage.

Non-I'NA workers, passengers, and members of the public could be exposed to the low levels of radiation that might exist around the INA system. There are three mijor exposure pathowese the public: cximstare of

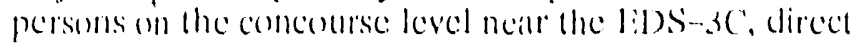
radialion expessure of passiengers to beta or gianmal fiedds

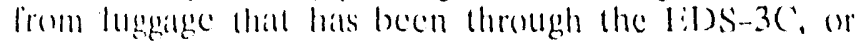
internal dese to passengers or ofther members of the public whes consume a fornd or other irradiated item that wats comtinined in the reclatimed luggage. lach of these exposure scenarios is evaluated in detail in Section 5.4 .3 .

\subsection{Construction Impacts}

The lat s' 3 ( ' silf: arcea will be designed and medified so ats (1) minimize construction impacts. All airport construction atcivitics to aceommondate the system will comply with licederal, state, and loc:al regulations governing heallh and silfely during, construction, ats will all aperatlions in connection with the transpontation, storage, and use of rationetive material. Work will be monitored by the arpont aluthority at catch site locallion, who, in most casces, also will be the governing aluthority issuing the initial comstruction permit.

A structural engine ering study will be reguired to consure

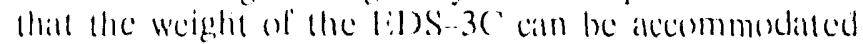
salfely an the concenderse fevel of airports. Airport patssenger departure and arrival areses are gencrally built 10 a much higher live-loal rateng than the eleviled floors within the arrpert terminth. Howerer, becaltse the clevalled-flour structure of airport terminals vartes becaluse of substimtial dilferences in design, the structural reguterments could chamge significantly from airport to

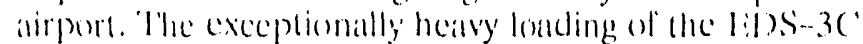
combined with the reyuirement to plate these systems on

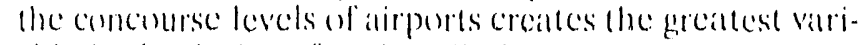
able in the design of an installation.

Using the information from the structural engencering study, a design teim should derelopr conceplual documents adderessing public access control, security, architectural, mechanicill, and clectrical respirements of the project (Peacenck, 1989). ()nee the conceptual design parckage has been compreted, it should be submitted to the owner, the primary user (the airline carrier), and the airport authority for initial review and apprevall. If the conceptual design is approved, the linal design decuments and eontrace cain be drawn up. These decuments should include dranvings, speciliealions, const estimates, and structural callewhtions showwing the method of distributing the lesut and/er reinforcing the fleser structure.

\subsubsection{Site Requirements}

1.obby or concourse'INA systems can be placed all virions

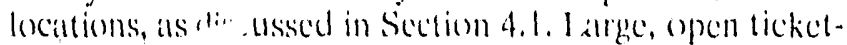
ing areas on the ground level of an airport are desirable

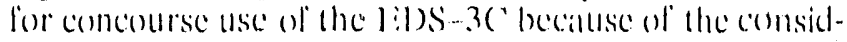
erably reduced cost of installation. Becaluse present airport facilities have not been planned lor a system an large

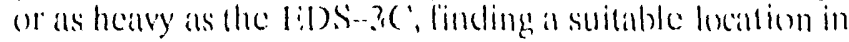
an existing airport maty be diflicult. Most installatlons will

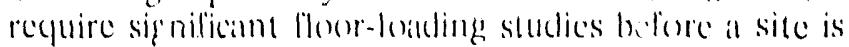
selected and, in some cases, maly even reguire building a lacility specilicilly constructed lor the system (curbside seconario).

In adedition (o) the requirements above, the surfied under the system must be horizontal and level fo within about 6 mm (1/4 in.) so that the system's modulat components can fit together and al lign properly. Adelitional space must

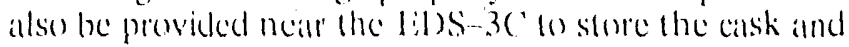
the addelitional raderestegical instrumentation that would be necessilly in calse of an concergency.

for installations at existing lincilitics, it may lee necessary (o) build up the surfice with (cement grout io ensure that the calsk will roll cassily and allign with the source-londeng pusitions.

Thansportation of the bangegnge from the 1:1)S-36 to the baggage holding area for holding onto aircralt also must be provided for. 'This may recpuire additional space fer

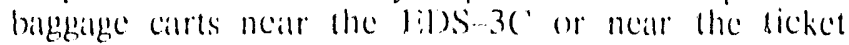
counter. 'There also must be a $2-m$ (6, (6-f) clearance on

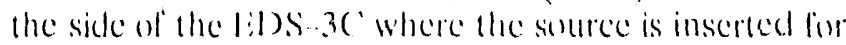

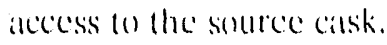

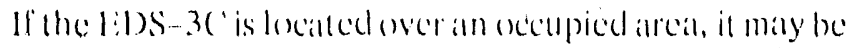

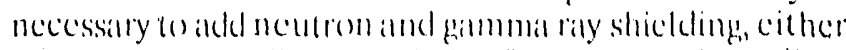

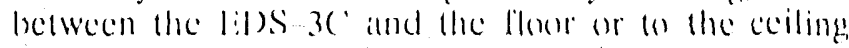
undernciath. The shickding shall be sulficient enough to bring the (h)se rille's on less thim i plsv/hr (0.1 mrem/hr)

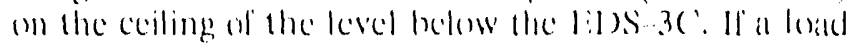
distribution platlorm is incerporatted into the design of the concourse installation, hem this shicelding shoukd be incorpentalcel molo it. 


\subsubsection{Land Use}

At the proposed Dulles International Airport site, the 'INA system will be installed at the United Airlines international ticket counter. As shown in Figure 5.1, the XENIS and the liSS-3C are at right angles to one another in order to "lit" the LDS-3C into an existing ticket counter area. A nearby utility room will serve as a storage facility for the cask and the associated survey equipment needed for the 1 idS-3C.

Additional construction needed at the United Airlines internatlonal tickes counter will aflect nearby passenger traffic patterns to some degree berause of its close proximity to the security area. It is anticipated that essential rigging equipment such as air dollies or forklilts could be moved into the terminal building during a week night ot on a weckend when traffic is at a minimum. If all the necessary requirements have been met and construction has been completed, the moving process should tatie no more than 2 to 3 days.

\subsection{Nonoperational Impacts}

\subsubsection{Transportation}

'The components ol the lios-30" will be shipped individually and will be assembled at the location where the system will be used. No radiation expesure to workers or to members of the public will result from cither the shipment or atsembly of the system because the radiation source will not have been installed in the system. "Ihe (1-252 soure will be shipped in one shiclded cask. lestlowing assembly of the $1: 1) S-3 C$, the source will be trans- ferred from the cask (sec ligure 5.2) to the system. Radiation exposure to individuals could occur during transport of the (1-252 soutec and during its installation ore operation at the aripurt.

Average estimalled radiation doses to the truck drivers, who might spend 24 hours at a distance of $2 \mathrm{~m}$ ( $6.6 \mathrm{ft})$ from the cask, are about $0.16 \mathrm{mSv}(16 \mathrm{mrem})$ per driver per delivery. Transportation regulations under 10 ClR 71.5()$(3)(\mathrm{d})$ elfectively restrict the radiation dose to ().(2) $\mathrm{mSv} / \mathrm{hr}$ (2 $\mathrm{mrcm} / \mathrm{hr})$ in any normally occupled parts of the vehicle. In addition, there can be no loading or unloading operations between the beginning and the end of the transportation. Assuming that there are two drivers per truck and that the used souree is returned yearly to the manulacturer, yearly replacement of the source is expected to result in a collective dose to the drivers of 6x10-4 person-Sv (6x10-2 person-rem) per'lNA system. If the average distance from the cast to the driver was increatied to $3 \mathrm{~m}(9.8 \mathrm{lt})$, the expected collective dose would decrease $102.8 \times 1(0-4$ person-Sv $(2.8 \times 10$-2 personrem). The dose to an individual member of the public during transportation of the souree from the manulacturer to the site would be less than $10 \mu \mathrm{Sv}$ (1 mrem).

\subsubsection{System Installation and Source Transfer}

The sourec transport calsk (sec liggure 5.2) is constructed of stedel, welded logether, and filled with a comprosite neutron and gatmmat aly shield of water-extended polyester with lead surrounding the source position. It is a

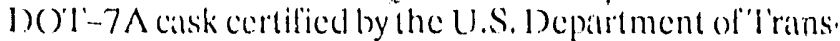
portation that is $0.75 \mathrm{~m}(2.5 \mathrm{ft})$ in diameter and $0.84 \mathrm{~m}$ (2.75 lit) long.

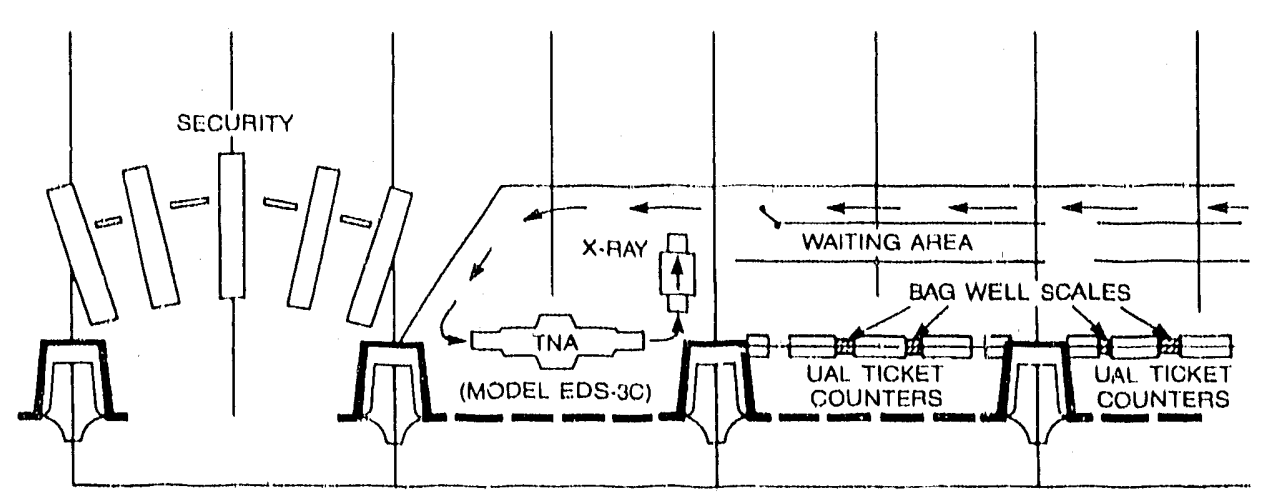

lïgure 5.1 Proposed l:DS-30 at Dulles International Airport 


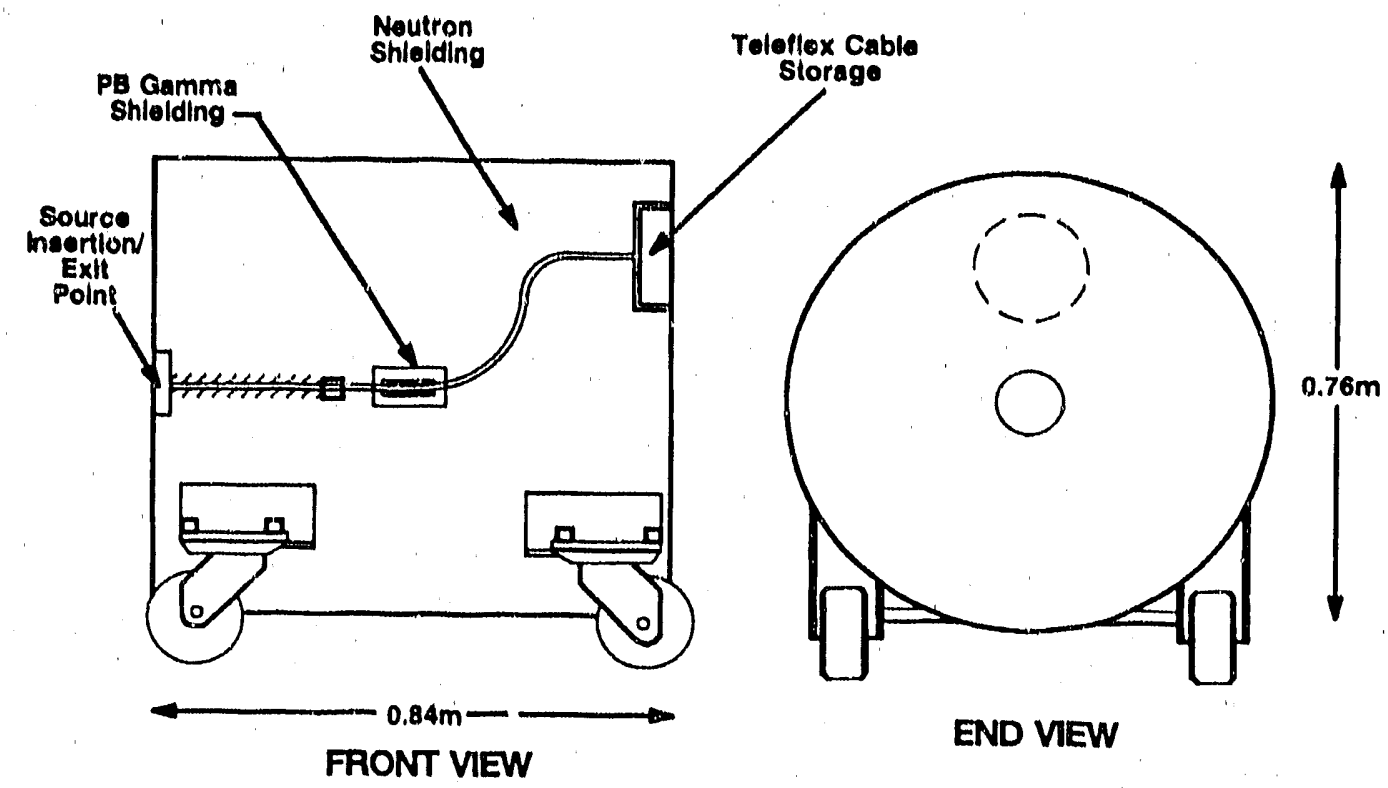

Figure 5.2 EDS-3C source transport cask

To transfer the source from the cask to the system, a special platform has been manufactured that helps guide the source into the EDS-3C (Figure 5.3). A polyethylene adapter with a conical hole fits into a recess in the end of the cask and is bolted onto the system for transfer. 'The cask is then rolled onto the platform and locked into position against the side of the EDS-3C, which engages the adapter with the cask recess. The source is transferred to the EDS-3C by pashing the Teleflex cable into the system until it stops. Alter the source is in the system and the cask and transfer adapter are removed, a flexible plastic tube is inserted over the cable and clamped into place. Its inner diameter is slightly greater than the diameter of the cable but less than the diameter of the source. At its longest length, it just reaches the "retracted source position" and thus serves as a stop to prevent the source from being retracted too far. See Appendix A for further details associated with the installation of and the radiation safety operating procedures for the EDS-3C.

The expected radiation doses outside a shipping cask loaded with a $150-\mu \mathrm{g}$ source of Cf-252 are shown in Figure 5.4. 'The nearest point that a member of the public could get to the cask during soure transfer would be approxi-

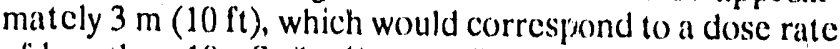
of less than $10 \mu \mathrm{Sv} / \mathrm{hr}(1 \mathrm{mrem} / \mathrm{hr})$.

\subsubsection{Radiation Exposure During Maintenance}

When the EDS-3C is in the operating mode, the sourec will reside in a bismuth gamma ray shield and will be surrounded by a neutron moderator and absorber. If the operators must get inside the EDS-3C to perform maintenance, the source will be placed in a retracted position. In this position, the sourec will be surrounded by a moderator and a $25.4-\mathrm{mm}$ (1-in.) Icad gamma radiation shicld. The radiation dose to EDSS-3C operators from clearing a baggage jam is expected to be less than $0.05 \mathrm{mSv}$ $(5 \mathrm{mrem})$. Experience with the EDS-3 at JFK International Airport indicates that baggage jams are rare and the vast majority of these jams can be cleared without entering the cavity. In the past 6 months of operention at JFK International Airport, it has not been necessary to enter the passigeway to dislodge jammed luggage.

Major maintenance work, such as repairing a broken conveyor, replacing Nal( $\mathrm{Il}^{\mathrm{l}}$ ) detectors, or repairing interiorcavity materials, requires partial disassembly of the 'INA system. For these types of repairs, the Cl-252 source will be removed from the system and will be placed in its shipping and storage cask. Once the source is removed from the system, radiation exposure during maintenance work will be minimal.

\subsection{Operational and Radiological Impacts}

\subsubsection{Neutron Dose Contours}

'The thermal neutron flux inside the shiclded I'NA system was mapperl using small holium-3 (He-3) detectors with a small $(0.2-\mu \mathrm{g})(1-252$ source substituted lor the normal 150- $\mu \mathrm{g}$ sourec. Flux maps were measured and then corrected for actual souree strength. The detectors were calibrated against activation lovils using the American 


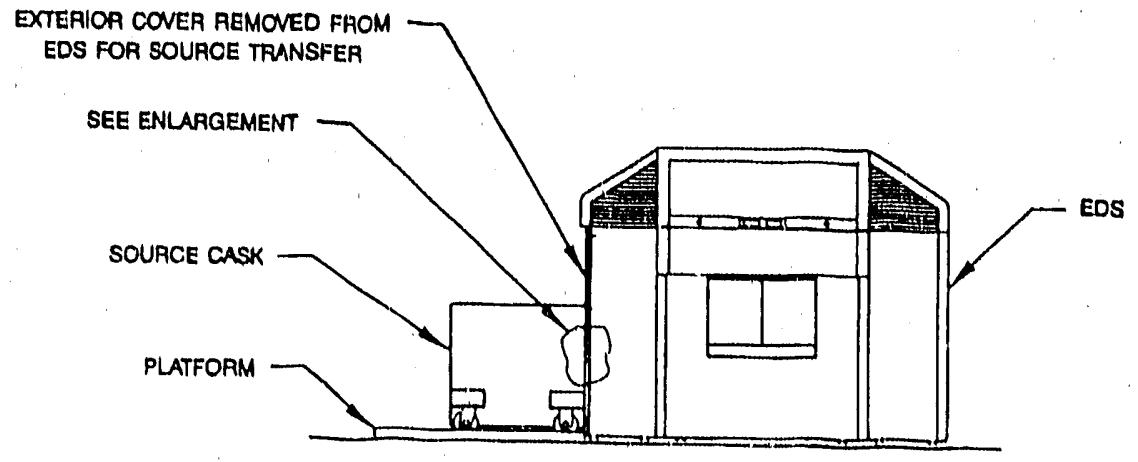

a)

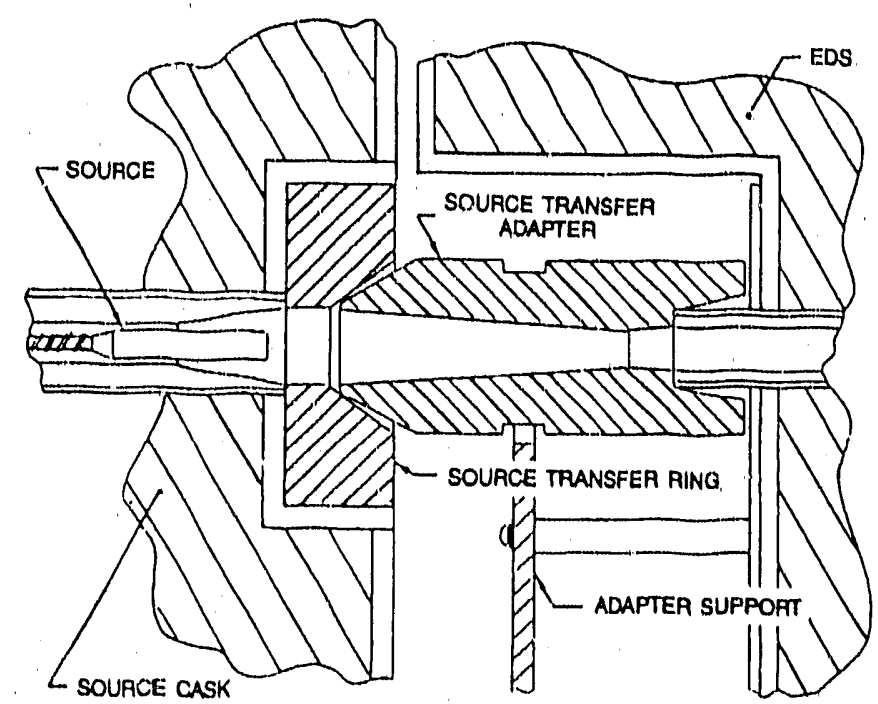

b)

Figure 5.3 Placement of cask for source transfer. (a) Overall view, (b) detail view of source transfer ring and source transfer adapter

Society for T'esting and Materials method (ASTM, 1989). 'The low-energy epithermal flux was measured in some of the same map locations using a cadmium foil-wrapped $\mathrm{He}-3$ detector; it was nominally 3 percent of the thermal value (see SAIC, 1989). The thermal flux peak was about $8 \times 10^{4}$ neutrons $/ \mathrm{cm}^{2}$-s for the $150-\mu \mathrm{g}$ source. The fluence impinging on a itcm as it travels through the center cavity at $15 \mathrm{~cm}$ ( 6 in.) per second was determined by integrating the mapped flux; it was calculated to be $4.5 \times 10^{5}$ neutrons/ $\mathrm{cm}^{2}$ 'The fast neutron fluence was estimated by calculating tir uncollided flux and integrating along the path of the item being scanned; it was calculated to be $2.5 \times 10^{5}$ neutrons $/ \mathrm{cm}^{2}$.

The neutron fluence calculated with the source in the operating position provides the basis for estimating the integrated neutron flux to which the baggage would be exposed. The measured fluence values were used in estimating the activation products in baggage contents using the calculated activation rates from Erdtmann's Neutron Activation Tables. Tables 5.1 and 5.2 show the potential activation products, activities, and dose rates for baggage contents containing $1-\mathrm{kg}(2.2-1 \mathrm{~b})$ masses of various elcments. Only reactions that produced initial activitics grcater than 0.001 becquerel $(\mathrm{Bq})(2.7 \times 10-8 \mu \mathrm{Ci})$ per gram of element are shown. The value of $0.001 \mathrm{~Bq} / \mathrm{g}$ was chosen because that is the amount of induced radioactivity equal to one-hundredth of that contained naturally in food (see Section 5.4.4).

A cursory glance at these tables shows that the vast majority of isotopes are rare earths and elements unlikely to be found in suitcases except in trace quantities. After only a 30 -second delay, the largest remaining isotopes are Sc-46m, V-52, In-116m(1), and Hf-179m, with an average dose rate of $0.18 \mu \mathrm{Sv} / \mathrm{hr}(18 \mu \mathrm{rem} / \mathrm{hr})$. All tables listing activity, dose rates, and total committed doses are in the 


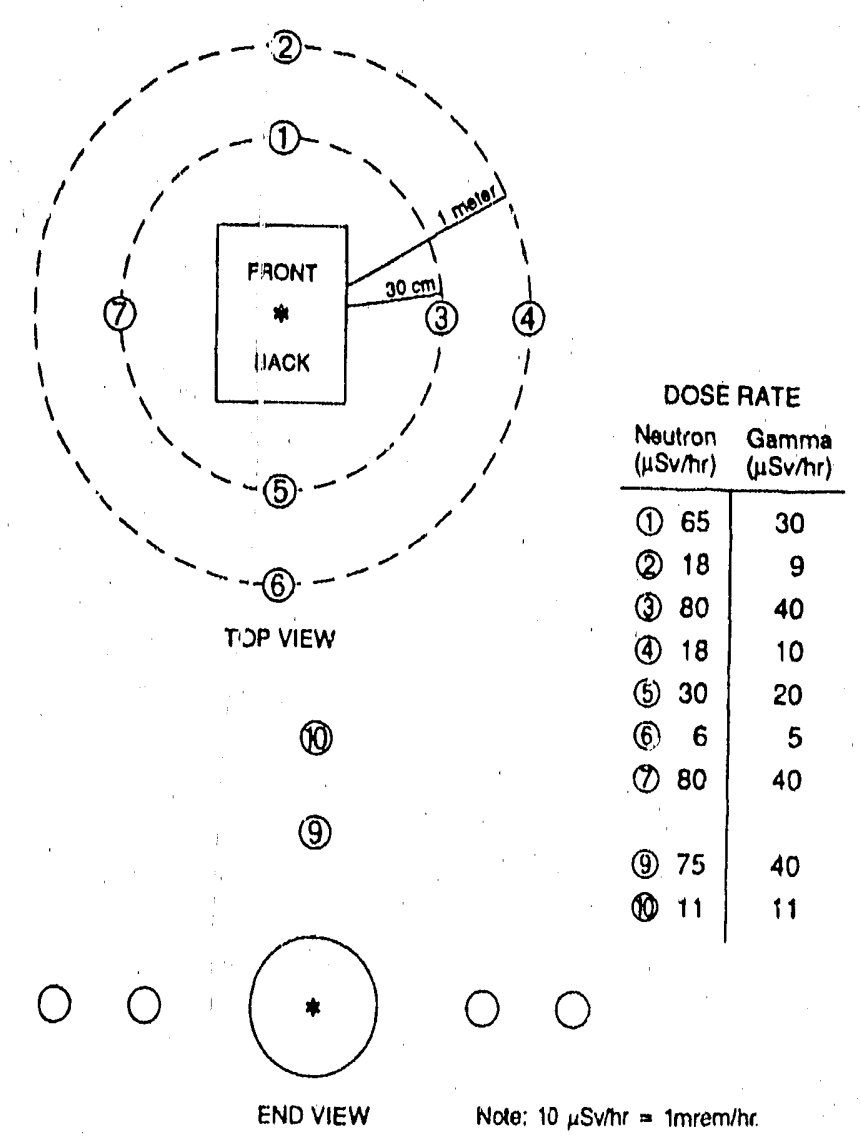

Figure 5.4 EDS-3C shipping cask dose rates

International System of Units (SI) (i.e., gray, sievert, and becquerel) (ICRU Report 33). ror corresponding tables using the English system of units (i.c., rad, rem, and microcurie), see Appendix B. Figure 5.5 shows the isodose contours (with loading and unloading platforms) that are based on dose rate measurements. Additional dose rate and fluence information can be found in Appendix C.

It should be noted that 1 sievert (Sv), the SI unit for dose, is equal to $100 \mathrm{rem}(R)$, the English unit. In addition, the becquerel (Bq) is equal to I disintegration per second, and 1 microcuric $(\mu \mathrm{Ci})$ is equal to $3.7 \times 10^{4} \mathrm{Bc}$.

Activation foils provided and analyzed by the National Institute of Standards and Technology (formerly the National Bureau of Standards) were used to measure the baggage passage neutron flux in the prototype TNA system, Model EDS-2. The results (see Appendix I)) were consistent with the determination of the thermal neutron fluence calculations in Tables 5.1 and 5.2.

\subsubsection{Radiation Exposure of Workers}

Workers such as operators, baggage handlers, and trained security screeners may be exposed to radiation from
EDS-3C oper :ons because of possible neutron activation of items is u ggage or from the small radiation ficlo in the area incy occupy. Workers may be exposed to radiation via four different pathways: exposure during normal operation to leakage radiation from the $\mathrm{Cf}-252$ source in the immediate area of the EDS-3C, direct radiation exposure to beta or gamma fields from luggage that has been through the EDS--3C, exposure of security screeners resulting from hand inspection of "suspect" irradiated luggage, and exposure during the transfer of the source to or from a shipping cask.

The direct radiation ficlds around the EDS- $3 \mathrm{C}$ have been measured. Figure 5.6 shows that the total dose rates (neutron plus gamma) in the area occupied during baggage loading and unloading are all less than $3 \mu \mathrm{Sv} / \mathrm{hr}$ $(0.3 \mathrm{mrem} / \mathrm{hr})$ at any distance $30 \mathrm{~cm}(1 \mathrm{ft})$ from the system. At distances greater than $1 \mathrm{~m}(3.3 \mathrm{ft})$, the total dose rates are all less than $0.9 \mu \mathrm{Sv} / \mathrm{hr}(0.09 \mathrm{mrcm} / \mathrm{hr})$. As an estimate, the average dose rates from cach end at $30 \mathrm{~cm}$ and $100 \mathrm{~cm}(1 \mathrm{ft}$ and $3.3 \mathrm{ft}$ ) were calculated to be 0.6 and $0.45 \mu \mathrm{Sv} / \mathrm{hr}(0.06$ and $0.045 \mathrm{mrcm} / \mathrm{hr})$, respectively. As a result, the average dose rate for personnel would be $0.5 \mu \mathrm{Sv} / \mathrm{hr}(0.05 \mathrm{mrcm} / \mathrm{hr})$.

If the EDS-3C is configured as shown in Figure 4.1, only one baggage handler would be near the TNA system
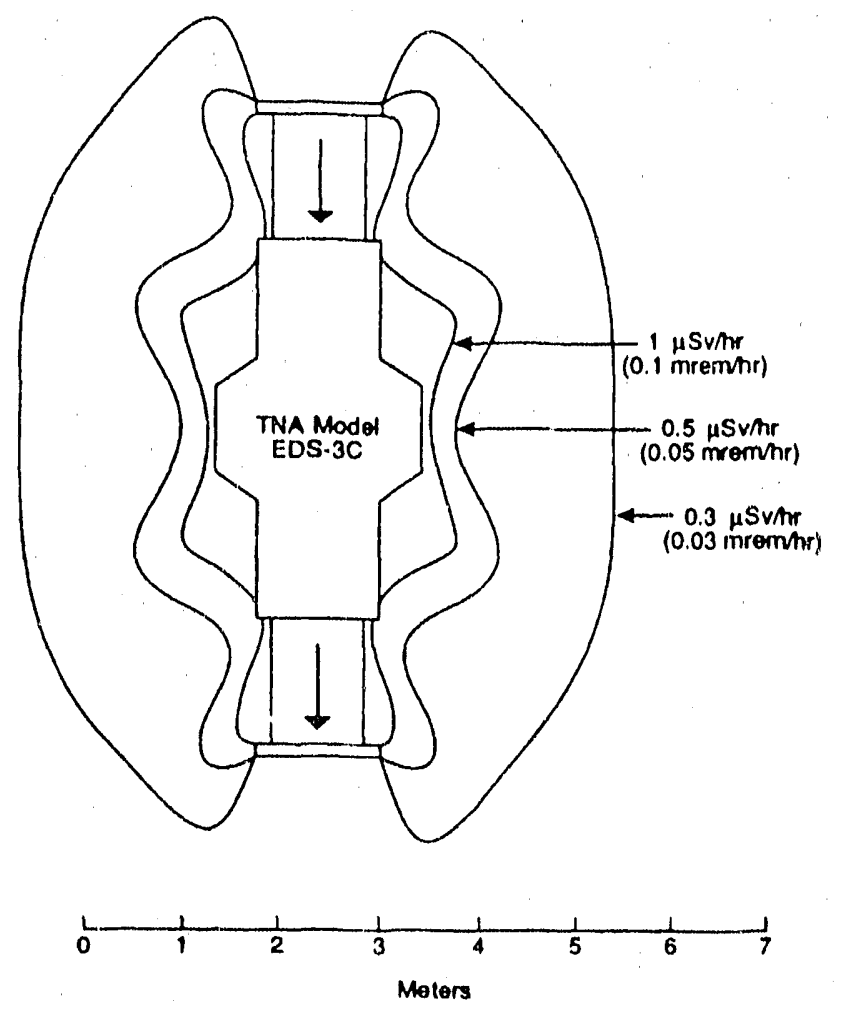

Figure 5.5 TNA system for lobby installation with issodose contours 
Table 5.1 Potential activation products (for slow neutrons*) of baggage contents containing $1-\mathrm{kg}(2.2-\mathrm{lb})$ masses of various elements

\begin{tabular}{|c|c|c|c|c|c|c|c|c|c|}
\hline \multirow[b]{2}{*}{ Product } & \multirow[b]{2}{*}{$\mathrm{Bq} / \mu \mathrm{g}$} & \multirow[b]{2}{*}{$\begin{array}{l}\text { Half-life } \\
(\min )\end{array}$} & \multirow[b]{2}{*}{$\begin{array}{l}\text { Gamma } \\
(\mathrm{MeV} / \mathrm{Bq})\end{array}$} & \multicolumn{2}{|c|}{$0.5-m i n$ delay } & \multicolumn{2}{|c|}{ 10-min delay } & \multicolumn{2}{|c|}{ 60-min delay } \\
\hline & & & & $\begin{array}{l}\text { Activity } \\
\text { (Bq/g) }\end{array}$ & $\begin{array}{l}\text { Dose rate } \\
(\mu \mathrm{Sv} / \mathrm{hr} / \mathrm{kg} \\
\text { (a) } 30 \mathrm{~cm})\end{array}$ & $\begin{array}{l}\text { Activity } \\
(B q / g)\end{array}$ & $\begin{array}{c}\text { Dose rate } \\
(\mu \mathrm{Sv} / \mathrm{hr} / \mathrm{kg} \\
@ 30 \mathrm{~cm})\end{array}$ & $\begin{array}{l}\text { Activity } \\
\text { (Bq/g) }\end{array}$ & $\begin{array}{l}\text { Dose rate } \\
(\mu \mathrm{Sv} / \mathrm{hr} / \mathbf{k g} \\
(@ 30 \mathrm{~cm})\end{array}$ \\
\hline $\mathrm{H}-3$ & $8.42 \mathrm{E}-10$ & $6.49 E+06$ & - & $3.79 E-11$ & - & $3.79 \mathrm{E}-11$ & - & $3.79 \mathrm{E}-11$ & - \\
\hline $\mathrm{N}-16$ & $3.50 \mathrm{E}-03$ & $1.19 \mathrm{E}-01$ & $4.60 \mathrm{E}+00$ & $8.56 \mathrm{E}-06$ & $6.39 \mathrm{E}-08$ & $8.05 E-30$ & $6.01 \mathrm{E}-32$ & $0.00 \mathrm{E}+00$ & $0.00 \mathrm{E}+00$ \\
\hline $0-19$ & $3.51 \mathrm{E}-113$ & $4.48 \mathrm{E}-01$ & $1.04 \mathrm{E}+00$ & $7.29 \mathrm{E}-05$ & $1.23 \mathrm{E}-07$ & $3.02 \mathrm{E}-11$ & $5.10 \mathrm{E}-14$ & $7.77 \mathrm{E}-45$ & $1.31 \mathrm{E}-47$ \\
\hline F-20 & $1.97 E-02$ & $1.83 \mathrm{E}-01$ & $1.64 \mathrm{E}+00$ & $1.33 E+00$ & $3.55 \mathrm{E}-03$ & $3.17 \mathrm{E}-16$ & $8.44 \mathrm{E}-19$ & $1.86 \mathrm{E}-98$ & $0.00 \mathrm{E}+00$ \\
\hline $\mathrm{Ne}-23$ & $2.43 E+01$ & $6.20 \mathrm{E}-01$ & $1.45 \mathrm{E}-01$ & $6.25 \mathrm{E}-01$ & $1.47 \mathrm{E}-04$ & $1.53 \mathrm{E}-05$ & $3.60 \mathrm{E}-09$ & $8.19 \mathrm{E},-30$ & $1.92 E-33$ \\
\hline $\mathrm{Na}-24$ & $1.80 E+00$ & $8.80 \mathrm{E}+02$ & $4.12 \mathrm{E}+00$ & $8.10 \mathrm{E}-02$ & $5.41 E-04$ & $8.04 \mathrm{E}-02$ & $5.37 \mathrm{E}-04$ & $7.73 \mathrm{E}-02$ & $5.16 \mathrm{E}-04$ \\
\hline $\mathrm{Mg}-27$ & $1.29 \mathrm{E}+00$ & $9.46 \mathrm{E}+00$ & $9.14 \mathrm{E}-01$ & $5.60 \mathrm{E}-02$ & $8.29 \mathrm{E}-05$ & $2.79 \mathrm{E}-02$ & $4.14 \mathrm{E}-05$ & $7.16 \mathrm{E}-04$ & $1.06 \mathrm{E}-06$ \\
\hline $\mathrm{Al}-28$ & $2.72 E+02$ & $2.24 \mathrm{E}+00$ & $1.78 \mathrm{E}+00$ & $1.05 E+01$ & $3.03 \mathrm{E}-02$ & $5.55 \mathrm{E}-01$ & $1.60 \mathrm{E}-03$ & $1.06 \mathrm{E}-07$ & $3.07 \mathrm{E}-10$ \\
\hline $\mathrm{Cl}-38$ & $5.55 \mathrm{E}+00$ & $3.72 E+01$ & $1.49 \mathrm{E}+00$ & $2.47 \mathrm{E}-01$ & $5.98 \mathrm{E}-04$ & $2.07 \mathrm{E}-01$ & $5.01 \mathrm{E}-04$ & $8.17 E-02$ & $1.97 \mathrm{E}-04$ \\
\hline Ar-41 & $1.06 \mathrm{E}+01$ & $1.10 \mathrm{E}+0^{\prime} 2$ & $1.28 \mathrm{E}+00$ & 4.75E-01 & $9.87 \mathrm{E}-04$ & $4.48 \mathrm{E}-01$ & $9.30 \mathrm{E}-04$ & $3.27 \mathrm{E}-01$ & $6.78 \mathrm{E}-04$ \\
\hline $\mathrm{Sc}-46 \mathrm{~m}$ & $4.73 E+04$ & $3.12 \mathrm{E}-01$ & $1.42 \mathrm{E}-01$ & $7.01 E+02$ & $1.61 \mathrm{E}-01$ & $4.81 E-07$ & $1.11 \mathrm{E}-10$ & $2.82 \mathrm{E}-55$ & $6.49 \mathrm{E}-59$ \\
\hline Ti-51 & $3.57 \mathrm{E}+00$ & $5.76 \mathrm{E}+00$ & $3.50 \mathrm{E}-01$ & $1.51 \mathrm{E}-01$ & $8.59 \mathrm{E}-05$ & $4.82 \mathrm{E}-02$ & $2.74 \mathrm{E}-05$ & $1.18 \mathrm{E}-04$ & $6.68 \mathrm{E}-08$ \\
\hline V-52 & $1.79 E+03$ & $3.75 E+00$ & $1.43 \mathrm{E}+00$ & $7.34 \mathrm{E}+01$ & $1.70 \mathrm{E}-01$ & $1.27 \mathrm{E}+01$ & $2.94 \mathrm{E}-02$ & $1.23 \mathrm{E}-03$ & $2.86 \mathrm{E}-06$ \\
\hline $\mathrm{Cr}-5 \mathrm{~s}$ & $3.22 \mathrm{E}+00$ & $3.56 \mathrm{E}+00$ & $6.57 \mathrm{E}-04$ & $1.31 \mathrm{E}-01$ & $1.40 \mathrm{E}-07$ & $2.07 \mathrm{E}-02$ & $2.20 \mathrm{E}-08$ & $1.23 \mathrm{E}-06$ & $1.31 \mathrm{E}-12$ \\
\hline $\mathrm{Mn}-56$ & $1.11 E+02$ & $1.55 E+02$ & $1.70 \mathrm{E}+00$ & $4.98 E+00$ & $1.37 \mathrm{E}-02$ & $4.78 \mathrm{E}+00$ & $1.32 \mathrm{E}-02$ & $3.82 \mathrm{E}+00$ & $1.05 E-02$ \\
\hline Co-60m & $2.33 E+03$ & $1.05 E+00$ & $1.23 \mathrm{E}-03$ & $7.54 \mathrm{E}+01$ & $1.50 \mathrm{E}-04$ & $1.43 \mathrm{E}-01$ & $2.84 \mathrm{E}-07$ & $6.65 \mathrm{E}--16$ & -21 \\
\hline $\mathrm{Ni}-65$ & $7.64 E+00$ & $1.51 \mathrm{E}+02$ & $5.63 \mathrm{E}-01$ & $3.43 E-01$ & $3.13 \mathrm{E}-04$ & $3.28 \mathrm{E}-01$ & $3.00 \mathrm{E}-04$ & $2.61 \mathrm{E}-01$ & $2.38 \mathrm{~F}$ \\
\hline $\mathrm{Cu}-64$ & $4.58 \mathrm{E}+00$ & $7.64 \mathrm{E}+02$ & $1.95 \mathrm{E}-01$ & $2.06 \mathrm{E}-01$ & $6.51 E-05$ & $2.04 \mathrm{E}-01$ & $6.46 \mathrm{E}-05$ & $1.95 E-01$ & $6.17 \mathrm{E}-05$ \\
\hline $\mathrm{Cu}-66$ & $1.47 E+02$ & $5.10 \mathrm{E}+00$ & $9.56 \mathrm{E}-02$ & $6.18 E+00$ & $9.58 \mathrm{E}-04$ & $1.70 \mathrm{E}+00$ & $2.64 \mathrm{E}-04$ & $1.90 \mathrm{E}-03$ & 2.95E-07 \\
\hline $\mathrm{Zn}-69$ & $3.69 \mathrm{E}+00$ & $5.70 \mathrm{E}+01$ & $4.78 \mathrm{E}-06$ & $1.65 \mathrm{E}-01$ & $1.28 \mathrm{E}-09$ & $1.47 \mathrm{E}-01$ & $1.14 \mathrm{E}-09$ & $8.01 E-02$ & $6.21 \mathrm{E}-10$ \\
\hline Ga-70 & $5.43 \mathrm{E}+01$ & $2.11 E+01$ & $5.55 \mathrm{E}-03$ & $2.40 \mathrm{E}+00$ & $2.16 \mathrm{E}-05$ & $1.76 \mathrm{E}+00$ & $1.58 \mathrm{E}-05$ & $3.41 \mathrm{E}-01$ & $3.06 \mathrm{E}-06$ \\
\hline Ga-72 & $2.59 \mathrm{E}+00$ & $8.46 \mathrm{E}+02$ & $2.03 E+00$ & $1.17 \mathrm{E}-01$ & $3.84 \mathrm{E}-04$ & $1.16 \mathrm{E}-01$ & $3.81 \mathrm{E}-04$ & $1.11 \mathrm{E}-01$ & $3.65 \mathrm{E}-04$ \\
\hline $\mathrm{Gc}-75 \mathrm{~m}$ & $6.38 \mathrm{E}+01$ & $8.15 E-01$ & $5.59 \mathrm{E}-02$ & $1.88 \mathrm{E}+00$ & $1.70 E-04$ & $5.82 \mathrm{E}-04$ & $5.28 \mathrm{E}-08$ & $2.00 \mathrm{E}-22$ & $1.81 E-26$ \\
\hline $\mathrm{Ge}-75$ & $1.05 E+00$ & $8.28 \mathrm{E}+01$ & $3.18 \mathrm{E}-02$ & $4.71 E-02$ & $2.43 \mathrm{E}-06$ & $4.35 \mathrm{E}-02$ & $2.24 \mathrm{E}-06$ & $2.86 \mathrm{E}-02$ & $1.47 \mathrm{E}-06$ \\
\hline $\mathrm{Ge}-77 \mathrm{~m}$ & $9.05 \mathrm{E}-01$ & $8.84 \mathrm{E}-01$ & $6.31 \mathrm{E}-02$ & $2.75 \mathrm{E}-02$ & $2.82 \mathrm{E}-06$ & $1.60 \mathrm{E}-05$ & $1.64 \mathrm{E}$ & $1.52 \mathrm{E}-2 \mathrm{~L}$ & $1.56 \mathrm{E}-26$ \\
\hline As-76 & $3.26 E+00$ & $1.58 E+03$ & $3.3^{\prime} 7 \mathrm{E}-0.1$ & $1.47 \mathrm{E}-01$ & $8.02 \mathrm{E}-05$ & $1.46 \mathrm{E}-01$ & $7.98 \mathrm{E}-05$ & $1.43 \mathrm{E}-01$ & $7.81 \mathrm{E}-05$ \\
\hline $\mathrm{Sc}-77 \mathrm{~m}$ & $5.69 E+03$ & $2.90 \mathrm{E}-01$ & $9.63 \mathrm{E}-02$ & $7.75 \mathrm{E}+01$ & $1.21 \mathrm{E}-02$ & $1.07 \mathrm{E}-08$ & $1.67 \mathrm{E}-12$ & $1.38 \mathrm{E}-60$ & $2.15 \mathrm{E}-64$ \\
\hline $\mathrm{Se}-79 \mathrm{~m}$ & $2.15 E+01$ & $3.91 E+00$ & $9.57 \mathrm{E}-03$ & $8.85 \mathrm{E}-01$ & $1: 37 \mathrm{E}-05$ & $1.64 \mathrm{E}-01$ & $2.55 \mathrm{E}-06$ & $2.33 E-05$ & $3.61 \mathrm{E}-10$ \\
\hline Sc- 81 & $1.33 E+01$ & $1.85 \mathrm{E}+01$ & $1.44 \mathrm{E}-02$ & $5.87 \mathrm{E}-01$ & $1.37 \mathrm{E}-05$ & $4.12 \mathrm{E}-01$ & $9.61 \mathrm{E}-06$ & $6.32 \mathrm{E}-02$ & $1.48 \mathrm{E}-06$ \\
\hline $\mathrm{Sc}-83$ & $3.45 \mathrm{E}+00$ & $2.25 E+01$ & $1.27 \mathrm{E}+00$ & $1.53 \mathrm{E}-01$ & $3.15 E-04$ & $1.14 \mathrm{E}-01$ & 2.35E-04 & $2.45 E-02$ & $5.04 \mathrm{E}-05$ \\
\hline $\mathrm{Br}-80 \mathrm{~m}$ & $5.48 \mathrm{E}+00$ & $2.65 \mathrm{E}+02$ & $2.41 \mathrm{E}-02$ & $2.46 \mathrm{E}-01$ & $9.62 \mathrm{E}-06$ & $2.40 \mathrm{E}-01$ & $9.39 \mathrm{E}-06$ & $2.11 \mathrm{E}-01$ & $8.24 \mathrm{E}-06$ \\
\hline $\mathrm{Br}-80$ & $2.91 E+02$ & $1.77 \mathrm{E}+01$ & $7.00 \mathrm{E}-02$ & $1.28 \mathrm{E}+01$ & $1.46 \mathrm{E}-03$ & $8.85 E+00$ & $1.00 \mathrm{E}-03$ & $1.25 E+00$ & $1.42 \mathrm{E}-04$ \\
\hline $\mathrm{Br}-82 \mathrm{~m}$ & $2.31 E+02$ & $6.10 \mathrm{E}+00$ & $4.22 \mathrm{E}-04$ & $9.82 \mathrm{E}+00$ & $6.72 \mathrm{E}-06$ & $3.34 E+00$ & $2.28 \mathrm{E}-06$ & $1.14 \mathrm{E}-02$ & $7.79 \mathrm{E}-09$ \\
\hline $\mathrm{Kr}-81 \mathrm{~m}$ & $3.77 \mathrm{E}+02$ & $2.22 \mathrm{E}-01$ & $1.27 \mathrm{E}-01$ & $3.56 \mathrm{E}+00$ & $7.34 \mathrm{E}-04$ & $4.70 \mathrm{E}-13$ & $9.69 \mathrm{E}-17$ & $7.72 \mathrm{E}-81$ & $1.59 \mathrm{E}-84$ \\
\hline $\mathrm{Kr}-83 \mathrm{~m}$ & $1.74 \mathrm{E}+01$ & $1.12 \mathrm{E}+02$ & $2.26 \mathrm{E}-03$ & $7.81 \mathrm{E}-01$ & $2.86 \mathrm{E}-06$ & $7.36 \mathrm{E}-01$ & $2.70 \mathrm{E}-06$ & $5.40 \mathrm{E}-01$ & $1.98 \mathrm{E}-06$ \\
\hline $\mathrm{Rb}-86 \mathrm{~m}$ & $4.20 \mathrm{E}+01$ & $1.02 \mathrm{E}+00$ & $5.46 \mathrm{E}-01$ & $1.35 \mathrm{E}+00$ & $1.19 \mathrm{E}-03$ & $2.12 \mathrm{E}-03$ & $1.87 \mathrm{E}-06$ & $3.74 \mathrm{E}-18$ & $3.31 \mathrm{E}-21$ \\
\hline $\mathrm{Rb}-88$ & $2.05 E+00$ & $1.78 \mathrm{E}+01$ & $6.37 \mathrm{E}-01$ & $9.05 \mathrm{E}-02$ & $9.35 \mathrm{E}-0.05$ & $6.25 E-02$ & $6.46 \mathrm{E}-05$ & $8.92 \mathrm{E}-03$ & $9.22 \mathrm{E}-06$ \\
\hline Y.90m & $4.16 E+00$ & $1.91 \mathrm{E}+02$ & $6.30 \mathrm{E}-01$ & $1.87 \mathrm{E}-01$ & $1.91 \mathrm{E}-04$ & $1.81 \mathrm{E}-01$ & $1.84 \mathrm{E}-04$ & $1.51 \mathrm{E}-01$ & $1.54 \mathrm{E}-04$ \\
\hline $\mathrm{Nb}-94 \mathrm{~m}$ & $3.80 \mathrm{E}+01$ & $6.26 \mathrm{E}+00$ & $1.17 \mathrm{E}-02$ & $1.62 \mathrm{E}+00$ & $3.07 \mathrm{E}-05$ & $5.65 E-01$ & $1.07 \mathrm{E}-05$ & $2.23 E-03$ & $4.23 \mathrm{E}-08$ \\
\hline Mo-101 & $1.35 E+00$ & $1.46 \mathrm{E}+01$ & $1.51 \mathrm{E}+00$ & $5.93 \mathrm{E}-02$ & $1.45 \mathrm{E}-04$ & $3.78 \mathrm{E}-02$ & $9.25 \mathrm{E}-05$ & $3.52 \mathrm{E}-03$ & $8.62 \mathrm{E}-06$ \\
\hline Rh-104m & $3.60 \mathrm{E}+03$ & $4.35 \mathrm{E}+00$ & $3.48 \mathrm{E}-02$ & $1.50 \mathrm{E}+02$ & $8.44 \mathrm{E}-(03$ & $3.29 \mathrm{E}+01$ & $1.86 \mathrm{E}-03$ & $1.14 \mathrm{E}-() 2$ & $6.45 \mathrm{E}-07$ \\
\hline Rh-104 & $1.54 \mathrm{E}+04$ & $7.05 E-01$ & $1.11 \mathrm{E}-02$ & $4.24 E+02$ & $7.63 \mathrm{E}-03$ & $3.73 E-02$ & $6.71 \mathrm{E}-07$ & $1.68 \mathrm{E}-23$ & $3.03 \mathrm{E}-28$ \\
\hline $\mathrm{P}^{2} \mathrm{~d}-107 \mathrm{~m}$ & $8.42 E+00$ & $3.55 \mathrm{E}-01$ & $1.52 \mathrm{E}-01$ & $1.43 \mathrm{E}-01$ & $3.52 \mathrm{E}-05$ & $1.26 \mathrm{E}-09$ & $3.11 \mathrm{E}-13$ & $5.14 \mathrm{E}-52$ & $1.27 \mathrm{E}-55$ \\
\hline $\mathrm{Pd}-109 \mathrm{~m}$ & $9.12 \mathrm{E}+00$ & $4.69 E+00$ & $1.14 \mathrm{E}-01$ & $3.81 \mathrm{E}-01$ & $7.05 \mathrm{E}-05$ & $9.36 \mathrm{E}-02$ & $1.73 \mathrm{E}-05$ & $5.79 E-05$ & $1.07 \mathrm{E}-08$ \\
\hline $\mathrm{Pd}-109$ & $3.37 \mathrm{E}+00$ & $8.08 E+02$ & $1.24 \mathrm{E}-(12$ & $1.52 \mathrm{E}-(01$ & $3.05 \mathrm{E}-06$ & $1.50 \mathrm{E}-01$ & $3.02 \mathrm{E}-06$ & $1.44 \mathrm{E}-01$ & $2.90 \mathrm{E}-06$ \\
\hline Ag-108 & $5.09 E+03$ & $2.41 \mathrm{E}+00$ & $2.94 \mathrm{E}-02$ & $1.98 E+02$ & $9.46 \mathrm{E}-03$ & $1.29 \mathrm{E}+01$ & $6.16 \mathrm{E}-(04$ & $7.36 \mathrm{E}-06$ & $3.51 \mathrm{E}-10$ \\
\hline $\mathrm{Ag}-110$ & $8.31 E+04$ & 4. $10 \mathrm{E}-01$ & $2.96 \mathrm{E}-02$ & $1.61 \mathrm{E}+03$ & $7.71 \mathrm{E}-02$ & $1.71 \mathrm{E}-04$ & $8.19 \mathrm{E}-09$ & $3.38 \mathrm{E}-41$ & $1.62 \mathrm{E}-45$ \\
\hline In-114 & $9.43 E+01$ & $1.20 \mathrm{E}+00)$ & $2.21 \mathrm{E}-03$ & $3.18 \mathrm{E}+00$ & $1.14 \mathrm{E}-05$ & $1.32 \mathrm{E}-02$ & $4.72 \mathrm{E}-08$ & $3.80 \mathrm{E}-15$ & $1.36 \mathrm{E}-20$ \\
\hline $\operatorname{In}-116 m(2)$ & $1.26 \mathrm{E}+06$ & $3.63 \mathrm{E}-02$ & $8.20 \mathrm{E}-() 2$ & $4.06 \mathrm{E}+00$ & $5.39 \mathrm{E}-04$ & $6.96 \mathrm{E}-79$ & $9.26 \mathrm{E}-83$ & $0.00 \mathrm{E}+00$ & $0.00 \mathrm{E}+00$ \\
\hline $\operatorname{In}-116 \mathrm{~m}(1)$ & $1.29 \mathrm{E}+03$ & $5.42 \mathrm{E}+01$ & $2.47 \mathrm{E}+00$ & $5.77 E+01$ & $2.31 \mathrm{E}-01$ & $5.11 E+01$ & $2.05 E-01$ & $2.70 \mathrm{E}+01$ & $1.08 \mathrm{E}-01$ \\
\hline
\end{tabular}

See footnotes at end of tible. 
Table 5.1 (continued)

\begin{tabular}{|c|c|c|c|c|c|c|c|c|c|}
\hline \multirow[b]{2}{*}{ Product } & \multirow[b]{2}{*}{$\mathrm{Bq} / \mu \mathrm{g}$} & \multirow[b]{2}{*}{$\begin{array}{l}\text { Half-life } \\
\text { (min) }\end{array}$} & \multirow[b]{2}{*}{$\begin{array}{l}\text { Gamma } \\
(\mathrm{MeV} / \mathrm{Bq})\end{array}$} & \multicolumn{2}{|c|}{$0.5-\mathrm{min}$ delay } & \multicolumn{2}{|c|}{ 10-min delay } & \multicolumn{2}{|c|}{ 60-min delay } \\
\hline & & & & $\begin{array}{l}\text { Activity } \\
(B q / g)\end{array}$ & $\begin{array}{l}\text { Dose rate } \\
\text { ( } \mu \mathrm{S} v / \mathrm{hr} / \mathrm{kg} \\
\text { (a) } 30 \mathrm{~cm})\end{array}$ & $\begin{array}{l}\text { Activity } \\
(\mathrm{Bq} / \mathrm{g})\end{array}$ & $\begin{array}{l}\text { Dose rate } \\
(\mu \mathrm{Sv} / \mathrm{hr} / \mathrm{kg} \\
\text { (ii) } 30 \mathrm{~cm})\end{array}$ & $\begin{array}{l}\text { Activity } \\
(B q / g)\end{array}$ & $\begin{array}{l}\text { Dose rate } \\
(\mu S v / \mathrm{hr} / \mathrm{kg} \\
\text { (a) } 30 \mathrm{~cm})\end{array}$ \\
\hline $\operatorname{In}-116$ & $1.36 \mathrm{E}+04$ & $2.37 \mathrm{E}-(01$ & $1.55 \mathrm{E}-02$ & $1.42 \mathrm{E}+02$ & & $1.22 \mathrm{E}-10$ & & $3.92 \mathrm{E}-74$ & $9.84 \mathrm{E}-79$ \\
\hline $\mathrm{Sn}-125 \mathrm{~m}$ & $1.09 \mathrm{E}+00$ & & $3.29 \mathrm{E}-01$ & $4.73 E-02$ & & $2.37 \mathrm{E}-02$ & & & $3.32 \mathrm{E}-(1) 7$ \\
\hline $\mathrm{Sb}-122 \mathrm{~m}$ & $7.08 \mathrm{E}-{ }_{-}-00$ & $4.21 \mathrm{E}+00$ & $5.96 \mathrm{E}-0.2$ & $2.93 \mathrm{E}-01$ & $2.84 \mathrm{E}-0.5$ & $6.14 \mathrm{E}-02$ & $5.94 \mathrm{E}-106$ & $1.64 \mathrm{E}-0.5$ & $1.58 \mathrm{E}-(09$ \\
\hline $\mathrm{Sb}-124 \mathrm{~m}$ & $8.42 E+00$ & $1.55 E+00$ & $3.48 \mathrm{E}-01$ & $3.03 \mathrm{E}-01$ & $1.71 E-(04$ & $4.33 \mathrm{E}-0.3$ & $2.45 \mathrm{E}-06$ & $8.48 \mathrm{E}-13$ & $4.78 \mathrm{E}-16$ \\
\hline l'c-131 & $2.08 \mathrm{E}+00$ & $2.50 \mathrm{E}+01$ & $3.54 \mathrm{E}-01$ & $9.23 \mathrm{E}-02$ & $5.30 \mathrm{E}$ & (19)-(12 & $4.07 \mathrm{E}$ & $1.77 \mathrm{E}-(12$ & -05 \\
\hline $\mathrm{I}-128$ & $2.00 \mathrm{~L}+02$ & $2.50 \mathrm{E}+01$ & $8.75 \mathrm{E} \ldots 2$ & $8.88 \mathrm{E}+00$ & & $6.82 \mathrm{E}+00$ & $9.68 \mathrm{E}-04$ & $71 E+100$ & $2.42 \mathrm{E} \cdots(04$ \\
\hline $\mathrm{Xc}-125 \mathrm{~m}$ & $1.70 \mathrm{E}+01$ & $9.50 \mathrm{E}-01$ & $1.11 \mathrm{E}-01$ & $5.31 \mathrm{E}-01$ & $9.56 \mathrm{E}-05$ & $5.20 \mathrm{E}-04$ & $9.35 \mathrm{E}-08$ & $7.50 \mathrm{E}--20$ & $1.35 E-23$ \\
\hline $\mathrm{Xc}-137$ & $1.99 E+00$ & $3.84 \mathrm{E}+00$ & $1.50 \mathrm{E}-01$ & $8.18 \mathrm{E}-02$ & $1.99 \mathrm{E}-05$ & $1.47 \mathrm{E}-(12$ & $3.58 \mathrm{E}-1) 6$ & $1.78 \mathrm{E}-1) 6$ & $4.32 \mathrm{E}-10$ \\
\hline Cs-134m & $9.28 \mathrm{E}+00$ & $1.74 \mathrm{E}-02$ & $2.34 \mathrm{E}-02$ & $9.38 \mathrm{E}-10$ & $3.56 \mathrm{E}-14$ & $0.00 \mathrm{E}+00$ & $0.00 \mathrm{E}+00$ & $0.00 \mathrm{E}+00$ & $0.00 \mathrm{E}+00$ \\
\hline $13 a-136 m$ & $1.31 E+03$ & & $1.92 E+00$ & $2.73 \mathrm{E}-28$ & & $0.00 \mathrm{E}+00$ & & $.0(0) \mathrm{E}+00$ & +60 \\
\hline $13 a-139$ & $1.55 \mathrm{E}+00$ & $8.33 \mathrm{E}+01$ & $4.18 \mathrm{E}-02$ & $6.95 \mathrm{E}-02$ & & $6.42 \mathrm{E}-1) 2$ & & & \\
\hline & $1.92 \mathrm{E}+00$ & $2.41 E+03$ & $2.32 \mathrm{E}+00$ & $8.64 \mathrm{E}-02$ & & $8.62 \mathrm{E}-02$ & & & $-(14$ \\
\hline $\operatorname{Pr}-142$ & $3.43 E+00$ & $1.15 \mathrm{E}+03$ & $5.83 \mathrm{E}-02$ & $1.54 \mathrm{E}-01$ & & $1.53 \mathrm{E}-01$ & & & \\
\hline $\mathrm{Ncl}-15 \mathrm{I}$ & $3.52 \mathrm{E}+00$ & $1.24 \mathrm{E}+01$ & $1.69 \mathrm{E}-01$ & $1.54 \mathrm{E}-() !$ & $4.22 E-(0.5$ & $9.06 E-02$ & $2.48 \mathrm{E}$ & $5.54 \mathrm{E}-(0) 3$ & -116 \\
\hline$S m-153$ & $1.19 \mathrm{E}+01$ & $2.79 \mathrm{E}+(13$ & $5.35 \mathrm{E}-(12$ & $5.35 \mathrm{E}-01$ & & $5.34 \mathrm{E}-01$ & & $5.28 \mathrm{E}-01$ & \\
\hline Sm-155 & $2.81 \mathrm{E}+01$ & $2.22 E+01$ & $8: 24 E-(12$ & $1.24 \mathrm{E}+00$ & $1.66 \mathrm{E}$ & $9.25 \mathrm{E}-(1) 1$ & & & -015 \\
\hline Eu-152m(2) & $9.21 \mathrm{E}+00$ & $9.60 \mathrm{E}+01$ & $7.38 \mathrm{E}-(12$ & 4.13E-01 & $4.94 \mathrm{E}$ & $3.86 \mathrm{E}-01$ & $4.61 \mathrm{E}$ & $2.96 \mathrm{E}-(1)$ & $3.22 \mathrm{E}-115$ \\
\hline Eu-152m(1) & $1.32 \mathrm{E}+03$ & $5.58 \mathrm{E}+02$ & $2.41 \mathrm{E}-01$ & $5.94 \mathrm{E}+01$ & $2.32 \mathrm{E}-(1) 2$ & $5.87 \mathrm{E}+01$ & $2.29 \mathrm{E}-102$ & $5.51 \mathrm{E}+01$ & $2.15 \mathrm{E}+(1)$ \\
\hline $\mathrm{Gol}-161$ & $2.19 \mathrm{E}+01$ & $3.70 \mathrm{E}+100$ & $3.09 \mathrm{E}-01$ & $8.97 \mathrm{E}-(01$ & $4.5(0 \mathrm{E}-0) 4$ & $1.51 \mathrm{E}-01$ & $7.59 \mathrm{E}-0.05$ & $1.30 \mathrm{E}-115$ & $1 \mathrm{E}-(19)$ \\
\hline $10 y-165 m$ & $1.64 \mathrm{E}+05$ & $1.26 \mathrm{E}+00$ & & $5.61 \mathrm{E}+03$ & & $3.02 \mathrm{E}+01$ & & & -16 \\
\hline Dy-165 & $8.69 \mathrm{E}+02$ & $1.41 E+(12$ & $E-1) 2$ & $3.90 \mathrm{E}+01$ & & $3.72 \mathrm{E}+01$ & $7.73 \mathrm{I}$ & $E+01$ & -104 \\
\hline-166 & $1.98 \mathrm{E}+01$ & -03 & $2.75 \mathrm{E}-$ & $8.91 \mathrm{E}-01$ & & $8.87 \mathrm{E}-01$ & $3.96 \mathrm{E}-$ & $8.68 \mathrm{E}-01$ & $3.87 \mathrm{E}-(15$ \\
\hline $\mathrm{Er}-167 \mathrm{~m}$ & $4.79 \mathrm{E}+104$ & $3.78 \mathrm{E}-02$ & $9.71 \mathrm{E}-(12$ & $2.25 \mathrm{E}-01$ & $3.55 \mathrm{E}-0.05$ & $5.16 \mathrm{E}-77$ & $8.13 \mathrm{E}-81$ & $0.00 \mathrm{E}+00$ & (1).00E $E+00$ \\
\hline Yb-175 & $1.39 \mathrm{E}+00$ & $0.03 E+03$ & $3.09 \mathrm{E}-(02$ & $6.25 \mathrm{E}-02$ & $3.13 E-106$ & $6.25 E-112$ & $3.13 E-116$ & $6.21 \mathrm{E}-1) 2$ & \\
\hline Yb-177 & $1.13 \mathrm{E}+00$ & $1.14 \mathrm{E}+02$ & $1.22 \mathrm{E}-01$ & $5.07 \mathrm{E}-(12$ & $1.00 \mathrm{E}-0.0$ & $4.79 \mathrm{E}-112$ & & -02 & $3-06$ \\
\hline $1 \mu-176 \mathrm{~m}$ & $4.78 \mathrm{E}+01$ & $2.21 E+112$ & $1.82 E-(1) 2$ & $2.15 E+00$ & $6.34 \mathrm{E}-05$ & $2.08 \mathrm{E}+00$ & & $1.78 \mathrm{E}+0 \mathrm{i}$ & $5.26 \mathrm{E}-105$ \\
\hline $1 \mu-177$ & $2.22 \mathrm{E}+00$ & $9.66 \mathrm{E}+0.3$ & $3 .(12 \mathrm{E}-1) 2$ & $9.99 \mathrm{E}-(12$ & $4.89 \mathrm{E}-(1) 6$ & $9.98 \mathrm{E}-122$ & $4.89 \mathrm{E}-106$ & $9.95 \mathrm{E}-102$ & $4.87 \mathrm{E}-106$ \\
\hline $\mathrm{Hf} \cdot 178 \mathrm{~m}$ & $1.10 \mathrm{E}+0.3$ & $7.17 E-(1) 2$ & $9.77 \mathrm{E}-(1) 1$ & $3.94 \mathrm{E}-011$ & $25 E-(14$ & $5.23 \mathrm{E}-41$ & $8.29 \mathrm{E}-44$ & $0.000 E+00$ & $0.000 \mathrm{E}+00$ \\
\hline $\mathrm{H}[-179 \mathrm{~m}$ & $2.46 E+0.4$ & $3.12 E-(1) 1$ & $2.87 \mathrm{E}-(1) 1$ & $3.65 E+(12$ & $1.70 \mathrm{E}-(01$ & $2.50 \mathrm{E}-0) 7$ & & & \\
\hline W-187 & $3.47 \mathrm{E}+(10)$ & $1.43 E+03$ & $4.31 \mathrm{E}-01$ & $1.56 \mathrm{E}-(0)$ & $1.09 \mathrm{E}-04$ & $1.55 \mathrm{E}-(0)$ & 1.09E-(14 & $1.52 \mathrm{E}-(0) 1$ & $1.06 \mathrm{E}-1) 4$ \\
\hline Rc-186 & $3.62 \mathrm{E}+00$ & $5.44 E+03$ & $1.80 \mathrm{E}-1) 2$ & $1.63 \mathrm{E}--01$ & $4.75 \mathrm{E}-116$ & $1.63 \mathrm{E}-01$ & $4.75 \mathrm{E}-(16)$ & $1.62 \mathrm{E}-01$ & $4.721 \mathrm{E}-106$ \\
\hline $\mathrm{Re}-188 \mathrm{~m}$ & $2.18 \mathrm{E}+01$ & $1.86 \mathrm{E}+01$ & $7.96 \mathrm{E}-(12$ & $9.63 \mathrm{E}-(1) 1$ & $1.24 \mathrm{E}-(1) 4$ & $6.76 \mathrm{E}-0) 1$ & $8.72 \mathrm{E}-115$ & $1.05 \mathrm{E}-01$ & $1.35 \mathrm{E}-015$ \\
\hline Re-188 & $1.85 E+01$ & $1.02 \mathrm{E}+03$ & $4.78 \mathrm{E}-02$ & $8.32 \mathrm{E}-(01$ & $6.45 \mathrm{E}-(1) 5$ & $8.27 \mathrm{E}-(1) 1$ & $6.41 \mathrm{E}-(155$ & $7.99 \mathrm{E}-011$ & $6.20 \mathrm{E}-115$ \\
\hline ()s-191m & $1.19 \mathrm{E}+00$ & $7.80 \mathrm{E}+12$ & $6.51 \mathrm{E}-03$ & $5.35 \mathrm{E}-02$ & $5.65 \mathrm{E}-07$ & $5.31 \mathrm{E}-12$ & $5.60) \mathrm{E}-117$ & $5.08 \mathrm{E}-(02$ & $5.36 \mathrm{E}-(17)$ \\
\hline $1 \mathrm{r}-192 \mathrm{~m}$ & $3.12 E+04$ & $1.40 E+00$ & $2.47 \mathrm{E}-(1) 4$ & $1.10 \mathrm{E}+03$ & $4.39 \mathrm{E}-(04$ & $9.95 E+00$ & $3.98 \mathrm{E}-116$ & $1.77 \mathrm{E}-10$ & $7.10 \mathrm{E}-17$ \\
\hline Ir-194 & $2.73 \mathrm{E}+01$ & $1.16 \mathrm{E}+03$ & $5.12 \mathrm{E}-02$ & $1.23 \mathrm{E}+100$ & $1 .(12 \mathrm{E}-0) 4$ & $1.22 \mathrm{E}+100$ & $1.01 \mathrm{E}-04$ & $1.29 \mathrm{E}+00$ & $9.84 \mathrm{E}-(1) 5$ \\
\hline $\mathrm{P} 1-199 \mathrm{~m}$ & $3.83 \mathrm{E}+00$ & $2.4(0 \mathrm{E}-1) \mathrm{j}$ & $3.42 \mathrm{E}-(1) 1$ & $4.07 E-(1) 2$ & $2.26 \mathrm{E}-05$ & $4.97 \mathrm{E}-14$ & $2.76 \mathrm{E}-17$ & $9.88 \mathrm{E}-77$ & $5.48 \mathrm{E}-80$ \\
\hline$P(-19)$ & $3.89 \mathrm{E}+00$ & $3 .(18 \mathrm{E}+01$ & $1.07 \mathrm{E}-01$ & $1.73 \mathrm{E}-01$ & $3.010 \mathrm{E}-05$ & $1.40 \mathrm{E}-(1) 1$ & $2.43 E-115$ & $4.54 E-(12$ & \\
\hline Au- 198 & $1.18 \mathrm{E}+(01$ & $3.88 E+103$ & $4.03 \mathrm{E}-01$ & $5.31 \mathrm{E}-(1) 1$ & $3.47 \mathrm{E}-(04$ & $5.30 \mathrm{E}-(0) 1$ & $3.46 \mathrm{E}-(1) 4$ & $5.25 \mathrm{E}-011$ & $3.43 \mathrm{E}-(14$ \\
\hline $\mathrm{Hg}-205$ & $2.03 E+00$ & $5.20 \mathrm{E}+001$ & $4.8(0) \mathrm{E}-113$ & $8.55 \mathrm{E}-(12$ & $6.65 \mathrm{E}-07$ & $2,41 \mathrm{E}-1) 2$ & $1.88 \mathrm{E}-(07$ & $3.118 \mathrm{E}-0) 5$ & $2.39 \mathrm{E}-10$ \\
\hline Ih-233 & $1.19 \mathrm{E}+(12$ & $2.23 \mathrm{E}+111$ & $1.08 \mathrm{E}-112$ & $5.27 E+100$ & $9.23 \mathrm{E}-(05$ & $3.92 \mathrm{E}+00$ & $6.87 \mathrm{E}-05$ & $8.30 \mathrm{E}-(0) 1$ & $1.45 \mathrm{E}-(15$ \\
\hline (J-2.39) & $1.01 E+02$ & $2.35 \mathrm{E}+01$ & $5.21 \mathrm{E}-112$ & $4.48 \mathrm{E}+00$ & $3.78 \mathrm{E}-(14$ & $3.38 \mathrm{E}+00$ & $2.86 \mathrm{E}-(14$ & $7.75 \mathrm{E}-(1) 1$ & $6.54 \mathrm{E}-(1) 5$ \\
\hline
\end{tabular}

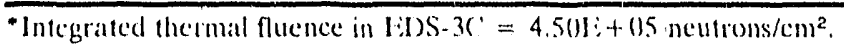

Note: $8.421 \mathrm{i}-10=8.42 \times 10.10 \mathrm{etc}$ 


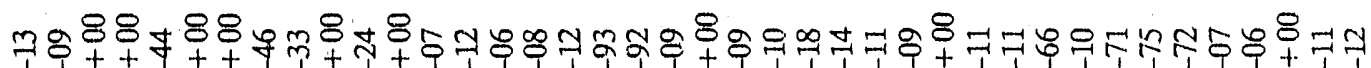

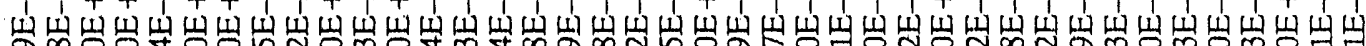

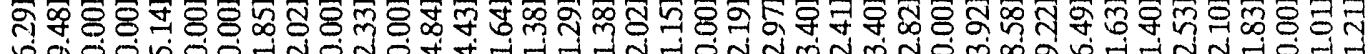

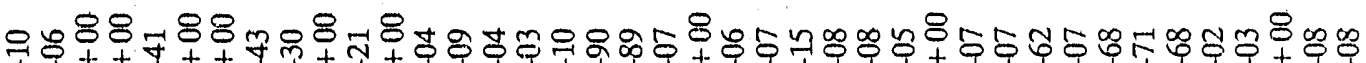

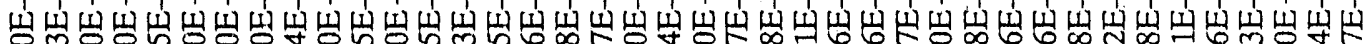
, minomion

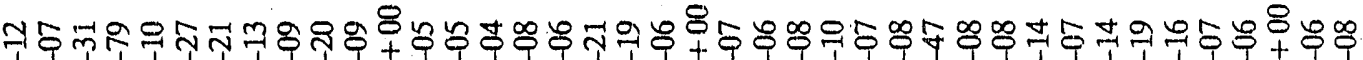

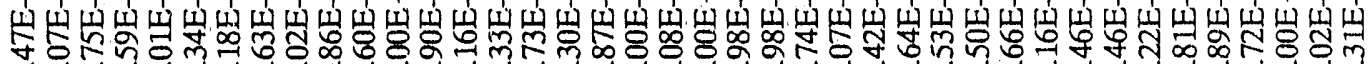

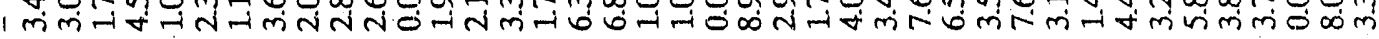

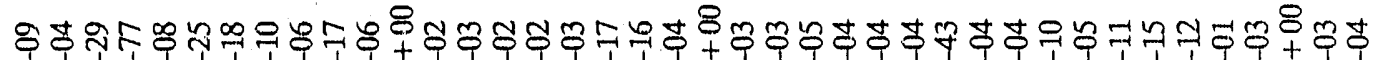

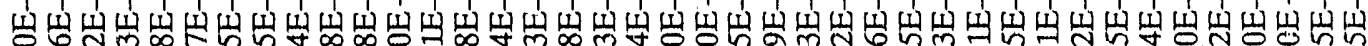

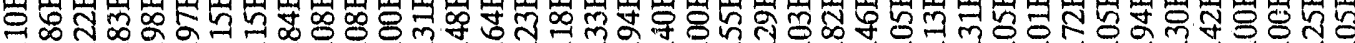

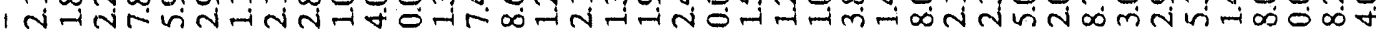

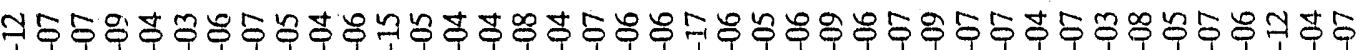

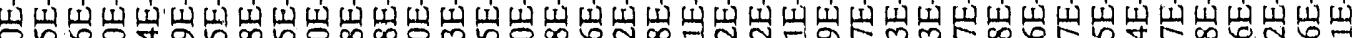

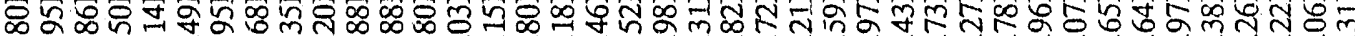

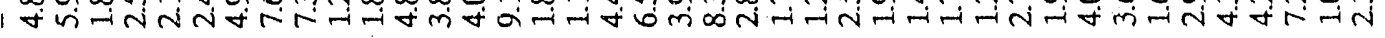

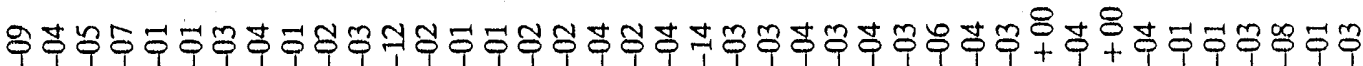

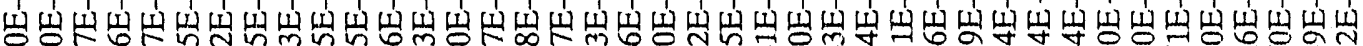

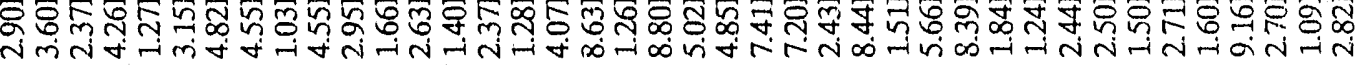

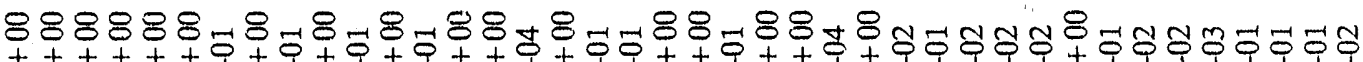

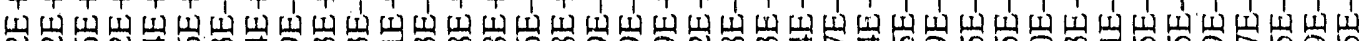

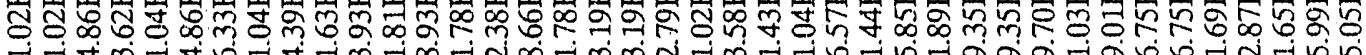

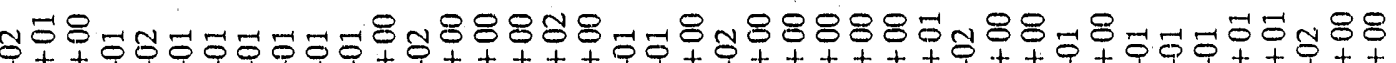

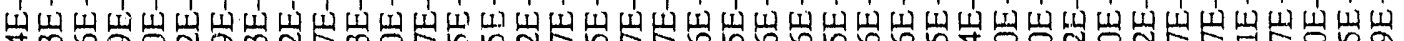

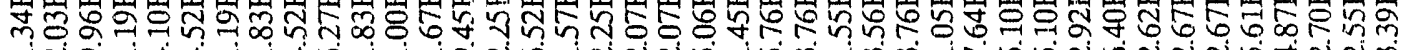

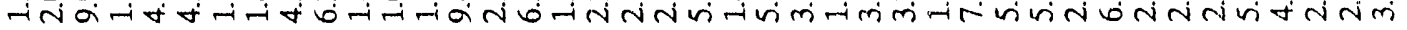

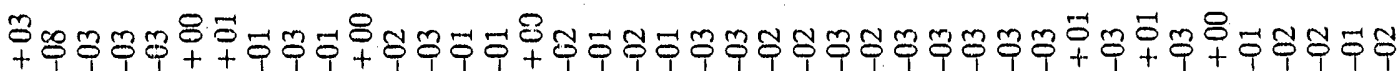

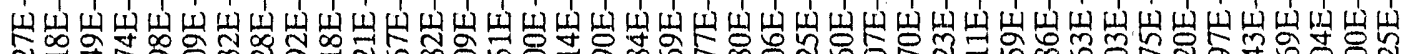
Эૈ,

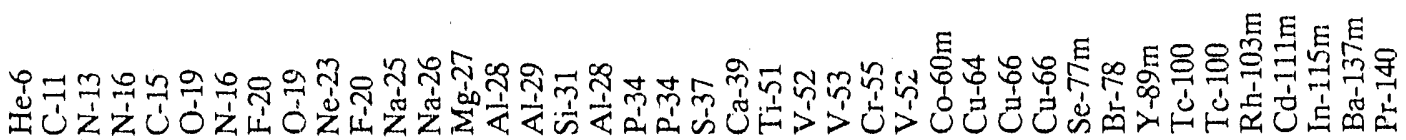

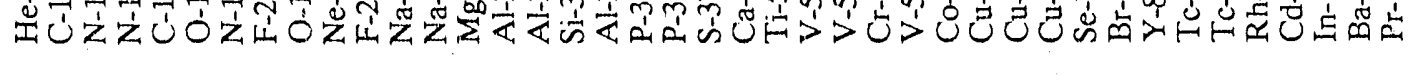




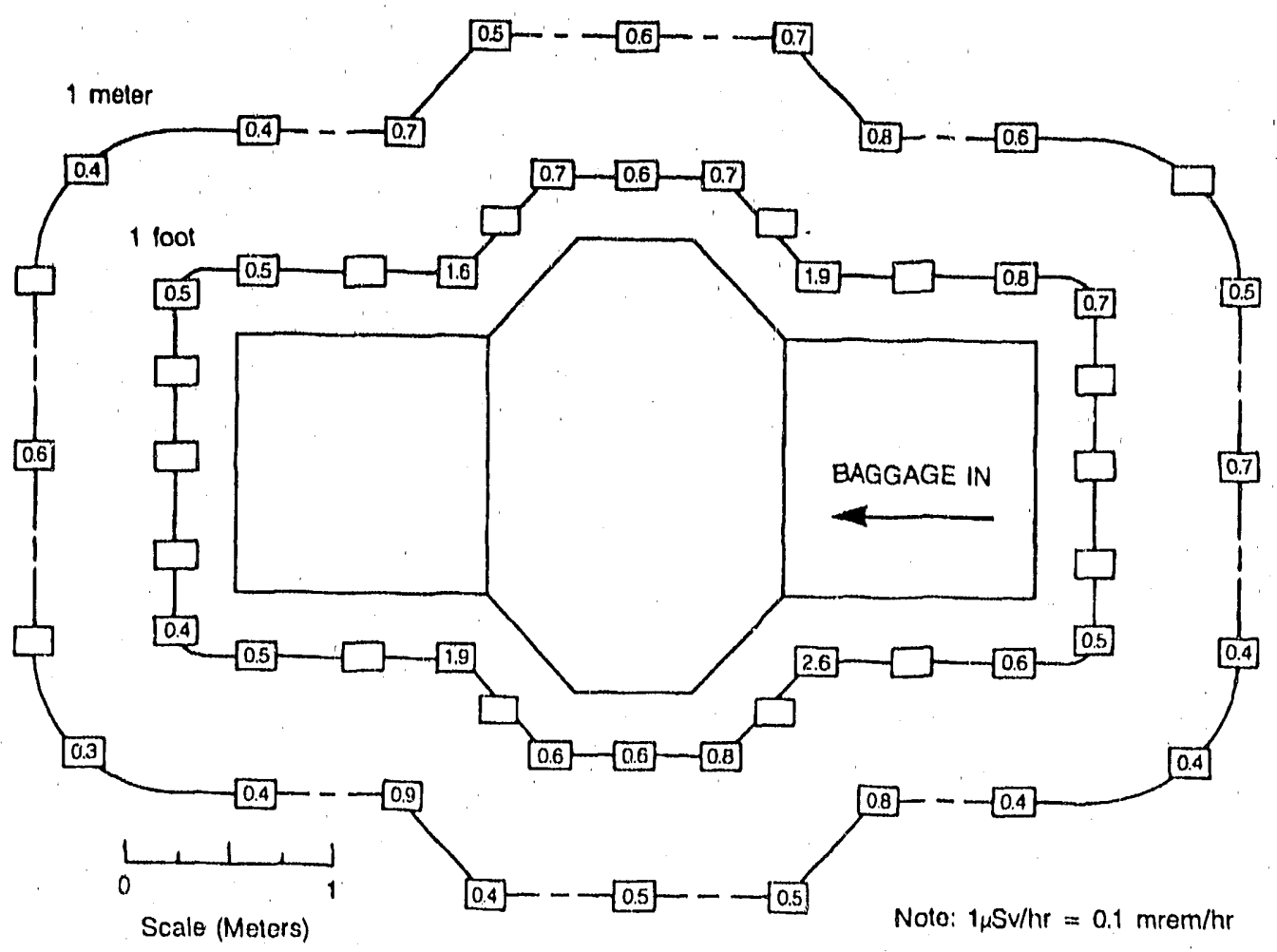

Figure 5.6 Total dose equivalent rates around EDS-3C ( $\mu$ Sv/hr)

when loading luggage onto the conveyor belt. The other baggage handler would be at the exit of the diverter, more

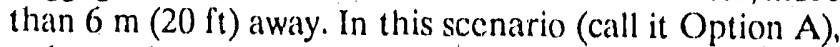
only one baggage handler would be in a potential radiation ficld of $0.5 \mu \mathrm{Sv} / \mathrm{hr}(0.05 \mathrm{mrcm} / \mathrm{hr})$. Because it is assumed that the EDS-3C will be in operation for 16 hours a day, this option requires threc full-timecquivalent personnel per operating urit (three 40-hr/wk shifts). For the proposed scenario at Dulles International Airport (call it Option B), however, the EDS-3C and the XENIS are at right angles to each other. In this case, both baggage handlers could be in radiation areas of $0.5 \mu \mathrm{Sv} / \mathrm{hr}$ $(0.05 \mathrm{mrcm} / \mathrm{hr})$. This option requires six full-timeequivalent personnel per operating unit (threc 40-hr/wk shifts).

The estimated annual dose to a baggage handler would be

$$
\begin{gathered}
0.5 \mu \mathrm{Sv} / \mathrm{hr} \times 40 \mathrm{hr} / \mathrm{wk} \times 50 \mathrm{wk} / \mathrm{yr}=1000 \mu \mathrm{Sv} \\
=1 \mathrm{mSV} / \mathrm{yr}(100 \mathrm{mrem} / \mathrm{yr})
\end{gathered}
$$

For Option B the estimated annual dose to baggage handlers would be $6 \times 10^{-3}$ person-Sv (6x10-1 person-rem) (6 baggage handlers $x 1 \mathrm{mSv} / \mathrm{yr}$ ); for Option $\mathrm{A}$ it would be $3 \times 10^{-3}$ person-Sv $\left(3 \times 10^{-1}\right.$ person-rcm) ( 3 baggage handlers $x 1 \mathrm{mSv} / \mathrm{yr}$ ) for each EDS-3C. For each of the scenarios proposed in Section 4.1, the calculated collec- tive dose of $6 \times 10-3$ person-Sv will be used as a conservative estimate of expected radiation dose. The EDS-3C, which will be used for lobby installations, is similat to the EDS-3, which is used for ramp installations, in terms of potential radiation exposure to 'TNA operators. As described in SAIC's 1988 environmental report, the annual exposure to T'NA operators was calculated by estimating the dose from both routine $[1.2 \mathrm{mSv} / \mathrm{yr}(120 \mathrm{mrem} / \mathrm{yr})]$ and source-transfer $[0.8 \mathrm{mSv} / \mathrm{yr}(80 \mathrm{mrem} / \mathrm{yr})]$ operations. The total exposure io an operator for each EDS-3C would be $2 \mathrm{mSv} / \mathrm{yr}(200 \mathrm{mrcm} / \mathrm{yr})$. For six full-timcequivalent operators, the collective dose for each system would be 0.012 person-Sv/yr (1.2 person-remiyr).

The total dose to workers from hand searching the lug. gage does not depend on the choice of EDS-3C installation scenario. If the 'INA system alarms, the baggage must be hand searched. This usually will take place immediately after the bag leaves the system, allowing only perhaps 15 seconds for activation products to decay. The security attendant conducting the scarch could get an additional dose from activation products, and because there is hand contact during the search, exposure to beta (and gamma) radiation may be possible.

Direct exposure rates from irradiated luggage are shown in Table 5.3. 'This is for an exposure $30 \mathrm{~cm}$ (1 fit) away from 
Table 5.3 Major activation products of baggage contents containing 1-kg (2.2-1b) masses of various elements

\begin{tabular}{|c|c|c|c|c|c|c|c|c|c|}
\hline \multirow[b]{2}{*}{ Product } & \multirow[b]{2}{*}{$\mathrm{Bq} / \mu \mathrm{g}$} & \multirow[b]{2}{*}{$\begin{array}{l}\text { Half-life } \\
(\mathrm{min})\end{array}$} & \multirow[b]{2}{*}{$\begin{array}{l}\text { Gamma } \\
(\mathrm{Mev} / \mathrm{Bq})\end{array}$} & \multicolumn{2}{|c|}{$0.5-\mathrm{min}$ delay } & \multicolumn{2}{|c|}{ 10-min delay } & \multicolumn{2}{|c|}{ 60-min delay } \\
\hline & & & & $\begin{array}{l}\text { Activity } \\
\text { (Bq/g) }\end{array}$ & $\begin{array}{l}\text { Dose rate } \\
(\mu \mathrm{Sv} / \mathrm{hr} / \mathrm{kg} \\
@ 30 \mathrm{~cm})\end{array}$ & $\begin{array}{l}\text { Activity } \\
\text { (Bq/g) }\end{array}$ & $\begin{array}{l}\text { Dose rate } \\
(\mu \mathrm{Sv} / \mathrm{hr} / \mathrm{kg} \\
@ 30 \mathrm{~cm})\end{array}$ & $\begin{array}{l}\text { Activity } \\
(\mathrm{Bq} / \mathrm{g})\end{array}$ & $\begin{array}{l}\text { Dose rate } \\
(\mu \mathrm{Sv} / \mathrm{hr} / \mathrm{kg} \\
@ 30 \mathrm{~cm})\end{array}$ \\
\hline$F-20$ & $1.97 \mathrm{E}+02$ & $1.83 \mathrm{E}-01$ & $1.64 \mathrm{E}+00$ & $1.33 E+00$ & $3.55 \mathrm{E}-03$ & $3.17 \mathrm{E}-16$ & $8.44 \mathrm{E}-19$ & $1.86 \mathrm{E}-98$ & $0.00 \mathrm{E}+00$ \\
\hline $\mathrm{Na}-24$ & $1.80 E_{1}+00$ & $8.80 \mathrm{E}+02$ & $4.12 \mathrm{E}+00$ & $8.10 \mathrm{E}-02$ & $5.41 \mathrm{E}-04$ & $8.04 E-02$ & $5.37 \mathrm{E}-04$ & $7.73 \mathrm{E}-02$ & $5.16 \mathrm{E}-04$ \\
\hline Al- 28 & $2.72 E+02$ & $2.24 E+00$ & $1.78 \mathrm{E}+00$ & $1.05 E+01$ & $3.03 \mathrm{E}-02$ & $5.55 \mathrm{E}-01$ & $1.60 \bar{E}-03$ & $1.06 \mathrm{E}-07$ & $3.07 \mathrm{E}-10$ \\
\hline $\mathrm{K}-42$ & $2.39 E-01$ & $7.42 E+02$ & $2.73 \mathrm{E}+02$ & $1.07 \mathrm{E}-(12$ & $4.76 \mathrm{E}-03$ & $1.07 \mathrm{E}-02$ & $4.72 \mathrm{E}-03$ & $1.02 \mathrm{E}-02$ & $4.50 \mathrm{E}-0 \mathrm{3}$ \\
\hline $\mathrm{Sc}-46 \mathrm{~m}$ & $4.73 E+04$ & $3.12 \mathrm{E}-01$ & $1.42 \mathrm{E}-01$ & $7.01 E+02$ & $1.61 \mathrm{E}-01$ & $4.81 \mathrm{E}-07$ & $1.11 \mathrm{E}-10$ & $2.82 \mathrm{E}-55$ & $6.49 \mathrm{E}-59$ \\
\hline V-52 & $1.79 E+03$ & $3.75 E+00$ & $1.43 \mathrm{E}+00$ & $7.34 \mathrm{E}+01$ & $1.70 \mathrm{E}-01$ & $1.27 \mathrm{E}+01$ & $2.94 \mathrm{E}-02$ & $1.23 \mathrm{E}-03$ & $2.86 \mathrm{E}-06$ \\
\hline$M n-56$ & $1.11 \mathrm{E}+02$ & $1.55 E+0.2$ & $1.70 \mathrm{E}+00$ & $4.98 \mathrm{E}+00$ & $1.37 E-02$ & $4.78 \bar{E}+00$ & $1.32 \mathrm{E}-02$ & $3.82 E+00$ & $1.05 \mathrm{E}-02$ \\
\hline $\mathrm{Se}-77 \mathrm{~m}$ & $5.69 \mathrm{E}+03$ & $2.90 \mathrm{E}-01$ & $9.63 \mathrm{E}-02$ & $7.75 \mathrm{E}+01$ & $1.21 \mathrm{E}-02$ & $1.07 \mathrm{E}-08$ & $1.67 \mathrm{E}-12$ & $1.38 \mathrm{E}-60$ & $2.15 E-64$ \\
\hline $\mathrm{Br}-80$ & $2.91 \mathrm{E}+02$ & $1.77 E+01$ & $7.00 \mathrm{E}-02$ & $1.28 \mathrm{E}+01$ & $1.46 \mathrm{E}-03$ & $8.85 \mathrm{E}+00$ & $1.00 \mathrm{E}-03$ & $1.25 \mathrm{E}+00$ & $1.42 \mathrm{E}-04$ \\
\hline $\mathrm{Rb}-86 \mathrm{~m}$ & $4.20 \mathrm{E}+01$ & $1.02 E+00$ & $5.46 \mathrm{E}-01$ & $1.35 \mathrm{E}+00$ & $1.19 \mathrm{E}-03$ & $2.12 \mathrm{E}-03$ & $1.87 \mathrm{E}-06$ & $3.74 \mathrm{E}-18$ & $3.31 \mathrm{E}-21$ \\
\hline $\mathrm{R} h-104 \mathrm{~m}$ & $3.60 \mathrm{E}+0.3$ & $4.35 E+00$ & $3.48 \mathrm{E}-02$ & $1.50 \mathrm{E}+02$ & $8.44 E-03$ & $3.29 \mathrm{E}+01$ & $1.86 \bar{E}-(03$ & $1.14 \mathrm{E}-02$ & $6.45 \mathrm{E}-07$ \\
\hline $\mathrm{Rh}-104$ & $1.54 E+04$ & 7.015E-01 & $1.11 \mathrm{E}-02$ & $4.24 \mathrm{E}+02$ & $7.63 \mathrm{E}-03$ & $3.73 \mathrm{E}-02$ & $6.71 E-07$ & $1.68 \mathrm{E}-23$ & $3.03 E-28$ \\
\hline $\mathrm{Ag}-108$ & $5.09 E+03$ & $241 E+00$ & $2.94 \mathrm{E}-02$ & $1.98 \mathrm{E}+02$ & $9.46 \mathrm{E}-(03$ & $1.29 \mathrm{E}+01$ & $6.16 \mathrm{E}-04$ & $7.36 \mathrm{E}-06$ & $3.51 \mathrm{E}-10$ \\
\hline Ag-110 & $8.31 E+04$ & $4.10 \mathrm{E}-01$ & $2.906-02$ & $1.61 E+03$ & $7.71 \mathrm{E}-02$ & $1.71 \mathrm{E}-04$ & $8.19 \mathrm{E}-09$ & $3.38 \mathrm{E}-41$ & $1.62 \mathrm{E}-45$ \\
\hline $\ln -116 m(1)$ & $1.29 E+03$ & $5.42 \mathrm{E}+01$ & $2.47 \mathrm{E}+00$ & $5.77 \mathrm{E}+01$ & $2.31 \mathrm{E}-01$ & $5.11 \mathrm{E}+01$ & $2.05 E-01$ & $2.70 E+01$ & $1.08 E-01$ \\
\hline In-116 & $1.36 \mathrm{E}+04$ & $2.37 \mathrm{E}-01$ & $1.55 \mathrm{E}-02$ & $1.42 E+02$ & $3.57 \mathrm{E}-03$ & $1.22 \mathrm{E}-10$ & $3.08 \mathrm{E}-15$ & $3.92 \mathrm{E}-74$ & $9.84 \mathrm{E}-79$ \\
\hline $1-128$ & $2.00 \mathrm{E}+02$ & $2.50 \mathrm{E}+01$ & $8.75 \mathrm{E}-02$ & $8.88 \mathrm{E}+00$ & $1.26 \mathrm{E}-03$ & $6.28 \mathrm{E}+00$ & $9.68 \mathrm{E}-04$ & $1.71 \mathrm{E}+00$ & $2.42 \mathrm{E}-04$ \\
\hline $\mathrm{Eu-152m(1)}$ & $1.32 E+03$ & $5.58 \mathrm{E}+02$ & $2.41 E-01$ & $5.94 \mathrm{E}+01$ & $2.32 E \cdot-02$ & $5.87 E+01$ & $2.29 \mathrm{E}-02$ & $5.51 \mathrm{E}+01$ & $2.15 \mathrm{E}-02$ \\
\hline$D y-165 m$ & $1.64 E+05$ & $1.26 \mathrm{E}+00$ & $1.09 \mathrm{E}-02$ & $5.61 E+03$ & $9.91 \mathrm{E}-02$ & $3.02 \mathrm{E}+01$ & $5.33 \mathrm{E}-04$ & $3.44 \mathrm{E} \cdots 11$ & $6.08 \mathrm{E}-16$ \\
\hline $\mathrm{Hf}-179 \mathrm{~m}$ & $2.46 E+04$ & $3.12 \mathrm{E}-(0) 1$ & $2.87 \mathrm{E}-(01$ & $3.65 \mathrm{E}+02$ & $1.70 \mathrm{E}-01$ & $2.50 \mathrm{E}-07$ & $1.16 \mathrm{E}-10$ & $1.47 \mathrm{E}-55$ & $6.82 \mathrm{E}-59$ \\
\hline Total & & & & & $1.03 E+00$ & & $2.82 \mathrm{E}-01$ & & $1.45 \mathrm{E}-01$ \\
\hline
\end{tabular}

Note: $1.07 \mathrm{E}+02=1.97 \times 10^{2} \mathrm{ctc}$

$1 \mathrm{~kg}(2.2 \mathrm{lb})$ of irradiated material that has decaycd $0.5,10$, and 60 minutes after leaving the EDS-3C. 'I he elements listed (taken from Tables 5.1 and 5.2) are those whose initial activities are greater than $1 \mathrm{~Bq} / \mathrm{g}$ of irradiated material 1 second after leaving the $\mathrm{EDS}-3 \mathrm{C}$.

Table 5.3 shows the clements that produce the largest activation products after passing through the EDS-3C. Although aluminum is not the element with the greatest activation, studies by Westinghouse have shown that it is the most predominant one found in luggage (Westinghouse, 1986). Therefore, calculations presented in this environmental assessment for skin dose have been based on the dose from aluminum. It should be noted that because of the short range for the beta particles in tissue, a relatively small area of tissue can be considered to be an infinite plane for dose calculation purposes. This dose is due to beta particles in a thin layer of activity equal to that generated by activation in two half thicknesses, which is $4.8 \mathrm{~Bq} / \mathrm{cm}^{2}\left(1.3 \times 10-4 \mu \mathrm{Ci} / \mathrm{cm}^{2}\right)$. All beta particles cmitted below two half thicknesses are self-absorbed in the aluminum and therefore do not contribute to the dose.

The following assumptions were made:
- The skin of the hand is in contact with a $10-\mathrm{cm}$ (4-in.) disk of aluminum for 60 seconds during the hand scarch.

- The entire suitcase frame is aluminum.

- Initially, approximately 10 pereent $(220,000)$ of the 2.2 million bags per year will require a hand search.

The computer code VARSKIN was used for calculating beta dose from skin contamination. Because of the limitations of VARSKIN, the smallest value that could be used to determine the beta skin dose for security screcness was $3.7 \times 10^{4} \mathrm{~Bq} / \mathrm{cm}^{2}\left(1 \mu \mathrm{Ci} / \mathrm{cm}^{2}\right)$. Table 5.4 shows that the dose rate for a $3.7 \times 10^{4} \mathrm{~Bq} / \mathrm{cm}^{2}$ source is $1.64 \times 10-{ }^{3} \mathrm{~Sv} / \mathrm{hr}$ $(0.164 \mathrm{rem} / \mathrm{hr})$. Because the aluminum suitcase only represents a source activity of $4.8 \mathrm{~Bq} / \mathrm{cm}^{2}\left(1.3 \times 10-4 \mu \mathrm{Ci} / \mathrm{cm}^{2}\right)$, the dose to both hands from a 60 -second search of an aluminum suitcase is $2.1 \mu \mathrm{Sv}(0.021 \mathrm{mrem})$. Because the International Commission on Radiological Protection has assigned a weighting factor for skin of 0.01 , the collective cffective dose equivalent for this assumption is $4.5 \times 10-4$ person-Sv/yr (4.5x10-2 person-rem/yr) for each system. This dose is shared among the three security personnel (one per shift) who conduct the searches. The passenger presenting the bag must be present during the physical 
Table 5.4 Calculated beta dose to the skin from a $3.7 \times 10^{4} \mathrm{~Bq} / \mathrm{cm}^{2}$ source

\begin{tabular}{|c|c|c|}
\hline \multirow[b]{2}{*}{ Variable } & \multicolumn{2}{|c|}{ Beta dose (Sv) } \\
\hline & $\begin{array}{l}\text { Averaged over } \\
\text { an area of } \\
\text { skin at the } \\
\text { basal layer }\end{array}$ & $\begin{array}{l}\text { At points } \\
\text { on the skin } \\
\text { basal layer }\end{array}$ \\
\hline \multicolumn{3}{|c|}{ Redius $(\mathrm{cm}) /$ area $\left(\mathrm{cm}^{2}\right)$} \\
\hline $0.5462 / 1.000$ & 0.0016 & - \\
\hline $6.14164 / 119.3869$ & 0.0011 & - \\
\hline \multicolumn{3}{|c|}{ Horizontal distance $(\mathrm{cm})$} \\
\hline 0.0000 & - & 0.0016 \\
\hline 3.8354 & - & 0.0015 \\
\hline 4.0214 & - & 0.0010 \\
\hline 4.1913 & - & 0.0016 \\
\hline 4.3449 & - & 0.0016 \\
\hline 4.4824 & - & 0.0015 \\
\hline 4.6037 & - & 0.0015 \\
\hline 4.7089 & - & 0.0015 \\
\hline 4.7978 & - & 0.0015 \\
\hline 4.8706 & - & 0.0015 \\
\hline 4.9272 & - & 0.0014 \\
\hline 4.9677 & - & 0.0012 \\
\hline 4.9919 & - & 0.0009 \\
\hline 5.0000 & - & 0.0008 \\
\hline 5.0081 & - & 0.0006 \\
\hline 5.0323 & - & 0.0004 \\
\hline 5.0728 & - & 0.0003 \\
\hline 5.1294 & - & 0.0002 \\
\hline 5.2022 & - & 0.0001 \\
\hline 5.2911 & - & 0.0001 \\
\hline 5.3963 & - & 0.0000 \\
\hline 5.5176 & - & 0.0000 \\
\hline 5.6551 & - & 0.0000 \\
\hline 5.8087 & - & 0.0000 \\
\hline 5.9786 & - & 0.0000 \\
\hline 6.1646 & - & 0.0000 \\
\hline
\end{tabular}

Note: The doses were calculated using VARSKIN MOD 1:

Disc source with radius $=5(1000) \mathrm{cm}$

Skin thickness $\quad=0.0070 \mathrm{~cm}$

Souree:

Radionuclide $=24: 9$

Average beta energy $=1.240 \mathrm{MeV}$

$X-90$ distance $=0.6470 \mathrm{~cm}$

Source strength $=3.7 \mathrm{l}+04 \mathrm{~B}(\mathrm{~g} /(\cdot \mathrm{l}))^{2}$

Irradiation time $\quad=60 \mathrm{~s}$

All rell damage oxeurs in an area with a radlus of $0.165 \mathrm{~cm}$. search, but may not participate directly in the search. The carricr shall retain control of the bag being searched, and the passenger may neither insert nor remove items from it.

The corresponding gamma ray dose was estimated by assuming that the suitcase would have the elemental composition shown in Table 5.5 (Westinghouse, 1986). The weight of aluminum was increased to $4.5 \mathrm{~kg}(9.9 \mathrm{lb})$ [from Westinghouse (1986)] to obtain a realistic gamma dose from an all-aluminum suitcase. Table 5.6 gives the activity and dose rates at $30 \mathrm{~cm}$ ( $1 \mathrm{ft}$ ). Clearly aluminum dominates the dose rate.

Initially, the alarmed-bag rate could be as high as 10 percent of the 2.2 million bags searched, or approximately 220,000 bags per year. Assuming that the average search takes 1 minute, a conservative estimate of the corresponding collective dose for each EDS-3C is 5.0x10-4 person-Sv/yr (5.0x 10 -2 person-rem/yr) $(220,000$ bags/yr x $1 \mathrm{~min} /$ bag $x 1 \mathrm{hr} / 60 \mathrm{~min} \times 1.38 \times 1(0.7 \mathrm{~Sv} / \mathrm{hr})$. Even if it is assumed that in the worst case, the suitcase contained $1 \mathrm{~kg}$ (2.2. lb) of every element listed in 'Table 5.3, the corresponding collective dose (at a $30-\mathrm{cm}$ distance) would be about $3.8 \times 10-3$ person-Sv/yr $(3.8 \times 10-1$ person-rem/yr) for each system. 'These doses are shared among the three individuals as stated above. The total dose from both beta and gamma radiation to each security sereener is $0.32 \mathrm{mSv} / \mathrm{yr}(32 \mathrm{mrem} / \mathrm{yr})$. 'The collective dose to this group of individuals is $9.5 \times 10-4$ person-Sv/yr $(9.5 \times 10-2$ person-rem/yr).

\subsubsection{Radiation Exposure of Passengers}

Passengers and other members of the public may be exposed to radiation from LDSS-3C operations beciluse of possible neutron activation of items in their baggage or because the device produces a small radiation field in the area they occupy. As stated earlier, passengers may be exposed to radiation via three different pathways: exposure of persons on the concourse level near the EDS-3C, direst radiation exposure of passengers to beta or gamma fields from luggage that has been through the LDS-3C, or internal dose to passengers or other members of the public who consume a food or other irradiated item that was contained in the reclaimed luggage.

In Sections 5.4.3.1 through 5.4.3.4, each of the concourse secnarios proposed in this assessment is evaluated. Typically, the passengers will deliver their luggage to an attendant or baggage handler at the entrance of the ISDS-3C. The attendant will place the luggage onto the conveyor beit, which will feed it into the liDS-3C.' I he baggage will then pass onto a roller platform or another conveyor belt from which it will be taken oll by another baggage atten. dant. In some cases, the passengers will not have access to their luggage onee it has been checked by the LISS-3C; in other scenarios, they may have to carry their lugggage to a 
Table 5.5 Elemental composition of the contents of an aluminum suitcase (quantities in grams)

\begin{tabular}{lrrrrrrrrr}
\hline Element & $\begin{array}{l}\text { Cloth. } \\
\text { ing }\end{array}$ & Shoes & $\begin{array}{l}\text { Toilet. } \\
\text { ries }\end{array}$ & $\begin{array}{l}\text { Touth. } \\
\text { paste }\end{array}$ & Shaver & Shampoo & Paper & $\begin{array}{l}\text { Suit. } \\
\text { case }\end{array}$ & Total \\
\hline Hydrogen & 307.0 & 55.0 & 23.0 & 16.5 & - & 34.0 & 141.0 & 254.0 & 830.5 \\
Carbon & 2546.0 & 490.0 & 145.0 & 10.6 & 2.2 & 194.0 & 1006.0 & 1307.0 & 5700.8 \\
Nitrogen & 483.0 & 145.0 & 27.0 & - & - & 7.0 & - & - & 662.0 \\
Oxygen & 1054.0 & 218.0 & 32.0 & 107.3 & - & 73.0 & 1124.0 & 1163.0 & 3771.3 \\
Sodium & - & - & - & 0.3 & - & - & - & - & 0.3 \\
Mangancse & - & 3.3 & - & - & 6.5 & - & - & - & 9.8 \\
Silicon & - & 0.9 & - & - & 1.8 & - & - & - & 2.7 \\
Phosphorous & - & 0.1 & - & 15.2 & 0.2 & - & - & - & 15.4 \\
Sulfur & - & 0.1 & - & 0.4 & 0.2 & - & - & - & 0.7 \\
Iron & - & 448.0 & - & - & 89.6 & - & - & - & 537.6 \\
Calcium & - & - & - & 19.6 & - & - & - & - & 19.6 \\
Aluminum & - & - & - & - & - & - & - & 4540.0 & 4540.0 \\
\hline
\end{tabular}

-All data are from Westinghouse (1986) teport, except the weight from aluminum (this amount was increased to reflect an all-alunninum suitease).

Table 5.6 Gamma dose rates from EDS-3C activation of the contents of an aluminum suitcase

\begin{tabular}{lrlll}
\hline Element & $\begin{array}{l}\text { Element } \\
\text { mass } \\
(\mathbf{g})\end{array}$ & $\begin{array}{l}\text { Suitcase } \\
\text { activity } \\
(\mathbf{B q})\end{array}$ & $\begin{array}{l}\text { Gamma } \\
(\mu \mathrm{Sv} / \mathbf{h r} / \mathbf{k g} \\
(\mathbf{3 0} \mathbf{c m})\end{array}$ & $\begin{array}{l}\text { Gamma dose } \\
\text { rate @ 30 cm } \\
(\mu \mathrm{Sv} / \mathbf{h r})\end{array}$ \\
\hline Hydrogen & 830.5 & - & - & - \\
Carbon & 5700.8 & $5.18 \mathrm{E}-09$ & - & - \\
Nitrogen & 662.0 & $8.88 \mathrm{E}-05$ & - & - \\
Oxygen & 3771.3 & $4.07 \mathrm{E}-01$ & - & - \\
Sodium & 0.3 & $2.29 \mathrm{E}-02$ & $5.41 \mathrm{E}-04$ & $1.62 \mathrm{E}-07$ \\
Manganese & 9.8 & $4.81 \mathrm{E}+01$ & $1.37 \mathrm{E}-02$ & $1.34 \mathrm{E}-04$ \\
Silicon & 2.7 & $1.30 \mathrm{E}-03$ & - & - \\
Phosphorous & 15.4 & $7.40 \mathrm{E}-09$ & - & - \\
Sulfur & 0.7 & - & - & - \\
Iron & 537.6 & - & - & - \\
Calcium & 19.6 & - & - & - \\
Aluminum & 4540.0 & $4.74 \mathrm{E}+04$ & $3.03 \mathrm{E}-02$ & $1.38 \mathrm{E}-01$ \\
$\quad$ Total & & & & $1.38 \mathrm{E}-01$ \\
\hline
\end{tabular}

Nole: $5.18 \mathrm{E}-(19)=5.18 \times 10)^{-8} \mathrm{ctc}$.

diflerent ticket counter and wait in line for some time before receiving their tickets. A complete summary of collective doses for each scenario is presented in Section 5.4.5.

Additional vertical shielding barriers will be placed at either end of the EIDS-3C to further lower the radiation exposure to members of the public and non-TNA personnel. These barriers will be constructed of hydrogenous material for neutron shiclding and heavy metal for gamma ray absorption. 'They will be sufficiently thick to reduce the penetrating radiation field to less than $1 \mu \mathrm{Sv} /$ hr $(0.1 \mathrm{mrcm} / \mathrm{hr})$ when the EDS-3C is running at peak capacity. For installations that could be accessible to the public, an exit housing for the conveyor belt with an opening for loading and unloading luggage will be installed. 
Population distribution data on the nutaber of international passengers enplaning at Jl'K International Airport were used to estimate the downward dose to passerigers located under the EDS-3C. At this very busy terminal, 9,010,570 international jassengers boarded an airplane in 1988 (Ryge, 199()). Statistics for 1987 (statistics for 1988 were not ayailable at the time of this writing) show that $2.2 \times 10^{7}$ passengers (on domestic and international flights) flew out of New York (U.S. Burcau of the Census, 1989). Because it is not reasonable to assume that all domestic and international flight passengers would either pass by the counter where the LDS-3C was located or pass underneath the LDS-3C, it was assumed that only the international flight passengers (about 40 percent of the total passengers at JFK Airport) would be in the vicinity of the EDS-3C. If non-passenger airport visitors and other air" port personnel amount to 100 pereent of the passenger population tensity, and only a small fraction (10 pereent) pass underneath the EDS-3C on their way to claim their luggage, the total number of people affected by the seenario would be $9.0 \times 10^{5}$.

In many cases, the baggage claim area is in the main terminal directly beneath the airline ticket counters. At San Francisco and Gatwick (London, England) International Airports, the average distance from the main level to the basement level (where the baggage reclaim areas are located) is $4.25 \mathrm{~m}$ (14 ft), and the concrete flooring between these two levels is approximately $20 \mathrm{~cm}(8 \mathrm{in}$.) thick. The dose rate decreases rapidly with increasing horizontal distane from the eenter of the 'I'NA system because of the inverse square law (se ligure 5.6). Assuming that the dose rate in the area directly underneath the INA system is $1 \mu \mathrm{Sv} / \mathrm{hr}(0.1 \mathrm{mrem} / \mathrm{hr})$ and that passengers only stay 15 minutes in the baggage reclaim area, the dose rate is $0.3 \mu \mathrm{Sv} / \mathrm{hr}(0.03 \mathrm{mrem} / \mathrm{hr})$. The total collective dose to this group of people passing underneath the LDS-3C is estimated to be

$$
\begin{gathered}
0.3 \mu \mathrm{Sv} / \mathrm{hr} \times 0.25 \mathrm{hr} \times 9 \times 10^{3} \text { passengers } \times 10-8 \mathrm{~Sv} / \mu \mathrm{Sv} \\
=6.8 \times 10)^{-2} \text { person-Sv/yr }
\end{gathered}
$$

\subsubsection{Behind the Check-In Counter}

In this secnario, the EDSS-3C will be placed behind the counter where passengers check their baggage, as they currently do for international flights. Because the bags will be placed onto the conveyor belt leading to the EDS-3C, the passenger will not be close to the INA system and will not receive any additional dose. Because the bag will not be returned to the passenger alfer inspection, there will be no dose from this pathway.

At the proposed site at the Dulles United Airlines international ticket counter, as many as 15 stations are available for ticket agents. Because these stations must be open for 16 hours a day, 7 days a week, this would require 50 full-time equivalent personnel (three $4($ )-hr/wk shifts,
50) wk/yr). 'These ticket personnel may be $2 \mathrm{~m}(6.6 \mathrm{ft})$ from the IDSS-3C, which would have a radiation area of about $0.3 \mu \mathrm{Sv} / \mathrm{hr}(0.03 \mathrm{mrem} / \mathrm{hr})$. In addition, the ticket agents will have to tag the luggage with a baggage claim check. Assuming an 8-hour shift for each ticket agent, the estimated dose to a ticket agent from neurby 'I'NA system operations would be $0.6 \mathrm{mSv} / \mathrm{yr}(60) \mathrm{mrcm} / \mathrm{yr})$. 'l he total collective dose for the ticket agents would be 0.03 personSv/yr (3 person-rem/yr).

If non-passenger airport visitors and other airport personncl amount to 100 pereent of the passenger population density, then it can be assumed that 9.0 $\left(10^{6}\right.$ nonpassengers could palss by the airline counter where the EDS-3C was located.

The estimated distance from the $1 \mathrm{BDS}-3 \mathrm{C}$ to nearby mombers of the public is about $10 \mathrm{~m}$ (33 ft). 'I'he potential radiation exposure from the EDS-3C at this distance is less than $1 \times 10-2 \mu S v / h r(1 \mu \mathrm{rem} / \mathrm{hr})$. Because the dose from natural background radiation is approximately $0.1 \mu \mathrm{Sv} / \mathrm{hr}(10 \mu \mathrm{rem} / \mathrm{hr})$, the dose to passengers walking by the EDS-3C (about 2 to 3 minutes) would be less than one-tenth the dose from natural background radiation.

Potential radiation exposure to operators $[6]^{*}$

$1.2 \times 10-2$ person-Sv

Potential radiation exposure to bagginge handler's $|6|^{*}$

$6 .(0 \times 10-3$ person-sv

Potential radiation exposure 10 ticket agents [45]*

3.(0) $10 .-^{2}$ person-Sv

Potential radiation exposure to security screeners $|3|^{*}$

$9.5 \times 1(1)-4$ person-Sv

Radiation exposure to the passengers $\left|1.1 \times 1()^{6}\right|^{*}$

(0) person-sv

Radiation exposurc to ncarby members of the public $\left[9.0 \times 100^{\circ}\right]^{*}$

Total for the behind-the-checkin-counter secenario

0 person-sv

$4.9 \times 1(0.2$ person-sv

\subsubsection{In Front of the Check.In Counter}

In this scenario, the entrance of the 'INA system will be placed in a public area in front of the check-in counter, and the exit will be placed behind the counter. 'The passenger will approach the system and wait in line until the luggage is loaded onto the conveyor belt. Members of the public could stand next to the I'NA system unless a barrier was erected, which would increase the system's already considerable size. Because the luggage will not be returned to the passenger after inspection, the passenger will not be exposed to any radiation from his or her luggage. An average dose rate of $0.3 \mu \mathrm{Sv} / \mathrm{hr}(0.03 \mathrm{mrem} / \mathrm{hr})$

\footnotetext{
"The numbers in brackets refer to the number of full-fime-eyuivilent workers, passengers, or nemby members of the public that could be affected.
} 
is assumed for a duration of 2 minutes (the time reculued to scan the bags of 10 passengers with 2 bags) while the passenger walts in line. This amount: 10 a $1 .(1) \times 1(1)-2 \mu$ Sv

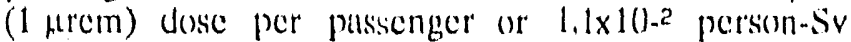
(1.1 person-rem) lor an estimated 1.1 million passengers per year. At Dulles Airport, approximately 430 international passengers per day lly on United Airlines (Hall, 199()). On the basis of these actual numbers, the total dose estimated at Dulles for this secnario is $1.6 \times 10.3$ person-Sv/yr (0.16 person-rem/yr), '1 this dose component applies to all concourse seenartos exeepl the one discussed in Section 5.4.3.1 (behind the check-in counter).

'The estimated distance from the lids - 30 to nearby members of the public is allout $4 \mathrm{~m}$ (13 ft). The postential radiation exposure from the 1 DSS-3C at this distance is $7.5 \times 10-2 \mu \mathrm{Sv} / \mathrm{hr}(7.5 \mu \mathrm{rem} / \mathrm{hr})$. Because the average dose from natural background radiation is $1 \times 1()-2 \mu \mathrm{Sv} / \mathrm{hr}$ $(1 \mu \mathrm{rem} / \mathrm{hr})$, the dose to passengers walking by the I:DS-3C would be less than that from background meliat-

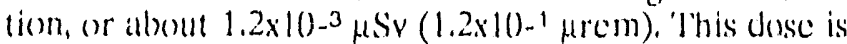
only a small fraction of the permissible limit of $5 \mathrm{mss} / \mathrm{yr}$ (50)( $\mathrm{mrem} / \mathrm{yr})$.

If it is assumed that members of the public are near this system for about I minute, the estimated annual collective dose to this group is $1.1 \times 10$-2 person-Sv (1.1 personrem).

Potential riadiation exposure 10 operators $|6|^{*}$

$$
1.2 \times 10-2 \text { persen-siv }
$$

Potential radiation exposure to

baggage handlers $|0|^{*}$

$0.0 \times 10.3$ person-siv

Potential radiation expesure 10 licket agents $|45|^{*}$

Potential radiation exposture (o) scenrity screcners $|3|^{*}$

\section{$3 .(0 \times 10-2 \operatorname{pors}(0)-5 v$}

$9.5 \times 11 .-4$ persion-Sy

Radiation exposure to the

patsengers $\left|1.1 \times 10^{6}\right|^{*}$

$1.1 \times 10-2$ person-sv

Radiation exposure to nearby members of the public $19.0 \times 100^{*} \quad 1.1 \times 10{ }^{2}$ person-sy

Thatal for the in-lront-ol-checkin-counter scenallio

\section{7. $1 \times 1(0-2$ person-sy}

\subsubsection{Pre.Check.In Area}

In this secnatro, the biss-3e will be placed between the terminal entrance and the tickel check-in counters (sec ligure 4.4). Passiengers will hand their luggage (1) an alltendant, who will place it on the IIDS-3C conveyor bell. The passengers will then walk along the length of the system as the luggage is scanned. Assuming that a passen

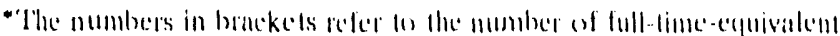

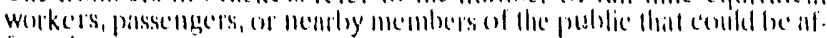
fectedi. ger walks reasemably close (o) the system, he or she will

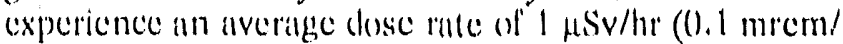
hr) for 60 seconds (26 seconds while the bag passess through the system plus some extra delay). 'I'his amounts to a dose of $1.7 \times 10-2 \mu \mathrm{Sv}(1.7 \mu \mathrm{rem})$ per passenger or 0.018 person-Sv (1.8 persen-rem) for an estimated 1.1 million passengers a year. Onec the luggage is cleared by the 1:1)S-3C, the allendant at the exit will band it with tamper-resistant security tape and return it to the passenger. The passenger will thon carty the luggage to the check-in counter, where it will be checked in for delivery to the aircrallt.

The amount of time that the passenger will earry the slightly radionative bag will vary significantly. If for any reason the airline were to cancel a scheduled filght, the passenger would be with the lugginge indefinitely. 'This would be the worst-cisse secnario lor this option. 'The total dose rate from all the elements listed in lable 5.3 is

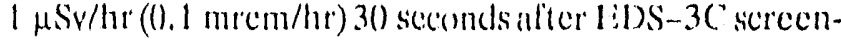
ing. After a 10-minute decily, however, the dose ralle decreases to $0.28 \mu \mathrm{Sv} / \mathrm{hr}(0.028 \mathrm{mrcm} / \mathrm{hr})$. Assuming that 1.1 million patsecngers would have to cirry two bags each from the liss-30 to the international ticket counter (about 5 minutes) and wait in line 15 minules to get to an airline tecket agent ( $(1.28 \mu \mathrm{Sv} / \mathrm{hr}$ ecould be used as the average dose rate), the estimated total collective dese annually to this group of passengers woukd be

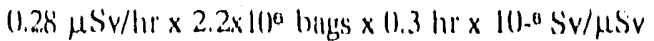

$$
\begin{aligned}
& =1.8 \times 10-1 \text { persom-s }-5 / y r
\end{aligned}
$$

The total dose to cach passenger from this secnario would be $1.8 \times 1()-1 \mu \mathrm{Sv} / \mathrm{yr}$ ( $18.5 \mu \mathrm{rem} / \mathrm{yr})$. 'The collective dose woukd be 2.(1) $\times 10$-1 persen-Siv/yr (20) person-rem/yr).

Because persomnel at the tickel counter al many airlines will have to tag the slightly radionetive lugghge with baggige claim checks and subseguently place the luggage on the conveyor belt to be transferred to the airplane, personnel also will receive a small additional dose. If 20 airlines have international ticket counters that are each stalfed with 10 tickel agents, the total number of full-time-eyuivalent personnel needed annually would be alpproximatcly 600). If ticket agents receive the luggage 10 minutes alfer bidos-30 sereening, the dese rate outside the luggige would be $(0.28 \mu \mathrm{S} v / \mathrm{hr}(0 .(28 \mathrm{mrem} / \mathrm{hr})$. Assuming it takes a ticket agent 1 minute to tag two bags from each passenger, the annual dose te eich ticket agent would he $17 \mu \mathrm{Sv} / \mathrm{yr}(1.7 \mathrm{mrem} / \mathrm{yr})$ :

$$
\frac{2.2 \times 10^{6} \text { hagsiyr }}{600110 \mathrm{kel} \text { agents/yr }} \times 0.28 \mu \mathrm{sv} / \mathrm{hr} \times 1 / 60 \mathrm{hr}:=17 \mu \mathrm{sv} / \mathrm{yr}
$$

The tolill collective desse to the licked persennel would be 1.(1) $1(1)-2$ persen-Sw/yr (1.) person-rem/yr). 
Passengers, thelr entourages, and non-l'NA personnel who also may noed to walk by the EDS- 3 C could recelve some radiation dose. If non-passenger alrport visitors and other alrport personnel amount to 100 percent of the passenger population density, and assuming that each passenger stays 2 minutes near the EDS-3C at a distance of $3 \mathrm{~m} \mathrm{(10} \mathrm{ft)} \mathrm{|radiation} \mathrm{dose} \mathrm{at} \mathrm{this} \mathrm{distance} \mathrm{is} 0.2 \mu \mathrm{Sv} / \mathrm{hr}$ $(0.02 \mathrm{mrem} / \mathrm{hr})$ ), the total collective dose would te

$$
\begin{aligned}
& 0.2 \mu \mathrm{Sv} / \mathrm{hr} \times 2 \mathrm{~m} / \mathrm{n} \times 1 \mathrm{hr} / 60 \mathrm{~min} \times 111-\mathrm{S} \mathrm{S} / \mu \mathrm{S} v \times 9.0 \times 10^{0} \\
& =6 .\left(2 \times 10 .-^{2} \mathrm{jerson} / \mathrm{Sv}\right.
\end{aligned}
$$

If the time for each passenger and accompanying visitor were to increase to 5 minutes, the estimnted total collective dose would be 0.15 person-Sv (15 person-rem).

\section{Potential radiation exposure to operators $|6|^{*}$}

Potential radiation exposture to baggage handlers $|6|^{*}$

$1.2 \times 10.2$ person-sv

Potential radiation expostare (o) ticket agents $\mid(60)]^{*}$

Potential radiation exposure to security screcners $|3|^{*}$

Radiation exposure to the passengers $\mid\left[.\left.|x| 0^{6}\right|^{*}\right.$

Radiation exposure to nearby members of the public $|9.0 \times 10|^{*}$

Thatal for the pre-check-in-area scemarion

$$
\text { 6.(0) } 10.3 \text { person-sv }
$$

1.(0) 10.2 person-Sv

$9.5 \times 10-4$ person-sv

$2 .(0 \times 10.1$ person-Sv

$6 .\left(1 \times 10.2^{2}\right.$ person-sy

$2.9 \times 10 . .1$ person-sy

\section{$5.4,3,4$ Curbside Areu}

In the last secenario, the 1:DS-3C will be placed along the departure curb antside the main airport terminal. The passengers will hand their luggage fo an altendant and wait for it to be cleared in order to receive a cham check. Depending on the specifie setup, the passenger might walk alongside the system to the exit. An average dose rate of (0.3 $\mu \mathrm{Sv} / \mathrm{hr}$ ( $(1.0 .3 \mathrm{mrem} / \mathrm{hr}$ ) is assumed for a duration of 10 minutes. Passengers will have to wait longer nealr the liss-30 than in the in-front-of-the-check-incounece scenario becaluse they will have to wait for the bagkinge claim chect. 'This amounts to a dose of $5 .() \times 1()-2 \mu S v(5 \mu \mathrm{rem})$ for ach pissisenger or $5.5 \times 10.2$ persen-Sv (5.5 persen-tem) for an estimated 1.1 million passerigers a year.

Al many intended curbside locations, three to five skycaps may be available for licketing checked-in luggage. Beciluse the sky-cilp stations could be open for 16 hours a day, 7 dilys a weck, this would recpuire als many as 1.5 full-

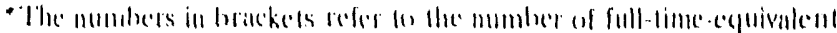

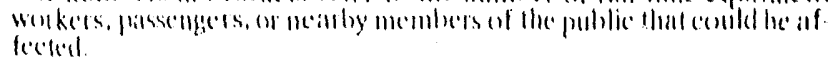

time-equivalent personnol (three 40)-hr/wk shifts, 50) wk/ yr). These skyacips will have to tag the luggage with a baggage claim check. Assuming it takes a sky-cap $1 \mathrm{~min}$ ute to tag two bags from ench passenger, that each bag contains all the elements listed in Table 5.3, and that the luggage contents have decrayed only 30 seconds, the estimated annual dose to each sky-cap would be $0.25 \mathrm{mSv} / \mathrm{yr}$ $(25 \mathrm{mrem} / \mathrm{yr})$ :

$$
\begin{gathered}
\frac{2.22 \times 10^{6} \mathrm{hags} / \mathrm{yr}}{15 \mathrm{sky}-\mathrm{oups}} \times \frac{0.1 \mu \mathrm{sv} / \mathrm{hr}}{\mathrm{bag}} \times 1 / 60 \mathrm{hr} \\
=247 \mu \mathrm{Sv} / \mathrm{yr}=0.25 \mathrm{mSv} / \mathrm{yr}
\end{gathered}
$$

The total collective dose to this group of workers would be $3.8 \times 10-{ }^{3}$ persion-Sv/yr $(3.8 \times 10-1$ person-rem/yr).

Other members of the public might pass near the system, but much fower than in the pre-check-in-arca scenario (Section 5.4.3.3). If the assumption is made that 10 percent of the public (non-passengers) might walk near the ID)S -3 C on their way to the terminal, then the collective close to this group would be $6.0 \times 1(0.3$ person-Sv (0.6 person-rem) $(0.1 \times 6.0 \times 1(1) 2$ person-Sv).

Potential radiation exposure to operalors $|6|^{*}$

$1.2 \times 10.2$ person-sv

Potential racliation exposure to sky-cilps $[1.5]^{*}$

$3.8 \times 10-3$ person-sv

Potential radiation exposure to ticket agents $|60(0)|^{*}$

() person-sv

Potential radiation expositure to security sereeners $|3| *$

$9.5 \times 1(1-4$ person-Sy

Radiation exposure to the passengers $\left.\mid\} .1 \times 10^{6}\right\}^{*}$

$5.5 \times 10.2$ person-Sy

Radiation exposure to nearby members of the public $\left|9 .(1):()^{5}\right|^{*}$

6.(1) 10.3 person-siv

lotal for the curbside-area scenario

$7.8 \times 10.2$ person-sy

\subsubsection{Effects of Irradiation on Baggage Contents}

food, medical supplies, and ofher consumalolo items are subjected daily to radiation exposures, without protective measures, above those which they would receive normally. 'l'his occurs white the items are in transit on airline flights to the desired destinution. Neutron and gaimma ray expossure mates have been measured for average light paths. A 5-hour transeontinental or transittlantic flight at $12 \mathrm{~km}(7.5 \mathrm{mi}) \mathrm{and}$ at mid-latitudes would result in an absorbed dose of 1.5 micrograys ( $\mu$ (iy) ( $1.5 \mathrm{mrad}$ ) or a dose equivalent of $2.5 \mu \mathrm{Sv}(2.5 \mathrm{mrem})$ to

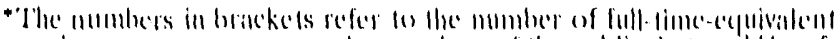

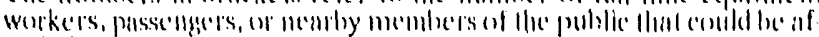
foretert
} 
the whole body (N('RR Report 94). An extreme case would be a 10 -hour polar llight, for example, from Califormia to liurone, in which ease long flight times and higher cosmic-ray intensities al high latitudes would result in an abserbed dose of $50 \mu$ (iy $(5$ mrad) or 10()$-\mu S v$ (1)-mrem) dose ecpuivalent. It should be noted, however, that frequent llyers and most erew members may receive annual dose equivalents of ahout $1 \mathrm{msiv}$ (10)( mrem), while some crew members maly receive dose equivalents that are several times higher (see N( RI' Report 94).

Passage through the INA system would expose medicine, lotiorl, drugs, or other items in a sutcitase fo a slow noutron fluenee of $4.5 \times 10)^{5}$ neutrons/ $\mathrm{cm}^{2}$ if the item were lecuted at the peak flux. 'This neutron exposutere is less than that experienced from cosmic ralys in Denver each year, which results in a dese equivalent ralle of $0.5 \mathrm{mSv} / \mathrm{yr}(50) \mathrm{mrcm} /$ yr) (sec N('Rl' Repurt (4).

\subsubsection{Consumuble ltems}

Passengers maly also carry consumalile items (including food) in their luggage. Small amounts of naturally oceurring radionuclides already exist in the forod that we eat. lior example, potussium-40 (K-4(1) is a naturally oceurring radionctive isotope that is contained in essentially all the food that we eat. It has an abundance (found in nature) of (0.0)117 pereent, a radioactive hall-life of $1.25 \times 10^{9}$ years, and a high-encegy gamma ray as well. Since k-40 has a specific activily of 8.38 picocuries per gram of potassium and peanuts, for example, contain 0.674 perecont potassium, I g (0.013.5 (6z) of peanuts contains (0.209 Bo of K.40) (National Institute of Standards and' I'echnolengy, 1989), It secms reasonable to consider all amount of indued radinactivity equal to one-hundredth of that contained naturally in a single peanut to be negligible. It is for this reason that Tables 5.1 and 5.2 only include induced raddioactivity greater that $0.0(0) 13 \mathrm{~g} / \mathrm{g}$ (see Section 5.4.1). ()nly four raclionctively induced elements-o rhodium (Rh), indium (In), curopium (liu), and dysprosium (Dy) (four relatively ritre elements) wowle woxeed the amount of natural raddonctivity in a 142-g (5-12x) bag of peanuts 10 minutes alter they left the IINA system.

Table 5.7 showws the daily intalkes of the elements that are the principal contributers to the dose that would be received and the dose estimates for each element under the atssumed conditions. The mein diaty intakes of vartous elements shown in this table were ohtained from IC 'RP Publicalion 23 and apply to the "reference man" concept in rindiation protection. The effective dose equivalents were calculaled using dose conversion fictors from IC 'RP' Publicatlon 30, which rellects the IC RRP bised system of dese limitation and the latest metibotic moctels and

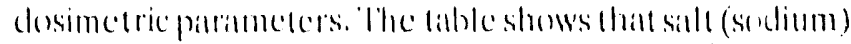

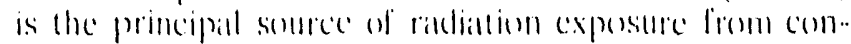

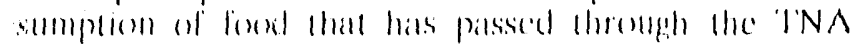

system. About 90) pereent of the committed effective dose equivalent of the $2.3 \times 10.4 \mu \mathrm{Sv}(2.3 \times 1() .5 \mathrm{mrem})$ would be due to ingestion of sodium and chlorinc. In principle, a passenger could open his or her luggage after a precheck-In inspection, take an item or two out of the checkin luggage to consume cither at the airport or later on the airplane. P'ersons consuming salt pills or highly salted foods after their luggage had been screened by the Iid)S-3C could recolve most of the radiation dose shown in 'rable 5.7.

Assuming 5 pereent of the 1.1 millicin international passengers whose lugguge is screened by the l:DS-30 carry salt tablets or snacks (such as peanuts or salami) in their luggage and subseguently eat these items (within 30 seconds after sereening), the collective dose to this group of

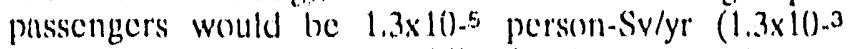
person-rern/yr). In ICRP Publication 23, a normal range of sodium ( $\mathrm{Na}$ ) intake for adults is indicated to be 2.8 to $7.8 \mathrm{~g} /$ day $(0.1 \mathrm{to}(0.3 \mathrm{az} /$ /day). In Japanese adults, however, intakes as high as $27 \mathrm{~g}(0.95$ (a) have been reported. 'The effective dose equivilent from a sodium intake of 27 ?" would be $8.6 \times 10.4 \mu \mathrm{Sv}(8.6 \times 10.5 \mathrm{mrem})$.

Both the daily intake and the dose conversion factor change with age. Table 5.8 shows both parameters for four different age groups for which dose conversion factors were available (NURF(3-0172). The results show that children receive a dose from Na-24 that is about 60) percent greater than that estimated for adults. In an extreme case, a child with a $12 \mathrm{~g} /$ /day (0.4-0z/day) sodium intike could receive a dose of $1.5 \times 10-4 \mu$ sv $(1.5 \times 10-5 \mathrm{mrem})$ from that intake.

Because of the large amount of $\mathrm{K}-40$ ) in the body [140 $\mathrm{g}$ (4.9 02 ) in "reference man"|, K-40 is the principal naturally occurring source of internal radiation (ICRP Publication 23). Potassium enters the body mainly through foodstufl's at the rate of about $2.5 \mathrm{~g} /$ day $(0.09 \mathrm{~g}$ o/day) or $28.3 \mathrm{kBg} / \mathrm{yr}$ (NCRP Report 94). For adults, the wholebody dose conversion factor is $5 .(1) \times 1()-3 \quad \mu \mathrm{Sv} / \mathrm{BC}$ $(18.5 \mathrm{mrum} / \mu \mathrm{Ci})$; therefore, the yearly dose from fondstuff's is $0.14 \mathrm{~ms}$ Sv/yr (14.1 mrem/yr) (see ICRP Publication 30). However, because potassium is an essential element and under metabolic control, variations in dietary emposition have little elfect on the body content or on the radiation dose recelved (NURI:(3-0172). lior eximple, the maximum potential dose from consumption of $10 \mathrm{~g}(0.35(\mathrm{z} z)$ of potassium that was in luggage that was sereened every week for 1 year by the lods-3(" would be

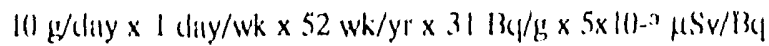

$$
\begin{aligned}
& =81 \mu S \mathrm{sv} / \mathrm{yr}(\mathrm{s} .1 \mathrm{mr}(\mathrm{m}) \mathrm{Hr})
\end{aligned}
$$

'This is only 57 pereent of the yearly dose received from londstulf's. 'Thus, the conserviltive assumption of taking 
'lable 5.7 Committed effective dose equivalent from daily intakes of elements 1 hour after bids-3C. sereening

\begin{tabular}{|c|c|c|c|c|c|c|c|}
\hline \multirow[b]{2}{*}{$\begin{array}{l}\text { Target } \\
\text { nuclidese }\end{array}$} & \multirow{2}{*}{$\begin{array}{l}\text { Menn } \\
\text { dully } \\
\text { lntake } \\
\text { (g) }\end{array}$} & \multirow{2}{*}{$\begin{array}{l}\text { lnduced } \\
\text { radion } \\
\text { nusclide }\end{array}$} & \multirow{2}{*}{$\begin{array}{l}\text { Wolghited } \\
\text { commintted } \\
\text { dose } \\
\text { equivalent } \\
\text { (Sv/liq) }\end{array}$} & \multicolumn{2}{|c|}{ Bec'querel/gram of element } & \multicolumn{2}{|c|}{$\begin{array}{l}\text { Committed effective dose } \\
\text { equivalent from } 1 \text { day's intake }\end{array}$} \\
\hline & & & & $\begin{array}{l}0.5 \cdot \min \text { delay* } \\
(1 \mathrm{l} q / \mathrm{g})\end{array}$ & $\begin{array}{l}\text { 10-min deluy* } \\
(13(\mathrm{~g} / \mathrm{g})\end{array}$ & $\begin{array}{l}0.5 y-\min \text { delay } \\
(\mu \mathrm{S} v)\end{array}$ & $\begin{array}{l}\text { 10-min delay } \\
(\mu \mathrm{S} v)\end{array}$ \\
\hline$N a-23$ & $4.40 E+(00)$ & $\mathrm{N} n-24$ & $3.87 \mathrm{E}-10$ & $8.10 \mathrm{E}-(12$ & $8.0 .3 E-0.2$ & $1.38 \mathrm{E}-114$ & $1.37 \mathrm{E}-104$ \\
\hline $\mid{ }^{3}-31$ & $1.401 \mathrm{E}+100$ & P.32 & $2.08 \mathrm{E}-(10)$ & $1.60 \mathrm{E}-(1) 3$ & 1.601E-(1)3 & $4 .(65 \mathrm{E}-0) 6$ & $4.65 \mathrm{E}-1) 6$ \\
\hline$C 1-37$ & $5.20 \mathrm{E}+00$ & C 1.38 & $5.40 E-11$ & $2.48 \mathrm{E}-(1) 1$ & $2 .(17 \mathrm{E}-0)$ & $6.95 E-105$ & $5.8 ? \mathrm{E}-11.5$ \\
\hline K-4l & $3.30 \mathrm{E}+00$ & $K-42$ & $2.97 \mathrm{E}-10$ & $1.08 \mathrm{E}-02$ & $1.07 \mathrm{E}-12$ & $1.06 \mathrm{E}-105$ & $1 .\left(141 E_{\cdots} \cdots(1) 5\right.$ \\
\hline Mn-55 & $3.70 \mathrm{E}-0.3$ & $\mathrm{Mn}-56$ & $2.52 \mathrm{E}-10$ & $5.00 \mathrm{E}+00$ & $4.77 \mathrm{E}+100$ & $4.66 \mathrm{E}-1) 6$ & $4.45 \mathrm{E}-06$ \\
\hline C.1. 63 & $3.50 \mathrm{E}-0.3$ & $\mathrm{Cu}-64$ & $1.16 \mathrm{E}-10$ & $200 \mathrm{E}-1) 1$ & $2 .(14 \mathrm{E}-() !$ & $8.37 \mathrm{E}-118$ & $8.29 \mathrm{E} \cdot(18$ \\
\hline As 75 & $1.0(1) \mathrm{E}-0.3$ & $\Lambda s-76$ & $1.28 \mathrm{E}-(1) 9$ & $1.47 \mathrm{E}-(1)$ & $1.46 \mathrm{E}-(1)$ & $1.88 \mathrm{E}-(1) 7$ & $1.87 \mathrm{E}-(17$ \\
\hline $13 r-79$ & $7.5(1) \mathrm{E}+1) 3$ & $13 r-811 m$ & $6.23 \mathrm{E}-11$ & $2.46 \mathrm{E}-1) 1$ & $2.40 \mathrm{E}-1) 1$ & 1. $15 \mathrm{E}-07$ & $1.12 \mathrm{E}-(1) 7$ \\
\hline $13 r-79$ & $7.50 \mathrm{E}-11.3$ & $33 r-80$ & $1.50 \mathrm{E}-11$ & $1.28 \mathrm{E}+01$ & $8.84 \mathrm{E}+100$ & $1.44 E-106$ & $9.95 \mathrm{E}-07$ \\
\hline 'l'olal & & & & & & $2.20 \mathrm{E}-(14$ & $2.16 \mathrm{E}-114$ \\
\hline
\end{tabular}

* liromin Thable 5.1.

Nole: $4.4(1):+101)=4.41) \times 111^{\circ}$ (1t)

Table 5.8 Age dependence of sodium intake and dose conversion fiactors (specific activity of $8.1 \times 10.4 \mathrm{Bg} / \mathrm{g}$ )

\begin{tabular}{|c|c|c|c|c|c|}
\hline \multirow[b]{2}{*}{ Cutegory (age) } & \multirow{2}{*}{$\begin{array}{l}\text { Sodium } \\
\text { intuke, } \\
\text { I } \\
\text { (g/day) }\end{array}$} & \multirow{2}{*}{\multicolumn{2}{|c|}{ 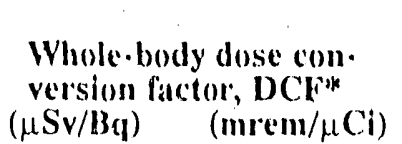 }} & \multicolumn{2}{|c|}{ Product of $1 \times$ DCF } \\
\hline & & & & $\left(\frac{\mu s v \cdot q}{B q / d a y}\right)$ & $\left(\frac{\text { mincin: }}{\mu \text { Ci-day }}\right.$ \\
\hline Infunt $(0.5 \mathrm{yr})$ & 0.5 & $2.71:-(1) 3$ & 10 & $1.41:-(1) 3$ & $5 .()$ \\
\hline ("hild (5 yr') & 2.0 & $1.61:-(1) 3$ & 5.8 & $3.21:-(0) 3$ & 11.6 \\
\hline Tecnager (15 yr) & 3.6 & $6.21:-04$ & 2.3 & $2.21:-113$ & 8.3 \\
\hline Adult $(>20 \mathrm{yr})$ & 4.4 & $4.61:-1) 4$ & 1.7 & $2 .(1):-(13)$ & 7.5 \\
\hline
\end{tabular}

"IC'RP' Publication 30.

Note: $2.71:-1) 3=2.7 \times 10)^{\circ}$ cle,

Source: NURli(;-0)172.

polassium (10 g) 30 seconds after it leares the INA system 52 times a year would not contribute significantly 0 the total radiation dose.

\subsubsection{Nonconsumable ltems}

Neutron activation of the elements in clothing (hydrogen, carbon, nitrogen, and oxygen does not lead to significant amounts of residual activity in suitcases, as indicated in Tables 5.1 and 5.2. Of the most highly activated isotopes alter a 1()-minute decay listed in lable 5.3 (vilnadium, manganese, indium, and europium), only inclium and to a lesser extent manganese are found in common objects. Indium, according to the Handbook of ('he'mistry and Physics, is principally used in alloys for jewelry and in dental alloys (Hodgman el al., 196(1)). Manganese is used primatrily in copper, iron, and nickel alloys. A survey of alloys indicates that the amount of manganese is generally less than 5 pereent. 'lypical items likely to contain these elements are jewelry, clock alarms, travel irons, clectric razors, hair dryers, portable radios, and nail files.

Gold is more likely to be lound in larger quantitics than manganese or indium. (iold alloys used for jewelry and other objects have a gold content of 5 (! 1070 pereent (Hodgman et al., 19)(0)). (atialogs show that most common gold jewelry such ats necklaces, carrings, and rings have a gold content ranging from absut 10 g 10.50 g $(0.3(\%)$ $1.8(\mathrm{w})$. Since the price of pold is currently about $\$ 15$ a gram (\$42) an ounec), one would expect that very expensive jewelry would be either woren or stored in ceirry-on luggage or purses by passengers. llowever, in an extreme calse, someone could concecivilbly place, for eximple, 40 g (1.4 (\%) of gende jewelry in his or her checked baggage. The 
product radionuclide, gold-- 198, has a hall-1ile of 2.7 days: therelore, nearly all the induced radionctivity would still be present when the owner claimed the leggenge.

The total beta particle dose at a depth of $0.007 \mathrm{~cm}$ (2.8x10.3 in.) beneath the skin directly under the jewelry is estimated to be about $23 \mu$ (iy ( 2.3 mlatd) if the jewelry is worn continuously for approximately 10 days after the luggenge is clatmed (Sherbini, 199(1)). The gamma dose adds appreximately $2 \mu S v(0.2 \mathrm{mrem})$; therefore, the lotal dose is $25 \mu \mathrm{Sv}(2.5 \mathrm{mrem})$. If the ICRP weighting factor for skin is used (0.01), the total eflective dose equivalent for this assumed exposure secnation is about $0.25 \mu \mathrm{Sv}$ (0.025 mrem). If 1 percent of the passengers carry gold jewelry in their luggage and then wear it indefinitely, the elfective dose equivilent is $2.8 \times 10.3^{3}$ person-Sv/yr (0.28 persem-1em/yr). 'this dose is well below the public cxposure limits recommended by ICRP.

Potential doses due to a malfunction of the 'l'NA system (such as a conveyor-belt breakdown, a power fatilure, or a bagkinge jom could be latger hecause of a longer neutron irradiation time. The potential effective dese equivalent from wearing gold jewelty for 10 digys following lads-3C screcong could be as high als $10 \mu$ Sv (1 mrem). Experience with ramp installation all dlek International Airpont has shown that these irmadiations are rate, usually less than one per month of operation. If this seenario oceurs once each month. the resulting collective eflective dese ecpuivalent is $1.2 \times 1()-4$ person-Siv/yr (1.2x10-2 person-rem/ $y(r)$.

lixisting lecderal guidance and liaboratury data both provide alssurance that neutron irratiation of luggige as proposed will not cause delecerious celfects. The leoded and 1) rug Administrillion (lil)A) hats approved neutron irradiation of ford using ( 9.252 sources $t(1)$ determine its mosisture content, such intadiation is permitted for absorbed doses of up to $2 \mathrm{~m}$ (iy (20) mrid) (21 clik l'art 179).

The elfect of the system on phongraphic film, including both movie film and high-specel film, is undetectable under hormal conditions. 'l'his was determined by testung several types of film that had been passed once and several times through the original prototype system, l:I)S-2 (Berkett and Scheneider, 1987), which contained 340 $\mu \mathrm{g}$ of (1--25\%. The film showed no effects from the riddiation expessure to the lidss-2 when subjected to 50 times the standard dese. When compared with eontrol samples. both sensiometric performanee and granularity were unchanged from those of control samples. The tests and results are discussed by Beckett and Schneider (1987).

\subsubsection{Summary of Collective Doses}

In the previous discussions in Section 5.4, the collective dose from various pathways was derived. 'l he collective doses to worker's and security sereeners do not depend on the choice of 'I'NA system installation seenario. 'The total doses to passengers fiom the activation of consumable items and apparel are greatest for the pre-check-in scenario, becaluse passengers (or members of the public) may have acess to checked luggige immediately aller it leaves the 'INA system. The downward contribution to the floor below the 'INA system may apply to all seenarios, and the maximum case is assumed.

The direct dose to other persens applies in varying degrees to all but the first secmario (behind the check-in counter). The secenario showing the largest collective dose is the pre-check-in-illeal scentrio.

lables 5.9 and 5.10 summatrize the annual collective and individual doses for each of the four secnarios described in this section. The doses for all the individuals involved (operators, baggige handlers, licket counter personnel, security screceners, passengers, and members of the public) are within the 10 ClR Part 20 limits for individuals in restricted and unesstricted areas. Thable 5.10 shows that the annual dese from natural background radiation is $3 \mathrm{mSv} / \mathrm{yr}(30) \mathrm{mrcm} / \mathrm{yr}$ ), which is more than the dose from any one of the secenarios presented (NCRP Report (94).

The collective doses were calculated for several secriaries involving a single l:1)S-3.3 installed and operated in four different ways at an airport. If several of these systems were installed in an airport, the doses would be controlled by the exposuresecenario (see Section 5.4.3.3) in which the passenger hands the luggage to a 'I'NA altendant for sereening, walks allong the system (in the area of highest exposure mate), and retrieves the luggenge at the exit of the system. Becaluse the passenger would presumably check the luggige through a single system, it is highly probable that the passenger checking in luggige would not be in the vicinity of more than one system. 'Therefore, the erollective and maximum doses in an airport using multiple systems in parallel probably would not execed the results of the analysis in this section. 
Table 5.9 Summary of collective doses from all scenarios

\begin{tabular}{|c|c|c|c|c|}
\hline \multirow[b]{2}{*}{ Radiation exposure } & \multicolumn{4}{|c|}{ Scenario } \\
\hline & $\begin{array}{l}\text { Behind the } \\
\text { counter } \\
\text { (person-Sv) }\end{array}$ & $\begin{array}{l}\text { In front of } \\
\text { the counter } \\
\text { (person-Sv) }\end{array}$ & $\begin{array}{l}\text { Pre-check-in } \\
\text { (person-Sv) }\end{array}$ & $\begin{array}{l}\text { Curbside } \\
\text { (person-Sv) }\end{array}$ \\
\hline \multicolumn{5}{|l|}{ Workers } \\
\hline Operators & $1.2 E-02$ & $1.2 \mathrm{E}-02$ & $1.2 \mathrm{E}-02$ & $1.2 \mathrm{E}-02$ \\
\hline Baggage handlers & $6.0 \mathrm{E}-03$ & $6.0 \mathrm{E}-03$ & $6.0 \mathrm{E}-03$ & $6: 0 \mathrm{E}-03$ \\
\hline Ticket counter personnel & $3.0 \mathrm{E}-02$ & $3: 0 \mathrm{E}-02$ & $1.0 \mathrm{E}-02$ & 0 \\
\hline Security screeners & $9.5 E-04$ & $9.5 E-04$ & $9.5 E-04$ & $9.5 \mathrm{E}-04$ \\
\hline Sky-caps & 0 & 0 & 0 & $3.8 \mathrm{E}-03$ \\
\hline Passengers & 0 & $1.1 \mathrm{E}-02$ & $2.0 \mathrm{E}-01$ & $5.5 \mathrm{E}-02$ \\
\hline \multicolumn{5}{|l|}{ Public } \\
\hline Below the TNA systern & $6.8 \mathrm{E}-02$ & $6.8 \mathrm{E}-02$ & $6.8 \mathrm{E}-02$ & $6.8 \mathrm{E}-02$ \\
\hline Near the TNA system & 0 & $1.1 \mathrm{E}-02$ & $6.0 \mathrm{E}-02$ & $6.0 \mathrm{E}-03$ \\
\hline \multicolumn{5}{|l|}{ From irradiation of baggage contents } \\
\hline Consumable items & 0 & 0 & $1.3 \mathrm{E}-05$ & 0 \\
\hline $\begin{array}{l}\text { Nonconsumable items (suitcase, } \\
\text { jewelry, etc.) }\end{array}$ & $2.8 \mathrm{E}-03$ & $2.8 \mathrm{E}-03$ & $2.8 E-03$ & $2.8 \mathrm{E}-03$ \\
\hline \multicolumn{5}{|l|}{ Total } \\
\hline Person-Sv & $1.2 \mathrm{E} 01$ & $1.4 E-01$ & $3.6 \mathrm{E}-01$ & $1.6 \mathrm{E}-01$ \\
\hline Person-rem & 12.0 & 14.2 & 36.0 & 15.5 \\
\hline
\end{tabular}

Note: $1.2 \mathrm{E}-02=1.2 \times 10^{2}$ etc.

Table 5.10 Summary of annual individual doses from all scenarios

\begin{tabular}{|c|c|c|c|c|c|}
\hline \multirow[b]{2}{*}{ Radiation exposure } & \multicolumn{5}{|c|}{ Scenario } \\
\hline & $\begin{array}{l}\text { Behind the } \\
\text { counier } \\
(\mathrm{mSv})\end{array}$ & $\begin{array}{l}\text { In front of } \\
\text { the counter } \\
(\mathrm{mSv})\end{array}$ & $\begin{array}{l}\text { Pre-check-in } \\
(\mathrm{mSv})\end{array}$ & $\begin{array}{l}\text { Curbside } \\
(\mathbf{m S v})\end{array}$ & $\begin{array}{l}\text { NRC } \\
\operatorname{limit}_{(\mathbf{m S v})}\end{array}$ \\
\hline \multicolumn{6}{|l|}{ Workers } \\
\hline Operators & $2.0 \mathrm{E}+00$ & $2.0 \mathrm{E}+00$ & $2.0 \mathrm{E}+00$ & $2.0 \mathrm{E}+00$ & $5.0 \mathrm{E}+01$ \\
\hline Baggage handlers & $1.0 \mathrm{E}+00$ & $1.0 \mathrm{E}+\mathrm{G0}$ & $1.0 \mathrm{E}+00$ & $1.0 \mathrm{E}+00$ & $5.0 E+00$ \\
\hline Ticket counter personnel & $6.0 \mathrm{E}-01$ & $6.0 \mathrm{E}-01$ & $1.7 \mathrm{E}-02$ & 0 & $5.0 \mathrm{E}+00$ \\
\hline Security screeners & $3.2 E-01$ & $3.2 \mathrm{E}-01$ & $3.2 \mathrm{E}-01$ & $3.2 \mathrm{E}-01$ & $5.0 \mathrm{E}+00$ \\
\hline Sky-caps & 0 & 0 & 0 & $2.5 \mathrm{E}-01$ & $5.0 \mathrm{E}+00$ \\
\hline Passengers & 0 & $1.0 \mathrm{E}-05$ & $1.8 \mathrm{E}-04$ & 5.0E-05 & $5.0 \mathrm{E}+00$ \\
\hline Public & & & , & & \\
\hline Below the TNA system & $7.5 \mathrm{E}-0.05$ & 7.5E-05 & $7.5 \mathrm{E}-05$ & $7.5 \mathrm{E}-05$ & $5.0 \mathrm{E}+00$ \\
\hline Near the TNA system & 0 & $1.2 \mathrm{E}-06$ & $6.7 \mathrm{E}-06$ & $6.7 \mathrm{E}-06$ & $5.0 \mathrm{E}+00$ \\
\hline \multicolumn{6}{|l|}{ From irradiation of baggage contents } \\
\hline Consumable items & 0 & 0 & $2.4 \mathrm{E}-07$ & 0 & - \\
\hline $\begin{array}{l}\text { Nonconsumable items (suitcase, } \\
\text { clothing, etc.) }\end{array}$ & $2.5 \mathrm{E}-04$ & $2.5 \mathrm{E}-04$ & $2.5 E-04$ & $2.51 ;--04$ & - \\
\hline
\end{tabular}

Notes: Natural sources of radiation: Natural background $3.0 \mathrm{E}+00$ Yearly dose from foodstuffs $1.4 \mathrm{E}-01$ $2.0 \mathrm{E}+00=2.0 \times 10^{\circ} \mathrm{etc}$. 


\section{EFFECTS OF ACCIDENTS}

For the purposes of environmental analysis, several accident scenarios were selected to conservatively bound a spectrum of accidents that could occur. Scenarios other than those discussed also would be possible, but their consequences are expected to be lower. The described scenarios are considered conservative in terms of both accident potential and radiological consequences.

In assessing potential accidents, two major factors were considered in developing a series of postulated accidents: the probability of occurrence and the subsequent severity of an accident. A complete range of postulated accidents was described in FAA's application for an amendment to its license for proposed operations. These included an accident involving the transfer of the californium-252 (Cf-252) source from the cask into the EDS-3C, an accident during transport from the manufacturer, and postulated operational accidents, such as a fire or an explosion.

The doses calculated for these accidents are effective dose equivalents resulting from the inhalation of dispersed radioactive material. Exposure pathways other than inhalation can be expected to result in minor increases in dose commitment received. Deposition of $\mathrm{Cl}-252$ in soil and/or vegetables may require decontamination if the accident involves significant amounts of Cf-252.

\subsection{Source-Transfer Accidents}

External dose rates during transfer of a source would be slightly higher than those during normal operations because the shiclding would be less as the source was moved from the transfer cask to the EDS-3C. The highest dose rate would occur at the time the source was passed from the cask into the IDSS-3C. If the souree were to become stuck in this position, a high radiation ficld would result.
Figure 6.1 illustrates the isodose contours for a source in a stuck position. Additional dose rate measurements can be found in the licensee's environmental report (SAIC, 1989).

The operating procedures for the EDS-3Cs installed in concourse areas require that the source be transferred when the number of people in the airport is low and that the immediate area be cordoned off at approximately

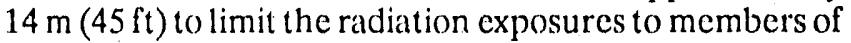
the public to $0.02 \mathrm{mSv} / \mathrm{hr}(2 \mathrm{mrem} / \mathrm{hr})$. TNA personnel would limit their exposure while working to dislodge the source by positioning themselves away from the interface between the cask and the EDS-3C. Their average dose rate would be about $0.2 \mathrm{mSv} / \mathrm{hr}(20 \mathrm{mrem} / \mathrm{hr})$ during the 15 minutes it might take to dislodge the source. The estimated collective dose for this scenario is less than $3.0 \times 10-4$ person-Sv (0.03 person-rem). The estimated probability that the source might become dislodged is less than 10-3 per source insertion or removal (SAIC, 1989).

\subsection{Transportation Accidents}

The environmental impacts of radioactive shipments involving all modes of transportation in the United States under regulations in effect as of June 30,1975, have been documented in the "Final Environmental Statement on the Transportation of Radioactive Material by Air and Other Modes" (NUREG-0170).

This section addresses the radiological impact of an accident resulting from the transportation of one Cf- 252 source annually. Minor traffic accidents would have no effect on the integrity of the cask containing the source and would not pose a radiological hazard (Bozorgmancsh, 1981).

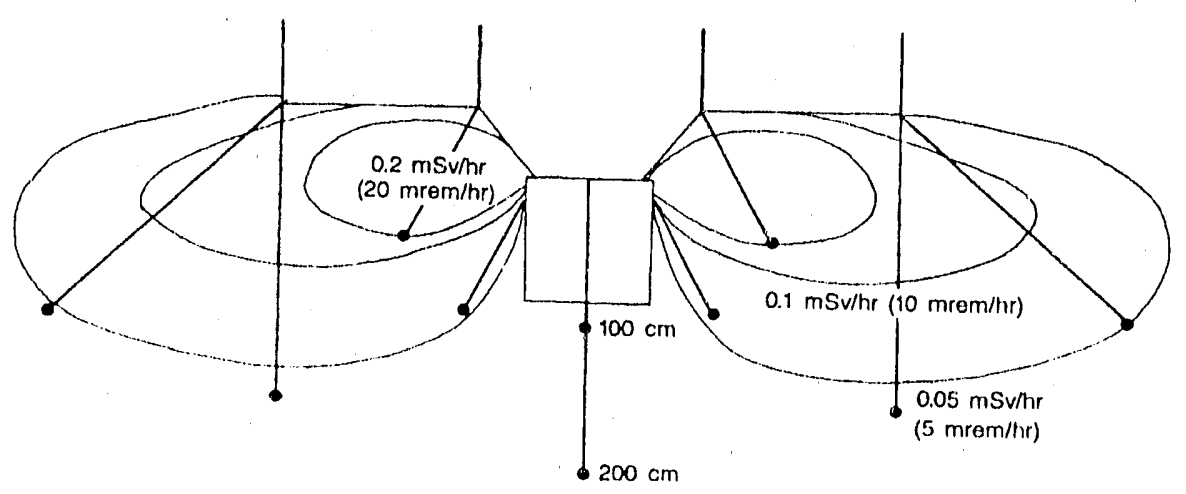

Figure 6.1 Isodose contours for source wedged at interface of cask and IDSS-3C 
The bulk of the cask is composed of water-extendedpolyester neutron shiclding, which does not melt like the borated wax compounds used previously in the prototype, Model EDS-2 (Ryge, 1989). Lead shielding around the center of the cask where the source is located reduces the gamma ray dose rate. Although the melting point of lead is about $327^{\circ} \mathrm{C}\left(620^{\circ} \mathrm{F}\right)$, a scrious crash followed by a hot fire of long duration could destroy the neutron shielding and seriously compromise the gamma ray shiclding. Tab!e 6.1 shows the dose equivalent rates from neutron and gamma radiation at various distances from an unshiclded

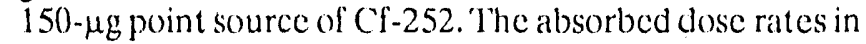
tissue are based on data given for a distance of $1 \mathrm{~m}(3 \mathrm{ft})$ in ICRP Publication 21. 'The dose equivalent rates in Table 6.1 are based on the assumption that the mean quality factor for neutrons will increase by a factor of 2 . The dose rates shown are the upper limits for a radiation field that might be present following a postulated severe accident and subsequent fire involving the truck transporting the source. The gamma ray doses rates would be much lower if the lead shield remained intact.

Table 6.1 Maximum potential dose equivalent rates from one $150 \cdot \mu \mathrm{g}$ Cf. 252 source following a severe accident and fire

\begin{tabular}{|c|c|c|c|}
\hline \multirow{2}{*}{$\begin{array}{l}\text { Distance } \\
{[\mathrm{m}(\mathrm{ft})]}\end{array}$} & \multicolumn{3}{|c|}{ Dose equivalent rate $(\mathrm{mSv} / \mathrm{hr})$} \\
\hline & Neutron & Gamma & Total \\
\hline $1(3.3)$ & $7.21 i+00$ & 2.11:-()1 & $7.4 \mathrm{E}+00$ \\
\hline $2(6.6)$ & $1.81 i+00$ & $5.0 \mathrm{E}:-02$ & $1.81+00$ \\
\hline $5(16.4)$ & $2.81:-01$ & $8.5 E-0) 3$ & $2.81:-01$ \\
\hline $10(32.8)$ & $7.51:-112$ & 2.11:-(0) & $7.71:-112$ \\
\hline
\end{tabular}

Note: $7.21 \mathrm{t}+00=7.2 \times 10^{\circ} \mathrm{etc}$.
Table 6.1 shows that the potential for serious exposure would not exist following a postulated accident involving a fire. Cleanup of the accident would be complicated. It might require bringing in a crane to manipulate the remains of the shiclded cask or bringing in another shiclded cask for source storage. A large watcr-filled tank could serve as both a receptacle for the source and a shielding tool to provide protection against radiation emitting from the source. Careful emergency planning for such scenarios would limit the dose during recovery of the source. A person working at an average distance of $10 \mathrm{~m}(33 \mathrm{ft})$ from the source for 4 hours could reccive a dose equivalent of about $0.3 \mathrm{mSv}(30 \mathrm{mrcm})$.

The second type of transportation accident is assumed to be even more severe that the seenario considered above. for this accident, it is assumed that the accident and subsequent fire lead to the complete fragmentation of the $\mathrm{Cf}-252$ source and its dispersion to the atmosphere. 'The accidental release of radioactivity from ground level and transported in the atmosphere under stable conditions was calculated at $4 \mathrm{~m} / \mathrm{s}$ (13 $\mathrm{ft} / \mathrm{s})$. NRC Regulatory Guide 1.145, "Atmospheric Dispersion Models for Potential Accident Consequence Assessments at Nuclear Power Plants," was used to caleulate the average $\chi / Q$ values of $6.4 \times 10-5 \mathrm{~s} / \mathrm{m}^{3}$ and $2.8 \times 10-5 \mathrm{~s} / \mathrm{m}^{3}$ at 50 and $300 \mathrm{~m}$ (54 and $328 \mathrm{yd})$, respectively, from the accident location.

Tables 6.2 through 6.5 summarize the offsite concentrations and annual inhalation doses for 10-, 50-, and 100-pereent dispersion from the (f-252 source at 50 and $300 \mathrm{~m}$, respectively, from the point of release. The resulting maximum inhalation dose for $10(0)$ pereent dispersion at a distance of 5() $\mathrm{m}$ is $2.4 \times 10-3 \mathrm{~Sv}(2.4 \times 1()-1 \mathrm{rcm})$, which is well within the U.S. Invironmental Protection Agency's (LPA, 1990) protective action guidelines (PAGs) of (0.25 Sv (25 rem) for emergency workers.

Table 6.2 Offsite concentrations [at $50 \mathrm{~m} \mathrm{(54} \mathrm{yd)]} \mathrm{of} \mathrm{airborne} \mathrm{releases}$ for various fractions of $\mathrm{Cf} \cdot 252$

\begin{tabular}{|c|c|c|c|c|c|c|}
\hline \multirow{2}{*}{$\begin{array}{l}\text { Total } \\
\text { source } \\
\text { activity } \\
\text { (MBq/yr) }\end{array}$} & \multirow[b]{2}{*}{$\begin{array}{l}\text { Release } \\
\text { fraction }\end{array}$} & \multirow[b]{2}{*}{$\begin{array}{l}\text { Emission } \\
(\mathrm{MBq})\end{array}$} & \multirow[b]{2}{*}{$\begin{array}{l}X / Q^{*} \\
\left(s / m^{3}\right)\end{array}$} & \multirow{2}{*}{$\begin{array}{l}\text { Maximum } \\
\text { permissible } \\
\text { concentra- } \\
\text { tion (MI'C) } \\
(\mathrm{Bq} / \mathrm{ml})\end{array}$} & \multicolumn{2}{|c|}{ Offsite concentration } \\
\hline & & & & & $\left(\mathrm{MBq} / \mathrm{m}^{3}\right)$ & $\begin{array}{l}\text { Fraction } \\
\text { of MPC } \\
(\%)\end{array}$ \\
\hline $2.961 \vdots+03$ & $1 .(0) 1:-01$ & $2.961 i+02$ & $6.4(0) \div-(0.5$ & $3.7(0):-(1) 8$ & $6.101 \div \cdot 10$ & 1.62 \\
\hline $2.961 \vdots+03$ & $5.001:-01$ & $1.481 i+(13$ & $6.4(1) 1:-1) 5$ & $3.701:-08$ & $3.001:-09$ & 8.12 \\
\hline $2.961:+03$ & $1.001 i+00$ & $2.961 i+03$ & $6.4(01:-05$ & $3.70 \mathrm{~J}:-08$ & $6.011:-09$ & 16.24 \\
\hline
\end{tabular}


Table 6.3 Annual inhalation dose to the nearest individual $50 \mathrm{~m}(54 \mathrm{yd})$ away from postulated $\mathrm{Cf} .252$ accident

\begin{tabular}{lll}
\hline $\begin{array}{l}\text { Activity* } \\
\text { inhaled } \\
(\mathbf{B q})\end{array}$ & $\begin{array}{l}\text { Dose conver. } \\
\text { sion factor** } \\
(\mathbf{S v} / \mathbf{5 0} \mathbf{y r} \cdot \mathbf{B q})\end{array}$ & $\begin{array}{l}\text { Committed } \\
\text { effective } \\
\text { dose } \\
\text { equivalent } \\
(\mathbf{S v} / \mathbf{5 0} \mathbf{y r})\end{array}$ \\
\hline $4.81 \mathrm{E}+00$ & $5.00 \mathrm{E}-05$ & $2.40 \mathrm{E}-04$ \\
$2.40 \mathrm{E}+01$ & $5.00 \mathrm{E}-05$ & $1.20 \mathrm{E}-03$ \\
$4.81 \mathrm{E}+01$ & $5.00 \mathrm{E}-05$ & $2.40 \mathrm{E}-03$ \\
\hline
\end{tabular}

* Breathing rate $=8.00 \mathrm{E}+03 \mathrm{~m}^{3} / \mathrm{yr}$.

*ICRP Publication 30.

Note: $4.81 \mathrm{E}+00=4.81 \times 10^{\circ} \mathrm{etc}$.

Table 6.4 Offsite concentrations [at $300 \mathrm{~m}(328 \mathrm{yd})$ ] of airborne releases for various fractions of $\mathrm{Cf} .252$

\begin{tabular}{|c|c|c|c|c|c|c|}
\hline \multirow[b]{2}{*}{$\begin{array}{l}\text { Total } \\
\text { source } \\
\text { activity } \\
\text { (MBq/yr) }\end{array}$} & \multirow[b]{2}{*}{$\begin{array}{l}\text { Release } \\
\text { fraction }\end{array}$} & \multirow[b]{2}{*}{$\begin{array}{l}\text { Emission } \\
(\mathrm{MBq})^{\circ}\end{array}$} & \multirow[b]{2}{*}{$\begin{array}{l}x / \mathbf{Q}^{*} \\
\left(\mathbf{s} / \mathbf{m}^{3}\right)\end{array}$} & \multirow{2}{*}{$\begin{array}{l}\text { Maximum } \\
\text { permissible } \\
\text { concentra. } \\
\text { tion (MPC) } \\
(\mathbf{B q} / \mathbf{m l})\end{array}$} & \multicolumn{2}{|c|}{ Offsite concentration } \\
\hline & & & & & $\left(\mathrm{MBq} / \mathrm{m}^{3}\right)$ & $\begin{array}{l}\text { Fraction } \\
\text { of MPC } \\
(\%)\end{array}$ \\
\hline $2.96 \mathrm{E}+03$ & $1.00 \mathrm{E}-01$ & $2.96 \mathrm{E}+02$ & $2.80 \mathrm{E}-05$ & $3.70 \mathrm{E}-08$ & $2.63 \mathrm{E}-10$ & 0.71 \\
\hline $2.96 \mathrm{E}+03$ & $5.00 \mathrm{E}-01$ & $1.48 \mathrm{E}+03$ & $2.80 \mathrm{E}-05$ & $3.70 \mathrm{E}-08$ & $1.31 \mathrm{E}-09$ & 3.55 \\
\hline $2.96 \mathrm{E}+03$ & $1.00 \mathrm{E}+00$ & $2.96 \mathrm{E}+03$ & $2.80 \mathrm{E}-05$ & $3.70 \mathrm{E}-08$ & $2.63 \mathrm{E}-09$ & 7.10 \\
\hline
\end{tabular}

* $X / Q$ at $300 \mathrm{~m}$.

Note: $2.96 \mathrm{E}+03=2.96 \times 10^{3} \mathrm{etc}$.

Table 6.5 Annual inhalation dose to the nearest individual $300 \mathrm{~m}(328 \mathrm{yd})$ away from postulated Cf.252 accident

\begin{tabular}{lll}
\hline $\begin{array}{l}\text { Activity* } \\
\text { inhaled } \\
(\mathbf{B q})\end{array}$ & $\begin{array}{l}\text { Dose conver- } \\
\text { sion factor** } \\
(\mathrm{Sv} / \mathbf{5 0} \mathbf{y r} \cdot \mathbf{B q})\end{array}$ & $\begin{array}{l}\text { Committed } \\
\text { effective } \\
\text { dose } \\
\text { equivalent } \\
(\mathbf{S v} / \mathbf{5 0} \mathbf{y r})\end{array}$ \\
\hline $2.10 \mathrm{E}+00$ & $5.00 \mathrm{E}-05$ & $1.05 \mathrm{E}-04$ \\
$1.05 \mathrm{E}+01$ & $5.00 \mathrm{E}-05$ & $5.26 \mathrm{E}-04$ \\
$2.10 \mathrm{E}+01$ & $5.00 \mathrm{E}-05$ & $1.05 \mathrm{E}-03$ \\
\hline
\end{tabular}

Breatining rate $=8.00 \mathrm{E}+03 \mathrm{~m}^{3} / \mathrm{yr}$.

* ICRP Publication 30.

Note: $2.10 \mathrm{E}+00=2.10 \times 10^{\circ} \mathrm{etc}$.

This scenario assumes that all the shielding materials are destroyed. The dose rate at $10 \mathrm{~m}$, a reasonable distance for fire control and containment, is approximately $7.7 \times 10-^{2} \mathrm{mSv} / \mathrm{hr}(7.7 \mathrm{mrem} / \mathrm{hr})$. For a maximum fire- fighting time of 4 hours, the total dose to an individual would be approximately $0.31 \mathrm{mSv}(31 \mathrm{mrem})$. Such a dose does not exceed the PAG limit of 1-rem whole-body dose (EPA, 1990). Although the dose estimates would not 


\section{Effects of Accidents}

necessitate offsite protective actions, all U.S. airports have implemented fire protection and emergency preparedness plans as part of their building code requirements.

The average distance from a supplier of $\mathrm{Cf}-252$ sources to various airport locations was approximately $1900 \mathrm{~km}$ $(1200 \mathrm{mi})$. The probability of a severe truck accident during shipment of a Cf-252 source to and from an airport is about 7.2x10-8/yr (Sandia National Laboratory, 1978). For actual locations, the accident probability ranges from $2.9 \times 10-8 / \mathrm{yr}$ to $1.4 \times 10-7 / \mathrm{yr}$.

The consequences of the postulated accident would depend on location. To assess the population dose resulting from the $\mathrm{Cf}-252$ dispersal accident, a reference population density of 386 persons $/ \mathrm{km}^{2}$ (1000 persons $/ \mathrm{mi}^{2}$ ) within a $16-\mathrm{km}(10-\mathrm{mi})$ radius of the accident location was used. It was assumed that 10 percent of the Cf-252, was released downwind and that a $60^{\circ}$ sector was affected. The total number of people affected in this postulated scenario would be $5.2 \times 10^{4}$. The collective dose received by individuals within that sector out to $16 \mathrm{~km}$ would be about 5.5 person-Sv ( 550 person-rem). It should be noted, however, that dispersion and dilution of the plume due to deposition of $\mathrm{Cf}-252$ on the ground will significantly reduce the radioactive airborne concentration at $16 \mathrm{~km}$. For further information regarding this scenario, see the licensee's environmental report (SAIC, 1989).

\subsection{Operational Accidents}

The possibility exists that an accident followed by a fire at an airport could happen. If a fire followed by a large explosion were to occur, the force of the explosion could destroy the inside chamber and leave the source virtually unshielded. Table 6.1 provides an upper bound for the radiation field that could result. Unless the source was blown completely away from the EDS-3C, the ficld would not be radially uniform because of the presence of the shielding components. The problem of retricving the source and placing it in a shielded container is similar to that described in Section 6.2, but the process could be aided with the use of the neutron and gamma-ray survey instruments that are always kept on site at the airport in another (but immediate) location.

To evaluate the possibility of such a bomb breaching the source encapsulation, a test was performed at the U.S. Burcau of Mines in 1988 using $4.5 \mathrm{~kg}(10 \mathrm{lb})$ of plastic explosive and a dummy (empty) source capsule simulated in an EDS-3C mockup device (U.S. Burcau of Mincs, 1988). The results showed that the detonation of the charge did very little damage to the surrounding enclosure, although the mockup itself was completely destroyed. Most of the framework for the mockup was shattered, and pieces of the bismuth block and paraffin shiclding were scattered around the area. The polyethylene tube containing the dummy source capsulc was found essentially undamaged under the debris. Although the inner metal sleeve and polyethylene were tightly swaged onto the source capsule, the source still appeared to be in good condition, as was later verified by the source manufacturer's leak tests. For further information regarding the results of these tests, see SAIC (1988). 


\section{DECOMMISSIONING}

The structural components of the EDS-3 and EDS-3C are not expected to contain significant amounts of radionuclides after 15 years of system operation. It is estimated that a total of $7.4 \times 10^{4} \mathrm{~Bq}(0.002 \mu \mathrm{Ci})$ would be present, mainly as a result of the activation of bismuth in the shield. Neutron activation of the concrete platform beneath the EDS-3C is also expected to be small. After the initial testing of the prototype model (EDS-2) at both Los Angeles and San Francisco International Airports was stopped in 1988, the concrete surface under the EDS-2 was surveyed with an ion chamber survey instrument. Although the system had only been tested for 6 weeks at each airport, no activity above background was observed.

Because concrete is used as a floor barrier at most airport facilities, the amount of activation products that may be found in concrete 15 years after system operation can be calculated. Concrete is a natural choice for a shielding material; it is cheap, structurally useful, and versatile. A great deal of work has been done on conventional and special shielding concretes, and a wide variety of composi- tions are described in literature. Water plays a significant role in ensuring the effectiveness of concrete as a ncutron shield because hydrogen is the most effective light element for slowing down neutrons from Cf- 252 .

For estimation purposes, it can be assumed that all the neutrons impinging on the surface below the 'TNA system are fission-spectrum neutrons (thermal neutrons would be strongly absorbed by the borated paraffin wax shiclding). The dose rate at the bottom center outside the EDS-3C exterior shielding is approximately $0.3 \mathrm{mSv} / \mathrm{hr}$ (30 mrem/hr). For fission-spectrum neutrons, $0.3 \mathrm{mSv} / \mathrm{hr}$ corresponds to 240 neutrons $/ \mathrm{cm}^{2}$-s. Table 7.1 lists the principal constituents of concrete and the long-term activation products from this neutron flux using the data from Erdtmann (1976). Assuming the constituents of concrete are those listed in Table 7.1, the total activity (for all products) remaining after 15 years is $65 \mathrm{~Bq}(0.0017 \mu \mathrm{Ci})$.

Although other elements such as chromium, manganese, vanadium, aluminum, sulfur, phosphorus, and titanium may also exist in elemental concrete, the elements listed in the table are the primary ones (Jaeger et al., 1970).

Table 7.1 Major constituents of concrete and long-term activation products

\begin{tabular}{|c|c|c|c|c|c|c|}
\hline Constituent & $\begin{array}{l}\text { Average } \\
\text { percent } \\
\text { composition } \\
\text { by weight }\end{array}$ & Product & Half-life & $\begin{array}{l}\text { Gamma } \\
\text { energy } \\
\text { (MeV) }\end{array}$ & $(\mathrm{Bq} / \mathrm{kg})^{\mathrm{A}}$ & $\begin{array}{l}\text { Activity } \\
\qquad(\mu \mathrm{Ci} / \mathbf{k g})\end{array}$ \\
\hline \multirow[t]{2}{*}{ Calcium (Ca) } & \multirow[t]{2}{*}{22} & $\mathrm{Ar}-37$ & $34.8 \mathrm{~d}$ & 0 & $4.4 \mathrm{E}+01$ & $1.2 \mathrm{E}-03$ \\
\hline & & $\mathrm{K}-42$ & $12.4 \mathrm{hr}$ & 1.52 & $6.7 \mathrm{E}-02$ & $1.8 \mathrm{E}-06$ \\
\hline Hydrogen $(\mathrm{H})$ & 1 & $\mathrm{H}-3$ & $12.3 \mathrm{yr}$ & 0 & $1.1 \mathrm{E}-01$ & $3.1 \mathrm{E}-06$ \\
\hline Oxygen $(\mathrm{O})$ & 51 & $\mathrm{O}-15$ & $2 \mathrm{~min}$ & 1.02 & $1.8 \mathrm{E}-03$ & $4.9 \mathrm{E}-08$ \\
\hline Silicon $(\mathrm{Si})$ & 22 & $\mathrm{Mn}-27$ & $10 \mathrm{~min}$ & 0.89 & $2.5 \mathrm{E}-02$ & $6.7 \mathrm{E}-07$ \\
\hline \multirow[t]{2}{*}{ Carbon (C) } & \multirow[t]{2}{*}{3} & $\mathrm{C}-11$ & $20 \mathrm{~min}$ & 1.02 & $4.8 \mathrm{E}-06$ & $1.3 \mathrm{E}-10$ \\
\hline & & Be--10 & $1.6 \mathrm{E}+06 \mathrm{yr}$ & 0 & $4.4 \mathrm{E}--02$ & $1.2 \mathrm{E}-06$ \\
\hline Iron $(\mathrm{Fc})$ & 0.5 & $M n-54$ & $312 \mathrm{~d}$ & 0.83 & $1.3 \mathrm{E}-01$ & $3.4 \mathrm{E}-04$ \\
\hline Manganese $(\mathrm{Mg})$ & 0.5 & $\mathrm{Na}-24$ & $15 \mathrm{hr}$ & 4.12 & $7.4 \mathrm{E}+00$ & $2.01:-04$ \\
\hline Total & & & & & $6.5 E+01$ & $1.8 \mathrm{E}-03$ \\
\hline
\end{tabular}

Note: $4.4 \mathrm{E}+01=4.4 \times 10^{\prime} \mathrm{ctc}$. 


\section{ALTERNATIVES}

\subsection{Attributes for Evaluation}

The primary considerations in a value-impact assessment are the attributes that are used to characterize the consew quences of a proposed action. For this assessment, the staff evaluated four categories: (1) costs of each alternative, (2) health and safety impacts, (3) economic impacts, and (4) radiological impacts. 'The costs related to cach alternative refer to the actual monetary expenditures required to implement and conduct operations under that alternative. As a baseline, the no-action alternative can be ascribed a cost of zero dollars. Although current policies and procedures for airline safety and security involve real cost expenditures, these costs are not considered in the present context becaluse the costs for the various action alternatives are evaluated relative to the no-action alternative.

Capital costs include all monetary expenditures required to cover intial costs of system construction and installation to the point where the system is functional. Capital costs in this assessment were amortized annually over the estimated 15-year operational life of the BDS-3C assuming an interest rate of 10 pereent. Operational costs include all labor, maintenance, and overhead expenditures required to operate the system. 'lo facilitate the evaluation of relative costs on a comparable basis, annual capital and operational costs were promated on a per-flightpassenger basis. Unit costs are expressed in terms of dollars per flight passenger.

Ihe stall also assessed the health and salfery impacts for each alternative. 'To determine occupational sallety, it analyzed the varying degrees of baggage handling and occupational habits for cach alternative. Industrial experience in regard to similar types of work environments (c.g., warchouse operations and parecl delivery) indicates the rates of lost time resulting from injury and aceidental deaths of workers per unit time that can be expected for these occupations.

Potential radiological conseguenecs constitute the major concern associated with the l'NA system. Because the baggage and its contents may be activated, both workers and the public may be exposed to the radiation emitted during the decaly of the induced radionetivity. In calses where hand search of alarmed bags (those that have indicated potentially positive for high nitrogen density) is required, residual radiation from the handling of the bags could also expose the public to small amounts of radiation. ler purposes of value-impact assessment, the collective dose measured in person-Sv (person-rem) is the measure used to quantify the effect.
The economic impacts discussed are largely qualitative. 'The alternatives related to the use of the 'INA system will reculure an additional 6 to 9 positions per operational unit; the hand-search alternative will require an equivalent increase of 33 positions. The cost in tariffs or dollar charge per flight passenger also was estimaled for each alternative.

\subsection{Identification and Assessment of Alternatives}

In accordane with the guidance in NURLG/CR-3568, FAA evaluated a number of alternatives and selected a range of possible options for the detection of explosives in checked airline baggage. 'The alternatives studied died not sulficiently meet the requirements for detection of explosives as defined by FAA in "Background lechnical Information for the Broad Agency Announcement" |U.S. Department of 'Iransportation, 1989)(a)|. These alternatives were the following:

- No action.

- Individual hand search of all checked luggage.

- Use of enhanced $x$ ray screening. 'This might include the use of eolor monitoring sereens with enhaneed image scanners to distinguish between organic artd inorganic matcrials.

- Use of chemical vapor detection methods. These might include use of chemical vapor detectors ("snif"fers") sensitive to explosives or use of trained catnines (ollactory methods).

- Use of the LDS-3 in the ramp area (as currently licensed):

- Use of the EDS-3C in the concourse area.

- Use of the IEDS-3C with enhanced radiation protection features fo further minimize possible human exposure to ionizing radiation in the concourse areat.

Of the alternatives considered, liAA eliminaled two as being inclifective and, therefore, not feasible (FAA, 1989). The alternatives considered to be inelfective (because of the l:AA requirement pertaining to the perentage of false positives and the 6 -second requirement for screening) were enhaneed $x$ ray screening and chemical vapor detection. The remaining allernatives are described in this section. To evaluate the relative advantages and disadvantages of these alternatives, the NRC stalf performed an assessment using the methodelogy in NURI:G/CR-3568.

'li) estimate the anticipated number of occupational accidents for each of the allernatives evaluated, the National 
Salcty Council's annual statistics for rates of occupational accidents were used (National Salety Council, 1986). I'hese rates are expressed in terms of resulting lost workdays. For example, the following industry-related jobs are cited in the decument published by the National Sallety (ouncil (1986):

\begin{tabular}{ll}
\hline Industry & $\begin{array}{l}\text { Lost workday/ } \\
\text { person.yr }\end{array}$ \\
\hline Iransportation and public utilitics & 1.05 \\
Manuficturing & 0.78 \\
Wholesale and retail trade & 0.50 \\
\hline
\end{tabular}

lo estimate the anticipated industrial accident rate, an average of the above three examples ( 0.75 lost workday/ person-yr) was used. Ior example, if one alternative required 20 employees to accomplish the job, the accident rate would be 15 lost workdays/yr (20 employees $x 0.75$ lost workclay/person-yr).

lor purposes of this assessment, the following operational assumptions were made for the EDS-3C:

- The estimated operating lile of the unit is 15 years.

- The unit inspects baggage at a rate of 400 bags an hour and operates 16 hours a day.

- Approximatcly 6000 bags a day are inspected. Assuming cach passenger has two bags, the baggage from about 1.1 million passengers will be inspected.

- Two operational personnel are required to attend the liDS-3C during operating hours. 'Ihis requires six full-time-equivalent personnel per operating unit (threc 4()-hr/wk shilts).

- Tiwo baggage handlers are required to load luggage onto the IEDS-3C during operating hours. This requires six full-time-equivalent personnel per operating unit (threc 40)-hr/wk shifts).

- listimated average annual personnel costs are as folIows: the laDS operator, $\$ 60,000$; each baggage handler, $\$ 45,(0) 0$; and each LiDS assistant or "runner," $\$ 35,000$ (all estimates include overhead costs). Salary estimales are from the International Association ()l Machinists.

\subsubsection{No Action}

This altermative assumes that present policies and proee. dures involving inspection of checked airline baggage are continued and that present levels of security are mainlained. No additional operalting or capital costs are assumed.

\subsubsection{Hand Search}

This alternative assumes that all checked luggige is individually hand searched. It will require a significant increase in inspection staff, along with allendant labor costs. It also may require changes in airline scheduling to allow for the additional time to complete inspection procedures. Because it is assumed that capital costs for this alternative are relatively small (i.e., inspection tables), they are not considered in this assessment.

The operating costs to consider for this alternative would be (1) costs associated with the additional space needed for the inspection tables arid (2) costs associated with the hiring of additional inspection personnel to hand search cach picce of luggage. The average space needed for 10 inspection stations would be $\left.186 \mathrm{~m}^{2}(2000) \mathrm{ft}^{2}\right)$, with a cost of approximately $\$ 269 / \mathrm{m}^{2}\left(\$ 25 / \mathrm{t}^{2}\right)$. 'lo inspect the same amount of baggage that an IDSS-3C would be able to sereen, approximately $67,000 \mathrm{hr} / \mathrm{yr}$ would be needed:

\section{$2 \times 10^{\circ} \mathrm{bags} / \mathrm{yr} \times 2 \mathrm{~min} / \mathrm{bang} \times 1 \mathrm{hr} / 60 \mathrm{~min}=060,666 \mathrm{hr} / \mathrm{yr}$}

If an employec working full time for 2000 hours a year is assumed, a total of 33 inspection personnel would be required to hand scarch the same number of bags as would be screened by one IDDS-3C.' l'o calculate the total labor costs, it was assumed that each inspector was paid $\$ 10$ an hour, with an annual salary of $\$ 20,000(\$ 10 / \mathrm{hr} x$ $2000 \mathrm{hr} / \mathrm{yr}$ ). For overhead, health insurance, general, and administrative expenses, another 100 percent was added. This amounts to $\$ 40,000$ in labor costs for each inspector, resulting in a total labor cost of $\$ 1,320,000$ for each inspection station $(33 \times \$ 40,000) /$ person-yr $)$.

The total annual costs for this alternative are as follows:

$$
\begin{array}{cr}
\text { Labor cost }(33 \times \$ 40,000 / \text { person-yr }) & \$ 1,320,000 \\
\text { Space cost }\left(\$ 269 / \mathrm{m}^{2} \times 186 \mathrm{~m}^{2}\right) & \frac{\$ 50,000}{} \\
\text { TOTAL ANNUAL COS'1 } & \$ 1,370,000
\end{array}
$$

Accordingly, for the hand-scarch option, the estimated accident rate is 25 lost workdays/yr ( 33 personnel $\times 0.75$ lost workday/person-yr).

\subsubsection{TNA System in Ramp Area}

'This alternative involves the use of the 'TNA system (EDS-3) in the ramp or cargo-handling area of an airport. This alternative is currently licensed and is being used at JFK International Airport in New York and Mami International Airport in Lilorida. It was evaluated in a previous environmental assessment (NRC, 1989).

Recent experience at JlK International Airport has shown that additional labor cost is associated with the ramp location relative to the propesed use of the lidS-3e in the loblyy or concourse arcit. This cost is related to the leggistical problem of locating and bringing 
passengers whose bags have alarmed to the TNA inspec. tion area (near the rarnp area of an alrport) where the bags in question are opened and inspected. This was assumed to require one assistant (during 'TNA system operation), 16 hours a day, 7 days a weck, for a total of three assistants. 'The additional labor costs for these three assistants are $\$ 35,000 \times 3=\$ 105,000$. Currently, two baggage handlers and two EDS-3 trained operators must attend the unit during its operation. This requires 12 full-timeequivalent personnel for each operating unit (six 40-hr/ wk shifts) at a cost of approximately $\$ 45,000$ a year for each baggage handler and $\$ 60,000$ a year for each operator. The average space needed for each EDS-3 is $93 \mathrm{~m}^{2}\left(1000 \mathrm{ft}^{2}\right)$, with a cost of approximately $\$ 269 / \mathrm{m}^{2}$ $\left(\$ 25 / \mathrm{ft}^{2}\right)$. The estimated accident rate for this alternative is 11.3 lost workdays/yr ( 15 personnel $x 0.75$ lost workday/ person-yr).

The capital, operational, and annual costs for this alternative are as follows:

\section{Capital Costs}

Estimatcd fabrication and construction costs

$\$ 1,000,000$

Installation costs

Site modification (includes housing)

$\$ 125,000$

'Transportation, setup, and testing

TOI'AI, CAPITAL, COSTS

$\$ 1,175,000$

Amortized Anmual Cost (\$/yr, $15 \mathrm{yr}$

(ii) $10 \%)$

$\$ 151,5(0)$

Operational Costs

Space cost $\left(\$ 269 / \mathrm{m}^{2} \times 93 \mathrm{~m}^{2}\right)$

$\$ 25,000$

labor cost

6 operators (i) $\$ 60,000 / \mathrm{yr}$

$\$ 360,000$

6 baggage handlors (a) $\$ 45,000 / \mathrm{yr}$

$\$ 270,(100)$

3 runners (ii) $\$ 35,000) / y$ r

$\$ 105,000$

Source change

$\$ 25,000)$

Calibration, leak testing, and repair

TO'TAI, OPERA'IIONAI, COSIS

$\$ 25,000$

$\$ 810,000$

TO'I'AI, ANNUAAI, COS'IS

$\$ 961,5() 0$

\subsubsection{TNA System in Concourse Area}

This alternative is as clescribed in this environmental assessment. The original I:DS-3 has been modified slightly for encourse installation (now designated as Model liDS-3() to decrease the external radiation levels. bifferent materials were selected to reduce neutron calp- ture gamma rays, and additional pancls of borated polyethylene and lead were added to further reduce the external dose rates. Dose rate data are glven in Seotion 3.1.

For this alternative, the cost of supplementary support and additional building materials needed for the installation of the EDS-3C at indoor and outdoor locations at the airport has been added. The indoor locations would include the following: behind the check-in counter, in front of the check-in counter, and at the pre-check-in area. The only outdoor location would be at the curbside. Because only 6 full-time operators and 6 full-time baggage handlers would be needed for the indoor secnarto, the estimated accident rate for this option is 9 lost workdays/yr (12 personnel x 0.75 lost workday/person-yr).

In the curbside scenario, however, the baggage may go directly into a baggage chute rather than staying on the same level as the EDS-3C. If this were the case, only three full-time baggage handlers would be needed to load luggage onto the system; all bags leaving the system would be automatically passed to the plane. The cstimated accident rate for the curbside option is 6.75 lost workdays/yr (9 personnel x 0.75 lost workday/person-yr). The decreases in estimated labor costs for the curbside secnario are reflected in Table 8.1 .

To estimate the costs associated with the construction and installation of the LDS-3C at the concourse level of an airport, a structural feasibility study was performed (sec Peacock, 1989). 'This study defined the structural concerns related to the support for the system, defined a conceptual solution for the support and placement of the system, and estimated the construction costs associated with the installation of the system. 'Table 8.1 shows the differences in capital and operational costs for both the curbside and indoor scenarios.

\subsubsection{TNA System With Enhanced Radiation Protection}

For this alternative, additional shiclding, moderators, and controls are added to the basic design of the IDIS-3C. 'Ihese additional materials are assumed to be capable of' reducing the radiation exposures by at least 50 pereent. Installation cost would be increased because of the added weight and materials.

Because 6 full-time operators and 6 full-time haggage handlers would be needed for this alternative, the estimated accident rate is 9 lost workdays/yr (12 personnel $x$ 0.75 lost workday/person-yr).

The capital, operational, and annual costs for this alternative are as follows: 
Table 8.1 Construction costs for curbside and indoor EDS-3C installations

\begin{tabular}{|c|c|c|}
\hline Attribute & $\begin{array}{l}\text { Curbside } \\
\text { installation }\end{array}$ & $\begin{array}{l}\text { Indoor } \\
\text { installation }\end{array}$ \\
\hline \multicolumn{3}{|l|}{ Capital Costs } \\
\hline Estimated fabrication costs for EDS-3C & $\$ 1,000,000$ & $\$ 1,000,000$ \\
\hline \multicolumn{3}{|l|}{ Construction Costs } \\
\hline Outside housing & $\$ 125,000$ & $\$ 0$ \\
\hline Median barricrs & $\$ 5,500$ & $\$ 0$ \\
\hline Structural design fee & $\$ 7,000$ & $\$ 3,000$ \\
\hline Analysis of load path through terminal & $\$ 0$ & $\$ 4,500$ \\
\hline Moving equipment & $\$ 0$ & $\$ 5,500$ \\
\hline Construction & $\$ 35,500$ & $\$ 35,500$ \\
\hline Transportation, sctup, and testing & $\$ 50,000$ & $\$ 50,000$ \\
\hline TO'TAL CAPIYAL COSIS & $\$ 1,223,000$ & $\$ 1,098,500$ \\
\hline Amortized unnual cupitul cost (\$/yr, 15 yr (i) $10 \%)$ & $\$ 157,700$ & $\$ 141,700$ \\
\hline \multicolumn{3}{|l|}{ Operational Costs } \\
\hline Space cost $\left(\$ 269 / \mathrm{m}^{2} \times 93 \mathrm{~m}^{2}\right)$ & $\$ 25,000$ & $\$ 25,000$ \\
\hline \multicolumn{3}{|l|}{1 abor cost } \\
\hline 6 operators (ii) $\$ 60,000 / \mathrm{yr}$ & $\$ 360,000$ & $\$ 360,000$ \\
\hline 6 baggage handlers (a) $\$ 45,000 / y r$ & - & $\$ 270,000$ \\
\hline 3 baggage handlers (a) $\$ 45,000 / y r$ & $\$ 135,000$ & - \\
\hline Source change & $\$ 25,000$ & $\$ 25,000$ \\
\hline Calibration, leak testing, and repair & $\$ 25,000$ & $\$ 25,000$ \\
\hline TO'TAI. OPIERATIONAL COSTS & $\$ 570,(0) 00$ & $\$ 705,000$ \\
\hline TO'TAI, ANNUAL, COS'IS & $\$ 727,700$ & $\$ 846,700$ \\
\hline
\end{tabular}

Cupitai Costs

Estimated fabrication and construction costs

$\$ 1,200,000$

Installation costs

$\$ 200,000$

TO'IAL. CAPI'TAL COSTS $\$ 1,400,000$

Amortized Annual Cost $(\$ / y r, 15 \mathrm{yr}$

(ii) $10 \%)$

$\$ 180,5(0)$

Operational Costs

Same ac those in Table 8.1 for indoor installation

'TOI'AL, OPI:RA'TIONAL, COSIS

$\$ 7(05,000)$

IO'TAI. ANNUAI, COSTS

\subsection{Summary}

Table 8.2 gives the value-impact summary for the four alternatives described in the previous sections in relation

to the nos-action alternative. The table shows that the average cost of the 'INA system, normalized to a perflight-passenger basis, is about $\$ 0.78$, and the per-flightpassenger cost for the hand-search alternative is about $\$ 1.25$. The difference is attributable to the number of employees needed to hand scarch baggage.

The cost effectiveness of a I'NA system with enhaneed radiation protection features car also be determined from this study. With a marginal annual dose reduction of 0.057 person-Sv $(5.7 \mathrm{rcm})$ and a differential annual cost of $\$ 38,8(0)$, the cost for this system would be about $\$ 6,800$ )/person-rem (the traditional unit of $\mathrm{rem}$ is used here for simplicity). 'This value exceeds the NRC guideline of $\$ 100 /$ person-rem (NURI:(G/13R-(0)58); therefore, under the assumptions applied in this anulysis, the enhanced radiation protection features would not be considered cosit effective. 
'Table 8.2 Value-impact summary for airline explosive detection alternatives

\begin{tabular}{|c|c|c|c|c|c|c|}
\hline \multirow[b]{2}{*}{ Attribute } & \multirow{2}{*}{$\begin{array}{l}\text { No } \\
\text { action }\end{array}$} & \multirow{2}{*}{$\begin{array}{l}\text { Hund } \\
\text { searcin }\end{array}$} & \multirow{2}{*}{$\begin{array}{l}\text { TNA system } \\
\text { in ramp } \\
\text { area }\end{array}$} & \multicolumn{2}{|c|}{$\begin{array}{l}\text { 'TNA system } \\
\text { as proposedel }\end{array}$} & \multirow{2}{*}{$\begin{array}{l}\text { 'INA system } \\
\text { with culuanced } \\
\text { radliation } \\
\text { profection }\end{array}$} \\
\hline & & & & Curbside & Indeor & \\
\hline \multicolumn{7}{|l|}{ Costs } \\
\hline Unit capital cost (\$) & 0 & () & $1,175,000$ & $1,223,0(0)$ & $1,(1) 88,500$ & $1,400,0000$ \\
\hline $\begin{array}{l}\text { Anortized annual capital } \\
\text { cost }(\$ / y r)\end{array}$ & (1) & ) & $151,5() 0$ & $157,7(0)$ & $141,7(00$ & $18(0,500$ \\
\hline Operational cost (\$/yr) & () & $1,370,(0)(0)$ & 810,000 & 570,000 & $7(05,0)(0)$ & $7(15,0000$ \\
\hline $\begin{array}{l}\text { Unit totul cost (\$/yr) } \\
\text { (amortized annual cost plus } \\
\text { operational cost) }\end{array}$ & () & $1,370,(0)(0)$ & 961,500 & 727.70() & 846,700 & 885,500 \\
\hline Cost per flight passenger (\$) & () & 1.25 & 0.87 & 0.66 & 0.77 & $(1.81$ \\
\hline \multicolumn{7}{|l|}{ Health und Sufety Impucts } \\
\hline Aircralt safety and security & No change & Improved & Improved & Improved & Improved & Imploved \\
\hline $\begin{array}{l}\text { Industrial accident rate } \\
\text { (lost workdays//unit/yr) }\end{array}$ & () & 25 & 11.3 & 6.7 & 9 & 9 \\
\hline \multicolumn{7}{|l|}{ Rudiological Impacts } \\
\hline \multicolumn{7}{|l|}{$\begin{array}{l}\text { Collective dose } \\
\text { (person-Sv/unit/yr) }\end{array}$} \\
\hline Occupational & () & () & 6.(1)1:-(1)3 & $1.21:-02$ & $1,21:-(1) 2$ & $6 .(1) 1:-1) 3$ \\
\hline Public & () & 0 & $1.01 i-(12$ & $1.51:--() 1$ & $1.41: \cdots(01$ & $6.41:-(02$ \\
\hline $\begin{array}{l}\text { Public (pre-check-in } \\
\text { scenariu) }\end{array}$ & NiA & $N / A$ & $N / A$ & NiA & $3.41:-01$ & $N / A$ \\
\hline Consumable items & () & 0 & 0 & 0 & $1.31:-0.5$ & 0 \\
\hline Nonconsumable items & 0 & 0 & $2.81:-0) 3$ & $2.81:-(1) 3$ & $2.81:-(1) 3$ & $2.81:-0) 3$ \\
\hline Total & 0 & () & $1.91:-(12$ & $1.61 ;-(0)$ & $4.91 i-(0) 1$ & $7.31:-(12$ \\
\hline \multicolumn{7}{|l|}{ Social and Economic: Impacts } \\
\hline Added employment & () & 33 & 15 & 9 & 12 & 12 \\
\hline \multicolumn{7}{|l|}{ Public fear due to } \\
\hline Radionclivity & None & None: & Increased & Increased & Increased & Increased \\
\hline Jlight risks & No change & Decreased & Decreased & Decreased & Decreased & Decreased \\
\hline
\end{tabular}

Note: $N / A=m$ mol inplicable.

$0.01:-10.3=6 .(1) \times 1(1-3) \cdot 1 c$. 


\section{SUMMARY ANI CONCLUSIONS}

\subsection{Summary of Environmental Impacts}

Reyuirements regarding the inspection of passengern' luggnge are not new. An Lixecutive () deder of January 5 , 1973. reguirod airline compunics to inspret all passengers and their hand-ciorried laggigge for concenled guns, clangerous weapons, explosiles, and incendlary devices before permitting the passengers to hoard commercial nircralt (NC RIP Report 95). By 1985, aldines scomned the luggage for about 400 million passenger trips using $x$ ray fluorosecopice seamning systems in the public acesses areas of airports. 'The federal performane standiard (21 CliR 102.4(1) for cabinel $x$ raly systems limits $x$ raly emissions at a point 5 em (2 in.) from the extermal surfice of the system (1) $1.3 \times 1()-7$ coulomb/kg $\{(0.5 \mathrm{mrcm})$ in any one hour. ()n the busis of this exposure ralle, this sourece would contrib-

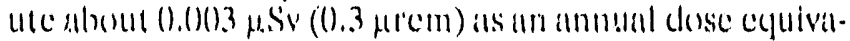
lent fo cals:h flight pussenger. Assuming 30 million passengers travel per year, the estimated annual collective effective dose equivalent is about 0.6 person-sv (fol) person-rem).

This assessinemt indiented that a structural engineering study will be recuired to ensure that the weight of the lid)S-30 can be accommodialded sillely on the concoutse level of airports. Construction, installation, and use of the l:1)S-3( will alfecel nearby passenger trallice pallerns to some degree at internattomal ticker counters. However, essential rigging eyujpment such ats air dollics or forklilts

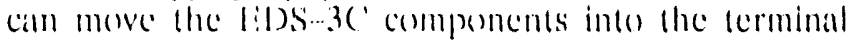
building during a weck night or on a weckend when traftic in the terminal is at a minimum.

'The NRe stalf assessed the internal dose (1) passengers from irradiated fondstulfis. It determined the total eflecetive dose ecpuivalent from the average daily intake of the major elements contributing the largest doses (using IC RP Publicallion 23). If s pereent of the passengers carried food items in their leggege and consumed it within 30 seconds of reclaiming their luggage (alter it wats sereened by the lat)s...3('), the annual collective dose 10 an estimaled 1.1 million passengers would be $1.3 \times 10.5$ persen-Sv $(1.3 \times 1(1)-3$ persen-rem).

The stall calleulated the collective eflective dese equivilent frem weitring 40 g (1.4 (1) of gold jewelry that had passed through the lads 3 ( . If I pereent of the passengers carried gonld jewelry in their longugge and subseguently wore it lor an extended period, the dese from this scenatries would be $2.8 \times 10.3$ persom-Siver (0.28 persom$\mathrm{rem} / \mathrm{yr})$. fior the purposes of envitommental annlysiss, the staft' ussessed the impact of seyeral different aceldent secenarlos to selectively bound a spectrum ol aceidents that could oceur, It evalualed three potential aecident secenartes (i.e., accidents that could oceur during solurece transter, transportation, and operation of the system) involving the partlal or complete fragmentation of the (1'-252 source. 'l he resulting maximum inhalation dese from the worstcase accident lnvolving 10(0)perecent dispersion of the souree al a distanes of $10(0) \mathrm{m}$ (110 yd) would be 1.(1) $10.3 \mathrm{~Sv}$ (0.10 rem), which is well wilhin the 1.1.s. Invironmental Protectlon Agency (1990) protective uction guldelines of $0.25 \mathrm{~Sv}(25 \mathrm{rem})$ for emergency workers.

'The stall perlormed a oust-benelit analysis of allernativess to the EDS-3C. 'The alternatives considered were the following: no acelon, individual hand search of checked luggage, use of the lids-3 in the ramp area, use of the

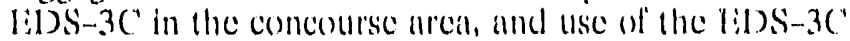
with enhanced radiation prosection features. 'l he evaluation elearly demonstrated that the biss-30 entbside alternative wats the most cost-ellective method ol sereening passenger check-in lugguge.

As illustrated in this assessment, the annual dose from LiDS-3C operations (o members of the public could be companed with that from $x$ raly inspection systems that have been in use since the early 197()s. Jiven in the worstcatse secnario (pre-check-in), the maximum individual dese for passengers was (). $18 \mu \mathrm{sv} / \mathrm{yr}$ ( $18 \mu \mathrm{rem} / \mathrm{yr})$, and 1 he maximum individual dose to members of the public wats

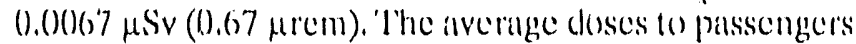
and members of the public firom all lesur seconatios were

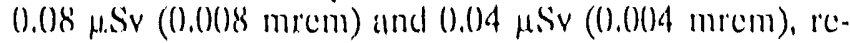
spectively. If the additional conservatism of the neutron yually lacedor was not used (10) rather than 2(1), the above calculated doses from the liDS -30 would be hall the doses shown.

On the basis of the foregoing assessment, the NRC statl' concludes that the envirommental effects of normal operation of the lids-3C when located in any one of the four concourse areas of an airport are expected to be extremely small. for all scenarios, the maximum vilues of radiation exposure that may be received by workers in restricted areas (such as the operators) and those in unrestricted areas (other non-'INA workers, passengers, and members of the public) are well below the limits specified in 10) (TiR Pint 20).

\subsection{Basis for Finding of No Significant Impact}

()n the basis of the foregoing assessment, the NRC ' stiolf' concludes that the environmental impacts that would 
result from the proposed licensing action would not be signilicant and do not warrant tho preparation of an environmental impact statement. Accordingly, the stafl has determined that a finding of no signifient impact is approprlate.

For further technical details with respect to this action, see the application for a license dated Oetober 31, 1986; amendments dated April 19 and August 22, 1989); the supporting onvironmental reports; and other related correspondened. 'llhese decuments (in Docket Number (13)-30885) and this linal environmental assessment may be examined or copled for a fee at both the NRC's Public Document Room at 2.21 1. Street NW. Washlngton, D.C. 20555, and the NRC"s Region I Public Decument Roum, 475 Allendale Ronal, King of Prussia, Pennsylvania 19406. 


\section{REFERENCES}

American Socicty for 'resting and Materials (ASIM), Anmual Book of ASTM Standards, Sec. 12, Vol. 12.02, "Standard Method for Determining Thermal Neutron Reaction and Fluence Rates by Radionctivation Techniques." Method L262-86, Philadelphia, Pennsylvania, 1989 edition.

Bockett, L., and M. Schneider, Polaroid Corporation, letter to C. Setier, Federal Aviation Administration, October 30, 1987.

Bozorgmanesh, H., "TRANSCASK, Certification and Analysis Scienco Applications Inc., Cf-252 Shipping Cask Assembly," unnumbered SAIC report, Santa Clara, California, 1981.

California Department of Heallh Services, CA-59)(-..1)-118-S, "Registry of Radioactive Sealed Sourecs and Devices for SAIC Model EDS-3C," Sacrimento, (alifornia, February 1990.

- - CA-59()-1)--122-S, "Registry of Radioactive Scaled Sources and Devices lor SAIC Model IBDS-3," August 1989.

Code of Federai Regulations, Title 10, "Energy," and 'Title 21. "Food and Drugs," U.S. Government Printing Office, Washington, D.C... revised periodically.

1:.I. du Pont de Nemours and Company, Savannah River Ialboratory, DP-1246, "Calilornium-252 Shielding Guide," Aiken, South Carolina, March 1971.

Virdt mann, (3., Neutron Activation Tables, Verlag Chemie, Weinheim, New York, 1976.

Hall, B, United Airlines, personal telephone conversation with C. (G. Jones, U.S, Nuclear Regulatory Commission, January 17, 1990) (documented in licensing file in NRC's Region I Public Document Room).

Hodgman, C. D., R. C. Weast, and A. M. Selby, eds., Hundbook of Chemistry and Physics, Chemical Rubber Publishing Co., Cleveland, ()hio, 1960).

Idaho Nalional Iingineering laboratory (INLI), I:G(jPHY-8274, "Linvironmental Assessment for lixplosive betection Systems Using 'Thermal Neutron Activation for Airline Baggage Inspection," Idaho Falls, Idaho, Seplember 1988.

International Commission on Radiation Units and Measurements, ICRU Report 33, "Radiation Quantities and Units," Bethelida, Maryland, April 15, 1980.
- - ICRLI Report 40, "I'he Quality linctor in Radiation Protection," April 4, 1986.

Internationul Commission on Radiological Protection, ICRP Publication 21, "Data for Protection Against Ioniz" ing Radiation From External Sources," supplement to ICRP' Publication 15, Peręamon Press, Oxford, England, 1971.

- - ICRP Publication 23, "Reference Man: Anatomical, Physiological, and Metabolic Characteristics," Per. gamon Press, 1975.

-..., ICRP Publication 28, "Statement From the 1978 Stockholm Mecting of the ICRP," Pergamon Press, 1978.

-D, ICRP Publication 30, "Limits for Intakes of Radionuclides by Workers," Parts 1-3 (with supplements), Pergamon Press, 1979-1982.

-.. "Statement firom the 1985 Paris Meeting of the IC"RP," Health Physics, Vol, 48, No, 6, June 1985, p), 828.

Jacger, R. G., L: P. Blizard, and A. B. Chilton, eds., Engineering Compendium on Rudiation Shielding, Vol. III, sponsored by the International Atomic Energy Agency, Springer-Verlag, New York, 1970.

Knoll, G. Li, Radiation Detection and Me'usurement, John Wiley and Sons, New York, 1979.

National Council on Radiation Protection and Measurements, NCRP Report 91, "Recommendations on I imits for lixposure to Ionizing Radiation," Bethesda, Maryland, June 1, 1987.

-..-, NCRP Report 94, "Iixposure of the Pepulation in the United States and Canada lirom Natural Background Radiation," December 30, 1987.

- -, NCRP Report 95, "Radiation lixposure of the U.S. lopulation From Consumer Products and Miscellaneous Sources," December 30, 1987.

National Institute of Standards and'I'echnology, "Quantitative Assessment of Induced Radionctivity in Baggage," final report covering all phases of Interagency Agreemont No, D'Tl:A-(03-87-A-000008, (Gatthersburg, Maryland, March 31, 1989.

National Sal'cty Council, Accident Facts, Chicago, Illinois, 1986.

Peacoek, 'IT. M., FI)L: LITD., Consulting lingineers, lotter to P. Ryge, scientific Applications International ("orporation |Appendix l, of SAIC (1989)|, November 16, 1989. 
Ryge, P., Science Applications International Corporation, letter to C. G. Jones, U.S. Nuclear Regulatory Commission, March 1989.

- -, Science Applications International Corporation, letter to C. G. Jones, U.S. Nuclear Regulatory Commission, January 11, 1990.

Sandia National Laboratory, SAND 77-1927, "Transport of Radionuclides in Urban Environments: Working Draft Assessment," Albuquerque, New Mexico, 1978.

Science Applications International Corporation (SAIC), "Environmental Report on Explosive Detection System Using Thermal Neutron Activation for Airline Baggage Inspection," final report, Santa Clara, California, June 1988.

- -, "Applicant's Environmental Report: Use of Thermal Neutron Based Explosive Detection System for Checked Raggage Inspection in Airport Lobby Areas," NRC Control Number 111217, revised report, December 1989.

Sherbini, S., U.S. Nuclear Regulatory Commission, Region I, memorandum to C. G. Jones, U.S. Nuclear Regulatory Commission, February 1990.

U.S. Bureau of the Census, Statistical Abstracts of the United States: 1989, 109th edition, Washington, D.C., 1989, pp. 611-612.

U.S. Burcau of Mines, "Report of Tests on the Survivability of the Neutron Source Capsule of the SAIC Nitrogen Explosive Detection System," Pittsburgh, Pennsylvania, September 1988.

U.S. Department of Transportation, Federal Aviation Administration (FAA), "Explosive Detection Systems for Checked Baggage; Final Rule (14 CFR Part 108)," Federal Register, Vol. 54, No. 170, September 5, 1989, pp. 36938-36949.
- -, TCBAA-90-001, "Background 'Technical Information for the Broad Agency Announcement," Washington, D.C., November 1989(a).

U.S. Environmental Protection Agency (EPA), Manual of Protective Action Guides and Protective Action for Nuclear Incidents, 520/1-75-001-A, Washington, D.C., January 1.990.

U.S. House of Representatives, Committee on Science, Space, and Technology, "Statement of Richard F. Lally (former Director of Aviation Security, FAA) to the Subcommittee on Transportation, Aviation and Materials," Washington, D.C., February 9, 1989.

U.S. Nuclear Regulatory Commission, "Environmental Assessment and Finding of No Significant Impact Related to Amendment of Materials License 29-13141-05; Department of Transportation, Federal Aviation Administration," Federal Register, Vol. 54, No. 156, August 15, 1989, pp. 33636-33639.

-_, NUREG-0170, "Final Environmental Statement on the Transportation of Radioactive Material by Air and Other Modes," Vols. 1 and 2, December 1977.

--, NUREG-0172, "Age-Specific Radiation Dose Commitment Factors for a One-Ycar Chronic Intake," November 1977.

--, NUREG/BR-0058, "Regulatory Analysis Guidelines of the U.S. Nuclear Regulatory Commission," January 1983.

--, NUREG/CR-3568, "A Handbook for ValueImpact Assessment," Battelle Memorial Institute, Pacilic Northwest Laboratory, December 1983.

Westinghouse Electric Corporation, "The Gamma and Neutron Irradiation of Pharmaceuticals," Contract No. 34-55524-WR, Pittsburgh, Pennsylvania, September 1986. 
APPENDIX A

INSTALLATION AND RADIATION SAFETY OPERATING PROCEDURES FOR EDS-3C 


\section{THERMAL NEUTRON ANALYSIS (TNA ${ }^{\text {TM }}$ ) EXPLOSIVE DETECTION SYSTEM}

RADIATION SAFETY OPERATING PROCEDURES

Revised

February 20, 1990

SCIENCE APPLICATIONS INTERNATIONAL CORPORATION 2950 Patrick Henry Drive

Santa Clara, CA 95054 


\section{CONTENTS}

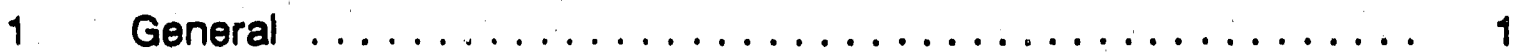

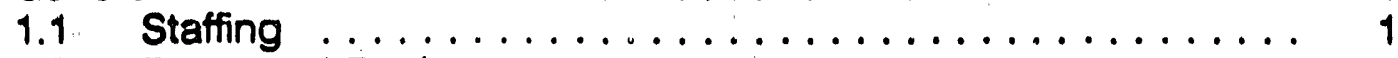

1.2 Personnel Dosimetry . . . . . . . . . . . . . . . . . 1

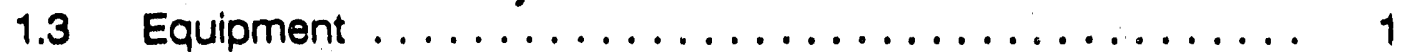

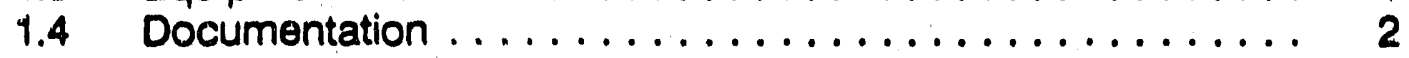

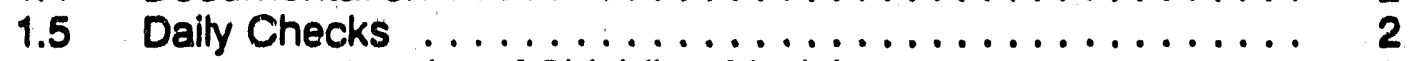

1.6 Access to Interior of Shielding Modules ... . . . . . . . . . 2

1.7 Access to Baggage Passageway .................. 3

1.8 Unattended System $\ldots \ldots \ldots \ldots \ldots \ldots \ldots \ldots$

1.9 TNA Daily $\log \ldots \ldots \ldots \ldots \ldots \ldots \ldots \ldots \ldots \ldots$

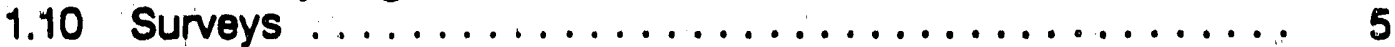

1.11 TNA Alarms ......................... 5

2 Source Handling ......................... 7

2.1 Transport Cask ...................... 7

2.2 Transfer and Retraction Hardware ................. 7

2.3 Special Considerations for Lobby installations . . . . . . . . . 11

2.4 Loading ........................... 11

2.5 Removal ............................... 16

2.6 Storage or Transport ...................... 16

2.7 Retraction ........................... 19

$3 \quad$ Emergency Procedures $\ldots \ldots \ldots \ldots \ldots \ldots \ldots$

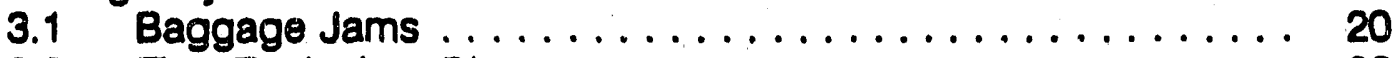

3.2 Fire, Explosion, Disaster . . . . . . . . . . . . . 22

3.3 Earthquake ........................ 22

3.4 Source Stuck at Interface .................... 23

3.5 Source Transfer Incidents . . . . . . . . . . . . . . . . . . . 24

3.6 Power Loss or System Failure . . . . . . . . . . . . . . . . . . . 24

3.7 Detection of Source Leak . . . . . . . . . . . . . . . . . . . 24

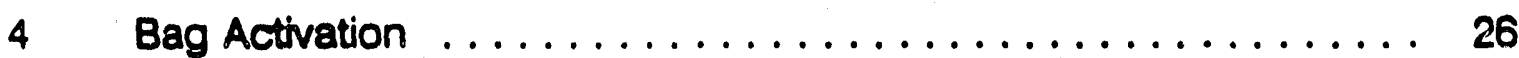

4.1 Monitoring ........................ 26

4.2 Exit Monitor System ........................ 26

4.3 Calibration/Check Procedure .................. 26

$5 \quad$ Ct-252 Source Leak Tost Procedure . . . . . . . . . . . . . . . . 28

5.1 Source Leak Test ....................... 28

5.2 Conveyor Belt Wipe Test . . . . . . . . . . . . . . . . 28

5.3 Sample Analysis ......................... 29 


\title{
SECTION 1
}

\author{
GENERAL
}

\subsection{STAFFING}

All work on and around the system shall be done under the immediate supervision of an authorized system operator who has been trained and qualified in operation, source handling, and emergency procedures. The operator must have received training and demonstrated proficiency in radiation safety and these procedures for the explosive detection system.

\subsection{PERSONNEL DOSIMETRY}

TNA operators shall wear a neutron/gamma radiation badge dosimeter for all work on and around the system when the source is on site. Other personnel such as baggage handlers whose work on the TNA is limited to loading and/or unloading baggage may also be required to wear dosimeters depending on the particular installation site. Personnel must not enter the baggage passage for any reason with the source in the operating position. Film badges shall be changed on a monthly basis. The contractor for this dosimetric device will be accredited by the National Voluntary Laboratory Accreditation Program (NVLAP).

\subsection{EQUIPMENT}

The following equipment shall be readily available on site, in operational condition, and calibrated appropriately. Portable survey meters will be calibrated every six months with sources whose calibration is traceable to NIST.

An ion chamber survey meter capable of reading $0.1 \mathrm{mrem} / \mathrm{hr}$.

A neutron survey meter capable of measuring levels as low as $0.1 \mathrm{mrem} / \mathrm{hr}$.

The baggage activation exit monitor system will be mounted so that all baggage leaving the TNA is monitored. Visable and audible devices will be used as required for alarm purpose. A check source shall be available for daily operational checks.

Long-handled tools for emergency source handling and baggage retrieval.

Warning signs, yellow/magenta ropes, etc., for defining a radiation area.

Source transport cask. 
Tamper-indicating seals, paper type, with SAIC logo.

\subsection{DOCUMENTATION}

The following documents will be on site and readily available:

Copy of the Radioactive Materials License and State $X$-ray machine registration.

Copies of applicable radiation safety regulations (e.g. NRC Regulations and any applicable State Regulations)

SAIC Radiation Safety Guide

Radiation Safety Operating Procedures for the TNA

Notices to employees and the public, as required

Emergency call list with numbers for:

- System Operators

- FAA (local)

- SAIC 24-hour Emergency Contact

- Airport Emergency Contact

- NRC Region Office

- State Radiation Protection Office

Copies of survey instrument calibrations, survey results, leak test results, personal dosimeter results, operator training certificates.

\subsection{DAILY CHECKS}

The alarm threshold for the bag activation exit monitor shall be tested daily with a check source. (See Section 4.3.) Operation of the shield doors and indicator lights shall be checked daily by obsenving the lights turn off and on while passing a bag through the system. Operation of the "X-ray-On" indicator lights shall also be checked daily. Completion of the above checks shall be logged daily.

\subsection{ACCESS TO INTERIOR OF SHIELDING MODULES}

The doors to the areas underneath the outer "skin" shall remain closed and locked; the keys will be kept in the possession of the system operator.

Access to the computer and HV power supply is limited to 1 hour per week (within any seven day period) with the source in the system. 


\subsection{ACCESS TO BAGGAGE PASSAGEWAY}

Access, meaning personnel physically entering into the baggage passage, is prohibited unless the source is in the RETRACTED position. Briefly (on the order of one minute) reaching into the passage with tools from outside is permitted without retraction of the source.

Access is permitted only by the system operator. Gamma and neutron survey meters will be used before any person enters the baggage passage to insure that the radiation dose equivalent level is acceptable, l.e. Indicating that the source is properly retracted.

The duration of stay by the operator inside the neutron interrogation region of the TNA, with the source in the retracted position, is limited to a cumulative total of one hour within any seven day period. The source will be removed from the system if the operator must be inside for longer than the one hour limit. The operator shall log his stay time in the interrogation region for dose acoumulation.

\subsection{UNATTENDED SYSTEM}

When the system must be left unattended, the entrance and exit doors to the baggage passageway will be closed and locked. The source shall be left in the OPERATING position to maintain the lowest external dose rates. The tamper-indicating seal must be in place. Figure 1 shows where this seal is to be located. The seal is the paper type imprinted with the SAIC logo. The date when seal was put in place shall be recorded on it.

\subsection{TNA DAILY LOG}

Radiation safety-related incidents shall be noted in the daily log by the system operator. Items to be noted shall include but not be limited to:

- Source transfers

- Source retractions

- Opening of the computer and high voltage supply access doors (include duration)

- Personnel entering the baggage passageway (include duration)

- Baggago jams (include reasons for jams)

- Inspections

- Emergencies

- Tamper-indicating seal breakage, by operator during source handling or by actual attempted tampering.

- Daily exit monitor callibration

- Door position indicator operation

- Proper operation of "X-ray-On" indicator light. 


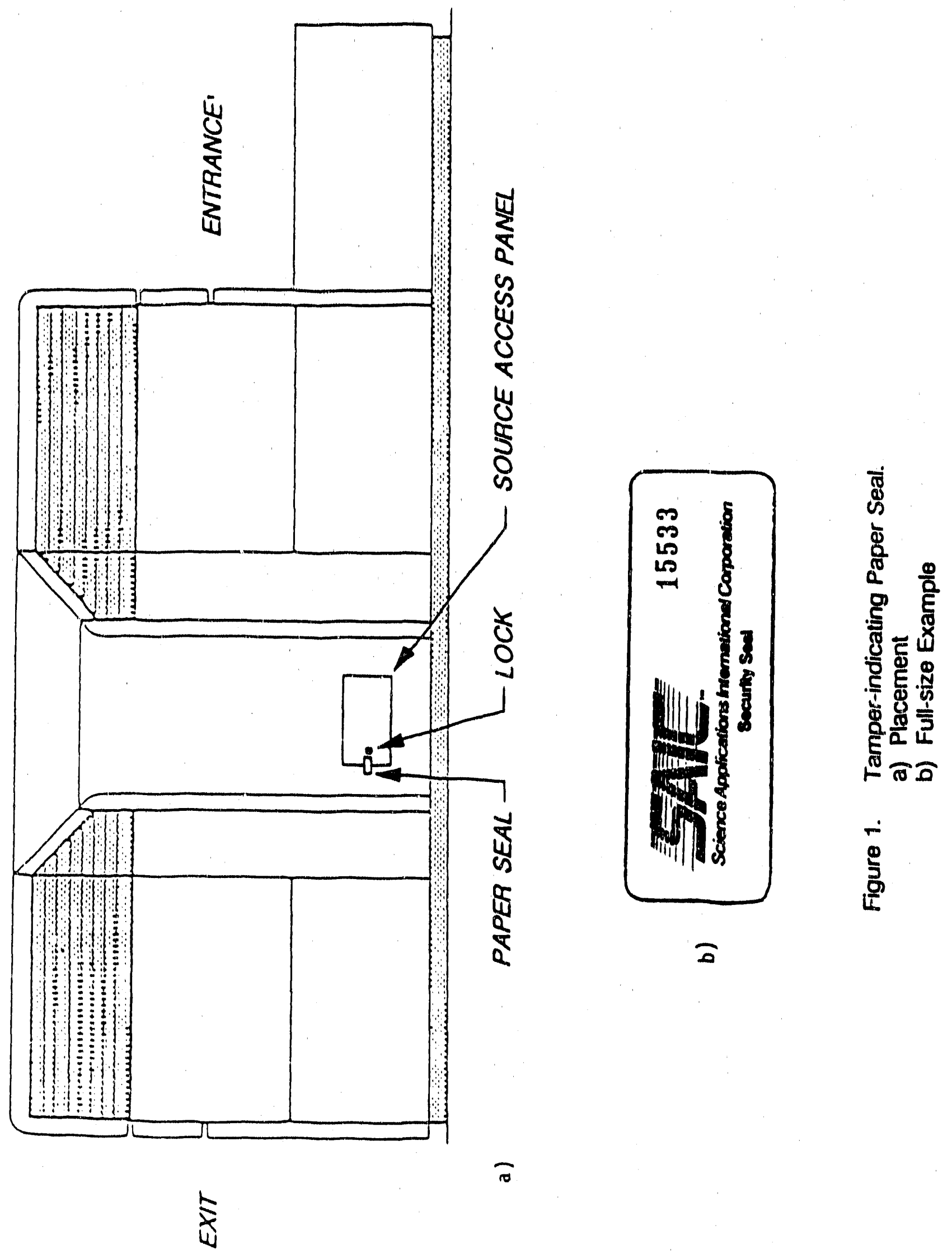


This log will be kept at the rNA site, available for inspection by the field maintenance staff, the radiation safety officer, and the regulatory agencles. The log shall be properly dated, and signed at completion of the work day.

\subsection{SURVEYS}

A radlation survey will be taken immediately following the initial source installation into the TNA, using both neutron and gamma ray survey meters capable of reading $0.1 \mathrm{mrem} / \mathrm{hr}$. If a maintenance activity or unusual occurrence might have affected the TNA shielding, a new neutron and gamma ray survey rnust be performed before proceeding with system operation.

After routine source re-loadings or replacements, a gamma/neutron survey shall be performed; however, if no changes to the system shielding accompanied such actions, only a gamma-ray survey will need to be taken.

Dose rates shall be measured $30 \mathrm{~cm}$ from the surface at the locations shown in the Figure 2. The readings shall be compared with the accompanying table of expected values with the source IN or RETRACTED. If readings inconsistent with the expected values are obtained (allowing for source decay), contact SAIC for instructions. Note survey results in the log book.

\subsection{TNA ALARMS}

If the TNA alarms, the alarm condition must be resolved. All alarms will be treated as due to real explosives and must be resolved before the bag is permitted to be placed on the aircraft. The most direct and sure method is by inspection of the bag's contents by trained security personnel in the presence of the passenger. The suspect bag or certain suspect contents from the bag may be passed through the TNA a second time to resolve the alarm. If suspect contents have been separated out from the bag, the nonsuspect portions must also be run through the TNA to clear that portion as well. In all cases, the bag or selected contents of a bag should not pass through the TNA more than a maximum of three times. The bag should be placed in a different orientation on each successive pass through the system. If the bag fails to clear after 3 times through the TNA, survey the bag for residual activity (se日 Sec. 4.1) and call security for hand search if required. 


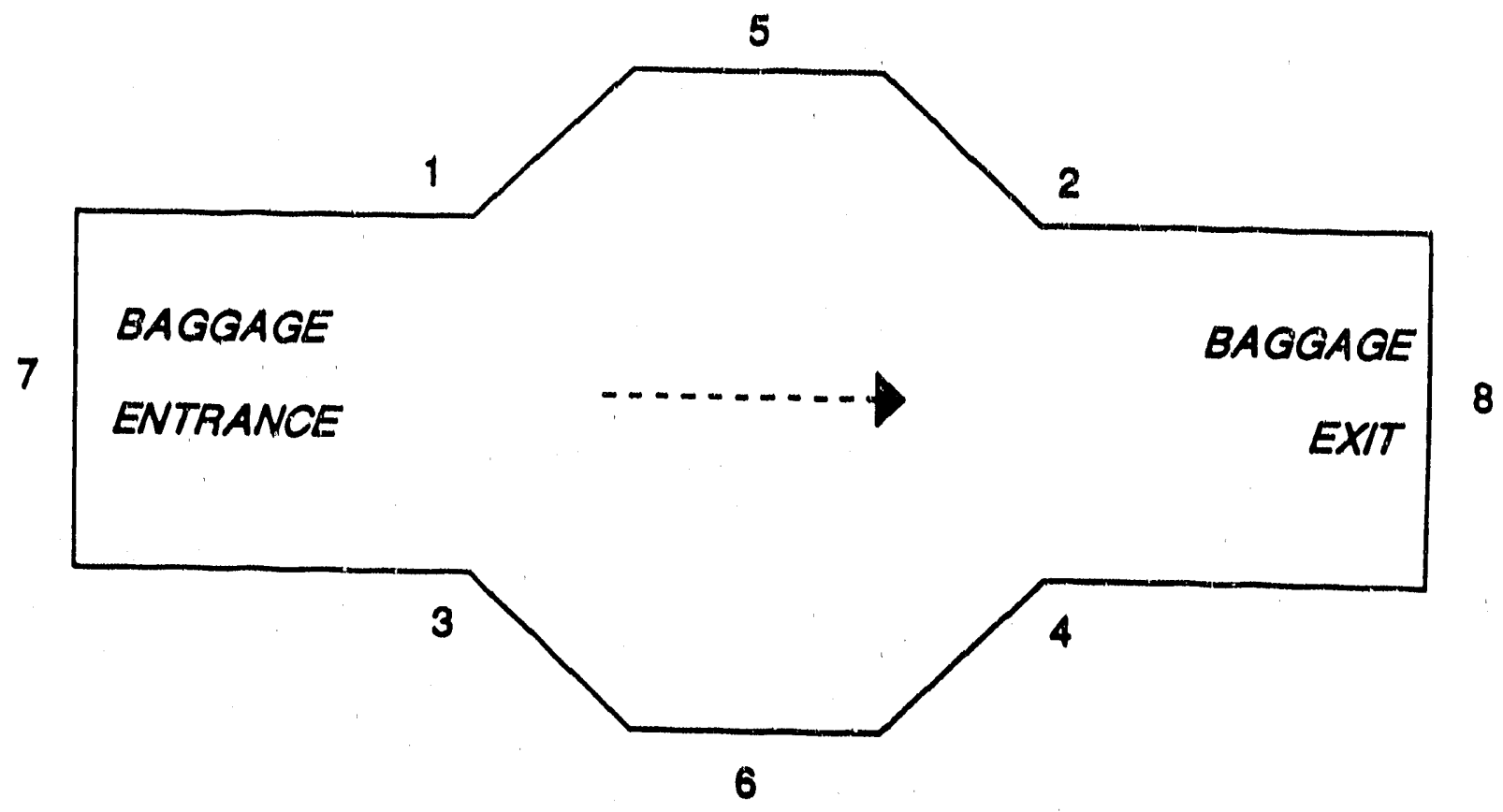

\begin{tabular}{|c|c|c|}
\hline \multicolumn{3}{|c|}{$\begin{array}{c}\text { DOSE RATE } \\
\text { (mrem/hr) }\end{array}$} \\
\hline Positions & Neutron & Gamma Ray \\
\hline $1-4$ IN & $<0.1$ & $<0.2$ \\
5,6 IN & $<0.1$ & $<0.1$ \\
7,8 IN & $<0.2$ & $<0.2$ \\
5 RETRACTED & $<0.4$ & $<0.2$ \\
\hline
\end{tabular}

Figure 2. Radiation Survey Locations and Expected Values. 
SECTION 2

SOURCE HANDLING

\subsection{TRANSPORT CASK}

The cask is bolted to the shipping platform for shipment. The platform is also used for source transfers to assure alignment of the cask with the TNA. The cask is in flush contact with the side of the TNA so that the source is never unshielded during transfer. The front of the cask (Figure 3a) has a Source Insertion/Exit Point in the center. The Source Insertion/Exit Point has a polyethylene plug to reduce radiation beam exting out of the source hole, to acceptable levels for shipment. This plug is covered by a removable metal plate.

The rear of the cask (Figure 3b) has a compartment for Teleflex cable storage. This is also covered by a removable metal plate. The compartment contains a padlock, a cable lock bracket, and a removable cable pressure bracket (Figure 30). When the cable lock bracket is fastened in place, it locks the Teleflex cable in position, holding the source in the center of the cask. The cable pressure bracket covers the cable lock bracket. The cable pressure bracket is removed by urlocking the padlock and lifting the bracket out and away from the lip on the bottom edge of the cable lock brackei. ine Telefiex cable is released by partially unscrewing the two flathead screws in the cable lock bracket until it is loose enough to raise. Then the bracket is lifted up and off the Teleflex cable and the right-hand screw is tighteried to hold it out of the way.

\subsection{TRANSFER AND RETRACTION HARDWARE}

Figure 4 shows the cask in position for source transfer, and a detailed view of the source transfer ring and source transfer adapter. The ring and adapter are only used for source transfer; they are stored inside the recess in the TNA. The loose support of the adapter allows it considerable leeway in adapting to misalignment of the cask and the TNA. Both the ring and the adapter are machined from polyethylene for low friction.

Figure 5 shows the retraction stop assembly in the source cask which prevents the source from being retracted farther than the intended distance. It consists of an aluminum holder to which a polyethylene tube is attached; the inside diameter of the tube $\left(0.25^{\prime \prime}\right)$ allows the Toleflex cable to pass easily $\left(0.21^{\prime \prime}\right)$ but it is too small to lot the source $\left(0.37^{\prime \prime}\right)$ go through. The tube is threaded and pinned into the holder. A swiveling bar engages the cable and clamps it in place. The bar is held in position by a padlock. When the bar is raised the cable is free to slide through. The holder is attached to the TNA by two screws which can be accessed only when the bar is raised. 
a)

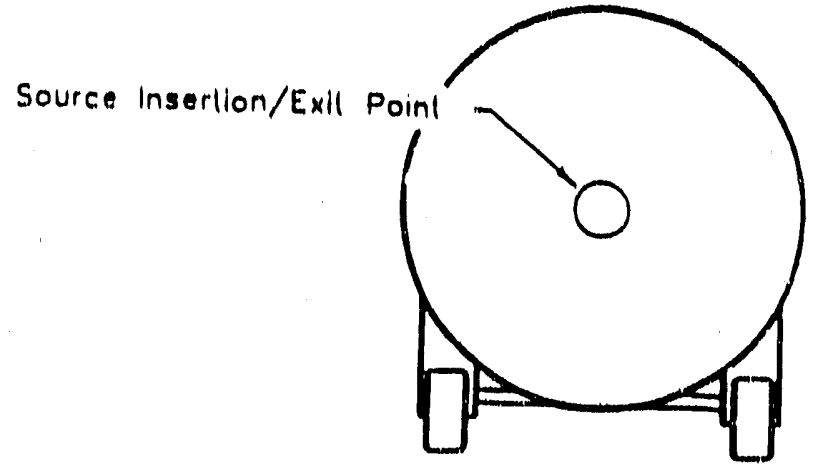

b)

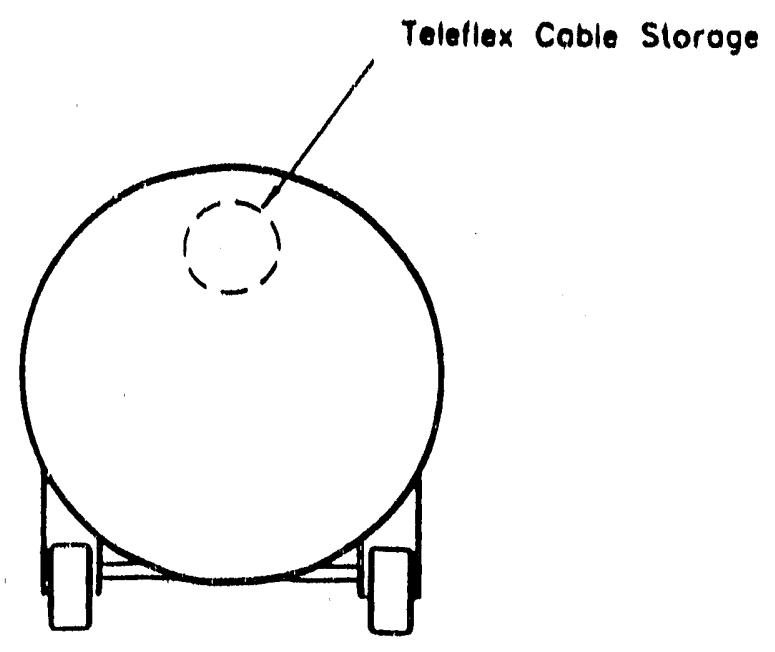

c)

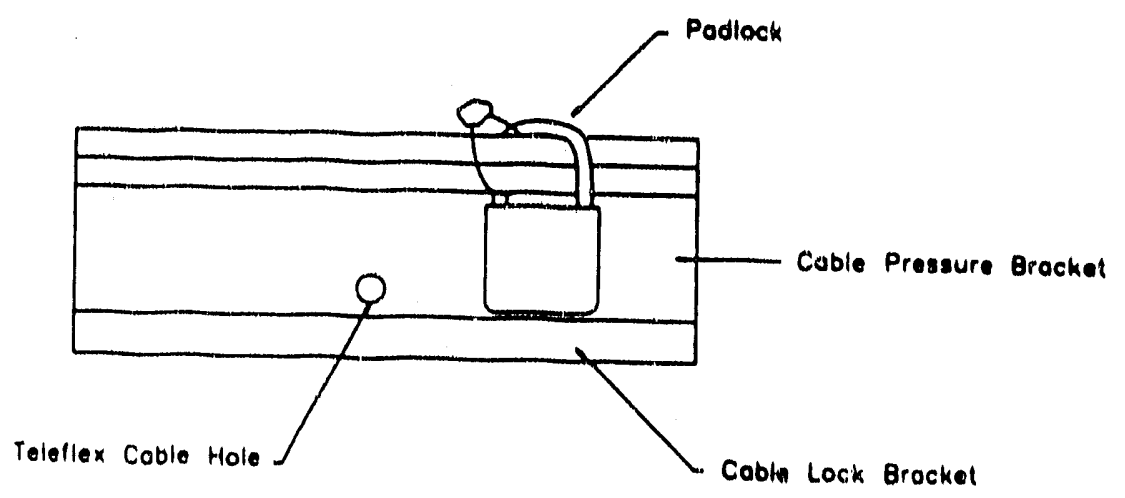

Figure 3. Transport Cask.

a) Front Viow

b) Rear Viow

c) Locking Assombly 


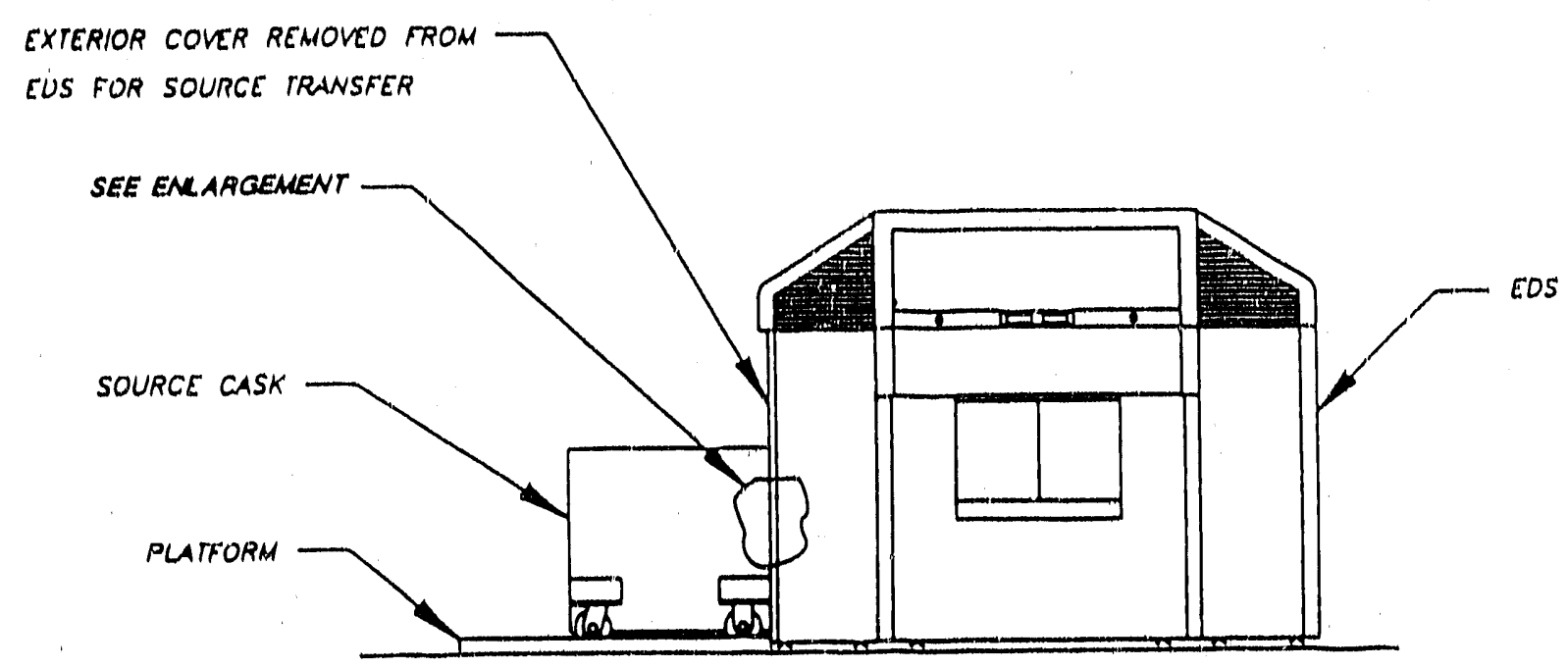

a)

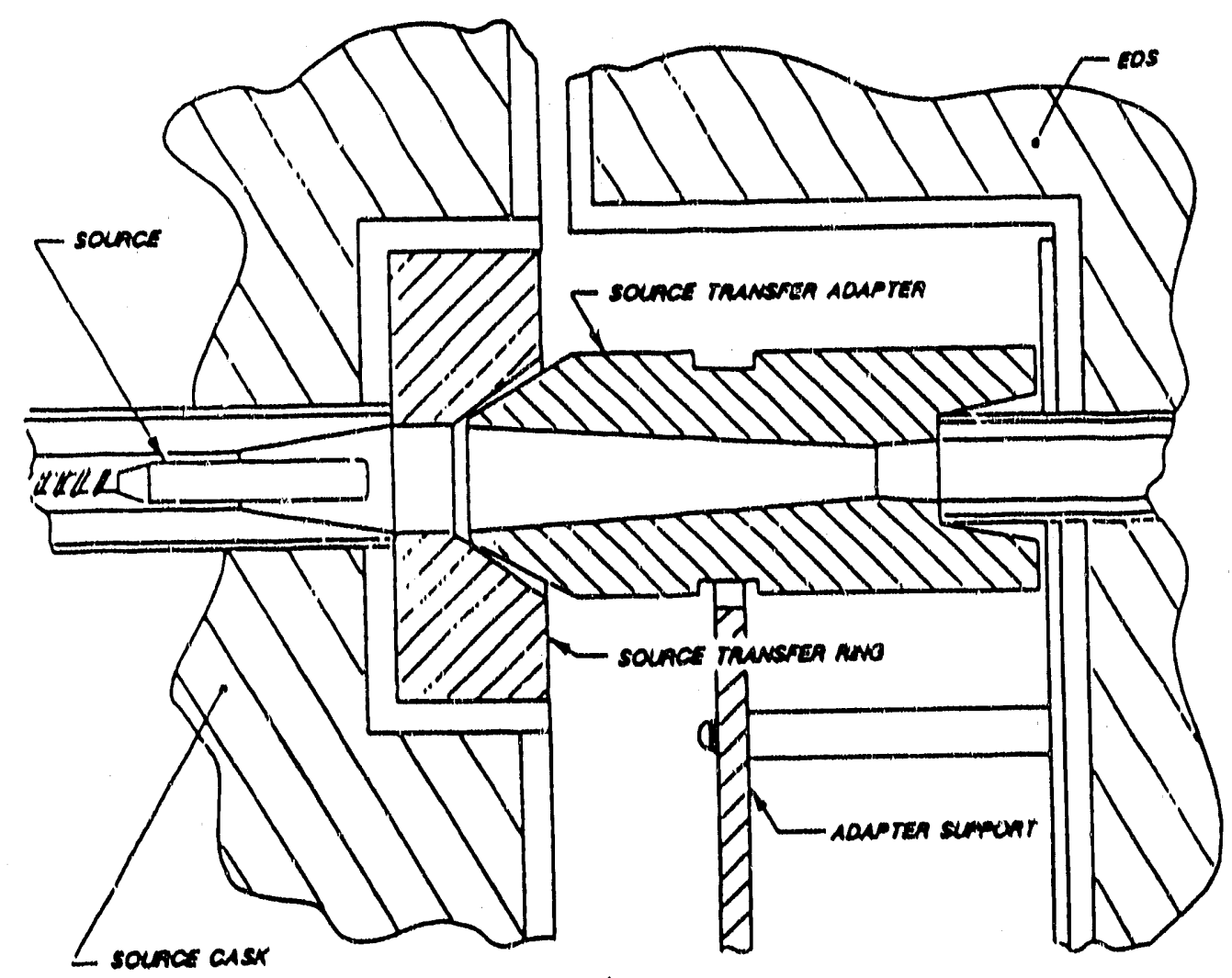

b)

Figure 4. Placement of Cask for Source Transfer.

a) Overall View

b) Detail Viow of Source Transfer Ring and Source Transfer Adapter 


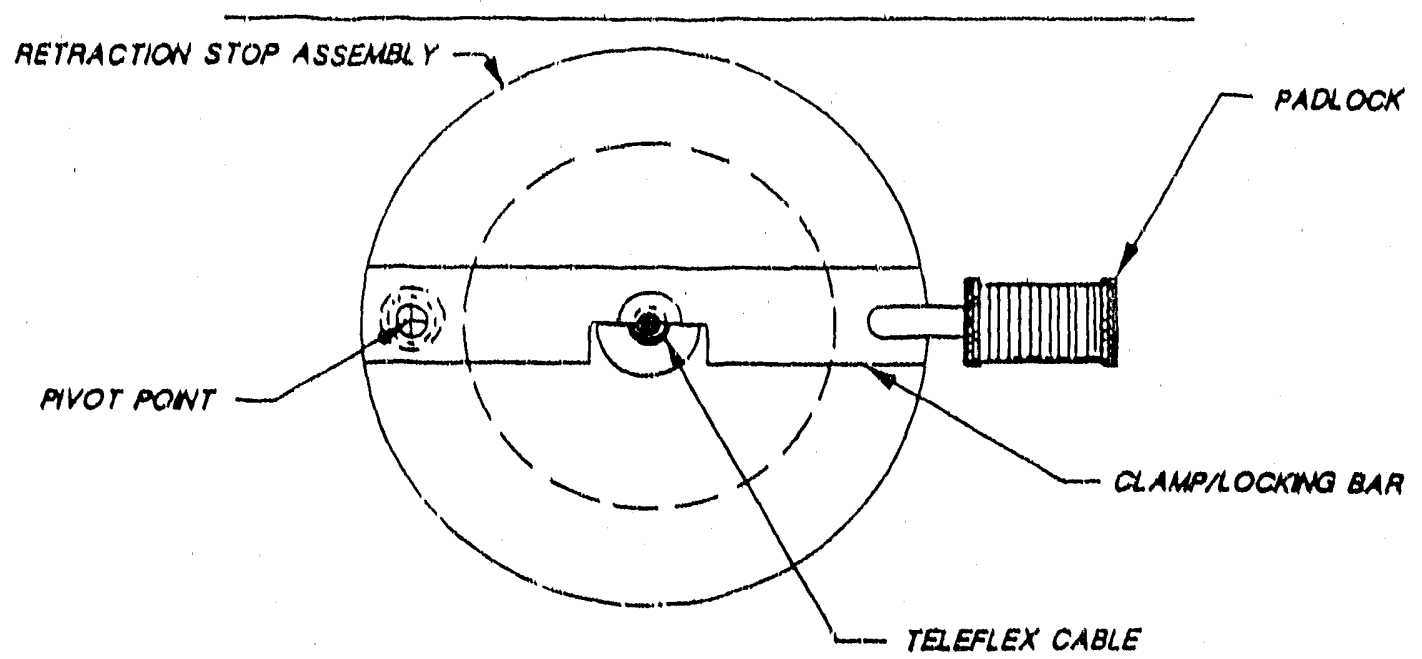

a)

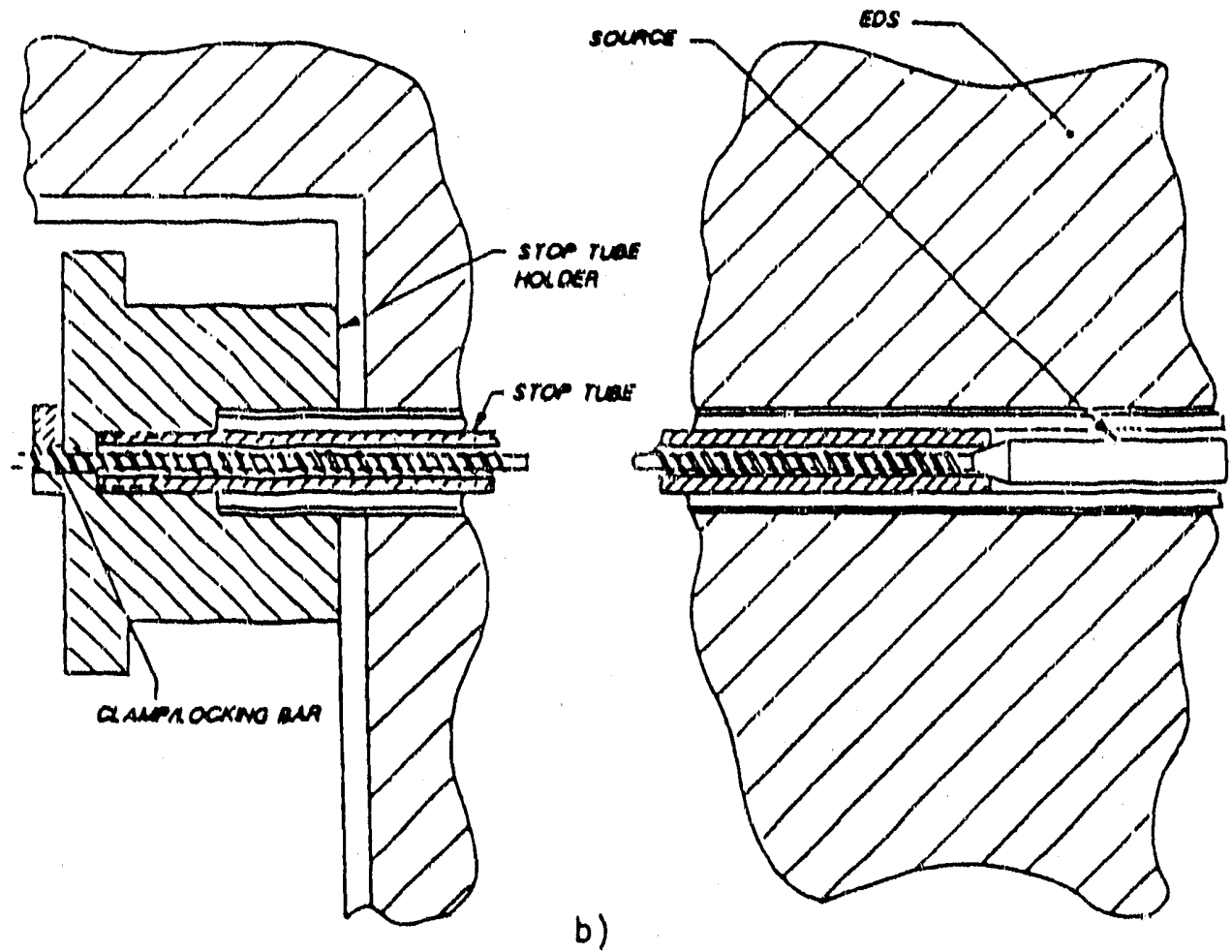

Figure 5. Retraction Stop Assembly.

a) Front View

b) Cross-section Viow 


\subsection{SPECIAL CONSIDERATIONS FOR INSTALLATIONS IN PUBLIC AREAS}

These safety-critical procedures must be observed to avoid oossible radiation exposure to members of the public.

Standard operations such as source installation, source exchange, or source removal for planned system maintenance shall be sctieduled at a time of day when few or no nonessential personnel are present, e.g., 12 midnight. Prior to beginning any transfer operation, the "Scheduling Checklist for Source Handling" (Figure 6) shall be completed to ensure coordination of date and time with airport facility managemont, airport security and airline management.

To avoid possible radiation exposure to the general public or airport personnel, an area out to 45 feet in all directions from the TNA unit shall be cordoned off using yellow/magenta rope and posted with "radiation area" warning signs. At 45 feet the dose rate from a bare 150 microgram Cl-252 source is less than $2 \mathrm{mrem} / \mathrm{hr}$. Also ensure that the airport security has cordoned off the areas above and below the unit. Only the TNA operator and other authorized personnel shall be allowed in the controlled area during source transfer operations.

When moving the source between the EDS unit and the cask, make sure the source is in its proper position by observing the cable markings (Figure 7). Use the gamma survey meter to confirm the source is the correct location.

Move the source quickly so as to minimize the time the source spends between positions, because the source path comes close to the underside of the TNA, resulting in high radiation levels in the downward direction.

It is imperative that the source not be stopped between the IN and RETRACTED positions.

\subsection{LOACING}

This is a safety-critical orocedure which could result in a high radiation area if not carried out property. It is possible to accidentally remove the bare source from the system. leaving it completely unshielded. The operator must review the proced ure carefulty before starting to make sure that it is fully understeed. Also review apolicable emergency procedures.

All source handling operations must be carried out by at least two people, one of whom is a qualified system operator. A survey meter must be used. Review Section 2.3 before starting.

The "Checklist for Source Loading" (Figure 8) is to be completed each time this operation is performed. 


\section{SCHEDULING CHECKLIST FOR SOURCE HANDLING}

Source handling operations for TNA systems shall be done at a time of day when a minimum number of people are present (e.g. 12 midnight). In all cases, an area to 45 feet from the TNA unit shall be cordoned off to avoid possible radiation exposure to nonessential personnel. Use yellow/magenta rope and post "radiation area" caution signs. Nonessential personnel includes everyone except the TNA operators performing the source handling and other authorized personnel who may be present for maintenance or as observers. Also ensure that the airport security has cordoned off the areas above and below the TNA unit.

The necessity for a scheduled source handling procedure is anticipated for:

$$
\text { DATE }
$$

TIME

The following must be notified. Indicate the name of the person contacted along with the date and time notified.

Name

Date Time

Airport Facility Management

Airport Security

Airline Management

The above personnel have been notified that a source handling procedure has been schedule at the time listed above.

Operator Signatures:

Figure 6. Scheduling Checklist for Source Handling. 


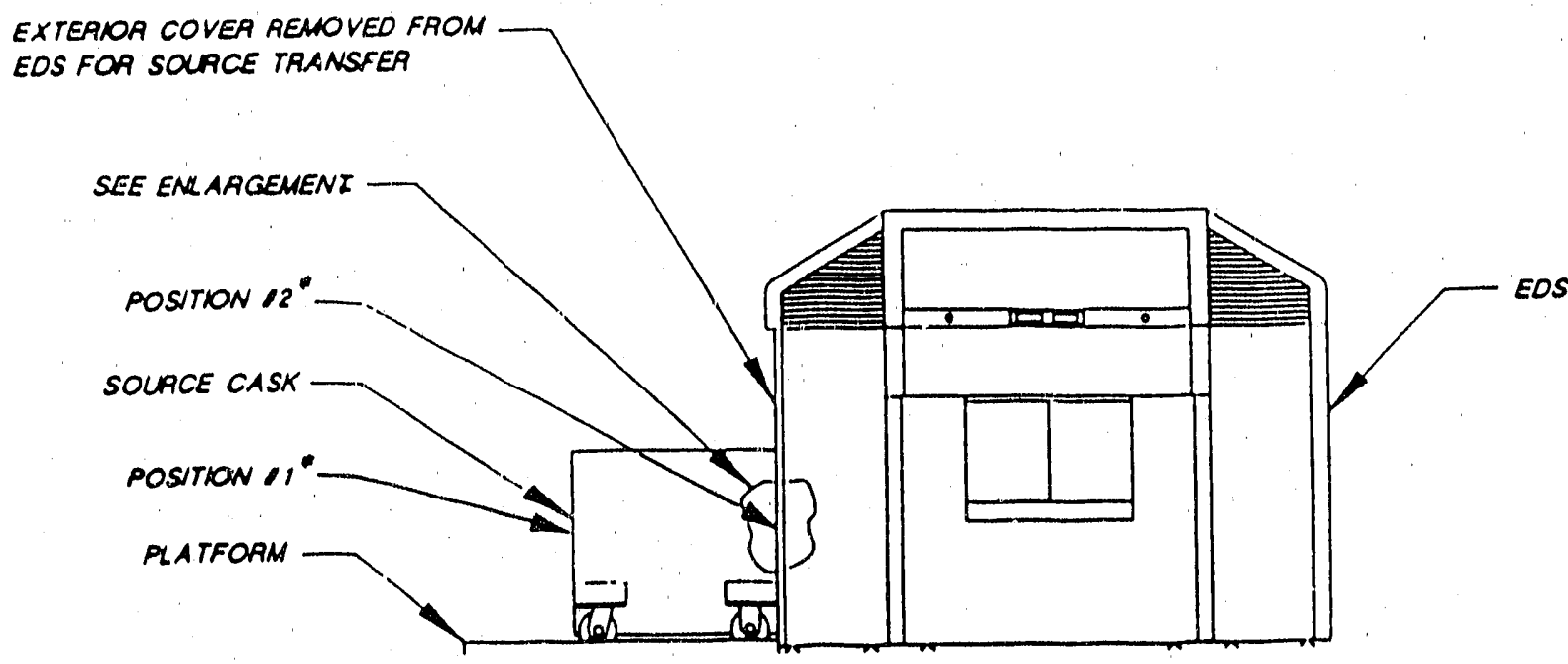

"teleflex cable vewno posmons

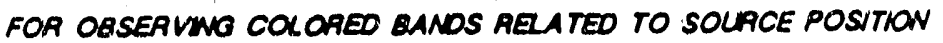

a)

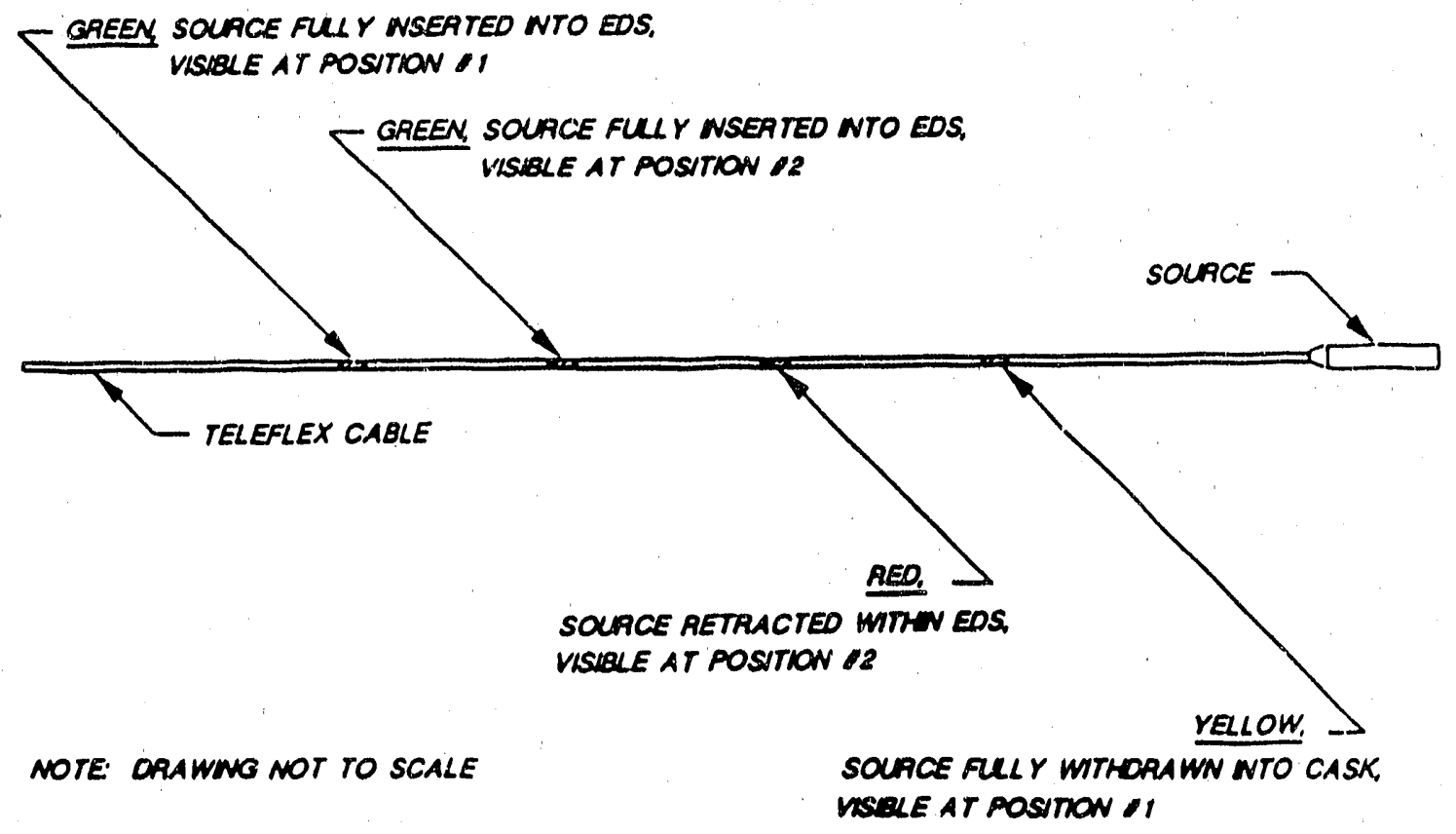

b)

Figure 7. Cable Markings.

a) Viewing Positions

b) Color Coding 


\section{CHECKLIST FOR SOURCE LOADING}

This is a safety-critical procedure which could result in a high radiation area if not carried out property. It is pessible to accidentally remove the bare source from the system leaving it completely unshielded. The operator must review the orocedure carefully before starting to make sure that it is fully understood. Also review apolicable emergency procedures

All source handling operations must be carried out by at least two people, one of whom is a qualified system operator. A gamma survey meter must be used. Review Section 2.3 before starting.

A copy of this checklist is to be completed each time the operation is performed.

Familiarize yourself with the entire procedure before starting. Check off each step as it is completed on a copy of this procedure.

_ Complete "Scheduling Checklist for Source Handling".

- Push up the TNA top cover and lift off the side panel.

- Unfasten the cask from the platform, roll it off onto the floor.

- Place the platform at the side of the TNA below the source access.

- Adjust the platform leveling screws to level the plattorm and line up the platform holes with the tapped holes in the TNA.

- Fasten the platform to the TNA with bolts.

- Bott the eye-hook bar to the system and the winch on to the cask.

- Roll the cask up to the platform, line up the wheels with the rail.

- Unlock and open the TNA source access door as wide as possible so it will not interfere with the cask movement.

- Hook cable to eye-hook and crank up to about two feet from TNA.

- Remove the cover plates from the cask Source Insertion/Exit Point and the Teleflex cable storage compartment by unscrewing the captive screws in the plate.

- From the FRONT of the cask, remove the polyethylene plug from the Source Insertion/Exit Point by unscrewing the two screws and pulling out the plug. Avoid the radiation beam coming from the cask source hole.

Figure 8. Checklist for Source Loading 
- Mount the source transfer ring on the front of the cask with its screws, with the conical hole toward the TNA. (See Figure 4).

Unscrew the Retraction Stop tube assembly (tube with attached aluminum piece) retaining screws and remove the assembly from the TNA.

Place the source transfer adapter on the adapter support loosely held in position for transfer. (See Figure 4):

Crank the cask up to the TNA slowty until it is in firm contact, guiding the ad apter as necessary to make sure that the adapter ongages the ring property.

- Unlock and disengage the cable clamp at the back of the cask.

Insert the source into the TNA by pushing the cable into the cask unitil it stops. A green mark on the cable will be at the cask surface. (See Figure 7.)

Verity source insertion with the gamma survey meter at the TNA surface above the cask. A reading less than $0.1 \mathrm{mrem} / \mathrm{hr}$ should be obtained.

- Release the ratchet and unwind the winch 15 turns, re-engage ratchet.

- Slowly roll the cask away to the winch cable limit, about $18^{\prime \prime}-2^{\prime}$, reaching in after about 6 " separation to hold the cable fixed at the TNA wall so that the source is not pulled out of the TNA.

_ Pull the cable through the front of the cask, making sure the source stays fully inserted in the TNA.

Remove the source transfer adapter, making sure the source stays fully inserted in the TNA, and lower the adapter support.

Place the Retraction Stop tube on the cable, tube first, and slide it toward the TNA, finally inserting it.

- Screw the Retraction Stop in place.

- Clamp the source with the clamp/locking bar and lock with padlock.

- Coil the excoss cable up neatly and tuck into the TNA source access recess.

- Release the winch ratchet and roll the cask off the platform, detach the platform.

Close and lock door, replace outer panel and lower the top panel. Store the cask on its platform. Store keys securely.

Replace tamper-indicating paper seal.

Figure 8 (con't). Checklist for Source Loading 


\subsection{REMOVAL}

This is a safety-crifical procedure which could result in a hiah radiation area it net carried eut oreperly. It is possible to accidentally remeve the bare source from the system. leaving it completely un shielded. The operator must review the proced ure carefully before starting te make sure that it is fully understoed. Also review apolicable emeraeney precedures,

All source handling operations must be carried out by at least two people, one of whom is a qualified system operator. A gamma survey meter must be used. Review Section 2.3 before starting.

The "Checklist for Source Removal" (Figure 9) should be completed each time this operation is performed.

\subsection{STORAGE OR TRANSPORT}

The following procedures shall be followed to prepare a source for storage or transport.

After placing the source in the cask, thread a tamper-indicating wire seal with the padlock through the locking holes. Close the padlock and affix a lead seal over the ends of the wire. (See Figure 3c.)

Coil up the remainder of the Teleflex cable and place it in the storage compartment. Replace the cover plate on the rear of the cask.

Unbolt the cask from the platform and roll the cask away from the TNA. Unbolt the platform from the TNA.

Insert the polyethylerie plug into the front of the cask and replace the cover plate on the front of the cask. Avoid radiation beam coming from cask source hole. Thread one tamper-indicating wire seal through the holes in the two bolts on the cover plates on the front and rear of the cask.

Replace and lock the cover panel on the TNA.

For shipment, roll the cask onto the platform and bolt them together. The platform serves as a shipping pallet. Follow DOT shipping procedures for labeling and completing the forms.

If the cask will remain in a public area with the source inside for longer than 1 hour, rope off area the within 3 feet of the cask and post radiation area signs.

Place tamper-indicating paper seals on cover plates on the front and rear of the cask. 


\section{CHECKLIST FOR SOURCE REMOVAL}

This is a safety-critical procedure which could result in a high radiation area if not carried out properity. It is possible to accidentally remove the bare seurce from the system. leaving it completely unshielded. The eperator must review the procedure carefully before starting to make sure that it is fully understeed. Alse review applicable emeraency procedures.

All source handling operations must be carried out by at least two people, one of whom is a qualified system operator. A survey meter must be used. Review Section 2.3 before starting.

A copy of this checklist is to be completed each time the operation is performed.

- Familiarize yourself with the entire procedure before starting. Check off each step as it is completed on a copy of this procedure.

_ Complete the "Scheduling Checklist for Source Handling".

_ Push up the TNA top cover and lift off the side panel.

_ Unfasten the cask from the platform, roll it off onto the floor.

- Place the platform at the side of the TNA below the source access.

- Adjust the platform leveling screws to level the platform and line up the platform holes

- with the tapped holes in the TNA.

- Fasten the platform to the TNA with bolts.

- Bott the eye-hook bar to the system and the winch on to the cask.

- Roll the cask up to the platform, line up the wheels with the rail.

- Unlock and open the TNA source access door as wide as possible so it will not interfere with the cask movement.

- Hook cable to eye-hook and crank up to about two feet from TNA.

- Remove the cover plates from the cask Source Insertion/Exit Point and the Teleflex

- cable storage compartment by unscrewing the captive screws in the plate.

From the FRONT of the cask, remove the polyethylene plug from the Source

- Insertion/Exit Point by unscrewing the two screws and pulling out the plug.

Figure 9. Checklist for Source Removal. 
- Mount the source transfer ring on the front of the cask with its screws, with the conical hole toward the TNA.

Unlock and lift the clamp/locking bar, releasing the cable.

Unscrow the Retraction Stop tube assembly retaining screws and remove the assembly from the TNA, being careful to leave the source fully inserted in the TNA.

Place the source transfer adapter over the cable, with the tapered end away from the TNA, slide it up to the TNA and position it on the adapter support loosely held in position for transfer, being careful to leave the source fully inserted in the TNA.

- Unlock and disengage the cable clamp at the back of the cask.

- Insert the free end of the cable into and through the cask.

Crank the cask up to the TNA slowiy until it is in firm contact, guiding the adapter and cable as necessary to make sure that the adapter engages the ring properly and the cable does not kink.

Draw the source into the cask by pulling the cable from the back of the cask until it stops. A yellow mark on the cable will be at the cask back surface indicating the source is in the cask. (See Figure 7.)

Verity that the source is in the cask with the gamma survey meter by moving it along the surface of the cask. A maximum reading will be obtained at the middle of the cask with lower, approximately equal readings at the ends of the cask.

- Clarnp and lock the source cable at the back of the cask.

- Coil up the excess cable and place it in the cask recess.

- Replace the cask plug and cask covers. Avoid radiation beam coming from the cask source hole.

Release the ratchet and unwind the winch 15 turns, re-engage ratchet, and roll the cask away to the winch cable limit.

Remove the source transfer adapter, and lower the adapter support.

Replace the Retraction Stop tube in the TNA and fasten.

Release the winch ratchet and roll the cask off the platform, detach the platform.

Close and lock door, replace outer panel and lower the top panel. Follow procedures for storage or transport as appropriate. Store keys securely.

Figure 9 (con't). Checklist for Source Removal. 


\subsection{RETRACTION}

Do not retract source during emergencies, except when the passageway must be entered by operator. Maxienum shielding exists only when source is in the normal operating position.

The source shall be moved to the RETRACTED position if it is necessary for the operator to enter the baggage passageway for any reason. The operator must not remain in the baggage passageway for longer than 1 hour por weok (total within any seven day period) even with the source retracted; note passaga activities in the log with times to keep track of the time.

If the source must be retracted, keep nonessential personnel out of the work area by roping off the area to 6 feet from the side of the TNA with the source access panel. Use magenta and yellow rope and post "radiation area" caution signs. To retract the source, flllow these procedures:

Unlock and remove the source cover panel from the TNA.

Pull the Teleflex cable until it is stopped bv the source retraction plug. Do not remove the retraction plug.

Lock the Teleflex cable in the RETRACTED position so that it does not move back into the system. 


\section{SECTION 3}

\section{EMERGENCY PROCEDURES}

These procedures shall be posted in a prominent position near the INA for immediate reference in the event of an emeroency. Fiqure 10 should be posted separately or as the first prge.

\subsection{BAGGAGE JAMS}

Baggage may be stopped in the TNA due to a baggage jam; such occurrences pose no imminent danger of radiation exposure to personnel. If a jam occurs, the baggage in the TNA should be removed as soon as possible to minimize bag activation.

First, determine the cause of the stoppage. This is accomplished by opening the exit and entrance shielding doors to visually inspect the baggage passageway while remaining outside the TNA. Latch the doors in the open position. Caution: The doors must be closed agsin as soon as possible to minimize exposure trom the oassege opening. Under no circumstances should the doors be left open lenger than 10 minutes, as the dese rate outside the TNA with all three doers epen is approximatelv $20 \mathrm{mrem} / \mathrm{hr}$

First, use long-handled tools to clear the baggage without entering the passageway.

If It is necessary to enter the baggage passageway to unjam the system, the source must first be retracted. (See Section 2.7). Access is permitted only by the system operator. Remember to use the gamma survey meter to ensure that the source is retracted before enterino passageway. If the operator's cumulative duration of stey inside the neutron interrogation region is areater than 1 hour per week (during and 7 dav period) the source must first be removed from the system prior to entiny by the operator.

After removing any bags that have remained in the system, use the gamma meter to survey them on the surface to ensure that the radiation level is less than $0.5 \mathrm{mrem} / \mathrm{hr}$. If the level is higher than $0.5 \mathrm{mrem} / \mathrm{hr}$, the bag must be put aside for at loast 5 minutes until the lovel decays to loss than $0.5 \mathrm{mrem} / \mathrm{hr}$. See Section 4.1 for bag activation procedures.

Once the stoppage is cleared, note the time and the reason for the stoppage in the TNA Daily Log. Also note if any of the stopped baggage surveyed above the $0.5 \mathrm{mrem} / \mathrm{hr}$ level. 


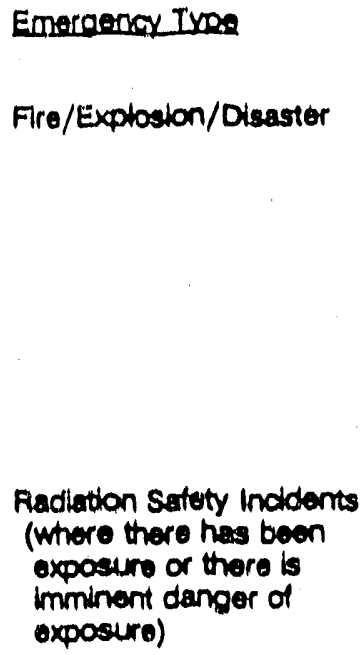
(Whore there has boen exposure or there is imminent danger of oxposira)

Radiution Sufety Indidents (stuck souros, transter problems, eta. where there be no mminent danger of exposire)

\section{Persens to be Centacted}

1. Arport Fire Department - Immedlate Emergency Assistance

2. Arport Securtity - Cordon off Area

3. Clty/State Radiation Control - Immedlate Radlologlcal Assistance

4. City/State Emergency Managerment

5. N.R.C. Region Office

6. SAIC/Santa Clara - Radiation Sadety Officer

7. SAIC/Santa Clara - Manager of Filld Operattons

8. Ulonse Holder (FM)

1. Arport Securtity - Cordon off Area

2. Clty/State Radiation Control

3. Olty/State Emergency Mensogernent

4. NRC Radlation Otfico

5. SAIC/Santa Clara - Radietion Safety Ofilcor

6. SNC/Sarta Clara - Marager of Find Operations

7. Lloense Holder (FAM)

1. Nrport Securtity - Cordon ofl Area

2. SNC/Santa Clara - Rachution Sefly Oillow

3. SAIC/Senta Clera - Menager of Fild Opertions if problom cannot be resolved

4. Clty/State Redietion Control

5. NRC Region Offics

6. Ulonsse Holder (FAM)

1. SAIC/Santa Clara - Manager of Field Operations

Operator Illness or

2. Operator to serve as replecement

Accident (vitich provents an operator from reporting to work)

System Failure, Imminemt or Actual (dus to harchwere of cotwwere problema)

1. SAIC/Santa Clara - Engineer (Contect elther engineer. Ho will contact the necessany personnd, by peger 1 nocessery, for repuir end/or shipment of pertis.)

2. SAKC, Rediation Safoty Ofiticer

Power Loss, Large-scalo

1. Arport Fucllty Mansogement

2. SAIC/Senta Clera - Manager of Fildd Operations

3. SNC Radiution Suloty Otficer

Power Loss, to Bullding

1. Arport Fecilly Mansoarnent

2. SNC/Senta Clare - Maneger of Field Operations

3. SNC Radivition Safoty Officer

Figure 10. Emergency Contact Guide 


\subsection{FIRE, EXPLOSION, DISASTER}

Fires, explosions, or other disasters give isse to concerns for irmminent danger of radiation exposure. The following procedure is supplled in checklist form for rapid and acourate handling of such emergencies.

_ Call the airport fire department.

- Remove any injured personnel to a safe distance.

- Give emergency first ald if necessary.

- Call airport security.

- Conduct area sunvey to determine level/extent of exposure or radloactive material release.

- Cordon off area to a safe distarice, where exposure level is less than $2 \mathrm{mrem} / \mathrm{hr}$.

_ Call state/local radiation control for immediate radiological assistance.

_ Maintain security until assistance arrives.

- Call NRC reglonal offico.

- Call SAIC radiation safety officer.

_ Call llcense holder.

- Render emergency assistance as needed.

\subsection{EARTHQUAKE}

Earthquakes give rise to concerns for imminent danger of radiation exposure. The following procedure is supplied in checklist form for rapid and accurate handling of such emergencles.

- Remove any injured personnel to a safe distance.

- Give emergency first aid if necessary.

- Visually inspect TNA for damage and areas where radiation may be released.

- Survey area surrounding machine. If high radiation levels exist:

_ Call airport security.

- Cordon off area to a safe distance, where exposure level is less than $2 \mathrm{mrern} / \mathrm{hr}$. 
_Call state/local radiation control for immediate radiological assistance.

- Maintain socurity until assistance arrives.

- Call NRC regional office.

- Call SAIC radlation safety officer.

- Call license holder.

If no significant radiation expos tre exists, clear the baggage from the system. If the power is off, follow the procedures in Section 3.6. When power is restored, or if power remained on after the earthquake, initiate system power up sequence.

\subsection{SOURCE STUCK AT INTERFACE}

A source stuck at the inteiface is a situation where there is imminent danger of radiation exposure. The following procedure for handling such a situation is given in checkllst form for rapid and accurate handling of such an emergency.

Alert airport securtty personnel present. Area should already be clear.

Ensure area within 45 feet of TNA has been cordoned off, and that the areas above and below the system are clear.

- Conduct a gamma survey to verify stuck source and determine extent of dose rate.

Attempt to dislodge source. Attempt to realign machine/cask mating by wiggling the cask from side to side, without moving the cask backwards. WABNING: De not attempt to back out the cask. This could result in a totally unshielded source.

__ If source doess nat dislodge:

- Call state/local radiation control for immediate radiological assistance.

- Call NRC regional office.

- Call SAIC radiation safety officer.

- Call llcense holder.

_- Maintain security uritil assistance artives. 


\subsection{SOURCE TRANSFER INCIDENTS}

Source transfer incidents include a source stuck in a cask or the TNA, a broken Teleflex cable, or a source coming off the end of the cable. These incidents pose no imminent danger of radiation exposure to personnel.

As source handling already requires airport securtity personnel to be present (see Section 2.3), Inform them of the situation. Ensure that the area within 45 feet of the TNA has been cordoned off, and that areas above and below the TNA are clear. Attempt in all cases to push the source into a normal operating position, but do not attempt repair. Call the SAIC radiation safety officer for further instructions. Also call: 1) state/local radiation control, 2) NRC regional office, and 3) license holder.

\subsection{POWER LOSS OR SYSTEM FAILURE}

Power loss or system failure (e.g. conveyer belt failure) poses no imminent danger of radiation exposure. In such incidents, clear baggage from the system with long-handled tools without entering the passageway. If it is necessary to enter the passageway, retract the source first. (See Section 2.7.) Use a gamma survey meter to ensure source has been retracted before entering passageway. Atter removing the baggage, ensure that the shielding doors are closed and place source back into normal operating position for maximum shielding. Survey each bag to onsure residual activation is less than $0.5 \mathrm{mrem} / \mathrm{hr}$. If the level is higher than $0.5 \mathrm{mrem} / \mathrm{hr}$, the bag must be put aside for at least 5 minutes until the level decays to less than $0.5 \mathrm{mrem} / \mathrm{hr}$. Call airport facility management to determirie extent of power loss or call SAIC for assistance in system failures. See Section 4.1 for bag activation procedures.

\subsection{DETECTION OF SOURCE LEAK}

In the unlikely event that a source leak test or conveyor belt wipe test reveals a leak, it is imperative to perform the following procedures to prevent the spread of contamination and release of airborne activity.

- Stop operation of the TNA system. Leave cask in place flush with the TNA system.

- Ensure area within 45 feet of TNA has been cordoned off, and that the areas above and below the system are clear.

- Conduct a gamma survey to determine extent of dose rate.

- Call state/local radiation control for immediate radiological assistance.

Call NRC regional office.

Call SAIC radiation safety officer. 
- Call license holder.

Maintain security until assistance arrives. 


\title{
SECTION 4
}

\author{
BAG ACTIVATION
}

\subsection{MONITORING}

All baggage leaving the systern passes the exit monitor detector. Baggage which does not trigger the alarm may be handed over to be loaded on aircraft.

Baggage which exceeds the activation threshold triggers the indicator light and audible alarms. Such bags must be checked with an ion chamber survey meter (Bicron RSO-5 or equivalent) on the surface of the bag to assure that the activity level is acceptable for loading on the aircraft. The dose rate must be less than $0.5 \mathrm{mrem} / \mathrm{hr}$ everywhere; if the bag exceeds this dose rate it must be put aside for at least 5 minutes and rechecked until the $0.5 \mathrm{mrem} / \mathrm{hr}$ level criterion is met. Five minutes is generally sufficient to ensure all residual activity of the bag and contents has decayed. Bags which continue to fail to meet the $0.5 \mathrm{mrem} / \mathrm{hr}$ criterion must remain aside since the bag itself may contain radioactive material. Notify local airport security personnel and the SAIC radiation safety officer for further instructions.

\subsection{EXIT MONITOR SYSTEM}

The baggage activation exit monitoring system consists of a detector assembly with lead collimator to view the baggage and an dose rate monitor type electronics package containing high voltage supply, amplification, count rate meter circuitry with adjustable threshold which triggers audible/visible alarm indicators and a signal to the TNA computer.

When a bag passes the detector, some of the activation gamma rays from the bag are detected. If the count rate exceeds the set threshold, the indicator light goes on, the audible alarm sounds and the circuit communicates the event to the TNA computer.

Bags which trigger the alarm are to be set aside to be checked using the survey meter. (See Section 4.1 above). The TNA identifies the activation alarm bags as well as explosive suspect bags. This typically operates with a mechanical diverter which physically separates these suspect bags from the baggage flow where they can be cleared individually.

\subsection{CALIBRATION/CHECK PROCEDURE}

This calib:ation procedure is used to set the exit monitor threshold where it will trigger on any bag which might have a surface dose rate above $0.5 \mathrm{mrem} / \mathrm{hr}$. 
Set threshold using a Cs-137 check source of 5 microcuries strength placed in the middle of a bag with light weight contents so that the threshold triggers when the bag passes. This bag will be one of the bags used for daily TNA operational checks. Exit monitor operation is to be verified daily as one of the regular daily system tests. 


\section{SECTION 5 \\ CF-252 SOURCE LEA.K TEST PROCEDURE}

The californium-252 sealed source must be tested for leakage of radioactive material every six months. This involves using a cotton swab to wipe the surfaces as close to the source as possible. (Wiping the source itself would result in an unacceptable exposure). Similarly, the conveyor belt is wiped as a check on accumulated activation contamination, also at six month intervals. The leak test samples are then sent to a specifically authorized agency for analysis. The address of the agency utilized in this case is:

Radiation Detection Company

ATTN: Chemistry Department

162 Wolfe Road

Sunnyvale, California 94086

The following materials are needed for the wipe tests:

- a wipe test cotton swab with plastic cover

- a wipe test filter paper with plastic bag

- an ion chamber gamma survey meter

\subsection{SOURCE LEAK TEST}

The source transport cask is placed in position for unloading the source. The procedures for these tasks are given in Sections 2.1, 2.5, and 2.6. The source is withdrawn into the cask, then reinserted back into the system.

The cotton swab cover is labelled with the source serial number and the current source strength is noted. The aperture of the source transport cask is wiped thoroughly with the swab, wiping as much area inside the aperture as can be reached. The cotton swab is then removed and inserted into its labelled cover.

\subsection{CONVEYOR BELT WIPE TEST}

The filter paper is used to wipe the surface of the TNA conveyor belt, wiping across the belt surface in at least four places.

The plastic bag is labelled, identifying the place and date, and the fitter paper placed in it. 


\subsection{SAMPLE ANALYSIS}

The cotton swab and filter paper are then held close to the survey meter to make a preliminary measurement. If the meter registers any radiation level above normal background, follow the emergency procedures in Sec. 3.7. If the radiation level of the test wipe is simply equal to the background levels, the test wipe is placed in an envelope and mailed to Radiation Detection Company.

The results of the wipe test analysis will be provided within two weeks. A record of these wipe tests and the analysis results must be maintained on file for three years following each test. 
APPENDIX B

TABLES IN ENGLISH SYSTEM OF UNITS CORRESPONDING

TO TABLES IN SECTIONS 5 AND 6 
Table 5.1(a) Potential activation products (for slow neutrons*) of baggage contents containing 1-kg (2.2-1b) masses of various elements

\begin{tabular}{|c|c|c|c|c|c|c|c|c|c|}
\hline \multirow[b]{2}{*}{ Product } & \multirow[b]{2}{*}{$\mathrm{dps} / \mu \mathrm{g}^{* * *}$} & \multirow[b]{2}{*}{$\begin{array}{l}\text { Hulf-life } \\
\text { (min) }\end{array}$} & \multirow[b]{2}{*}{$\begin{array}{l}\text { Gamma } \\
\text { (Mev/ } \\
\text { dist) }\end{array}$} & \multicolumn{2}{|c|}{ 0.5-min delay } & \multicolumn{2}{|c|}{ 10.min delay } & \multicolumn{2}{|c|}{ 60-min delay } \\
\hline & & & & $\begin{array}{l}\text { Activity } \\
(\mu \mathrm{Ci} / \mathrm{g})\end{array}$ & $\begin{array}{l}\text { Dose rate } \\
(\mathrm{mrem} / \mathrm{hr} / \\
2.2 \mathrm{lb} \\
\text { (i) } 1 \mathrm{ft})\end{array}$ & $\begin{array}{l}\text { Activity } \\
(\mu \mathrm{Ci} / \mathrm{g})\end{array}$ & $\begin{array}{l}\text { Dose rate } \\
\text { (mrem/hr/ } \\
2.2 \mathrm{lb} \\
\text { (ii) } 1 \mathrm{ft})\end{array}$ & $\begin{array}{l}\text { Activity } \\
(\mu \mathrm{Ci} / \mathrm{g})\end{array}$ & $\begin{array}{l}\text { Dose rate } \\
\text { (mrem/hr) } \\
2.2 \mathrm{lb} \\
\text { (ii) } 1 \mathrm{ft})\end{array}$ \\
\hline $\mathrm{H}-3$ & $8.42 \mathrm{E}-10$ & $6.49 E+06$ & - & $1.02 \mathrm{E}-15$ & $0.00 \mathrm{E}+00$ & $1.02 \mathrm{E}-1.5$ & $0.00 \mathrm{E}+00$ & $1.02 E-15$ & $0.00 \mathrm{E}+00$ \\
\hline $\mathrm{N}-16$ & $3.50 \mathrm{E}-03$ & $1.19 \mathrm{E}-01$ & $4.60 E+00$ & $2.31 E-10$ & $6.39 \mathrm{E}-109$ & $2.18 \mathrm{E}-34$ & $6.01 \mathrm{E}-33$ & $0 .(10) E+(0)$ & $0.00 \mathrm{E}+100$ \\
\hline $0-19$ & $3.51 E-03$ & $4.48 \mathrm{E}-01$ & $1.04 E+00$ & $1.97 \mathrm{E}-09$ & $1.23 \mathrm{E}-08$ & $8.17 \mathrm{E}-16$ & $5.10 \mathrm{E}-15$ & $2.10 \mathrm{E}-40$ & $1.31 \mathrm{E}-48$ \\
\hline$F-20$ & $1.97 \mathrm{E}+02$ & $1.83 \mathrm{E}-01$ & $1.64 E+00$ & $3.61 \mathrm{E}-05$ & $3.55 \mathrm{E}-04$ & $8.58 \mathrm{E}-21$ & $8.44 \mathrm{E}-20$ & $0 .(0) \mathrm{E}+00$ & $0.00 \mathrm{E}+000$ \\
\hline $\mathrm{Ne}-23$ & $2.43 \mathrm{E}+01$ & $6.20 \mathrm{E}-(11$ & $1.45 \mathrm{E}-01$ & 1.69E-05 & $1.47 \mathrm{E}-0.5$ & $4.13 E-10$ & $3.60 \mathrm{E}-10$ & $2.21 \mathrm{E}-34$ & $1.92 \mathrm{E}-.34$ \\
\hline $\mathrm{Na}-24$ & $1.80 \mathrm{E}+00$ & $8.80 \mathrm{E}+02$ & $4.12 E+00$ & $2.19 \mathrm{E}-06$ & $5.41 \mathrm{E}-05$ & $2.17 \mathrm{E}-06$ & $5: 37 \mathrm{E}_{-}-05$ & $2.00 \mathrm{E}-00$ & $5.16 E-105$ \\
\hline $\mathrm{Mg}-27$ & $1.29 \mathrm{E}+00$ & $9.46 E+00$ & $9.14 \mathrm{E}-0.1$ & $1.51 \mathrm{E}-06$ & $8.29 \mathrm{E}-06$ & $7.54 \mathrm{E} \cdots(17$ & $4.14 \mathrm{E}-06$ & $1.94 \mathrm{E}-118$ & 1.06E--107 \\
\hline A $1-28$ & $2.72 E+02$ & $2.24 E+100$ & $1.78 \mathrm{E}+00$ & $2.83 \mathrm{E}-04$ & 3.0.3E-03 & $1.50 \mathrm{E}-05$ & $1.60 \mathrm{E}-0) 4$ & $2.87 \mathrm{E}-12$ & $3.07 \mathrm{E} ;-11$ \\
\hline $\mathrm{Cl}-38$ & $5.55 \mathrm{E}+00$ & $3.72 E+01$ & $1.49 \mathrm{E}+(10$ & $6.69 \mathrm{E}-06$ & $5.98 \mathrm{E}-105$ & $5.60 \mathrm{E}-06$ & $5.01 \mathrm{E}-0 \mathrm{~S}$ & $2.211 \mathrm{E}-1) 6$ & $1.97 \mathrm{E}-105$ \\
\hline$A r-41$ & $1.06 \mathrm{E}+01$ & $1.10 E+02$ & $1.28 \mathrm{E}+00$ & $1.29 E-05$ & $9.87 \mathrm{E}-05$ & $1.21 \mathrm{E}-05$ & $0.30 \mathrm{E}-105$ & $8.835-06$ & $6.78 \mathrm{E}-(15$ \\
\hline $\mathrm{K}-42$ & $2.39 \mathrm{E}-(01$ & $7.42 E+(12$ & $2.73 E+02$ & $2.91 \mathrm{E}-07$ & $4.76 \mathrm{E}-04$ & $2.88 \mathrm{E}-07$ & $4.72 \mathrm{E}-(14$ & $2.751 \mathrm{-1}-17$ & $4.5(1) E-04$ \\
\hline $\mathrm{Sc}-46 \mathrm{ml}$ & $4.73 E+(14$ & $3.12 \mathrm{E}-01$ & $1.42 \mathrm{E}-() 1$ & $1.89 \mathrm{E}-02$ & $1.61 \mathrm{E}-12$ & $1.30 E-11$ & $1.11 \mathrm{E}-11$ & $7.62 \mathrm{E}-60$ & $(.49 \mathrm{E} .60)$ \\
\hline $11 i-51$ & $3.57 \mathrm{E}+00$ & $5.76 \mathrm{E}+110$ & $3.50 \mathrm{E}-011$ & $4.00 \mathrm{E}-06$ & $8.59 \mathrm{E}-06$ & $1.30 \mathrm{E}-06$ & $2.74 \mathrm{E}-06$ & 3.1810 .00 & 6.68E- 109 \\
\hline$V-52$ & $1.79 \mathrm{E}+03$ & $3.75 E+00$ & $1.43 \mathrm{E}+00$ & $1.98 \mathrm{E}-03$ & $1.70 \mathrm{E}-(02$ & $3.43 \mathrm{E}-(14$ & $2.94 \mathrm{E}-1(13$ & $3.3 .3 \mathrm{E}-(18)$ & $2.86 \mathrm{E}-(17$ \\
\hline $\mathrm{Cr}-55$ & $3.22 \mathrm{E}+00$ & $3.56 \mathrm{E}+00$ & $6.57 \mathrm{E}-(04$ & $3.55 \mathrm{E}-06$ & $1.4(1) E-08$ & $5.59 \mathrm{E}-117$ & $2.2(1 \mathrm{E}-(1)$ & $3.31 \mathrm{E}-11$ & $1.3118-13$ \\
\hline$M n-56$ & $1.11 E+(12$ & $1.55 \mathrm{E}+112$ & $1.70 \mathrm{E}+(00$ & $1.35 E-04$ & $1.37 E-(13$ & $1.29 \mathrm{E}-(14$ & $1.32 E_{-}-(1) 3$ & $1.01,35:-(14$ & 1.015E-1).3 \\
\hline$(0-6(1) 11$ & $2.33 \mathrm{E}+113$ & $1 .(15 \mathrm{E}+100$ & $1.23 \mathrm{E}-(1) 3$ & $2 .(14 E-(1) 3$ & $1.501 \mathrm{E}-015$ & $3.85 E-1) 6$ & $2.84 E-1) 8$ & $1.8(1):-20)$ & $1.33 \mathrm{E}-22$ \\
\hline $\mathrm{Ni}-65$ & $7.64 E+00$ & $1.51 E+102$ & $5.63 \mathrm{E}-(1)$ & $9.27 \mathrm{E}-(16$ & $3.13 \mathrm{E}-(15$ & $8.88 \mathrm{E}-116$ & $3.001:-105$ & $7.06,1, \cdots 160$ & $2.3818-(15$ \\
\hline ( $11-64$ & $4.58 \mathrm{E}+00$ & $7.64 \mathrm{E}+012$ & $\mid .95 E-(0)$ & $5.571 \mathrm{E}-0.6$ & $6.51 \mathrm{E}-106$ & $5.52 \mathrm{E}-166$ & $0.4613-160$ & $5.28 \mathrm{E} \ldots 16$ & $6.171 \% 116$ \\
\hline Cu-cos & $1.47 \mathrm{E}+12$ & $5.10 E+(10)$ & $9.56 \mathrm{E}-112$ & $1.67 \mathrm{E}-(1) 4$ & $9.58 E-05$ & $4.59 \mathrm{E}-(15)$ & $2.64 \mathrm{E} \ldots(15)$ & $5.15 \mathrm{E}-118$ & $2.95 \mathrm{E}-118$ \\
\hline $7.17-(69)$ & $3.69 \mathrm{E}+00$ & $5.70 \mathrm{E}+(11$ & $4.78 \mathrm{E}-106$ & $4.46 \mathrm{E}-106$ & $1.28 \mathrm{E}-10$ & $3.97 \mathrm{E}-06$ & $1.14 \mathrm{E}-111$ & 2.161: . (1) & $0.2|1-1|$ \\
\hline (ial-7u) & $5.43 E+01$ & $2.11 E+01$ & $5.55 \mathrm{E}-(0.3$ & $6.5(1)--0.5$ & $2.16 \mathrm{E}-116$ & $4.76 \mathrm{E}-(1) 5$ & $1.58 \mathrm{E}:-16$ & $9.2118 \ldots 06$ & 3.116,E-1)7 \\
\hline (ial-72 & $2.50 \mathrm{E}+100$ & $8.40 \mathrm{E}+12$ & $2 .(13 \mathrm{E}+0)(0$ & $3.15 E-(1) 6$ & $3.84 E-0.5$ & $3.12 \mathrm{E}-1)(1$ & $3.811:-11.5$ & $3.10101 \div(16)$ & $3.6,51 \%-115$ \\
\hline (ic $-7.5 \mathrm{~m}$ & $(0.38 \mathrm{E}+01$ & $8.15 \mathrm{E}-(1) 1$ & $5.50 \mathrm{E}-(12$ & $5.1771-(15)$ & $1.701:-015$ & $1.57 \mathrm{E}-108$ & $5.28 E-(1)$ & $5.411 \div 27$ & $1811:-27$ \\
\hline (icis 75 & $1.115 \mathrm{E}+10(1)$ & $8.28 E+(11$ & $3.18 \mathrm{E}-112$ & $1.27 E-106$ & $2.431 \div-117$ & $1.17 \mathrm{E}-(16$ & $2.24 \mathrm{E}$ & $7.731:-177$ & $1.471 \div-117$ \\
\hline (ic-77m & $0.115[:-111$ & $8.84 \mathrm{E}-111$ & $0.311:-112$ & $7.44 E-117$ & 2.821:- -117 & $4.341:-10$ & $1.641:-10$ & $4.111: 27$ & $1.5(1):-27$ \\
\hline As-76 & $3.26 \mathrm{E}+(10)$ & $1.58 \mathrm{E}+0.3$ & $3.371: \cdots(11$ & $3.96 \mathrm{E}-106$ & $8 .(121-06)$ & .955:-160 & $7.081 \div .106$ & $3.801: 116$ & $7.811: 06$ \\
\hline$S c-77 m$ & $5.6915+10.3$ & $2.9(11:-(1)$ & 9. $6.31:-12$ & $2.1111:-113$ & $1.211 \mathrm{E}-113$ & 2 9ा:- 13 & $1.671-1.3$ & $3.731 \div-0.5$ & $2.151 \div-0.5$ \\
\hline$S c-74111$ & $2.151 \mathrm{t}+01$ & $391 \mathrm{E}+100$ & $9.571:-113$ & 2.39): 115 & $1.3719-116$ & $4.441:-106$ & $2.551: 07$ & $0.3(1) \div-111$ & $3.611 \div-11$ \\
\hline$S c-81$ & $1.33 \mathrm{E}+101$ & $1.851 \mathrm{z}+01$ & $1.4412-12$ & $1.501 \mathrm{E}-(0.5$ & $1.371:-116$ & $1.1116-115$ & $9.611:-117$ & $1.711: 116$ & $1.481: .17$ \\
\hline $\mathrm{Se}-8.3$ & $3.455+100$ & $2.251+101$ & $1.271 E+1011$ & $4.13 E-(1) 6$ & $3.15 E-015$ & $3.186:-106$ & $2.351 \div-115$ & $6.611: 117$ & $5.1141: 010$ \\
\hline $13 r-8() n 1$ & $5.48 \mathrm{E}+(11)$ & $2 .(55 E+112$ & $2.411:-12$ & $0.661:-106$ & $9.625-1.17$ & $0.491:-1) 6$ & 9.39)!--117 & $5.7111: \cdots 116$ & $8.241: 117$ \\
\hline $131^{-}-80$ & $2.91 E+(12$ & $1.771:+01$ & $7.10(1):-02$ & $3.47 \mathrm{E}-114$ & $1.46 \mathrm{E}-104$ & $2.3910-114$ & $1 .(11) \mathrm{E}-114$ & 3.3815015 & $1.421: 15$ \\
\hline $13 r-82 i 11$ & $2.311 i+112$ & $6.101 \mathrm{E}+00$ & $4.221:-114$ & $2.65 E-(04$ & $0.72 \mathrm{E} \cdots 117$ & $9 .(12 \mathrm{E}-1) 5$ & $2.26 \mathrm{E}-17$ & $3.1181:-117$ & $7.791 \div 111$ \\
\hline $\mathrm{Kr}-81 \mathrm{~m}$ & $3.771 \mathrm{i}+112$ & $2.22 \mathrm{E}-(1) 1$ & $1.27 \mathrm{E}-(1) 1$ & $9.63 \mathrm{~b}-115$ & $7.341:-115$ & $1.271 x-17$ & $9.691:-18$ & $2 .(19) 18.5$ & $1.501:-8.5$ \\
\hline $\mathrm{Kr}-83 \mathrm{~m}$ & $1.74 \mathrm{E}+(1)$ & $1.12 E+12$ & $2.26 \mathrm{E}-11.3$ & $2.111 E-115$ & $2.801 \mathrm{E}-(1) 7$ & 1.995:-115 & $2.7111:-117$ & $1.461:-115$ & $1.981:-.117$ \\
\hline $\mathrm{R} b-86 \mathrm{~m}$ & $4.2(1 \mathrm{E}+0) 1$ & $1 .(12 \mathrm{E}+100$ & $5.46 \mathrm{E}-1) 1$ & $3.64 \mathrm{E}-1.5$ & 1.191:-114 & $5.72 \mathrm{~L}$ & $1.871:-117$ & $1.011:-22$ & $3.311 ;-22$ \\
\hline $12 b-88$ & $2.05 E+(10)$ & $1.78 \mathrm{E}+01$ & $6.37 \mathrm{E}-111$ & $2.45 \mathrm{E}-\mathrm{-1}) \mathrm{G}$ & $9.35 \mathrm{E}-160$ & $1.6(1) \div(6)$ & $0,461:-016$ & $2.411: \ldots 117$ & $9.221:-117$ \\
\hline Y-9()m & $4.16 E i+1)(1)$ & $1.91 E+112$ & $6.3(1) \mathrm{E}-1) 1$ & $5.115 \mathrm{E}-06$ & 1.9) $10-0.5$ & $4.881: 110$ & $1.841: 115$ & $4.177 \mathrm{E}-116$ & 1.5415 .015 \\
\hline $\mathrm{N}(1-94 \mathrm{mI}$ & $3.8(1 \mathrm{E}+01$ & $6.26 \mathrm{E}+100$ & $1.17 \mathrm{E}-12$ & $4.37 \mathrm{E}-115$ & $3 .(17 \mathrm{E}-1) 6$ & $1.531: \cdots 115$ & J.071:-116 & $0.0131: 118$ & $4.231 \div-\cdots(10)$ \\
\hline$M(1)-101$ & $1.35 E+(30)$ & $1.46 \mathrm{E}+(11)$ & $1.51 \mathrm{E}+100$ & $1.601 \mathrm{E}-106$ & $1.45 \mathrm{E}-1.5$ & $1.121:-110$ & $9.258 \div 0$ & $0.521:-118$ & $8.621 ; \ldots 107$ \\
\hline $\mathrm{Rh}-104 \mathrm{~m}$ & 3.6(1E + +3 & $4.35 \mathrm{E}+100$ & $3.48 \mathrm{E}-12$ & $4 .(14 \mathrm{~L}:-113$ & $8.44 \mathrm{E}-114$ & $8.901 \mathrm{E} \cdot 114$ & $1.8015,-144$ & $3 .(101: \ldots 07$ & $0.451: \ldots 18$ \\
\hline$R / 1-104$ & $1.54 E+04$ & 7.(15E-(1) & $1.111 \mathrm{E}-(12$ & $1.15 E-112$ & $7,6.315-104$ & $1.1111:-116$ & $6.711:-118$ & $4.551 \div-26$ & $3.1131 ;-29$ \\
\hline $\mathrm{Pd}-107 \mathrm{~m}$ & $8.42 \mathrm{E}+100$ & $3.55 \mathrm{E}-(01$ & $1.52 \mathrm{E}-01$ & $3.86 \mathrm{E}-1) 6$ & $3.52 E-1) 6$ & $3.411:-14$ & $3.111:-14$ & $1.301 \div-50$ & $1.271 \div-56$ \\
\hline$P(1-109)$ & $9.12 E+00$ & $4.69 \mathrm{E}+100$ & $1.14 \mathrm{E}-(1) 1$ & $1.03 \mathrm{E}-0.5$ & $7 .(15 \mathrm{E})(1) 6$ & $2.531 \mathrm{i}-10$ & $1.731 \mathrm{1}$ & $1.571: 119$ & $1.071:-10$ \\
\hline $\mathrm{P}(\mathrm{l}-109$ & $3.37 \mathrm{E}+00$ & $8.108 E+02$ & $1.24 \mathrm{E}-112$ & $4.10 E-(06$ & $3.115[1-07$ & $4.0615 \cdots 100$ & $3 .(121: \ldots 177$ & $3.801 \div-16$ & 2.91: \\
\hline $\mathrm{Ag}-108$ & $5.09 \mathrm{E}+103$ & $2.41 \mathrm{E}+00$ & $2.94 \mathrm{E}-112$ & $5.36 \mathrm{E}-(1) .3$ & $9.461:-(14$ & $3.491 \div-114$ & $0.161 \mathrm{~B} \cdots 5$ & $1.901: \cdots 10$ & $3.51 \mathrm{E}-11$ \\
\hline$A g-110$ & $8.31 E+04$ & $4.10 \mathrm{E}-(01$ & $2.96 \mathrm{E}-(1) 2$ & $4.34 \mathrm{E}-(1) 2$ & $7.711-(1) 3$ & $4.61 \mathrm{E}-(19)$ & $8.191:-111$ & $9.141 \div 46$ & $1.621:-46$ \\
\hline $\ln -114$ & $9.43 E+01$ & $1.20 \mathrm{E}+00$ & $2.21 \mathrm{E}-(1) 3$ & $8.59 \mathrm{E}-115$ & $1.14 \mathrm{E}-\ldots$ & $3.56 \mathrm{E}-1) 7$ & $4.72 \mathrm{E}(1)$ & $1.0 .31 \div \quad 10$ & $1.368-2 \mid$ \\
\hline In-116m(2) & $1.26 \mathrm{E}+116$ & $3.63 E-102$ & $8,201:-112$ & $1.10 \mathrm{E}-1) 4$ & $5.39 \mathrm{E}-0.05$ & $1.88 E-83$ & $9.261 \div-84$ & $0.0(1) i+100$ & $0 .(1) \mathrm{E}+(0)$ \\
\hline $\operatorname{In}-116 \mathrm{~m}(1)$ & $1.29 \mathrm{E}+113$ & $5.42 E+01$ & $2.47 E+00$ & $1.56 E-0.3$ & $2.31 \mathrm{E}-(12$ & $1.38 \mathrm{E}-0.3$ & $2.05 \mathrm{E}-112$ & $7.281: .104$ & $1.081 \div-12$ \\
\hline
\end{tabular}

See formotes at cind of table. 
Table 5.1(a) (continued)

\begin{tabular}{|c|c|c|c|c|c|c|c|c|c|}
\hline \multirow[b]{2}{*}{ Product } & \multirow[b]{2}{*}{$\mathrm{dps} / \mu \mathrm{g}^{* * *}$} & \multirow[b]{2}{*}{$\begin{array}{l}\text { Half-llfe } \\
\text { (min) }\end{array}$} & \multirow[b]{2}{*}{$\begin{array}{l}\text { Gamnia } \\
\text { (Mev/ } \\
\text { dist) }\end{array}$} & \multicolumn{2}{|c|}{$0.5 \cdot \mathrm{min}$ delay } & \multicolumn{2}{|c|}{ 10-min delay } & \multicolumn{2}{|c|}{ 60-min delay } \\
\hline & & & & $\begin{array}{l}\text { Activity } \\
(\mu \mathrm{Cl} / \mathrm{g})\end{array}$ & $\begin{array}{l}\text { Dose rate } \\
\text { (mrem/hr/ } \\
2.2 \mathrm{lb} \\
\text { (ii) } 1 \mathrm{ft})\end{array}$ & $\begin{array}{l}\text { Activity } \\
(\mu \mathrm{Ci} / \mathrm{g})\end{array}$ & $\begin{array}{l}\text { Dose rate } \\
\text { (mrem/hr/ } \\
2.2 \mathrm{lb} \\
\text { (ii) } 1 \mathrm{ft})\end{array}$ & $\begin{array}{l}\text { Activity } \\
(\mu \mathrm{Cl} / \mathrm{g})\end{array}$ & $\begin{array}{l}\text { Dose rate } \\
\text { (mrem/hr/ } \\
2.2 \mathrm{lb} \\
\text { (Q) } 1 \mathrm{ft})\end{array}$ \\
\hline $\operatorname{In}-116$ & $1.36 E+04$ & $2.37 \mathrm{E}-0.1$ & $1.55 \mathrm{E}-02$ & $3.83 E-03$ & $3.57 \mathrm{E}-(1) 4$ & $3.31 \mathrm{E}-15$ & $3.08 \mathrm{E}-16$ & $1.06 \mathrm{E}-78$ & $9.84 \mathrm{E} \ldots 80$ \\
\hline $\mathrm{Sn}-125 \mathrm{~m}$ & $1.09 E+00$ & $9.52 \mathrm{E}+00$ & $3.29 \mathrm{E}-01$ & $1.28 \mathrm{E}-06$ & $2.52 \mathrm{E}-06$ & $6.401 \mathrm{E}-07$ & $1.26 \mathrm{E}-106$ & $1.68 \mathrm{E}-08$ & $3.32 E-08$ \\
\hline $\mathrm{Sb}-122 \mathrm{~m}$ & $7.08 E+00$ & $4.21 E+00$ & $5.96 \mathrm{E}-(1) 2$ & $7.93 \mathrm{E}-106$ & $2.84 \mathrm{E}-(1) 6$ & $1.66 \mathrm{E}-06$ & $5.94 \mathrm{E}-(17$ & $4.42 \mathrm{E}-10$ & $1.58 \mathrm{E}-10$ \\
\hline $\mathrm{Sb}-124 \mathrm{~m}$ & $8.42 \mathrm{E}+00$ & $1.55 \mathrm{E}+00$ & $3.48 \mathrm{E}-01$ & $8.19 \mathrm{E}-1) 6$ & $1.71 E-015$ & $1.17 \mathrm{E}-107$ & $2.45 \mathrm{E}-107$ & $2.29 \mathrm{E}-17$ & $4.78 \mathrm{E}-17$ \\
\hline $\mathrm{Te}-131$ & $2.08 \mathrm{E}+00$ & $2.510 \mathrm{E}+01$ & $3.54 \mathrm{E}-(01$ & $2.49 \mathrm{E}-06$ & $5.30 \mathrm{E}-06$ & $1.92 \mathrm{E}-166$ & $4.07 \mathrm{E}-06$ & $4.79 \mathrm{E}-07$ & $1.02 \mathrm{E}-06$ \\
\hline $1-128$ & $2.00 \mathrm{E}+02$ & $2.50 \mathrm{E}+01$ & $8.75 E-(12$ & $2.4(1) \mathrm{E}-(1) 4$ & $1.26 \mathrm{E}-(14$ & $1.84 \mathrm{E}-(1) 4$ & $9.68 \mathrm{E}-0.5$ & $4.61 \mathrm{E}-0.5$ & $2.42 E-0) 5$ \\
\hline $\mathrm{Xc}-125 \mathrm{~m}$ & $1.70 \mathrm{E}+01$ & $9.50 \mathrm{E}-01$ & $1.11 \mathrm{E}-(1) 1$ & $1.44 \mathrm{E}-05$ & $9.56 \mathrm{E}-06$ & $1.40 \mathrm{E}-08$ & $9.35 E-(1)$ & $2.03 \mathrm{E}-24$ & $1.35 E-24$ \\
\hline Xe 137 & $1.99 \mathrm{E}+00$ & $3.845+(93$ & $1.50 \mathrm{E}-(0)$ & $2.21 \mathrm{E}-\cdots(1)$ & $1.99 \mathrm{E}-06$ & $3.98 \mathrm{E}-017$ & $3.58 \mathrm{E}-107$ & $4.80 \mathrm{E}-11$ & $4.32 \mathrm{E}-11$ \\
\hline C.s-134m & $9.28 E+00$ & $1.741-02$ & $2.34 \mathrm{E}-(12$ & $2.54 \mathrm{E}-14$ & $3.56 \mathrm{E}-15$ & $0.00 \mathrm{E}+0.0$ & (1.)(K)E + (K) & $0.00 \mathrm{E}+(00)$ & $0 .(0) \mathrm{E}+00$ \\
\hline $13 a-136 m$ & $1.31 E+0.3$ & $5.13 \mathrm{E} \quad 0.3$ & $1.92 \mathrm{E}+16)$ & $7.39 E-3.3$ & $8.51 E-32$ & $0.061 E+00$ & $0 .(0) E+100$ & $0.00 \mathrm{E}+100$ & $(0.00 \mathrm{~B}+(\mathrm{X})$ \\
\hline $13 a-139$ & 1.SSE + (x) & $8.33 \mathrm{E}+101$ & $4.18 \mathrm{E}-(12$ & $1.88 \mathrm{E}-06$ & $4.71 E-107$ & $1.738 \mathrm{E}-0 \mathrm{6}$ & $4.35 \mathrm{E}-107$ & $1.141:-16$ & $2.87 \mathrm{E}-117$ \\
\hline$|x|-14 \mid$ & $1.92 \mathrm{E}+100$ & $2.41 \mathrm{E}+03$ & $2.32 \mathrm{E}+00$ & $2.3 .3 E-\ldots 06$ & $3.25 \mathrm{E}-(1) 5$ & $2.3318-16$ & $3.24 \mathrm{E}-115$ & $2.3(1) \mathrm{E}-1) 6$ & $3.10 \mathrm{E} \sim 05$ \\
\hline $\operatorname{Pr}-142$ & $3.43 E+(k)$ & $1.15 E+103$ & $5.83 \mathrm{E} \ldots 12$ & $4.17 E-(16$ & $1.46 \mathrm{E}-106$ & $4.15 E \ldots() 6$ & $1.45 \mathrm{E}-106$ & $4.02 \mathrm{E} \ldots(1) 6$ & $1.41 \mathrm{E}-16$ \\
\hline$N(1 \cdot 1.51$ & $3.52 \mathrm{E}+00$ & $1: 24 \mathrm{E}+01$ & $1.69 \mathrm{EE}-(11)$ & $4.16 E-06$ & $4.22 \mathrm{l}:-106$ & $2.451:-06$ & $2.481:-116$ & $1.501 \mathrm{E},-077$ & $1.52 \mathrm{E}-(17$ \\
\hline Sm-153 & $1.19 \mathrm{E}+01$ & $2.79 E+0.3$ & $5.35 E-112$ & $1.45 E \ldots(15$ & 4.651:-106, & $1.441:-105$ & $4.638-0)$ & $1.431 \%-05$ & $4.58 \mathrm{E}-1 \mathrm{~K}$ \\
\hline $\sin -155$ & $2.81 E+111$ & $2.22 E+01$ & $8.241:-112$ & $3.36 \mathrm{E} \div 0 \mathrm{~S}$ & $1.0,0,115$ & $2,5011: \ldots 115$ & $1.241:-115$ & $5.25 E \ldots 06$ & $2.601 \mathrm{E} \ldots(\mathrm{K})$ \\
\hline$[\mathrm{i} u-1,52 \mathrm{~m}(2)$ & $9.211 E+00$ & $9.60 E+01$ & $7.38 \mathrm{E}-\ldots 12$ & $1.12 E-05$ & $4941 \div-166$ & $1.17418-115$ & 4.615106 & $7.26 \mathrm{E}-106$ & $3.22 \mathrm{E}-16$ \\
\hline$E u-152 m(1)$ & $1.32 E+10.3$ & $5.58 \mathrm{E}+12$ & $2.41 \mathrm{E}-111$ & $1.60) \mathrm{E}-1.3$ & $2.32 \mathrm{E}-113$ & $1.501: \cdots(13$ & $2.2115: \ldots(13$ & $1.49 \mathrm{I}:-0.3$ & $2.15 \mathrm{E}-(0) 3$ \\
\hline (i) 161 & $2.19 E+101$ & $3.70 \mathrm{E}+001$ & $3,(0)[-(1)]$ & $2.43 E-11.5$ & $4.5011: \cdots 11.5$ & $4.1091 \mathrm{-1}(1)$ & $7.591:-016$ & $3.51 \mathrm{E}-10$ & $6.5011:-10$ \\
\hline 1) $y-16.5 m$ & $1.64 \mathrm{E}+105$ & $1.26 E+00$ & $1.1091:-12$ & $1.521:-(1) 1$ & $9.911: \cdot 0.3$ & $8.151:-(14$ & $5.33 \mathrm{E}-115$ & $9.20 \mathrm{E}-16$ & $6.188 \mathrm{E}-17$ \\
\hline 1) $y-16.5$ & $8.69)+012$ & $1.41 E+(12$ & $1.28 \mathrm{E}-112$ & $1.0155-11.3$ & 8. $11118-115$ & $1.1111:-11.3$ & $7.731:-11.5$ & $7.871:-1) 4$ & $6 .(24 \mathrm{~F})-(15)$ \\
\hline $110-160$ & $1.98 \mathrm{E}+(1)$ & $1.611+113$ & $2.751:-112$ & $2.41 \mathrm{E}-0.5$ & $3,971 \mathrm{~B}(16$, & $2.4111:-115$ & $3.961: \cdots 16$ & $2.35 \mathrm{E}-10.5$ & $3.87 \mathrm{E}-106$ \\
\hline Er-167m & $4.79 E+114$ & $3.78 \mathrm{E}-1) 2$ & $9.711:-112$ & $6.09 \mathrm{E}-(1) 6$ & $3.551: \ldots 16$ & $1.401:-81$ & $8.13 \mathrm{E}-82$ & (1). (1) 1$) E+(x)$ & (I. (N)E + (K) \\
\hline Y'b-175 & $1.30 \mathrm{E}+101$ & $6.03 .3 E+10.3$ & $3 .(10) 15122$ & $1.601: \ldots 10$ & $3.1,31 \div \cdot 07$ & $1.691:-116$ & $3.1 .31: 117$ & $1.685:-160$ & $3,11 \mathrm{E}-(17$ \\
\hline Yb- 177 & $1.135 E+1111$ & $1.14 E+12$ & $1.221:-111$ & $1.371: 116$ & $1.001 \mathrm{E}-106$ & 1.291:-116 & $9.471:-17$ & $9.54[;-117$ & $6.99 \mathrm{E}-117$ \\
\hline $1.11-176 \mathrm{~m}$ & $4.78 E+111$ & $2.211 E+(12$ & $1.821:-12$ & $5.8011: \ldots 15$ & $6.34 \mathrm{E}-116$ & $5.635 \div-115$ & $6.151:-196$ & $4.821 \div \ldots 15$ & $5.2618-16)$ \\
\hline $1.4-177$ & $2.22 \mathrm{E}+100$ & $9.66 \mathrm{E}+0.3$ & $3.121 \div-122$ & 2.7110106 & $4.891 \div 117$ & $2.7016-(16)$ & 4.801: 117 & $2.6915-1 k_{2}$ & $4.87 \mathrm{E}-107$ \\
\hline $111-178 m$ & $1.1012+10.3$ & $7.17 \mathrm{E}-112$ & $9.771:-111$ & $1.1171:-115$ & $0.25 \mathrm{E}-115$ & $1.411: 4.5$ & $8.201:-45$ & $0 .(1011 E+10)$ & $(1 .(K) E+(K)$ \\
\hline $111-179 \mathrm{~m}$ & $246 \mathrm{E}+114$ & 3.12E-(1)1 & $2.871:-111$ & $0.851 ;-113$ & $1.701 \div-12$ & $6.751: 12$ & $1.161:-11$ & $3.96 \mathrm{E}:-60)$ & $0.82 \mathrm{E} \cdots 00$ \\
\hline W-187 & $3.47 E+1111$ & $1.43 E+1.3$ & $4.311:-111$ & $4.221 \div(16$ & 1.10) $:-115$ & $4.2118:-16 \%$ & $1.1091: 05$ & 4.1101:-106 & 1.(101:-0.15 \\
\hline Re-186 & $3.621 E+191)$ & $5.44 F+0.3$ & $1.801 E-102$ & $4.4011 ; 106$ & $4.75 \mathrm{E}-117$ & 4.4115:-16) & 4.75L-117 & $4.371: \ldots 16$ & $4.72 \mathrm{~L}-117$ \\
\hline$R c-188 m$ & $2.181+01$ & $1.86 \mathrm{E}+0)$ & $7.901:-112$ & $26111:-115$ & $1.241 \div 0.5$ & $1.83 \mathrm{E}(1.5$ & $8.72 E-1)(6$ & $2.84 \mathrm{E}-106$ & $1.358:-(k)$ \\
\hline$R c_{-1}-188$ & $1.85 E+101$ & $1.11218+0.3$ & $4.781:-12$ & $2.251:-11.5$ & $6.451 \div-106$ & 2.2314 .015 & 6.411600 & 2. $16 \mathrm{E}: 0 \mathrm{~s}$ & (1.201:-(16) \\
\hline () $\mathrm{s}-101 \mathrm{~m}$ & $1.10 E+100$ & $7.8011+112$ & $6.511:-01.3$ & $1.451:-116$ & $5.65 \mathrm{E}-108$ & $1.431 \mathrm{E}-166$ & $5.6(1) 1+1) 8$ & $1.37 \mathrm{E}-106$ & $5.361:-118$ \\
\hline $1 r-192 m$ & $3.12 \mathrm{E}+114$ & $1.401 \mathrm{E}+100$ & $2.47 \mathrm{E}-114$ & $2.906 \ldots(12)$ & $4.39 \mathrm{E}-115$ & 2.69):-114 & $3.98 \mathrm{E}-107$ & 4.791:-15 & $7.101:-18$ \\
\hline $1 \mathrm{r} \cdot 194$ & $2.731 E+101$ & $1.16 E+1) 3$ & $5.121 ;-(12$ & $3.32 \mathrm{E}:-0.5$ & $1.112 E-115$ & $3.3(1) E:-15$ & $1.1111:-115$ & $3.201 \mathrm{E}-(15)$ & $9.84 E-(1) 6$ \\
\hline$P_{1-190 m}$ & $3.83 \mathrm{E}+00$ & 2.4(1)E- (1)1 & $3.421:-111$ & $1.1018-00$ & $2.26[\mathrm{E}(1) 6$ & $1.341:-18$ & $2.76 \mathrm{E}-18$ & $2.67 \mathrm{E}-81$ & $5.48 \mathrm{~L}-81$ \\
\hline $1+190$ & $3.89 E+101$ & $3.118 E+01$ & $1.11718-11)$ & $4.681: \cdots 100$ & $3.100 \mathrm{E}-00$ & $3.78 \mathrm{E}-106$ & $2.43 \mathrm{E}-106$ & $1.23 \mathrm{E}-16$ & $7.871 \mathrm{E}-017$ \\
\hline$\wedge u-108$ & $1.18 \mathrm{E}+01$ & $3.88 \mathrm{E}+0.3$ & $4.113 \mathrm{E}-111$ & $1.441:-.15$ & $3.47 \mathrm{E}-115$ & $1.43 \mathrm{E}-0.5$ & $3.46 \mathrm{E}-115$ & $1.42 \mathrm{E}-1.5$ & $3.43 E-015$ \\
\hline $1 \mathrm{Hg}-2(15$ & $2.03 E+10(1$ & $5.2(1 \mathrm{E}+11)$ & $4.8(1) \mathrm{E}-113$ & $2.311: \cdots 00$ & $6.65 \mathrm{E}-1) 8$ & $6.511:-107$ & $1.88 \mathrm{E} \ldots 18$ & $8.31 \mathrm{E}-10$ & $2.39 \mathrm{E}-11$ \\
\hline I'h-2.33 & $1.19 E+122$ & $2.23 \mathrm{E}+011$ & $1.08 \mathrm{E}-112$ & $1.425-104$ & $9.23 E-1) 6$ & $1 .(161:-1) 4$ & $6.871: 106$ & $2.24 \mathrm{E}-115$ & $1.45 E-(16$ \\
\hline (1) -239 & $1.011 E+02$ & $2.35 \mathrm{E}+01$ & $5.211-112$ & $1.2113-114$ & 3.78E-115 & $9.15 \mathrm{E}-105$ & 2.86150015 & $2.09 \mathrm{E}-015$ & $6.54 \mathrm{E}-166$ \\
\hline
\end{tabular}

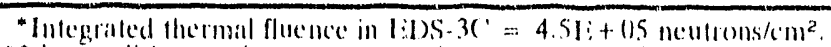

* dps = disintegration(s) per second.

tolis = disintegration.

Note: $8.421:-10=8.42 \times 10.10 \mathrm{clc}$. 


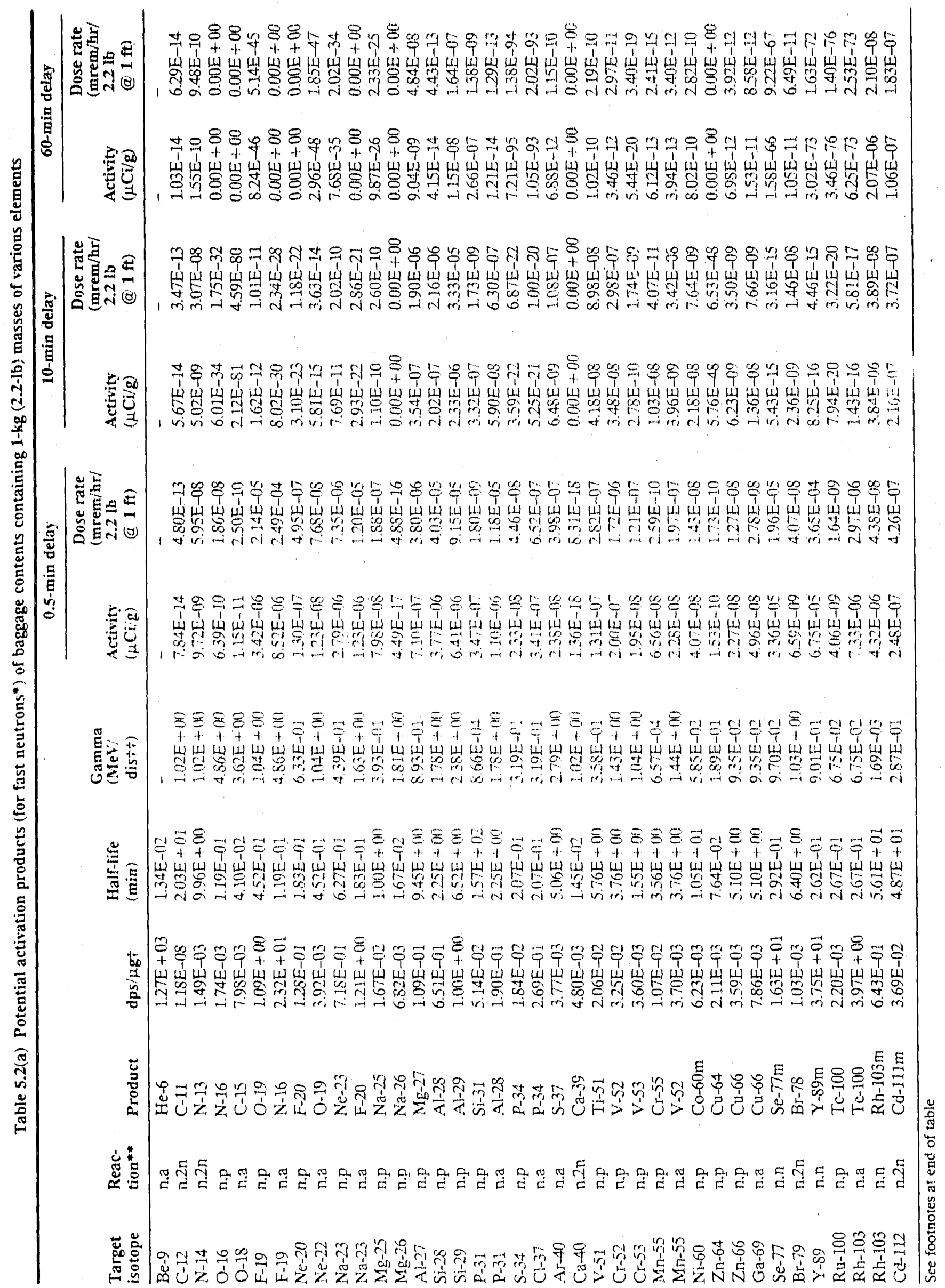




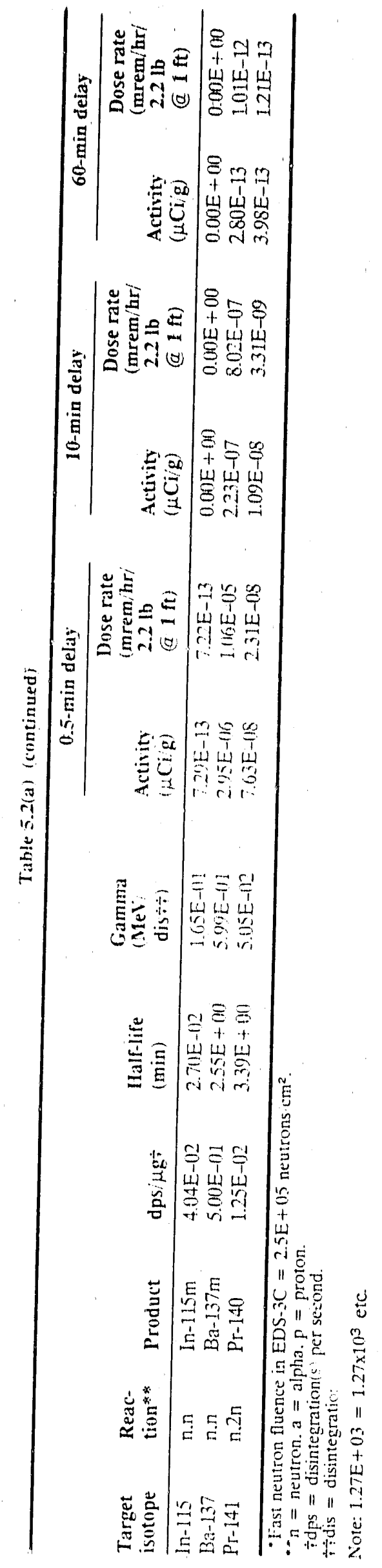

NIIRI:(; ; 1.39) 
Table 5.3(a) Major autivation products of baggage contents containing 1-kg (2.2-1b) masses of various element:

\begin{tabular}{|c|c|c|c|c|c|c|c|c|c|}
\hline \multirow[b]{2}{*}{ Praduct } & \multirow[b]{2}{*}{$\mathrm{dps} / \mu \mathrm{g}^{*}$} & \multirow[b]{2}{*}{$\begin{array}{l}\text { Half-life } \\
\text { (min) }\end{array}$} & \multirow[b]{2}{*}{$\begin{array}{l}\text { Gamma } \\
\text { (Mev/ } \\
\text { dis**) }\end{array}$} & \multicolumn{2}{|c|}{$0.5 \cdot \mathrm{min}$ delay } & \multicolumn{2}{|c|}{ 10-min delay } & \multicolumn{2}{|c|}{ 60-min deluy } \\
\hline & & & & $\begin{array}{l}\text { Activity } \\
(\mu \mathrm{Ci} / \mathrm{g})\end{array}$ & $\begin{array}{l}\text { Dose rate } \\
(\mathrm{mrem} / \mathrm{hr} / \\
2.2 \mathrm{lb} \\
\text { (d) } 1 \mathrm{ft})\end{array}$ & $\begin{array}{l}\text { Activity } \\
(\mid, \mathrm{Cl} / \mathrm{h})\end{array}$ & $\begin{array}{l}\text { Dose rinte } \\
(\mathrm{mrem} / \mathrm{hr} / \\
2.2 \mathrm{lb} \\
\text { (ii) } 1 \mathrm{ft})\end{array}$ & $\begin{array}{l}\text { Activity } \\
(\mu \mathrm{Cl} / \mathrm{g})\end{array}$ & $\begin{array}{l}\text { Dose rute } \\
\text { (mrem/hr/ } \\
2.2 \mathrm{lb} \\
\text { (ii) } 1 \mathrm{ft})\end{array}$ \\
\hline $\mathrm{F}-20$ & $1.97 E+02$ & $1.83 \mathrm{E}-01$ & $1.64 \mathrm{E}+00$ & $3.61 \mathrm{E}-0.5$ & $3.55 \mathrm{E}-0.04$ & 8.58E--21 & $8,44 \mathrm{E}-20$ & $0.00 \mathrm{E}+0.0$ & $0.0(1) E+000$ \\
\hline $\mathrm{Na}-24$ & $1.80 E+00$ & $8.80 E+02$ & $4.12 E+00$ & $2.19 \mathrm{E}-06$ & $5.41 \mathrm{E}-05$ & $2.17 \mathrm{E}-06$ & $5.37 \mathrm{E}-0.5$ & 2.(0)E-(1)G & $5.16 \mathrm{E}-(15)$ \\
\hline$A 1-28$ & $2.72 E+12$ & $2.24 E+C 0$ & $1.78 E+100$ & $2.83 \mathrm{E}-04$ & $3.03 \mathrm{E}-0.3$ & $1.50 \mathrm{E}-05$ & $1.60 \mathrm{E}-0) 4$ & $2.87 \mathrm{E}-12$ & $3.071 \mathrm{E}-11$ \\
\hline $\mathrm{K}-42$ & $2.39 \mathrm{E}-01$ & $7.42 \mathrm{E}+02$ & $2.73 E+02$ & $2.91 \mathrm{E}-07$ & $4.76 \mathrm{E}-04$ & $2.88 \mathrm{E}-(1) 7$ & $4.72 \mathrm{E}-(14$ & $2.75 \mathrm{E}-(17$ & $4.5(1) \mathrm{E}-(14$ \\
\hline $\mathrm{Sc}-46 \mathrm{~m}$ & $4.73 E+04$ & $3.12 \mathrm{E}-01$ & $1.42 E-(01$ & $1.89 \mathrm{E}-02$ & $1.61 \mathrm{E}-02$ & $1.30 \mathrm{E}-11$ & $1.11 \mathrm{E}-11$ & $7.62 \mathrm{E}-60$ & $0.491 ;-(0)$ \\
\hline V.52 & $1.79 \mathrm{E}+03$ & $3.75 \mathrm{E}+00$ & $1.43 \mathrm{E}+00$ & $1.98 \mathrm{E}-(0) 3$ & $1.70 \mathrm{E}-02$ & $3.43 \mathrm{E}-(04$ & $2.94 \mathrm{E}-(1) 3$ & $3.33 \mathrm{E}-(18)$ & $2.8611-117$ \\
\hline$M n-56$ & $1.11 E+02$ & $1.55 \mathrm{E}+02$ & $1.70 \mathrm{E}+00$ & $1.35 \mathrm{E}-04$ & $1.37 \mathrm{E}-03$ & $1.20 \mathrm{E}-04$ & $1.32 \mathrm{E}_{-1}(1) 3$ & $1.03 E-(14$ & $1.0585-(1) 3$ \\
\hline $\mathrm{Sc}-77 \mathrm{II}$ & $5.69 \mathrm{E}+03$ & $2.90 \mathrm{E}-01$ & $9.63 \mathrm{E}-02$ & $2.10 \mathrm{E}-03$ & $1.21 \mathrm{E}-03$ & $2.90 \mathrm{E}-13$ & $1.67 \mathrm{E}-13$ & $3.73 E-6.5$ & $2.15 \mathrm{E}-6.5$ \\
\hline $13 r-80$ & $2.91 E+02$ & $1.77 \mathrm{E}+01$ & $7.00 \mathrm{E}-(12$ & $3.47 \mathrm{E}-04$ & $1.46 \mathrm{E}-04$ & $2.39 \mathrm{E}-04$ & $1.001 \mathrm{E}-04$ & $3.38 \mathrm{E}-(15$ & $1.421 \mathrm{I}-(15 \mathrm{~S}$ \\
\hline $\mathrm{Rb}-86 \mathrm{~m}$ & $4.20 \mathrm{E}+01$ & $1.02 E+00$ & $5,46 E-01$ & $3.64 \mathrm{E}-05$ & $1.19 E-04$ & $5.72 E-08$ & $1.87 \mathrm{E}-117$ & $1,(11 \mathrm{E}-22$ & $3.311--22$ \\
\hline $12 h-104 m$ & $3.60 E+03$ & $4.35 F+00$ & $3.48 \mathrm{E}-(12$ & $4.04 \mathrm{E}-03$ & $8.44 E-04$ & $8.90 \mathrm{E}-104$ & $1.86 \mathrm{E}-04$ & $3.100 \mathrm{E}-117$ & $6.4512 \cdots 08$ \\
\hline$R h-104$ & $1.54 E+04$ & $7.05 \mathrm{E}-0.1$ & $1.11 \mathrm{E}-02$ & $1.15 \mathrm{E}-02$ & $\% .63 \mathrm{E}-04$ & $1.01 \mathrm{E}-06$ & $6.71 \mathrm{E}-(18$ & $4.55 E-28$ & $3 .(1.31: \cdots 29$ \\
\hline $\mathrm{Ag}-108$ & $5.09 \mathrm{E}+0.3$ & $2.41 E+00$ & $2.94 \mathrm{E}-02$ & $5.36 \mathrm{E}-0.3$ & $9.46 \mathrm{E}-04$ & $3.49 \mathrm{E}-(1) 4$ & $6.16 \mathrm{E} \ldots(15)$ & $1.908-10$ & $3.511 \%-11$ \\
\hline $\mathrm{Ag}-110$ & $8.31 \mathrm{E}+04$ & $4.10 \mathrm{E}-01$ & $2.96 \mathrm{E}-02$ & $4.34 \mathrm{E}-(12$ & $7,71 \mathrm{E}-(03$ & $4.61 \mathrm{E}-09$ & $8.10 \mathrm{E}-10$ & $9.14 E--40$ & $1.621:-46$ \\
\hline $\ln -116 \ln (1)$ & $1.29 E+03$ & $5.42 \mathrm{E}+01$ & $2.47 \mathrm{E}+00$ & $1.56 \mathrm{E}-0.3$ & $2.31 \mathrm{E}-02$ & $1.38 \mathrm{E}-0.3$ & $2 .\left(15 E_{-1}-1\right) 2$ & $7.281:-104$ & $1.1181:-112$ \\
\hline $111-116$ & $1.36 \mathrm{E}+04$ & $2.37 \mathrm{E}-(01$ & $1.55 \mathrm{E}-02$ & $3.83 \mathrm{E}-(03$ & $3.57 \mathrm{E}-04$ & $3.31 \mathrm{E}-15$ & $3.11818-16$ & $1.061:-78$ & $9.841 \div 811$ \\
\hline $1-128$ & $2.00 \mathrm{E}+02$ & $2.50 \mathrm{E}+01$ & $8.75 E-(12$ & $2.40 \mathrm{E}-04$ & $1.26 \mathrm{E}-04$ & $1.84 \mathrm{E}-(14$ & $9.681 \mathrm{E}-0.5$ & $4.611 .-115$ & $2.421:-11.5$ \\
\hline Eu-152m(1) & $1.32 E+0.3$ & $5.58 \mathrm{E}+02$ & $2.41 \mathrm{E}-01$ & $1.60 \mathrm{E}-0.3$ & $2.32 \Gamma-0.3$ & $1.50) \mathrm{E}-(1.3$ & $2.2018 .-013$ & $1.491:-11.3$ & $2.151:-113$ \\
\hline 1) $y=16.5 \mathrm{~m}$ & $1.64 \mathrm{E}+05$ & $1.26 \mathrm{E}+00$ & $1.09 \mathrm{E}-02$ & $1.52 \mathrm{E}-01$ & $9.91 \mathrm{E}-0.3$ & $8.15 \mathrm{E}-1.4$ & $5.33 \mathrm{E}-015$ & $0.291:-16$ & $0.1181 \div, 17$ \\
\hline $118-179 m$ & $2.46 E+04$ & $3.12 \mathrm{E}-01$ & $2.87 E-01$ & $9.85 \mathrm{E}-0.3$ & $1.70 \mathrm{E}-(12$ & $6.75 \mathrm{E}-12$ & $1.161:-11$ & $3.901:-010$ & $0.821 \div-010$ \\
\hline l'otal & & & & & $1.03 \mathrm{E}-0) 1$ & & $2.82 \mathrm{E} \ldots 12$ & & $1.451 \div(12$ \\
\hline
\end{tabular}

"dps = disintegration(s) per second.

* dis $=$ disiostegration.

Nole: $1.971:+02=1.97 \times 10^{2} \mathrm{etc}$. 
Table 5.4(a) Calculated beta dose to the skin from a $1 \mu \mathrm{Cl} / \mathrm{cm}^{2}$ source

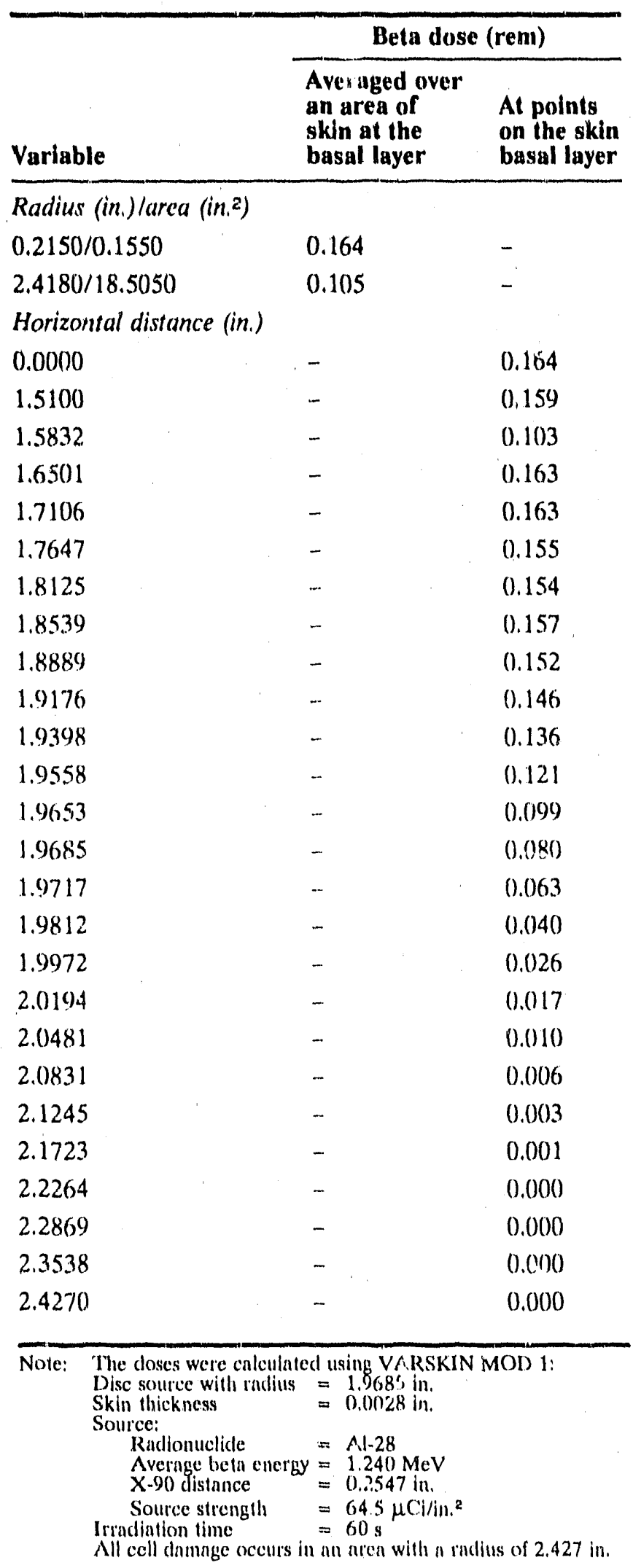


T'uble 5.5 (a) Elemental composition of the contents of an aluminnm suitcase (quantities in ounces)

\begin{tabular}{|c|c|c|c|c|c|c|c|c|c|}
\hline Nement & $\begin{array}{l}\text { Cloth. } \\
\text { ing }\end{array}$ & Shoes & $\begin{array}{l}\text { Tollet. } \\
\text { ries }\end{array}$ & $\begin{array}{l}\text { Trooth. } \\
\text { paste }\end{array}$ & Shaver & Shampoo & Paper & $\begin{array}{l}\text { Sult. } \\
\text { case }\end{array}$ & 'lotal \\
\hline Hydrogen & 10.8 & 1.9 & 0.8 & 0,6 & - & 1.2 & 5.0 & 9.0 & 29.3 \\
\hline Carbon & 89.8 & 17.3 & 5.1 & 0.4 & 0.08 & 6.8 & 35.5 & 46.1 & 201.1 \\
\hline Nitrogen & 17.0 & 5.1 & 1.0 & - & - & 0.2 & - & - & 23.4 \\
\hline Oxygen & 37.1 & 7.7 & 1.1 & 3.8 & - & 2,6 & 39.7 & 41.0 & 133.0 \\
\hline Sodium & $\ldots$ & - & - & 0.01 & - & - & - & -- & 0.01 \\
\hline Manganese & - & 0.1 & - & - & 0.2 & - & - & -- & 0.3 \\
\hline Silicon & - & 0.03 & - & - & 0.06 & - & - & - & 0.1 \\
\hline Phosphorous & - & 0.003 & - & 0.5 & 0.007 & - & - & - & 0.5 \\
\hline Sulfur & - & 0.003 & - & 0.01 & 0.007 & - & - & - & 0.0 .2 \\
\hline Iron & - & 15.8 & ... & - & 3.2 & - & - & - & 19.0 \\
\hline Calcium & - & - & - & 0.7 & - & - & - & - & 0.7 \\
\hline Aluminum* & .. & - & - & - & - & - & - & 160.1 & 160.1 \\
\hline
\end{tabular}

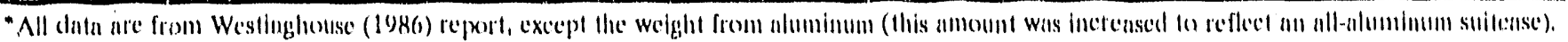

Table 5.6(a) Gumma dose rates from EDS.3C activation of the contents of an aluminum suitcase

\begin{tabular}{|c|c|c|c|c|}
\hline Element & $\begin{array}{l}\text { Element } \\
\text { mass } \\
(0 t)\end{array}$ & $\begin{array}{l}\text { Suitcuse } \\
\text { activity } \\
(\mu \mathrm{Ci})\end{array}$ & $\begin{array}{l}\text { Gamma } \\
(\mathrm{mrem} / \mathrm{hr} / \\
2.2 \mathrm{lb} \\
\text { (a) } 1 \mathrm{ft})\end{array}$ & $\begin{array}{l}\text { Gammu dose } \\
\text { rate (a) } 1 \text { ft } \\
\text { (mrem/hr) }\end{array}$ \\
\hline Hydrogen & 29.3 & - & - & - \\
\hline Carbon & 201.1 & $1.401:-13$ & - & - \\
\hline Nitrogen & 23.4 & $2.401:-09$ & - & - \\
\hline Oxygen & 133.0 & $1.101:-05$ & - & - \\
\hline Sodium & 0.01 & $6.20 \mathrm{E}--07$ & $5.411:-(0) 5$ & $1.54 \mathrm{I}-08$ \\
\hline Manganese & 0.03 & $1.30 \mathrm{E}-03$ & $1.371:-03$ & $1.17 \mathrm{E}-06$ \\
\hline Silicon & 0.1 & $3.501:-08$ & - & - \\
\hline Phosphorous & 0.5 & $2.001:-13$ & - & - \\
\hline Sulfur & 0.02 & - & - & - \\
\hline Iron & 19.0 & & - & - \\
\hline Calcium & 0.7 & - & - & - \\
\hline Aluminum & 160.1 & $1.281 \%+00$ & $3.031 i-1) 3$ & $1.381:-02$ \\
\hline 'lotal & & & & $1.38 \mathrm{~L} i-() 2$ \\
\hline
\end{tabular}

Nole: $1.401:-13=1.4(1) 1(1)-13 \mathrm{clc}$. 


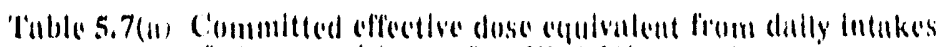

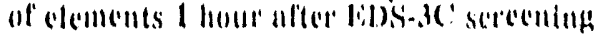

\begin{tabular}{|c|c|c|c|c|c|c|c|}
\hline \multirow[b]{2}{*}{$\begin{array}{l}\text { l'urget } \\
\text { nucllele }\end{array}$} & \multirow{2}{*}{$\begin{array}{l}\text { Meun } \\
\text { dullyy } \\
\text { lintuke } \\
\text { (oz) }\end{array}$} & \multirow{2}{*}{$\begin{array}{l}\text { Ludluced } \\
\text { radila- } \\
\text { nuclide }\end{array}$} & \multirow{2}{*}{ 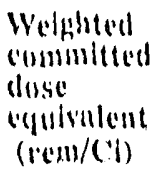 } & \multicolumn{2}{|c|}{ 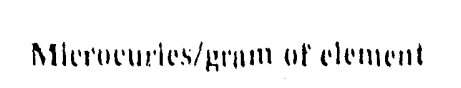 } & \multicolumn{2}{|c|}{ 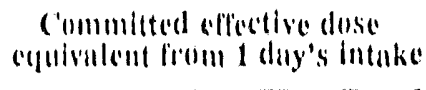 } \\
\hline & & & & $\begin{array}{l}(1.5 \cdot m / 11) d(1) y^{*} \\
(\mu(1 / 4)\end{array}$ & $\begin{array}{l}10-\min (1+1) y^{*} \\
(\mu(\mathrm{i} / \mathrm{h})\end{array}$ & $\begin{array}{l}0.5-11111 \text { doluy } \\
(1111(111)\end{array}$ & $\begin{array}{l}\text { 10-1uilu delay' } \\
\text { (mireiu) }\end{array}$ \\
\hline $\mathrm{N}(1-2.3$ & $1.551: \ldots 111$ & $\mathrm{~N}(1-2,4$ & $1.4 .11:+10.3$ & $6.2111 \div 015$ & $0.151: \ldots 105$ & $1.3301: 115$ & $1.371:-115$ \\
\hline$|2-3|$ & $4.941:-112$ & $1-32$ & $7.771:+11.3$ & $1.271 \% 1016$ & $1.221: 06$ & $4.651: 077$ & 4.6515017 \\
\hline$(1) \cdot .37$ & 1.8418 .111 & $(1-38$ & $2.0010+102$ & $1 .(10) 60114$ & $1.5111: 11.4$ & $0.451: 116$ & 58210106 \\
\hline$k-41$ & 1.161:-1)1 & $k \cdot 42$ & $1.1101:+113$ & $8.241:-16$ & $8.101: \ldots 116$ & $1.1161: 116$ & $1,11.41: 116)$ \\
\hline Mn-5.5 & $1.3116 . \cdots 14$ & M11-S6 & $9.3215+102$ & 3.8215 .113 & $3,6,51: 10,3$ & $4.601 \div 107$ & $4.451: 117$ \\
\hline$(11)-63,3$ & $1.241, \ldots(1.4$ & $(11.64)$ & $4.2011+(12$. & 1.5816114 & $1.5(10: \ldots 1.4$ & $8.871 \div(11)$ & $8.21)(1 .-(1)$ \\
\hline A.s-7.5 & $3.5 .31 \div 11.5$ & $\therefore s-76$ & $4.7418+10.7$ & $1.121: \ldots(1) .1$ & 1.121:-114 & I.SBL: IS & $1.871: 18$ \\
\hline $131-79$ & $2.6 .5 \mathrm{~L} \ldots(1) 4$ & $|3 r-8(1)| 1 \mid$ & $2.3118+112$ & $1.8915:-11.4$ & 1.s.t1:11.4 & $1.151: 118$ & 1.121:-18 \\
\hline $131 \cdot \cdots 79$ & 2.6515 .114 & $|3|-8 \mid$ & $5.551 ;+111$ & $0.8,36 \div .11,3$ & $0.771: 0.3$ & $1.411: 017$ & 1).51: 188 \\
\hline 'lulal & & & & & & $\therefore 211 \div 115$ & $3.161: 05$ \\
\hline
\end{tabular}

- lifumir liahle 5.1(a).

Nole: $1.551 ;-011=1.55 \times 110-1$ (16.

luble $5.9(a)$ Simmmary of collective doses from all scruarios

\begin{tabular}{|c|c|c|c|c|}
\hline \multirow[b]{2}{*}{ Radiation exponsure } & \multicolumn{4}{|c|}{ Sicenurio } \\
\hline & $\begin{array}{l}\text { Buhind the } \\
\text { counter } \\
\text { (perstoly-rom) }\end{array}$ & $\begin{array}{l}\text { In firment of } \\
\text { the cotunter } \\
\text { (person-fem) }\end{array}$ & $\begin{array}{l}\text { Pre-check-in } \\
\text { (personterem) }\end{array}$ & 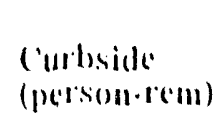 \\
\hline \multicolumn{5}{|l|}{ Momkentis } \\
\hline ()porallers & $1.21 \div+110$ & $1.21: 1010$ & $1.21: 100$ & $1.21 \div+1)(1)$ \\
\hline Bangegere handlers & $(0 .(1) 1 \div(1) 1$ & $(1.111 \div(1) 1$ & $(1 .(1) \div \div(1) 1$ & $6 .(1) \vdots 111$ \\
\hline licket counter persomncl & $3 .(1) \div+100$ & $3 .(11: 10)$ & $1 .(11 \div+100$ & 0 \\
\hline Secorrity screconers & $9.51: \cdots(12$ & $9.51:(0) 2$ & $0.51: 0.2$ & $0.51 \div(1) 2$ \\
\hline Sky-(z)ps & $(1)$ & (1) & 0 & $3.81 \div 01$ \\
\hline Pexiscruscrss & () & $1.11 i+100$ & $2(1) 1 \div+1) 1$ & $5.51 \vdots+100$ \\
\hline \multicolumn{5}{|l|}{ Public } \\
\hline 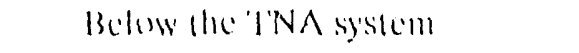 & $(3.81 \div+1)(1)$ & $(0.81)+1)(1)$ & $(1.6) \div 1.1)(1)$ & $0.826+1)$ \\
\hline Néar lho 'INAsystcm & () & $1.11: 1011$ & $(1 .(1) 1 ;+1)(x)$ & $(1 .(1) 1 \div(1) 1$ \\
\hline \multicolumn{5}{|l|}{ 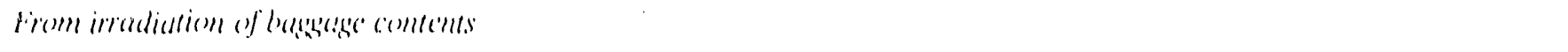 } \\
\hline ('mstumable ifems & () & (1) & $1.31: 11.3$ & $(1$ \\
\hline $\begin{array}{l}\text { Nonconstmmable itcoms (sublcasce, } \\
\text { clothing! celc.) }\end{array}$ & $2.81:-() 1$ & 2.8'1: (1) & $2.151 \vdots \cdots(1) 1$ & $2.81 \div(1)$ \\
\hline Tinal & $1.21 \div+01$ & $1.61 \vdots+1) 1$ & $3 .(11 \div+1) 1$ & $1 .(01 \vdots+011$ \\
\hline
\end{tabular}

No1t: $1.21 \div+101)=1.2 \times 10^{\circ}$ (1) 
Table 5.10(a) Summary of annual individual doses from all scenarios

\begin{tabular}{|c|c|c|c|c|c|}
\hline \multirow[b]{2}{*}{ Radiation exposure } & \multicolumn{5}{|c|}{ Scenario } \\
\hline & $\begin{array}{l}\text { Behind the } \\
\text { counter } \\
\text { (mrem) }\end{array}$ & $\begin{array}{l}\text { In front of } \\
\text { the counter } \\
\text { (mrem) }\end{array}$ & $\begin{array}{l}\text { Pre-check.in } \\
(\text { mrem })\end{array}$ & $\begin{array}{l}\text { Curbside } \\
\text { (mrem) }\end{array}$ & $\begin{array}{l}\text { NRC } \\
\text { limit } \\
\text { (mrem) }\end{array}$ \\
\hline \multicolumn{6}{|l|}{ Workers } \\
\hline $\begin{array}{l}\text { Operators } \\
\text { Baggage handlers } \\
\text { Ticket counter personnel } \\
\text { Security screeners } \\
\text { Sky-caps }\end{array}$ & $\begin{array}{l}2.0 \mathrm{E}+02 \\
1.0 \mathrm{E}+02 \\
6.0 \mathrm{E}+01 \\
3.2 \mathrm{E}+01 \\
0\end{array}$ & $\begin{array}{l}2.0 \mathrm{E}+02 \\
1.0 \mathrm{E}+02 \\
6.0 \mathrm{E}+01 \\
3.2 \mathrm{E}+01 \\
0\end{array}$ & $\begin{array}{l}2.0 \mathrm{E}+02 \\
1.0 \mathrm{E}+02 \\
1.7 \mathrm{E}+00 \\
3.2 \mathrm{E}+01 \\
0\end{array}$ & $\begin{array}{l}2.0 \mathrm{E}+02 \\
1.0 \mathrm{E}+02 \\
0 \\
3.2 \mathrm{E}+01 \\
2.5 \mathrm{E}+01\end{array}$ & $\begin{array}{l}5.0 \mathrm{E}+03 \\
5.0 \mathrm{E}+02 \\
5.0 \mathrm{E}+02 \\
5.0 \mathrm{E}+02 \\
5.0 \mathrm{E}+02\end{array}$ \\
\hline Passengers & 0 & $1.0 \mathrm{E}-03$ & $1.8 \mathrm{E}-02$ & $5.0 \mathrm{E}-03$ & $5.0 \mathrm{E}+02$ \\
\hline \multicolumn{6}{|l|}{ Public } \\
\hline $\begin{array}{l}\text { Below the TNA system } \\
\text { Near the TNA system }\end{array}$ & $\begin{array}{l}7.5 \mathrm{E}-03 \\
0\end{array}$ & $\begin{array}{l}7.5 \mathrm{E}-03 \\
1.2 \mathrm{E}-04\end{array}$ & $\begin{array}{l}7.5 \mathrm{E}-03 \\
6.7 \mathrm{E}-04\end{array}$ & $\begin{array}{l}7.5 \mathrm{E}-03 \\
6.7 \mathrm{E}-04\end{array}$ & $\begin{array}{l}5.0 \mathrm{E}+02 \\
5.0 \mathrm{E}+02\end{array}$ \\
\hline \multicolumn{6}{|l|}{ Frcm irradiation of baggage contents } \\
\hline $\begin{array}{l}\text { Consumable items } \\
\text { Nonconsumable items (suitcase, } \\
\text { clothing, ctc.) }\end{array}$ & $\begin{array}{l}0 \\
2.5 \mathrm{E}-02\end{array}$ & $\begin{array}{l}0 \\
2.5 \mathrm{E}-02\end{array}$ & $\begin{array}{l}2.4 \mathrm{E}-05 \\
2.5 \mathrm{E}-02\end{array}$ & $\begin{array}{l}0 \\
2.5 \mathrm{E}-02\end{array}$ & - \\
\hline
\end{tabular}

\begin{tabular}{ll}
\hline Notes: & Natural sources of radiation: \\
Natural background & $3.0 \mathrm{E}+02$ \\
Yearly dose from foodstuffs & $1.4 \mathrm{E}+01$ \\
& $2.0 \mathrm{E}+02=2.0 \times 10^{2} \mathrm{ctc}$.
\end{tabular}

Table 6.2(a) Offsite concentrations [at $50 \mathrm{~m}$ (54 yd)] of airborne releases for various fractions of $\mathbf{C f} \mathbf{2 5 2}$

\begin{tabular}{|c|c|c|c|c|c|c|}
\hline \multirow{2}{*}{$\begin{array}{l}\text { Total } \\
\text { source } \\
\text { activity } \\
\text { (Ci/yr) }\end{array}$} & \multirow[b]{2}{*}{$\begin{array}{l}\text { Release } \\
\text { fraction }\end{array}$} & \multirow[b]{2}{*}{$\begin{array}{l}\text { Emission } \\
\text { (Ci) }\end{array}$} & \multirow[b]{2}{*}{$\begin{array}{c}x / Q^{*} \\
\left(\mathbf{s} / \mathbf{m}^{3}\right)\end{array}$} & \multirow{2}{*}{$\begin{array}{l}\text { Maximum } \\
\text { permissible } \\
\text { concentra- } \\
\text { tion }(\mathrm{MPC}) \\
(\mu \mathrm{Ci} / \mathrm{ml})\end{array}$} & \multicolumn{2}{|c|}{ Offsite concentration } \\
\hline & & & & & $\left(\mathbf{C i} / \mathrm{m}^{3}\right)$ & $\begin{array}{l}\text { Fraction } \\
\text { of MPC } \\
(\%)\end{array}$ \\
\hline $8.00 \mathrm{E}-02$ & $1.00 \mathrm{E}-01$ & $8.00 \mathrm{E}-03$ & $6.40 \mathrm{E}-05$ & $1.00 \mathrm{E}-12$ & $1.62 \mathrm{E}-14$ & 1.62 \\
\hline $8.00 \mathrm{E}-02$ & $5.00 \mathrm{E}-01$ & 4.00E-02 & $6.40 \mathrm{E}-05$ & $1.00 \mathrm{E}-12$ & $8.12 \mathrm{E}-14$ & 8.12 \\
\hline 8.00E-02 & $1.00 \mathrm{E}+00$ & $8.00 \mathrm{E}-02$ & $6.40 \mathrm{E}-05$ & $1.00 \mathrm{E}-12$ & 1.62E-13 & 16.24 \\
\hline
\end{tabular}

${ }^{*} \times / \mathrm{Q}$ at $? 0 \mathrm{~m}$.

Note: $8.00 \mathrm{E}-02=8.00 \times 10)^{2} \mathrm{ctc}$. 
Table 6.3(a) Annual inhalation dose to the nearest individual $50 \mathrm{~m}(54 \mathrm{yd})$ awaly from postulated $\mathrm{Cf} \cdot \mathbf{2 5 2}$ accident

\begin{tabular}{lll}
\hline $\begin{array}{l}\text { Activity* } \\
\text { inhaled } \\
\text { (mCi) }\end{array}$ & $\begin{array}{l}\text { Dose conver- } \\
\text { sion factor** } \\
\text { (rem/50 yr-mCi) }\end{array}$ & $\begin{array}{l}\text { Committed } \\
\text { effective } \\
\text { dose } \\
\text { equivalent } \\
\text { (rem/50 yr) }\end{array}$ \\
\hline $1.30 \mathrm{E}-07$ & $1.85 \mathrm{E}+05$ & $2.40 \mathrm{E}-02$ \\
$6.49 \mathrm{E}-07$ & $1.85 \mathrm{E}+05$ & $1.20 \mathrm{E}-01$ \\
$1.30 \mathrm{E}-06$ & $1.85 \mathrm{E}+05$ & $2.40 \mathrm{E}-01$ \\
\hline
\end{tabular}

Breathing rate $=8.00 \mathrm{E}+03 \mathrm{~m}^{3} / \mathrm{yr}$.

*ICRP Publication 30.

Note: $1.30 \mathrm{E}-07=1.30 \times 10^{-7} \mathrm{etc}$.

Table 6.4(a) Offsite concentrations [at $300 \mathrm{~m}$ (328 yd)] of airborne releases for various fractions of $\mathbf{C f} \cdot \mathbf{2 5 2}$

\begin{tabular}{|c|c|c|c|c|c|c|}
\hline \multirow{2}{*}{$\begin{array}{l}\text { Total } \\
\text { source } \\
\text { activity } \\
\text { (Ci/yr) }\end{array}$} & \multirow[b]{2}{*}{$\begin{array}{l}\text { Release } \\
\text { fraction }\end{array}$} & \multirow[b]{2}{*}{$\begin{array}{l}\text { Emission } \\
\text { (Ci) }\end{array}$} & \multirow[b]{2}{*}{$\begin{array}{l}\chi / Q^{*} \\
\left(\mathbf{s} / \mathbf{m}^{3}\right)\end{array}$} & \multirow{2}{*}{$\begin{array}{l}\text { Maximum } \\
\text { permissible } \\
\text { concentra- } \\
\text { tion (MPC) } \\
(\mu \mathrm{Ci} / \mathrm{ml})\end{array}$} & \multicolumn{2}{|c|}{ Offsite concentration } \\
\hline & & & & & $\left(\mathrm{Ci} / \mathrm{m}^{3}\right)$ & $\begin{array}{l}\text { Fraction } \\
\text { of MPC } \\
(\%)\end{array}$ \\
\hline $8.00 \mathrm{E}-02$ & $1.00 \mathrm{E}-01$ & $8.00 \mathrm{E}-03$ & $2.80 \mathrm{E}-05$ & $1.00 \mathrm{E}-12$ & $7.10 \mathrm{E}-15$ & 0.71 \\
\hline $8.00 \mathrm{E}-02$ & $5.00 \mathrm{E}-01$ & $4.00 \mathrm{E}-02$ & $2.80 \mathrm{E}-05$ & $1.00 \mathrm{E}-12$ & $3.55 \mathrm{E}-14$ & 3.55 \\
\hline $8.00 \mathrm{E}-02$ & $1.00 \mathrm{E}+00$ & $8.00 \mathrm{E}-02$ & $2.80 \mathrm{E}-05$ & $1.00 \mathrm{E}-12$ & $7.10 \mathrm{E}-14$ & 7.10 \\
\hline
\end{tabular}

* $X / Q$ at $300 \mathrm{~m}$.

Note: $8.00 \mathrm{E}-02=8.00 \times 10^{-2}$ etc.

Table 6.5(a) Annual inhalation dose to the

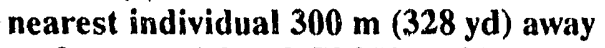
from postulated $\mathrm{Cf} .252$ accident

\begin{tabular}{lll}
\hline $\begin{array}{l}\text { Activity* } \\
\text { inhaled } \\
\text { (mCi) }\end{array}$ & $\begin{array}{l}\text { Dose conver. } \\
\text { sion factor** } \\
\text { (rem/50 yr-mCi) }\end{array}$ & $\begin{array}{l}\text { Committed } \\
\text { effective } \\
\text { dose } \\
\text { equivalent } \\
\text { (rem/50 yr) }\end{array}$ \\
\hline $5.68 \mathrm{E}-08$ & $1.85 \mathrm{E}+05$ & $1.05 \mathrm{E}-02$ \\
$2.84 \mathrm{E}-07$ & $1.85 \mathrm{E}+05$ & $5.26 \mathrm{E}-02$ \\
$5.68 \mathrm{E}-07$ & $1.85 \mathrm{E}+05$ & $1.05 \mathrm{E}-01$ \\
\hline
\end{tabular}

- Breathing rate $=8.00 \mathrm{E}+03 \mathrm{~m}^{3 / y r}$.

* "ICRP Publication 30).

Note: $5.68 \mathrm{E}-08=5.68 \times 10)^{-\theta} \mathrm{etc}$. 
APPENDIX $\mathbf{C}$

DOSE RATE AND FLUENCE INFORMATION FOR EDS-3C 
Dose rates for heistrons and gamma rays were measured using survey instruments for various positions and system conditions. Measurements were performed with and without the extra shielding on the sides of the system, both with the source in the operating position and in the retracted position. Additional measurements were made with the source cask placed against the system with the source positioned at the interface to simulate a source stuck in mid-transfar at the worst case position. The results of earlier measurements of radiation from the ends of the system are also given.

\section{METHOD OF DOSE RATE MEASUREMENT}

Neutron dose rates were measured using the Nuclear Research Corporation Model NP.2 Srioopy. Two instruments were used. The NP-2 uses a BF3 proportional counter inside a roughly 9" $x 9^{\prime \prime}$ cylindrical moderator/absorber to achieve a rem response. At a detector count rate of approximately two counts per second, a one $\mathrm{mrem} / \mathrm{hr}$ dose rate reading is produced.

Because most of the dose rates were at the extreme low end of the meter range, the meter readings were hard to read and subject to the statistical fluctuations of individual neutrons. To alleviate this problem and achieve better precision, the readings were obtained by counting pulses from the NP-2 counter output in a counter gated by a timer. For all except the interface measurements, a counting time of 1000 seconds was used. The counter-to-dose rate calibration was obtained separately for each meter using reproducible positions at which the dose rates were high enough to provide reliable direct readings of the meter face. The statistical contribution to the counting error averaged about $10-20 \%$ at the one sigma level. The calibration error of the NP- 2 is given as $15 \%$.

Gamma ray dose rates were obtained using a Bicron Corporation "micro rem" meter, calibrated by the manufacturer.

Figure F-1 shows the positions used for the dose rate measurements, measured at mid-cavity height. The position numbers refer to the following tables of dose rates.

Neutron dose rates given are the conventional rem readings multiplied by a factor of two in anticipation of the ICRP recommended change being put into the regulations (ICRP Publication 45; also see Section 5 of this report).

All the dose rates are normalized to the nominal maximum source strength of 150 micrograms. The data are given to three places for more accurate rounding. 


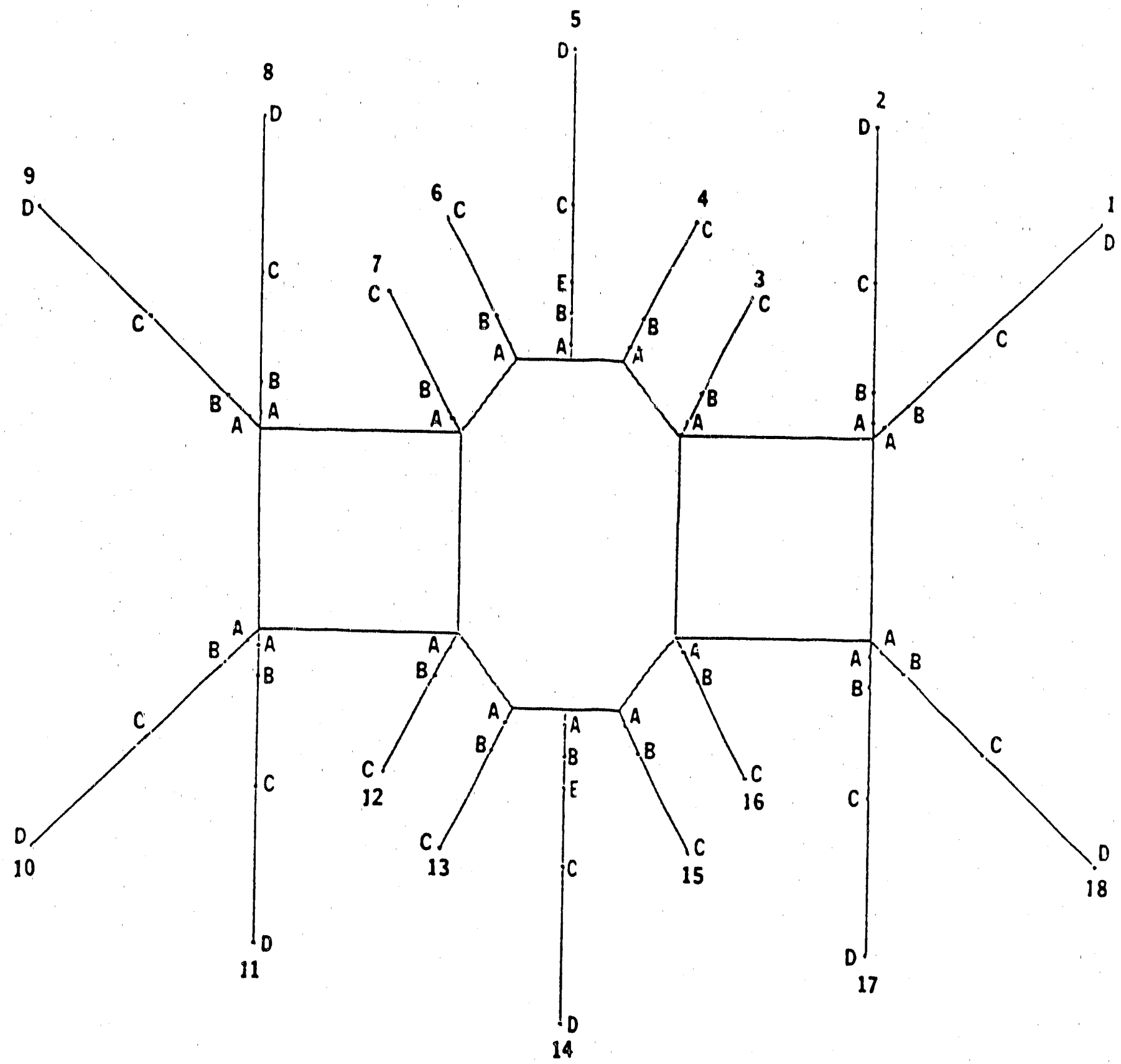

Figure F-l. Positions for dose rate measurements. 


\section{MEASUREMENT RESULTS}

Tables F-1 and F-2 show results with and without extra shielding with the source in the operating position. Tables $\mathrm{F}-3$ and F-4 give the results with the source in the retracted position. Figure F-2 shows approximate isodose contours for the data of Table F-1, with extra shielding, source in operating position.

For the transfer interface measurements, the cask was placed in contact with the system as for a source transfer. The source was then retracted to the interface position, using the neutron dose rate meter to find the maximum dose rate position. Measurements for this condition are given in Table F-5 and associated isodose contours glven in Figure F-3.

When the EDS is in use for screening baggage, the doors will be pushed partially open by the bags to permit thern to flow through. The opening is then obstructed by the bag which shields some of the neutrons and gamma rays. Individual bags vary greatly in their effectiveness as shielding, but they are on the average fairty good absorbers.

The neutron and gamma ray dose rates were measured with baggage flowing in a recycling mode. The bags were filled with clothing items, though generally not as heavily packed as bags actually seen at airports; actual heavy bags would give lower dose rates. The bag flow rate was at or above the maximum rate that the system computer can handle, 10 or more bags per minute. At this rate the doors are continuously being held partly open by the bags so that they never fully close. Lower bag flow rates result in lower dose rates.

Measurements were made on axis $100 \mathrm{~cm}$ from the entrance and exit ends of the EDS. The position of the body of an individual working as a baggage handler loading or unloading the EDS was also measured; this position is $75 \mathrm{~cm}\left(30^{\prime \prime}\right)$ from the end of the EDS and $50 \mathrm{~cm}$ (20") off axis. These measurements were made at the mid-height of the baggage passage. For comparison, measurements were also made at these same positions without baggage flow and with the doors closed. The results of these measurements are given in Table F-6. 
Table F-1. EDS-3 Dose Rates with Extra Shielding

Source in operating position

Neutron Q F multiplier = 2

Normalized to $150 \mathrm{mlcrogram}$ source

Dose Rates

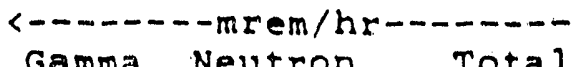

Position Gama Neutron Total

10 cm:

(A)

$\begin{array}{llll}1 & 0.043 & 0.030 & 0.073 \\ 2 & 0.056 & 0.024 & 0.080 \\ 3 & 0.173 & 0.166 & 0.339 \\ 4 & 0.037 & 0.034 & 0.071 \\ 5 & 0.037 & 0.036 & 0.073 \\ 6 & 0.025 & 0.045 & 0.070 \\ 7 & 0.142 & 0.105 & 0.247 \\ 8 & 0.031 & 0.023 & 0.053 \\ 9 & 0.031 & 0.018 & 0.049 \\ 10 & 0.037 & 0.018 & 0.056 \\ 11 & 0.037 & 0.014 & 0.051 \\ 12 & 0.161 & 0.127 & 0.288 \\ 13 & 0.031 & 0.036 & 0.067 \\ 14 & 0.037 & 0.030 & 0.067 \\ 15 & 0.037 & 0.034 & 0.071 \\ 16 & 0.204 & 0.155 & 0.359 \\ 17 & 0.043 & 0.020 & 0.064 \\ 18 & 0.043 & 0.022 & 0.065\end{array}$

$30 \mathrm{~cm}$ :

(B)

$\begin{array}{rlll}1 & 0.037 & 0.033 & 0.070 \\ 2 & 0.050 & 0.031 & 0.080 \\ 3 & 0.111 & 0.083 & 0.194 \\ 4 & 0.037 & 0.034 & 0.071 \\ 5 & 0.025 & 0.037 & 0.062 \\ 6 & 0.031 & 0.038 & 0.069 \\ 7 & 0.099 & 0.060 & 0.159 \\ 8 & 0.031 & 0.022 & 0.053 \\ 9 & 0.025 & 0.025 & 0.049 \\ 10 & 0.025 & 0.017 & 0.042 \\ 11 & 0.031 & 0.018 & 0.049 \\ 12 & 0.099 & 0.092 & 0.191 \\ 13 & 0.031 & 0.032 & 0.063 \\ 14 & 0.037 & 0.022 & 0.059 \\ 15 & 0.037 & 0.039 & 0.076 \\ 16 & 0.130 & 0.127 & 0.257 \\ 17 & 0.043 & 0.016 & 0.060 \\ 18 & 0.037 & 0.014 & 0.051\end{array}$

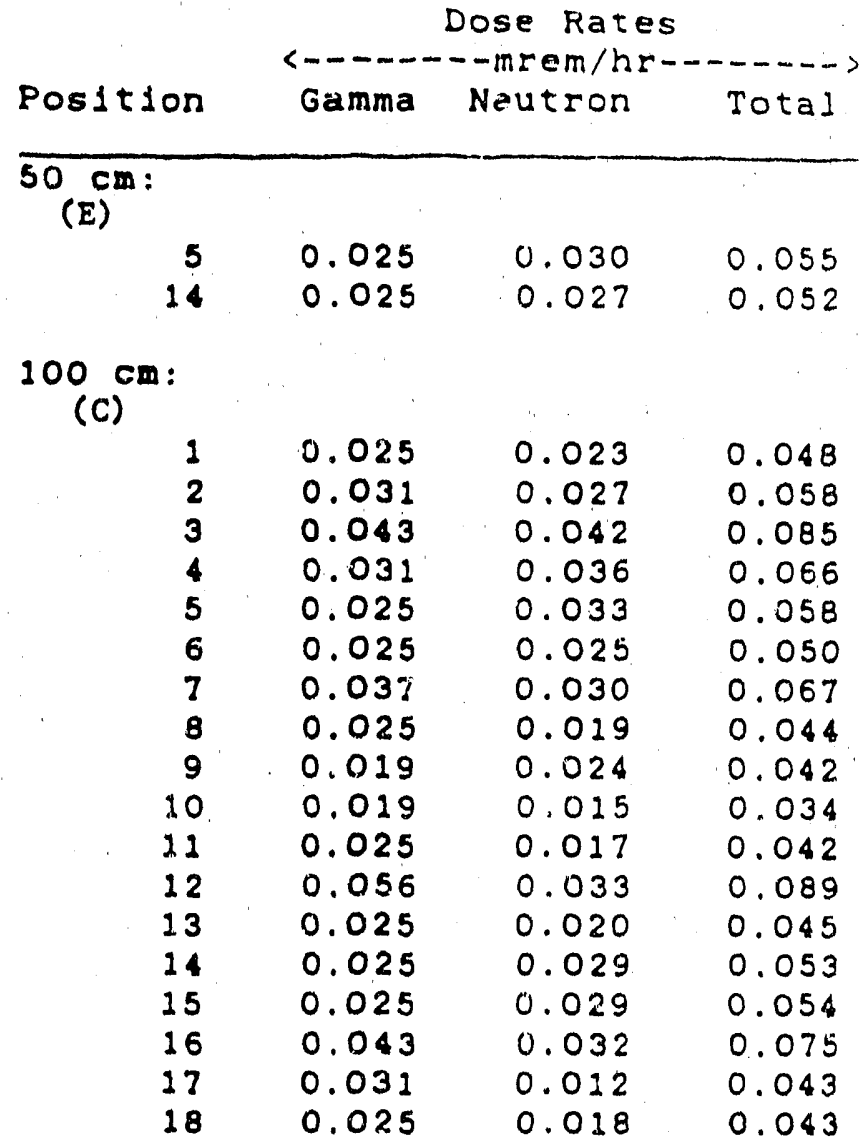

$200 \mathrm{~cm}:$

(D)

$\begin{array}{lll}0.012 & 0.023 & 0.036 \\ 0.025 & 0.031 & 0.056 \\ 0.019 & 0.025 & 0.043 \\ 0.019 & 0.022 & 0.040 \\ 0.019 & 0.020 & 0.038 \\ 0.012 & 0.016 & 0.028 \\ 0.019 & 0.016 & 0.034 \\ 0.019 & 0.013 & 0.032 \\ 0.025 & 0.012 & 0.036 \\ 0.019 & 0.009 & 0.027\end{array}$


Table F-2. EDS-3 Dose Rates, NO Extra Shielding

Source in Operating Position

Neutron $Q$ F multiplier $\quad 2$

Normalized to 150 inlcrogram source

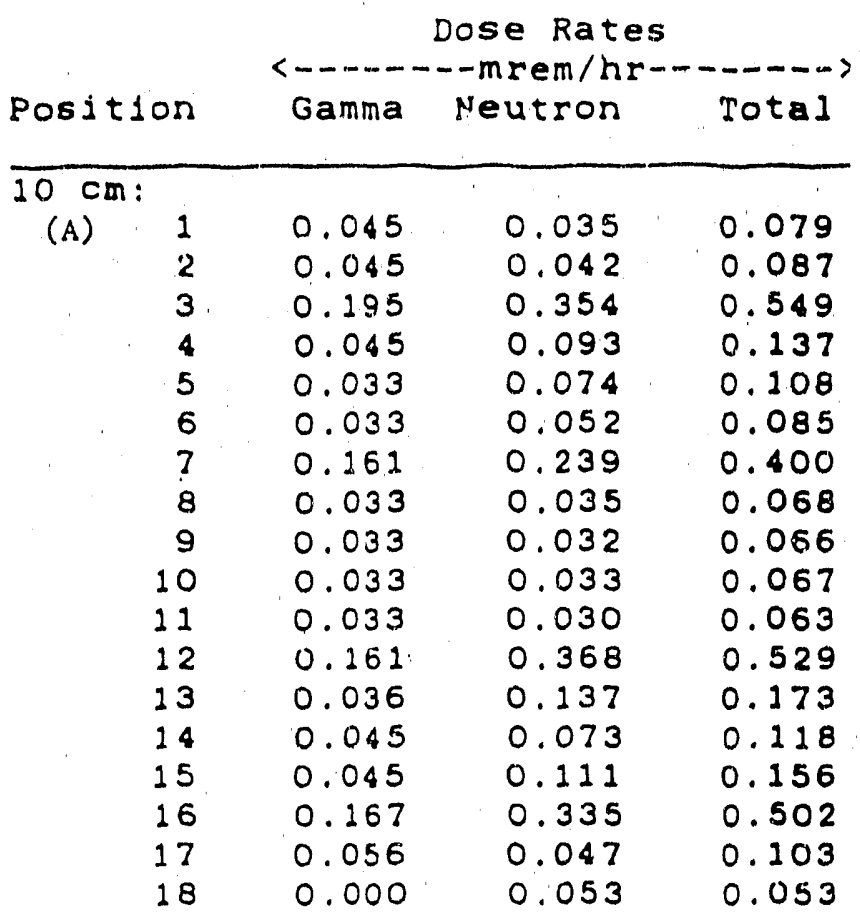

$30 \mathrm{~cm}:$

(B)

$\begin{array}{llll}1 & 0.033 & 0.019 & 0.052 \\ 2 & 0.045 & 0.037 & 0.082 \\ 3 & 0.139 & 0.184 & 0.324 \\ 4 & 0.045 & 0.067 & 0.111 \\ 5 & 0.033 & 0.042 & 0.075 \\ 6 & 0.033 & 0.037 & 0.071 \\ 7 & 0.111 & 0.116 & 0.228 \\ 8 & 0.036 & 0.041 & 0.076 \\ 9 & 0.028 & 0.036 & 0.064 \\ 10 & 0.028 & 0.033 & 0.061 \\ 11 & 0.390 & 0.059 & 0.449 \\ 12 & 0.122 & 0.210 & 0.333 \\ 13 & 0.036 & 0.083 & 0.119 \\ 14 & 0.045 & 0.047 & 0.092 \\ 15 & 0.045 & 0.072 & 0.116 \\ 16 & 0.167 & 0.210 & 0.377 \\ 17 & 0.045 & 0.045 & 0.089 \\ 18 & 0.000 & 0.067 & 0.067\end{array}$

(E)

$\begin{array}{rlll}5 & 0.028 & 0.037 & 0.065 \\ 14 & 0.033 & 0.052 & 0.085\end{array}$

$100 \mathrm{~cm}:$

(C)

$\begin{array}{rlll}1 & 0.024 & 0.033 & 0.058 \\ 2 & 0.033 & 0.057 & 0.090 \\ 3 & 0.053 & 0.061 & 0.114 \\ 4 & 0.033 & 0.074 & 0.108 \\ 5 & 0.022 & 0.026 & 0.048 \\ 6 & 0.028 & 0.030 & 0.058 \\ 1 & 0.045 & 0.068 & 0.113 \\ 8 & 0.028 & 0.022 & 0.050 \\ 9 & 0.022 & 0.041 & 0.063 \\ 10 & 0.020 & 0.033 & 0.053 \\ 11 & 0.031 & 0.031 & 0.062 \\ 12 & 0.045 & 0.090 & 0.135 \\ 13 & 0.028 & 0.061 & 0.088 \\ 14 & 0.028 & 0.051 & 0.079 \\ 15 & 0.033 & 0.062 & 0.095 \\ 16 & 0.056 & 0.073 & 0.129 \\ 17 & 0.033 & 0.059 & 0.093 \\ 18 & 0.000 & 0.045 & 0.045\end{array}$

$200 \mathrm{~cm}:$

(D)

$\begin{array}{rlll}1 & 0.017 & 0.017 & 0.034 \\ 2 & 0.022 & 0.028 & 0.051 \\ 5 & 0.017 & 0.017 & 0.034 \\ 8 & 0.022 & 0.020 & 0.042 \\ 9 & 0.013 & 0.041 & 0.054 \\ 10 & 0.013 & 0.036 & 0.049 \\ 11 & 0.022 & 0.030 & 0.052 \\ 14 & 0.020 & 0.027 & 0.047 \\ 17 & 0.022 & 0.038 & 0.061 \\ 18 & 0.000 & 0.048 & 0.048\end{array}$


Table F-3. EDS-3 Dose Rates with Extra Shielding

Source In Retracted Position

Neutron $Q F$ multiplier.

Normalized to 150 mlcrogram source

Dose Rates
Position Gamma Neutron Total Position

Dose Rates
Gamma

IO cm:

(A)

0.041
0.042

$\begin{array}{lll}2 & & 0.042 \\ 3 & 0.003 & 0.027\end{array}$

0.031

$50 \mathrm{~cm}$ :

(E)

\begin{tabular}{|c|c|c|c|}
\hline 4 & 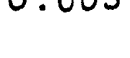 & 0.028 & 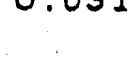 \\
\hline 5 & 0.004 & 0.036 & 0.040 \\
\hline 6 & & 0.051 & \\
\hline 7 & & 0.046 & \\
\hline 8 & & 0.054 & \\
\hline 9 & & 0.052 & \\
\hline 10 & 0.033 & 0.136 & 0.170 \\
\hline 11 & 0.042 & 0.123 & 0.165 \\
\hline 12 & 0.0 .56 & 0.163 & 0.219 \\
\hline 13 & 0.056 & C. 257 & 0.313 \\
\hline 14 & 0.139 & 2.275 & 0.414 \\
\hline 15 & 0.069 & 0.240 & 0.309 \\
\hline 16 & 0.056 & 0.164 & 0.219 \\
\hline 17 & 0.042 & 0.193 & 0.235 \\
\hline 18 & 0.028 & 0.148 & 0.175 \\
\hline
\end{tabular}

$30 \mathrm{~cm}$ :

(B)

$\begin{array}{llllll}1 & & 0.038 & & \\ 2 & & 0.047 & & 1 \\ 3 & 0.007 & 0.031 & 0.038 & 1 \\ 4 & & 0.042 & & 1 \\ 5 & 0.008 & 0.051 & 0.059 & 200 \mathrm{~cm}: \\ 6 & & 0.052 & & (D) \\ 7 & 0.009 & 0.045 & 0.053 & \\ 8 & & 0.063 & & \\ 9 & 0.007 & 0.049 & 0.056 & \\ 10 & 0.047 & 0.141 & 0.187 & \\ 11 & 0.056 & 0.158 & 0.214 & \\ 12 & 0.100 & 0.166 & 0.266 & 1 \\ 13 & 0.102 & 0.306 & 0.408 & 1 \\ 14 & 0.139 & 0.396 & 0.535 & 1 \\ 15 & 0.104 & 0.294 & 0.397 & 1 \\ 16 & 0.102 & 0.208 & 0.311 & 1 \\ 17 & 0.072 & 0.180 & 0.253 & \\ 18 & 0.045 & 0.145 & 0.190 & \end{array}$

(c)

(C)

$1 \quad 0.052$

$3 \quad 0.037$

40.066

$5 \quad 0.057$

$6 \quad 0.041$

$\begin{array}{lll}7 & 0.009 & 0.042\end{array}$

$8 \quad 0.063$

$\begin{array}{lll}9 & 0.008 & 0.061\end{array}$

$10 \quad 0.050 \quad 0.122$

$\begin{array}{lll}11 & 0.072 & 0.193\end{array}$

0.051

120.122

0.250

0.068

0.173

0.266

13

0.100

0.286

0.373

$14 \quad 0.111$

0.301

0.386

150.100

0.282

0.412

16

0.117

0.273

0.382

17

0.075

0.195

0.390

18

0.047

0.107

0.270

0.154

18

0.045

0.145

0.011

0.050

0.061

0.050

0.036

0.051

0.057

0.042

0.042

0.053

0.087

0.104

0.098

0.172

0.154

0.134

0.234

18

0.068

0.184

0.104 
Table F-4. EDS-3 Dose Rates, No Extra Shlelding

Source in Retracted Position

Neutron $Q$ multiplier = 2

Normalized to 150 mlcrogram source

Dose Rates
Position Gamma Neutron Total

$10 \mathrm{~cm}:$

(A) 1

2

3

5

6

7

8

10

11

12

13

14

15

16

17

18
0.050

0.060

0.100

0.090

0.100

0.085

0.110

0.060

0.055

$30 \mathrm{~cm}:$

(B)

$$
\begin{array}{r}
1 \\
2 \\
3 \\
4 \\
5 \\
6 \\
7 \\
8 \\
9 \\
10 \\
11 \\
12 \\
13 \\
14 \\
15 \\
16 \\
17 \\
18
\end{array}
$$$$
4
$$

$\begin{array}{ll}0.223 & 0.273 \\ 0.247 & 0.307 \\ 0.195 & 0.295 \\ 0.319 & 0.409 \\ 0.241 & 0.341 \\ 0.333 & 0.418 \\ 0.254 & 0.364 \\ 0.280 & 0.340 \\ 0.239 & 0.294\end{array}$

0.063

0.238

0.289

0.293

0.358

0.370

0.427

0.338

0.290

0.239

0.288

0.404

0.458

0.478

0.505

0.557

0.503

0.410

0.299

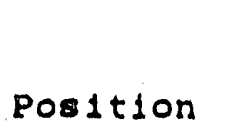

$50 \mathrm{~cm}:$

(E)

14

$14 \quad 0.150$

0.453

0.603

$100 \mathrm{~cm}$

1

2

3

4

5

6

7

8

9

10

11

12

13

14

15

16

17

18

0.090

0.181

0.105

0.276

0.160

0.369

0.120

0.391

0.150

0.376

0.130

0.175

0.115

0.075

0.374

0.377

0.309

0.204

0.271

0.381

0.529

0.511

0.526

0.504

0.552

0.424

0.279

$200 \mathrm{~cm}:$

(D)
0.055
0.070
0.090
0.085
0.060

0.125

0.156

0.204

0.175

0.118

0.180

0.226

0.294

0.260

0.178 


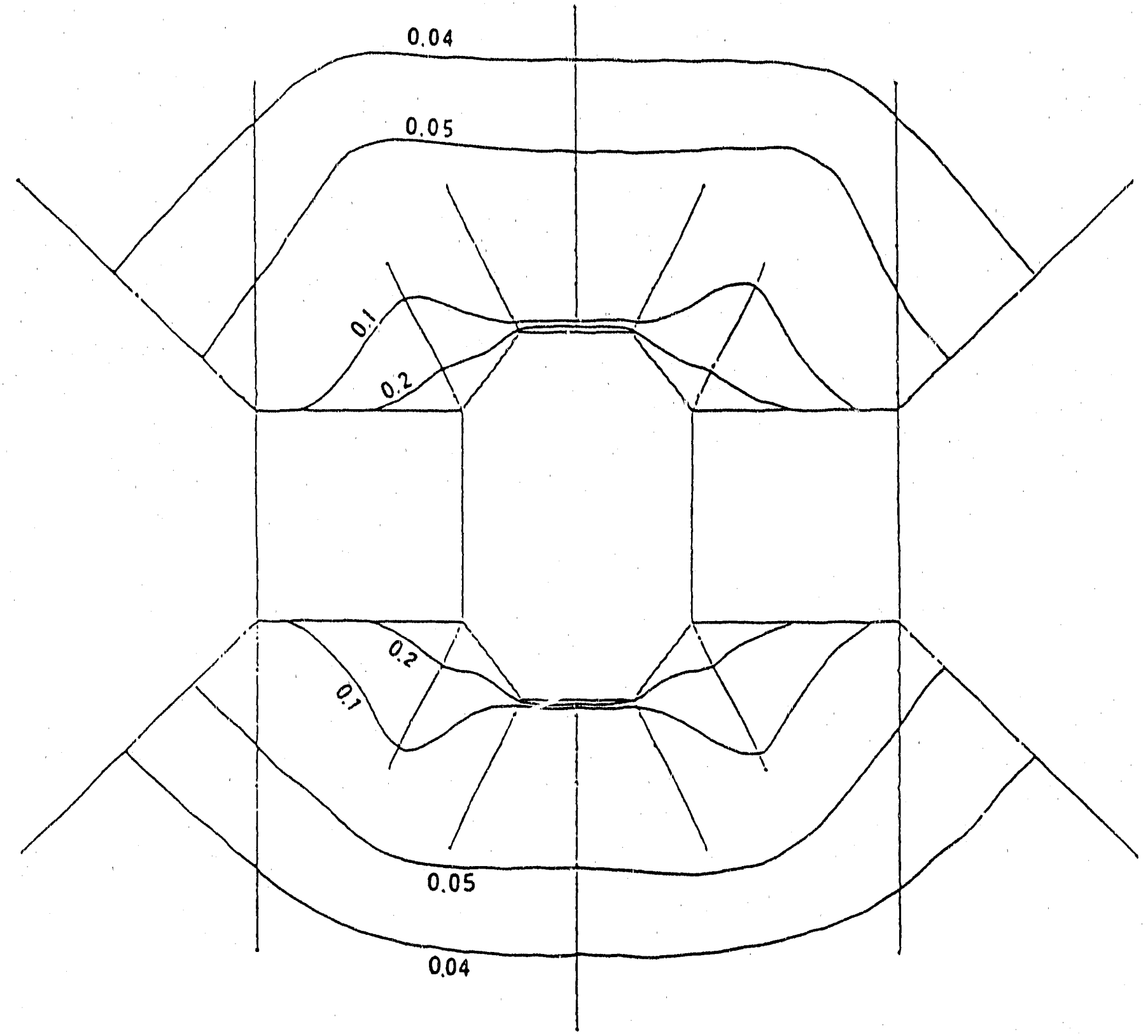

Figure F-2. Isodose contours based on dose rate measurements. 


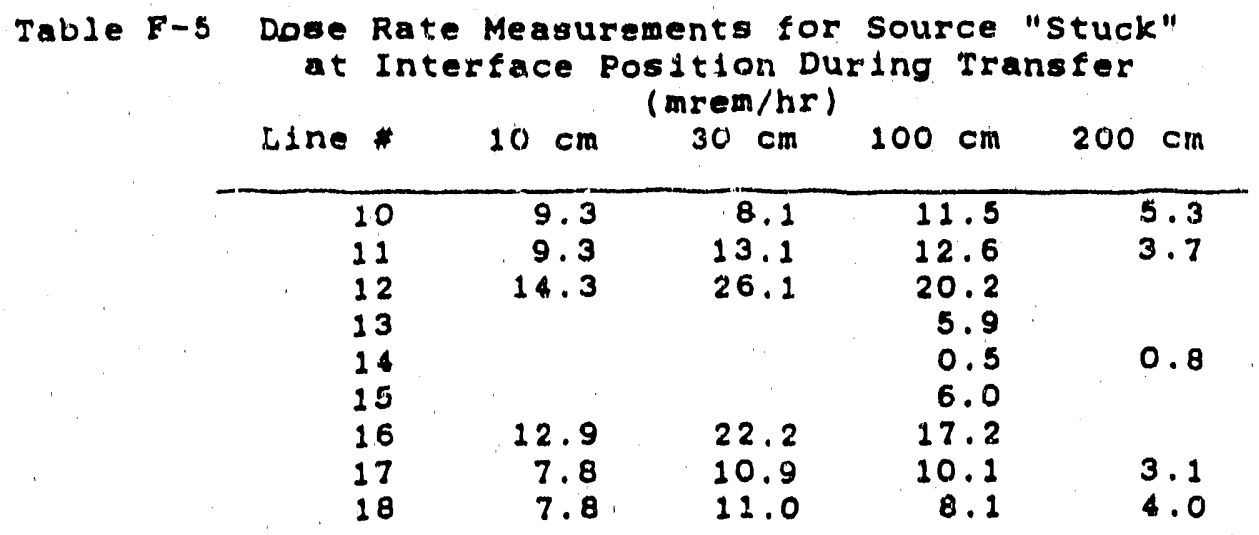

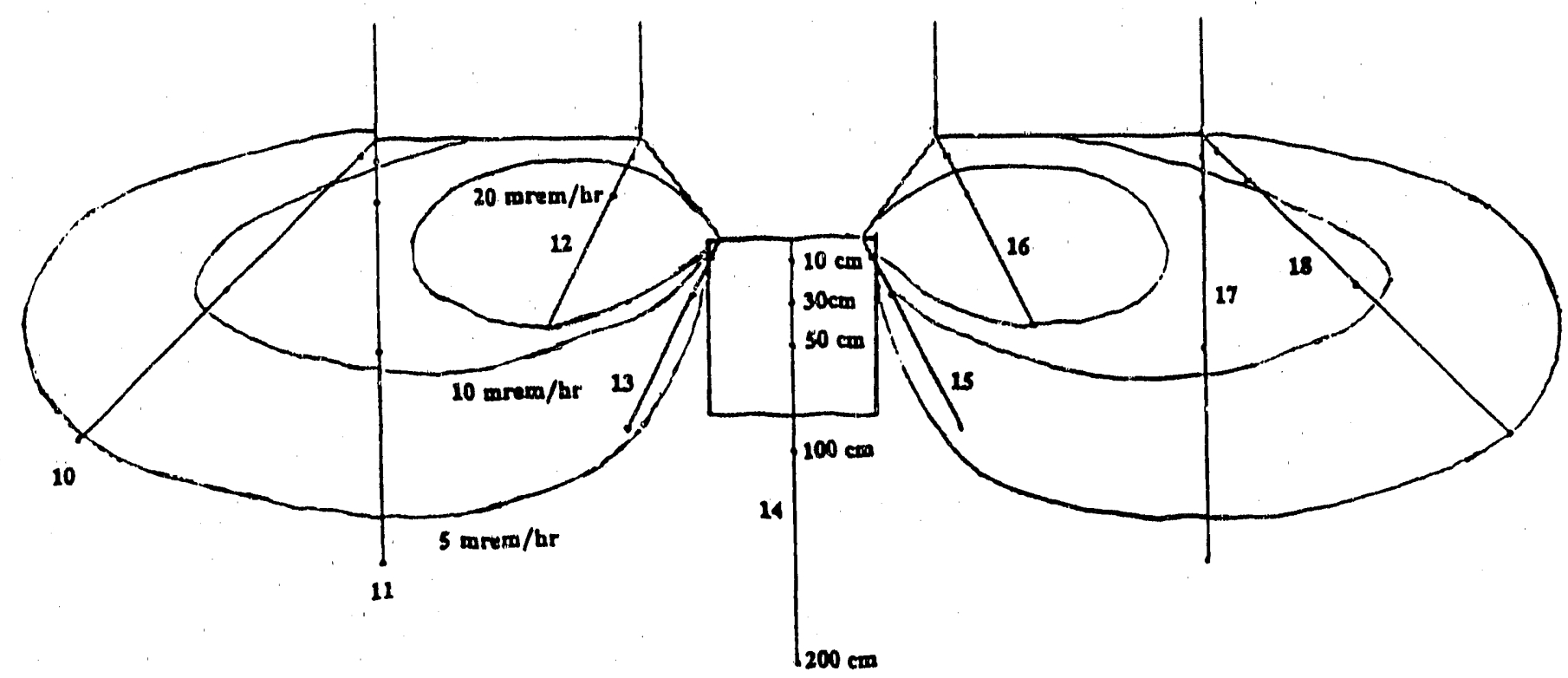

Figure F-3. Isodose contours for source "stuck" at interface of cask and EDS-3 system. 
Table F-6. EDS DOSE RATES FROM ENDS

\begin{tabular}{|c|c|c|c|c|}
\hline POSITION & $\begin{array}{l}\text { NEUTRON } \\
\text { DOSRAT }\end{array}$ & $\begin{array}{l}<<-- \text { SCAL } \\
N \text { DOSRAT } \\
Q F=2\end{array}$ & $\begin{array}{l}\text { TO } 150 \\
\text { GAMMA } \\
\text { DOSRAT }\end{array}$ & $\begin{array}{l}\text { Ug }-\rightarrow \text { ? } \\
\text { TOTAL } \\
\text { DOSRAT }\end{array}$ \\
\hline $\begin{array}{l}100 \mathrm{CM} \text {, entrance } \\
\text { Handler, entrance } \\
100 \mathrm{~cm} \text {, exit } \\
\text { Handler, exit }\end{array}$ & $\begin{array}{l}0.095 \\
0.092 \\
0.082 \\
0.053\end{array}$ & $\begin{array}{l}0.205 \\
0.199 \\
0.177 \\
0.115\end{array}$ & $\begin{array}{l}0.097 \\
0.086 \\
0.129 \\
0.065\end{array}$ & $\begin{array}{l}0.303 \\
0.285 \\
0.306 \\
0.180\end{array}$ \\
\hline $\begin{array}{l}\text { no baggage flow, } \\
100 \mathrm{~cm} \text {, exit } \\
\text { Handler, exit }\end{array}$ & $\begin{array}{l}\text { pors clos } \\
0.012 \\
0.009\end{array}$ & $\begin{array}{l}0.027 \\
0.020\end{array}$ & $\begin{array}{l}0.043 \\
0.043\end{array}$ & $\begin{array}{l}0.070 \\
0.063\end{array}$ \\
\hline
\end{tabular}




\section{APPENDIX D NATIONAL INSTITUTE OF STANDARDS AND TECHNOLOGY REPUR'T ON TNA SYSTEM}


QUANTITATIVE ASSESSMENT OF INDUCED RADIOACTIVITY IN BAGGAGE

Final Report

Covering All Phases of Interagency Agreement No. DTFA03-87-A-00008

March 31, 1989

Prepared for

Federal Aviation Administration

Technical Center

Atlantic City Airport, NJ 08405

\section{Donald A. Becker \\ Nuclear. Methods Group \\ Center for Analytical Chemistry \\ National Institute of Standards and Technology \\ Galthersburg, MD 20899}




\section{QUANTITATIVE ASSESSMENT OF INDUCED \\ RADIOACTIVITY IN BAGGAGE}

\section{INTRODUCTION}

This report is the Final Report of the Interagency Agreement between the Federal Aviation Administration (FAA) (Aviation Security Branch: ACT-360; Contract No. DTFA03-87-A-00008) and the National Institute of Standards and Technology (NIST) [formerly, National Bureau of Standards (NBS)]. The title of this project is "Quantitative Assessment of Induced Radioactivity in Baggage". The Interagency Agreement became effective In April 1987. This report covers all work accomplished during the entire 2 year project.

The overall approach used by NIST involves the evaluation of induced radioactlvity in each element in the periodic table, and consists of three phases. These phases are: 1) neutron activation calculations; 2 ) neutron fluence characterization; and 3) quantitative assessment of actual induced radioactivities.

The first phase, neutron activation calculations, involves the critical evaiuation of activation calculations for the prototype neutron activation sysiems, and the development of a complete set of expected induced radioactivities for all elements, including thermal, epithermal, and fast neutron activations. These calculations are based on neutron fluence rates and energy spectra information provided by the FAA contractor developing the prototype systems.

The second phase consists of a systematic characterization of the neutron fluence rates in the prototype baggage transporting systems. This includes a mapping of the thermal fluence rate over the baggage travel area. Further, the neutron energy spectrum characteristics will be evaluated for the baggage irradlation area. This latter Information should provide useful information on the actual epithermal and fast neutron components, if any, but may be limited due to the relatively low fluence rates expected.

The third phase of the project is the quantitative determination of actual induced radioacthity levels for a number of elements, using one or both of the FAA prototype neutron actlvation detection systems, as avallable. The data from this phase provides a verification of the calculated induced activities. The data from all three phases will then provide a comprehensive understanding of the levels of induced radioactivities to be expected from any element or combination of elements which passes through the thermal neutron activation explosive detection system (EDS). Once fully understood, the data will provide the means to systernatically establish a verified maximurn and expected induced radioactivity level for any material. 
This project required 2 years for completion. The first 6 months of work (FY87) included all of phase one and part of phase two. The second year of work included the completion of phase two and all of phase three. In addition, the FAA requested and obtained a six month no-cost extension to this project. This Final Report contains all of the information from the entire project including all information previously reported to the FAA.

\section{PHASE 1. NEUTRON ACTIVATION CILLCULATIONS}

Neutron irradiation of the various elements to form radioactive products is well understood, and the physics is relatively straightforward. The equation to calculate these values is as follows:

$$
A_{0}=\frac{m \cdot a \cdot N_{0}}{A}\left(\phi+h \sigma+\phi_{e p l} l\right)\left(1-e^{-\lambda t}\right)
$$

where:

$$
\begin{aligned}
& A_{0}=\text { initlal radioacthity, at zero decay time in units of Becquerels (disintegrations/second) } \\
& \mathrm{m}=\text { mass of element in grams } \\
& \text { a }=\text { isotopic abundance of target isstope ( } 1.00=100 \% \text { abundance) } \\
& N_{0}=\text { number of atoms/gram atomic weight }\left(6.022 \times 10^{23}\right) \text {. } \\
& A=\text { gram atomic weight of the element } \\
& \text { Qth }=\text { thermal neutron fluence rate }\left(n \mathrm{~cm}^{-2} \mathrm{sec}^{-1}\right) \\
& \sigma=\text { thermal neutron cross section in barns }\left(10^{-24} \mathrm{~cm}^{2}\right) \\
& \phi_{\text {epi }}=\text { epithermal neutron fluence rate }\left(n \mathrm{~cm}^{-2} \sec ^{-1}\right) \\
& 1=\text { resonance integral in barns }\left(10^{-24} \mathrm{~cm}^{2}\right) \\
& \lambda=\text { decay constant }\left(\sec ^{-1}\right)=\frac{\ln 2}{\text { haliflife }(\mathrm{sec})} \\
& \mathrm{t} \quad=\text { irradiation time (sec) }
\end{aligned}
$$

Thus, the factor $\frac{m \cdot a \cdot N_{0}}{A}$ calculates the number of atoms of the element being irradiated; $\left(1-e^{-\lambda t}\right)$ the saturation factor which is a characteristic of the halfife of the activation product; $\phi$ tho calculates the reaction rate per atom for thermal neutrons; and $\phi_{e p i} 1$ calculates the reaction rate per atom for epithermal neutrons. (Note: For this work the "thermal" neutron fluence and cross sections are defined as the $2200 \mathrm{~m} / \mathrm{s}$ fluence and cross sections. Further, caution must be used in calculating the eplthermal reaction rate per atom because the resonance iritegral I is highly dependent on the irradiation facility used.)

The above calculation holds for the normal case of a single activation product. In sorne cases there are multiple activation pioducts, and more complicated calculations are required. While multiple activation 
products will not be discussed in detail here, they have been taken into consideration where appropriate for the calculated activity values contained in this report.

\section{Neutron Energles: T'nermal, Epithermal. Fast}

Nuclear l'eactors '́ueled by urarlum-235 are the most common source of neutrons for irradiation. Their neutron energy spectrum consists of three components: thermal neutrons; epithermal neutrons; and fission spectrum (or fast) neutrons. A typlcal neutron spectrum plot is shown in Figure 1 , with the three components clearly shown. The fission spectrum neutrons (or fast flux) are those obtained from the fission process, Hself, with Intle or no moderation or thermalization. As these fast neutrons are moderated or slowed down, they contribute the second component to the spectrum, the eplthermal flux. Finally, when the neutrons have been totally thermalized, they have only the normal thermal energy or Maxwellian distribution (thermal neutrons). Different irradiation environments or conditions will result in different ratios of the three components, as can be seen in Figure 2, which shows the neutron energy spectrum for the National Bureau of Standards Reactor (NBSR), pneumatic tube irradlation position FIT-4. It is clear that this position is highly thermalized, with very little contribution from fast flux.

While most of the information and cross sections available in the literature have been determined for uranium-235 fission neutrons, the neutron energy spectrum for ${ }^{252} \mathrm{Cf}$ fission neutrons is virtually identically to that from ${ }^{235} \mathrm{U}$, and thus data from uranium fission neutrons can be correctly applied to californium neutrons and vice versa. In fact, a recent publication, Compendiurn of Benchmark Neutron Fields for Reactor Dosimetry [1], contains substantial information gained from ${ }^{252} \mathrm{Cf}$ measurements which is used for ${ }^{235} \mathrm{U}$ reactor dosimetry. A comparison between the unmoderated fission spectrum from ${ }^{252} \mathrm{Cf}$ and the unmoderated fission spectrum from $U^{235}$ is taken from this publication and shown as Figure 3, and demonstrates the similarity between these two fission spectra. It should also be obvious that since the neutron energy loss and thermalization processes for the two types of fission spectra are the same, the thermal and epithermal portions of the ${ }^{252} \mathrm{Cf}$ neutron energy spectrum under consideration here will be essentially identical to the ${ }^{235} \mathrm{U}$ data In the literature.

\section{D-D Neutron Generater as a Neitron Source}

The deuterium-deuterium (D-D) neutron generator is a small charged particle accelerator, which accelerates charged deuterium atoms to an energy of $150-200 \mathrm{kV}$ and directs them into a deuterium target. The D-D generator is a variation of the better known deuterium-tritium (D-T) neutron generator which produces fast neutrons with an average energy of approximately $14 \mathrm{MeV}$ which are used for a variety of purposes.

The D-D generator utilizes the nuclear reaction:

$$
{ }^{2} \mathrm{H}+{ }^{2} \mathrm{H} \rightarrow{ }^{3} \mathrm{He}+{ }^{1} \mathrm{n}+3.266 \mathrm{MeV}
$$


with an average neutron energy output of approximately $2.5 \mathrm{MeV}$ in the frontal direction [5]. However, this energy is somewhat variable depending on the neutron direction. For example, at zero degrees from frontal, a $200 \mathrm{kV}$ D-D generator emits neutrons of $3.05 \mathrm{MeV}$, compared to an energy of $2.10 \mathrm{MeV}$ at $150^{\circ}$ from frontal [5]. These neutrons are moderated and thermalized in similar ways to the fission spectrum neutrons discussed above with the advantage that no high energy neutrons above $\sim 3.5 \mathrm{MeV}$ are produced. Thus, in the highly thermalizing environment used by the contractor in the explosive detection system (EDS), the neutron energy spectrum experienced by the baggage should not be greatly different from that expected from the ${ }^{252} \mathrm{Cf}$ sysiem. If it is significantly different, the neutron energy measurements which are described below should document any such differences.

\section{Neutron Energy Measurements}

Measurements of neutron energies (i.e., thermal, epithermal, fast) with foil techniques are made with several conventions which, while not strictly accurate for all cases, are sufficlently accurate so that exceptions may be neglected. The first convention is that all ( $n$, gamma) nuclear reactlons which are due to neutron energies below $0.5 \mathrm{eV}$ (the energy below which $1 \mathrm{~mm}$ of Cd absorbs virtually all neutrons; the "cadmium cutoff") are called thermal neutrori reactions, and are defined using $\phi$ th and $\sigma$. (Note: An assumption is made here that the thermalization process occlirs at roughly room temperature $\left(20^{\circ} \mathrm{C}, 293^{\circ} \mathrm{K}\right)$ and the neutrons thus have a velocity of approximately $2200 \mathrm{~m} / \mathrm{s}$ ). The second convention is that all ( $\mathrm{n}$, gamma) nuclear reactions which occur due to neutrons which are not absorbed by $1 \mathrm{~mm}$ of $\mathrm{Cd}$ are called epithermal neutron reactions, and are defined using $\phi_{e p l}$ and the resonance integral cross section I. (Note: As mentioned previously, caution must be used when selecting the appropriate resonance integral to match as closely as possible the irradiation environments.) The fast neutrons are characterized by fast neutron reactions such as ( $n, p)$, ( $n$, alpha), and $(n, 2 n)$. These fast neutron reactions have threshold energles for their production and individual measured or calculated cross sections.

These above conventions are used throughout the nuclear scientiflc community, and will help to understand the calculations used in Phase 1 of this project as well as the measurement techniques used in Phases 2 and 3.

\section{Calculated Activities}

Calculated radioactivities from one pass in a theoretical neutron interrogation system are shown in Table 1. These values are based on a number of assumptions including the neutron fluence rate, the neutron energy spectrum, the effective irradiation time, and on the literature values for nuclear constants. Each of these assumptions is discussed below. A second table (Table 2) lists the 35 nuclear reactions which produce the highest activity levels for one or more of the decay conditions shown. This table will also be discussed more fully below. 
The general assumptions used in Table 1 are as follows:

$$
\begin{aligned}
& \text { Thermal neutron fluence rate }=1 \times 10^{6} \mathrm{n} \cdot \mathrm{cm}^{-2} \mathrm{sec}^{-1} \\
& \text { Epithermal neutron fluence rate }=2 \times 10^{4} \mathrm{n} \cdot \mathrm{cm}^{-2} \mathrm{sec}^{-1} \\
& \text { Fast neutron fluence rate } \quad=1 \times 10^{5} \mathrm{n} \cdot \mathrm{cm}^{-2} \mathrm{sec}^{-1} \\
& \text { Effective irradiation time } \quad=1 \text { second }
\end{aligned}
$$

The thermal neutron fluence rate and effective irradiation time were chosen to provide a total neutron dose close to, but slightly higher than, the neutron dose information provided by the FAA contractor (SAIC). The best estimate of the contractor for tine existing ${ }^{252} \mathrm{Cf}$ system (with two opposed $143 \mu \mathrm{g}$ sources) was a total average fluence of $\sim 5 \times 10^{5}$ neutrons $/ \mathrm{cm}^{2}$ per pass. Thus, the $1 \times 10^{6}$ thermal neutrons for a one second. irradiation used in calculations for the theoretical interrogation system as shown in Table 1 should always produce a calculated activity which is somewhat higher than expected in the aciual system(s).

The nuclear constants used in these calculations were generally those contained in Erdtmann's Neutron Activation Tables [2]. All activation products with halfives greater than 0.1 second were considered.' Initial activities shown in Table 1 were obtained from this compllation, with modifications for the fluence rates given above. In addition, two computer programs were written in the BASIC language on a CP/M microcomputer to calculate initlal activities and decayed activities from the basic nuclear constants. Using these computer programs, checks were made of the calculated activities found in Reference 2, and with a few exceptions (most of which were typographical errors in the book) the data agreed very well.

It should also be noted that these calculations assumie zero neutron self-shielding effects, which is the appropriate "worst case" assumption. Elements with high neutron cross sections and/or resonance integrals (e.g., greater than $\sim 10$ barns) begin to see an effect called neutron self-shielding, where the interior of a thick sample "sees" fewer neutrons than the exterior of the sample, due to neutron absorption by the exterior. Thus, one gram of gold in a spherical shape would activate much less than, say, one gram of gold as a thin gold plating on the surface of many articles scattered throughout a container. This effect would reduce the expected activities of many of the activation products listed in Table 1, but is an uncontrollable variable. As a consequence, the zero neutron self-shielding assumption is used.

In Table 1, only reactions which produced initial activities greater than 0.001 Becquerel/gram of element (disintegration $/ \mathrm{sec} / \mathrm{g}$ ) are shown. This level was chosen in order to prevent the table from becoming totally useless due to excessive size, yet contain all activities that are significant. The basis for choosing the value of $0.001 \mathrm{Becquerel} / \mathrm{g}$, was the levels of naturally occurring radioactlvity found in food. For example, ${ }^{40} \mathrm{~K}$ is a naturally occurring radioactive isotope which is contained in essentially all food that we eat. It has an abundance of $0.0117 \%$, a halflife of $1.25 \times 10^{9}$ years, and a high energy gamma-ray line as well. Since ${ }^{40} \mathrm{~K}$ 
has a specific acthity of 838 plcocuries/gram of potassium, and, for example, peanuts contain $0.674 \%$ potassium [3], one gram of peanuts has $5.65 \mathrm{pCl}$ of ${ }^{40} \mathrm{~K}$ or 0.209 Becquerels (dps). It seems reasonable to consider an amount of induced radloacthity equal to $1 / 100$ that contained naturally in a single peanut to be negligible. It should alsc be noted that the naturally occurring radionuclides ${ }^{14} \mathrm{C}$ and ${ }^{3} \mathrm{H}$ add a further $50 \%-100 \%$ of dose to that due to the ${ }^{40} \mathrm{~K}$ disintegrations in foods.]

The data in Table 1 does not contain information on the type of emissions from the varlous activation products, because of the varied potentlal use of this information. Thus, a nuclear reaction which has a relatively high acthity level but no gamma-ray ernission may be significant for some considerations (e.g., ingestion of food) but not others (e.g., baggage handling). Information on the particle and gamma-ray emission abundances $a^{n-1}$ energies of the various radioisotopes are readily avallable and can be factored in when this information is required for health physics purposes.

Table 2 contains a listing of the thirty-five activation products from Table 1 whose actlvity exceeded one of these criteria: $>100$ Becquerel/g at zero decay; $>10$ Becquerel/g at 1.0 minute decay; $>1$ Becquerel/g at 1.0 hour decay. These times were selected to lllustrate: at zero decay, the maximum activity produced; at one minute deczy, an actlity level which may be relevant for baggage handiers; and at one hour decay, most likely the earliest time at which an ainine passenger could recelve their baggage after completion of a flight. Ii can be seen from Table 2 that in only three cases, for indium, europium and dysprosilum (three relatively rare elements), would the radioactivity induced in a gram of the pure element after 1 hour decay exceed the amount of natural radioactivity in a 2 ounce bag of peanuts. It should also be noted that all of the activities shown in Table 2 were calculated by computer and the results agreed well with the data in Reference 2.

\section{PHASE 2. EVALUATION OF NEUTRON FLUENCE RATES AND ENERI: IES IN THE BAGGAGE IRRADIATIONSYSTEMS}

The second phase consists of a systematic characterization of the actual neutron fluence rates experienced by baggage passing through the two experimental thermal neutron explosive detection systems (EDS). Thero were a total of four irradlations in the EDS systems to measure the neutron fluences and energies seen by folls passing through the systems. Two Irradiations used the ${ }^{252} \mathrm{Cr}$ EDS, and two irradiations used the deuterium-deuterium (D-D) neutron generator EDS system. All irradiations and the results obtained are discussed in detall below, after a brief description of the techniques used for these determinations. 


\section{Neutron Measurements Usina Foll Techniques}

The measurement of a neutron field using the foll actlvation technique is both relatively simple and fairly accurate. The varlous elements which may be used as Indicator folls undergo nuclear reactlons according to the previously described equation when passed through an EDS system or other neutron field, and they are then counted on a callbrated radloactivity detector in order to accurately determine the induced number of disintegrations per unit time.

The equation used earller in this report for the activation calculations can be rearranged as follows:

$$
\phi=\frac{C \cdot A}{m \cdot a \cdot N o \cdot \sigma\left(1 \cdot e^{-\lambda K}\right) \varepsilon G}
$$

whiere:

$$
\begin{aligned}
& \phi \quad=\text { neutron fluence rate }\left(n^{\bullet} \mathrm{cm}^{-2} \mathrm{sec}^{-1}\right) \text { (for the neltron energy range of interest) } \\
& \mathrm{C}=\text { net detector counts pe: second of the gamma-ray of interest corrected for decay, } \\
& \text { deadtime and pulse plleup }\left(\sec ^{-1}\right) \\
& A=\text { gram aiomic weight of the element } \\
& \mathrm{m}=\text { mass of element in grams } \\
& \text { a }=\text { isotopic abundance of target isotope }(1.00=100 \% \text { abundance }) \\
& N_{0}=\text { number of atoms/gram atomic weight }\left(6.022 \times 10^{23}\right) \\
& \sigma=\text { neutron cross section in barns }\left(10^{-24} \mathrm{~cm}^{2}\right) \text { (for the neutron energy range of interest) } \\
& \lambda=\text { decay constant }\left(\sec ^{-1}\right)=\frac{\ln 2}{\text { halfife }(\mathrm{sec})} \\
& \mathrm{t}=\text { irradiation time (sec) } \\
& \varepsilon \quad=\text { detector efficiency for the gamma-ray of interest and the counting geometry used to } \\
& \text { obtain C } \\
& \mathrm{G}=\text { gamma-ray abundance (number of emitted } \gamma \text {-rays at the energy of interest per } \\
& \text { disintegration) }
\end{aligned}
$$

The above equation can be used with the $2200 \mathrm{~m} / \mathrm{s}$ (thermal) rieutron cross section (oth) and the actlvity found in a bare foll after subtraction of the actlyity determined in a cadmium covered foll $\left[C=\left(C_{b a r e}-C_{c d}\right)\right]$ to establish the thermal neutron fluence rate in a system. The same equation can be used with the resonance integral (I) and the activity found in a cadmium covered foil $\left(C_{c d}\right)$ to estimate the eplthermal neutron fluence rate in a system. However, it should be noted that the epithermal neutron cross sections vary considerably for different elements, and most elements have high resonance absorption peaks in their activation spectrum. Therefore, the uncertaintles associated with the epithermal fluence values are correspondingly greater. For fast neutrons, the same equation is used but an entirely different nuclear reaction is used, with a neutron 
energy threshold and specific reaction cross section. These calculations are used below to measure neutron fluence rates in the two EDS systems.

The use of multiple folls as was done for the irradiations described later allows an inference of both the thermal and epithermal fluences, based on the following derivation:

Since

$$
(\phi \sigma)_{\text {total }}=\left(\phi_{\text {th }} \sigma \text { th }+\phi_{\text {epl }}\right)
$$

then

$$
\begin{aligned}
& =\phi_{\text {th }}\left[\frac{\phi_{\text {th }} \sigma_{\text {th }}+\phi_{\text {epl }}}{\phi_{\text {th }}}\right] \\
& =\phi_{\text {th }}\left[\sigma_{\text {th }}+\frac{\phi_{\text {epl }}}{\phi_{\text {th }}} 1\right]
\end{aligned}
$$

Therefore, if, as in NBSR RT-4, the $\phi_{\text {epl }}=0.02 \phi_{\text {th }}$ is known, then for a well characterized facllity llke RT-4 the epithermal contribution can be estimated by $\phi \sigma=\phi$ th $[\sigma \mathrm{th}+0.02 \mathrm{l}]$, and the thermal fluerice can be estimated using a bare foll, by use of the of $=\sigma$ th +0.021 relationship $[04=$ total (thermal + epithermal) cross section, in barns].

Thus, the epthermal fluence fractlon, $\phi_{\theta p} / \phi_{t h}$, can be roughly estimated by irradiating several elemerital folls with differing resonance integral cross sections $I$, and solving the calculations for various epithermal fractions until the thermal fluence values agree. This was done for the first two irradiations described below, and reasonable values for the epthermal fraction were obtained. In the second two irradiations, actual cadmium covered foll irradiations were made using gold folls and the gold-cadmium ratio determined for both the $D-D$ and ${ }^{252} \mathrm{Cf}$ systems, as well as for several of the NIST nuclear reactor irradiation positions.

\section{Irradiation \#1 - Californium - 252 System}

The first foll irradiation in an EDS for this project took place on July 6, 1987, using the ${ }^{252}$ Cf EDS system as set up for testing at the San Francisco airport. A package of three foils, including one each of gold, tungsten and copper, were irradiated by SAIC. The folls were positioned inside a piece of luggage and passed 10 times through the EDS. The ten passes were completed at 22:50 EDT on July 6, 1987, and that time was taken as the effective To. Thus all foil activities were decay corrected to that time.

Unfortunately, transfer of the irradiated folls to NIST by SAIC ran afoul of an air flight which was cancelled en route, and so we were not able to obtain the folls until $\sim 40$ hours after the end of irradlation. Two of the folls, gold and tungsten, could still be counted. The copper-64 activity, with a 12.7 hour half-lfe, was not able to 
be used. The loss of the copper activity is particularly unfortunate because the small resonance integral for the copper provides a good measure of the thermal neutron fluence without significant activation by epithermal neutrons.

Results obtalned from this first Irradlatlon are given in Table 3. As can be seen from this table, the gold and tungsten foil data agree reasonably well, and provide an estlimate of the total neutron fluence for the ${ }^{252} \mathrm{Cf}$ system of $\sim 7 \times 10^{5} \mathrm{n} \cdot \mathrm{cm}^{-2}$ per pass ( $\pm 20 \%$ relative). Evaluation of the apparent epithermal fraction provided an'estlmate of $6 \%$ eplthermal neutrons. This I apparent epithermal fraction has a higher uncertainty than does the second Irradiation, because no copper daia was avallable to confirm the true thermal neutron fluence value. Note also that the fluence rate given above is for the date of irradlation only, July 6, 1987, due to the decay of ${ }^{252} \mathrm{C}$ with a 2.64 year halfilfe. (Note: The actual fluence values shown in Tables 2 and 3 have been recalculated using tho gold-cadmium ratio data obtained from irradlations 3 and 4 . This data now provldes an improved evaluation of the epithermal neutron contribution, and this will be discussed more completely under the Neutron Energy Measurements section in this report.)

\section{Irradlation \#2-U-D Neutron Generator System}

The second foll Irradlation took place in the prototype D-D neutron generator EDS system. The foil samples were irradlated between 15:56 and 19:39 (EDT) on September 21, 1987, by passing them through the EDS systern a total of 100 times by the FAA contractor, SAIC. A total of five different folls were used, the copper, gold and tungsten used previously plus folls of nickel and titanium in an attempt to measure the fast neutron fluence.

According to P. Ryge of SAIC, the five folls were kept in the original mailing envelope, placed inside a suitcase near the top, with the remainder of the suitcase filled with "normal" travel items. This sultcase was then passed through the system 100 times over the approximately 4 hour period. The series of passes were expected to be representative of typical rieutron exposure in an EDS system.

Since the irradiation process took such a long time (approximately 4 hours) an "average" end-of-Irradlation time of 18:00 on September 21, 1987 was used for the calculations. In order to evaluate what effect on the results this long irradlation period might have, a calculation was also made for the hypothetical situation of a continuous irradiation of 4 hours duration. The results of this calculation for copper-64 (the worst case) show only a small effect of about $10 \%$ (for copper; less for tungsten and gold), and this data is included with all data from this second irradiation. This small effect was considered to be within the measurement uncertainty, and thus all other calculations assume the single Irradiation at 18:00 hours. 
The results from this second irradlation are given in Table 4. A transfer tirne to NIST of approximately 15 hours for the folls permitted measurement of the copper-64 radloactivity, and this provided a better estimate of both the neutron fluence/pass and the epithermal fraction. An estimate of the total neutron fluence for this D-D neutron generator system is about $3 \times 10^{5} \mathrm{n} \cdot \mathrm{cm}^{-2}$ per pass $( \pm 20 \%$ relatlve). Evaluation of the eplthermal fraction provldes a very approximate value of $5 \%$ eplthermal neutrons.

Measurement of the radloactlitty in the fast neutron folls (nickel and titanium) for Irradlatlon \#2 provided no detectable radloactlvity above background from fast neutron actlvation. This is very llkely due to the very low fast neutron component in the D-D EDS system. An additional atternpt to measure the fast neutron component was carrled out in the third Irradlation, and is described in that section.

\section{Irradlation \#3-D-D Noutron Generator System}

The third EDS irradlation took place again in the prototype D-D neutron generator system which was at that time located at the Los Angeles International Alrport. The foll samples were flxed to a cardboard holder in a sealed package, which was then placed unopened in a "packed" suitcase and irradlated for 100 passes through the system by SAIC. The Irradlations took place between 6:00 and 8:00 pm (EST) on Monday, December 7, 1987. A total of four different folls were in the package ( $\mathrm{Au}, \mathrm{NI}, \mathrm{Cu}, \mathrm{W}$ ) plus a cadmium covered goid foll. According to $P$. Ryge of SAIC, the package was handled in a way to be "representative of normal exposure to the baggage transfer EDS systems."

Based on the data developed for irradlation \#2 and described there, the end of irradlation time (Tzero) used was 8:00 pm EST, Decernber 7, 1987.

The results from this third irradiation are given in Table 5. Again the transfer time for the folls package to NIST was about 15 hours, providing good counting data for the gold, copper and tungsten folls. The measured total neutron fluence per pass was approximately $2.2 \times 10^{5} \mathrm{n}^{-} \mathrm{cm}^{-2}$, with an uncertainty of approximately $20 \%$ (relattve).

Agaln, there was no measurable radloactivity above background for the nickel foll, due no doubt to the very small fast neutron component in the EDS systems. A calculation of the minimum radloactivity detectable in the counting system used gave a value of $<2 \times 10^{3}$ fast neutrons/pass, which is less than $1 \%$ fast neutrons.

A gold-cadmium ratlo was measured in this irradlation, and these results will be discussed below under the section entitled Neutron Energy Measurements. 


\section{Irradiation \#4. Callfornlum-252 System}

The fourth and final EDS irradiation of this project took place between 08:47 and 11:25 on March 29, 1988. The sample materials had been sent to P. Rygge of SAIC flxed in position inside of a largle corrugated cardboard container. This container is shown schematically in Figure 4, and was the largest possible container still able to fit through the EDS system.

The system used for this fourth Irradlatlon was the ${ }^{252} \mathrm{Cf}$ system, which was set up and working at the San Franclsco alrport. The box was passed unopened through the system 100 times. A transfer time of approximately 28 hours dellvered it to NIST at approximately 16:00 hours, March 30, 1988.

The box contained a total of elght bare gold folls distributed as shown in Figure 4, a ninth gold foll encapsulated In cadmium $(0.1 \mathrm{~cm}$ thick) for the cadmlum ratio measurement, a copper foll, and a set of three small pure bismuth pellets. The large number of gold folls in this irradlation were used to measure the neutron fluence varlation throughout the Irradlatlon volume. Positions were selected to represent the extreme locations possible in the EDS systems.

The results from Irradlation \#4 are given in Tables 6 and 7. Table 6 prov des the measured neutron fluence per pass for both copper and gold, and agreement between the two is very good. There is also good agreement with the gold and tungsten fluence values in Table 3, made using only ten passes in the ${ }^{252} \mathrm{Cf}$ system in the first EDS Irradlation. Initiaily, th was puzzling that there did not seem to be an appropriate reduction in the !ast ${ }^{252} \mathrm{Cr}$ irradlation to account for decay of the sources, but upon calculation, the amount of decay expected is only about $17 \%$, which could effectively be masked due to the large variation of relative fluences in the irradiation container due to position as discussed below (almost 50\%).

Table 7 gives the results from the measurement of neutron fluence vs. position in the irradlation container. From this data, it is apparent that the neutron fluence is about $30 \%$ higher in the vertical center portion of the irradlation cavity (Figure 4, A-3 to A-5) compared to the vertical stdes of the cavity (Flgure 4, A-1 to A-2, and $A-4$ to $A-6$ ). The top-to-bottom fluence variation is much smaller, particularly at the edges. It should also be noted that this box was filled with several full boxes of paper towels and some additional crumpled paper towels, to add stability and weight for the handling and irradlation processes. The effectlve density and composition was estimated to be a little less dense than usual baggage, but not appreclably different from the contents of a suitcase primarily packed with clothing.

\section{Neutron Eneray Measurements}

Neutron energy characterization was made of the EDS systems by using gold-cadmium ratio measurements for estimating the epithermal neutron fluences and with several atternpts at measuring fast neutrons through 
use of threshold foils. These two methods are discussed senarately below. The cadmium ratio of any element is defined as the ratio of the raoibactivity induced in a barts ic." of the element to the radioactivity induced in a similar foil of the same element which is located in exactly the same positions, except completely encased with interlocking covers of $1 \mathrm{~mm}$ thick cadrnium metal. Thus, for gold the cadmium ratio $\mathrm{Au}(\mathrm{Cd})$ is defined as:

$$
A u(C d)=\frac{A_{\phi}(\text { bare })}{A \phi(C d)}
$$

where:

$$
\begin{aligned}
& A \phi(\text { bare })=\text { saturated activity at zero decay for the bare foil, and } \\
& A \phi(c d)=\text { saturated activity at zero decay for the cadmium covered foil. }
\end{aligned}
$$

Gold-cadmium ratio measurements were made in irradiations 3 and 4 . This information plus similar measurements for three irradlation positions in the NIST nuclear research reactor (fueled by ${ }^{235} \mathrm{U}$ ) are shown in Table 8. It should be emphasized that while gold-cadmlum ratio and fluence measurements are by far the most commonly used foil measurements in the nuclear field, and the high sensitivity made gold an obvious choice for this EDS siudy, such measurements are highly dependent upon specific folls used due to neutron self-shielding effects and the very high resonance cross sections for gold-197 (the mono-nuclidic stable isotope of gold). In this study, the gold-cadmium ratio for the ${ }^{252}$ CF EDS was very similar to the NBSR RT-3 Irradiation facility, and thus the calculated fluence measurements could be compared directly to the known fluense values for this NBSR facility. What was somewhat surprising was that the neutron energy spectrum for the D-D EDS was substantially "rarder" (i.e., had more energetic neutrons and a lower Au(Cd) ratio) than that from the ${ }^{25 \hat{C}} \mathrm{Cf}$ EDS. When corrected for neutron self-shielding in the gold folls [8], the D-D system measurement indicated that $48 \%$ of the neutrons had energies above about $0.5 \mathrm{ev}$ (the cadmium cut-off energy), versus $29 \%$ eplcadmium neutrons for the ${ }^{252} \mathrm{Cf}$ EDS. (Note: The NBSR RT-3 irradiation facility had $26 \%$ epicadmium neutrons.)

In addition to the epithermal (l.e., epicadmium) measurements made with cadmium ratios, measurements were attempted using fast neutron threshold foils of titanium and/or nickel in irradiations number 2 and 3 . All such attempts gave results in which the fast neutron product, if present, could not be detected above the background radioactivity, even with very long counts. This was not a surprise since the actual number of fast neutrons above about $2 \mathrm{MeV}$ (the threshold for these fast neutron reactions) was expected to be very small. The data obtained from the best count (from a nickel foil) was used to calculate a "less than" value, which showed that there was $<2 \times 10^{3}$ fast neutrons $/ \mathrm{cm}^{2} /$ pass (above the $2.2 \mathrm{MeV}$ threshold for this specific nuclear reaction). An actual measurement of the ${ }^{58} \mathrm{Co}$ radioactivity from the ${ }^{58} \mathrm{Ni}(\mathrm{n}, \mathrm{p})^{58} \mathrm{Co}$ nuclear reaction on a nickel 
foil irradiated in the NBSR RT-3 facility, when normalized to the $2.2 \times 10^{5} \mathrm{n} \cdot \mathrm{crn}^{-2}$ expected for a single pass in the D-D EDS, gave a value of 0.001 count/3 hours counting time. Even with 100 passes through the system, the expected 0.1 count/ 3 hours would be totally lost in the background of the lowest background counting system avallable. Thus, direct fast neutron measurements using threshold foils are just not possible for either EDS system unless the entire counting system is brought to the EDS system so short-lived radioactivities could be attempted, and possibly could not be measured even then due to absolute sensitivity limitations.

\section{PHASE 3. QUANTITATIVE DETERMINATION OF INDUCED RADIOACTIVITY LEVELS}

In order to verify the calculated activity values reported in Phase 1 of this study, actual measured activity levels were determined in elements exposed to the appropriate neutron fluences. This was accomplished using two different methods as described below.

Method 1 entailed the counting of induced radioactivity in pure element folls actually passed through the ${ }^{252} \mathrm{Cr}$ EDS and the D-D EDS. There are very few elements with both the sensitivity and the appropriate halfife to allow such measurements without actually moving an entire germanium detector and counting system to the airport location where the EDS was located. Three elements (copper, tungsten and gold) were used to develop this data, and the results are found in Table $9\left({ }^{252} \mathrm{CF}\right.$ EDS) and Table 10 (D-D EDS).

In addition, Method 2 was employed. This method utilized the NIST nuclear reactor (NBSR) RT-3 irradiation facility, shown in Table 8 to have neutron fluence characteristics very similar to the ${ }^{252}$ Cf FnS except that the neutron fluence is about $1.3 \times 10^{8}$ times higher. A sample of well characterized material (NIST Standard Reference Material 1633, Coal Fly Ash), which has a large number of known elemental concentrations was irradiated in RT-3, counted, and the actual induced radioactivities measured were corrected to the $8 \times 10^{5}$ $\mathrm{n} \cdot \mathrm{cm}^{-2}$ fluence expected for one pass through the ${ }^{252} \mathrm{Cf}$ EDS. These results are found in Table 11 for 13 additional elements.

In all cases the actual measured activity levels found corresponded closely to the expected activity levels as found in Table 1 and shown again in Tables 9 through 11.

In addition to the above, one case merited special consideration. In Table 1, for the element bismuth $(Z=83)$, a special case is noted in a footnote. This concerns the potentlal problem of trie bismuth-210 activation product decaying to polonium-210, which is an alpha emitter. This would most probably be ignored except that a common over-the-counter medicine contains large quantities of bismuth. Since alpha particles are easily stopped by something as thin as a sheet paper, they are usually only of concern when they may be inhaled (as radon) or ingested through food or medication. 
It was therefore thought useful to consider the effect of neutron exposure in an EDS to the production of polonium-210 from blsmuth. This was done in two ways: first, a detalled calculation was made following the production of bismuth-210, beta decay to polonium-210, and the alpha decay of polonium-210. Second, several pellets of pure bismuth were irradiated in Irradiation \#4, with 100 passes through the ${ }^{252} \mathrm{CF}$ EDS. This bismuth was then dissolved and the bismuth/polonium precipitated out, recovered, and counted in an alpha detection system.

The results of the above bismuth evaluations indicated that the amount of polonium-210 produced in these EDS systems is minimal. Calculation showed that 100 grams of bismuth passed through a neutron fluence of $1 \times 10^{6} \mathrm{n} \cdot \mathrm{cm}^{-2}$. would produce a maximum of 0.0004 decays of polonium-210 per second (d/s). Measurement of the radlochemically prepared bismuth/polonium sample (blsmuth welght $=150.6 \mathrm{mg}$ ) which had been passed 100 times through the ${ }^{252}$ CF EDS gave no alpha counts detected for a 100 minute count, confirming the calculation of minimal production of polonium-210.

\section{SONCLUSION}

Although the initial FAA project was for the evaluation and characterization of only the ${ }^{252} \mathrm{Cf}$ EDS, soon afterwards it became apparent that for a substantial portion of the project period only the D-D system was avallable for Irradlations. This, coupled with the expressed interest of FAA in the characteristics of both system, fostered the expansion of the project (with no additional funding) to both the ${ }^{252} \mathrm{Cf}$ and D-D systems as described below.

All three phases of this project as described in the Introduction have been completed. In Phase 1, calculations were made for the neutron irradiation of all elements under conditions similar to that found in the EDS systerns, and these data are found in Tables 1 and 2. In Phase 2, the neutron fluence rates, neutron distributions, and neutron energy characteristics of both of the EDS systems were systematically evaluated and data recorded In Tables 3 through 8. In Phase 3, quantitative measurements of induced radioactivity in 16 elements were made and good agreement with the calculated activities from Table 1 found. These data are found in Tables 9 through 11 .

The combiried information found in this report provides a comprehensive understanding of the neutron irradiation characteristics of these two EDS systems, and provides as well the information necessary to quantitatively evaluate the induced level of radioactivity which would be produced in any specified materlal passing through a thermal neutron EDS system. 


\section{BEFERENCES}

1. J. A. Grundl and C. M. Eisenhauer, Compendium of Benchmark Noutron Flelds for Beactor Dosimetn NBSIR 85-3151, U. S. Dept. of Commerce, Washington D. C. (1986).

2. G. Erdtmann, Neutron Actwation Tables, Verlag-Chemie Publishing Co., NYC (1976).

3. C. T. Young, Nuts, In Klrk-Othmer Concise Encyclopedia of Chemical Technoleay, Wiley-Interscience Publishing Co., NYC (1985), p. 807.

4. W. N. McElroy, et. al., HEDL Progress Report (October, 1971).

5. S. S. Nargolwalla and E. P. Frzybylowicz, Actwation Analysis with Neutron Generaters John Wiley \& Sons, NYC (1973).

6. ASTM Annual Book of Standards, Volume 12.02, Method E262-86, "Standard Method for Determining Thermal Neutron Reaction and Fluence Rates by Radloactivation Techniques, " ASTM, Philadelphla, PA (1987).

7. D.A. Becker and P.D. LaFleur, "Characterization of a Nuclear Reactor for Neutron Activation Analyses," J. Radioanal. Chem. 19, 149-157 (1974).

8. N.P. Baumann, "Resonance Integrals and Self-Shielding Factors for Detector Folls," Report No. DP-817, Savannah River Laboratory (1963). 


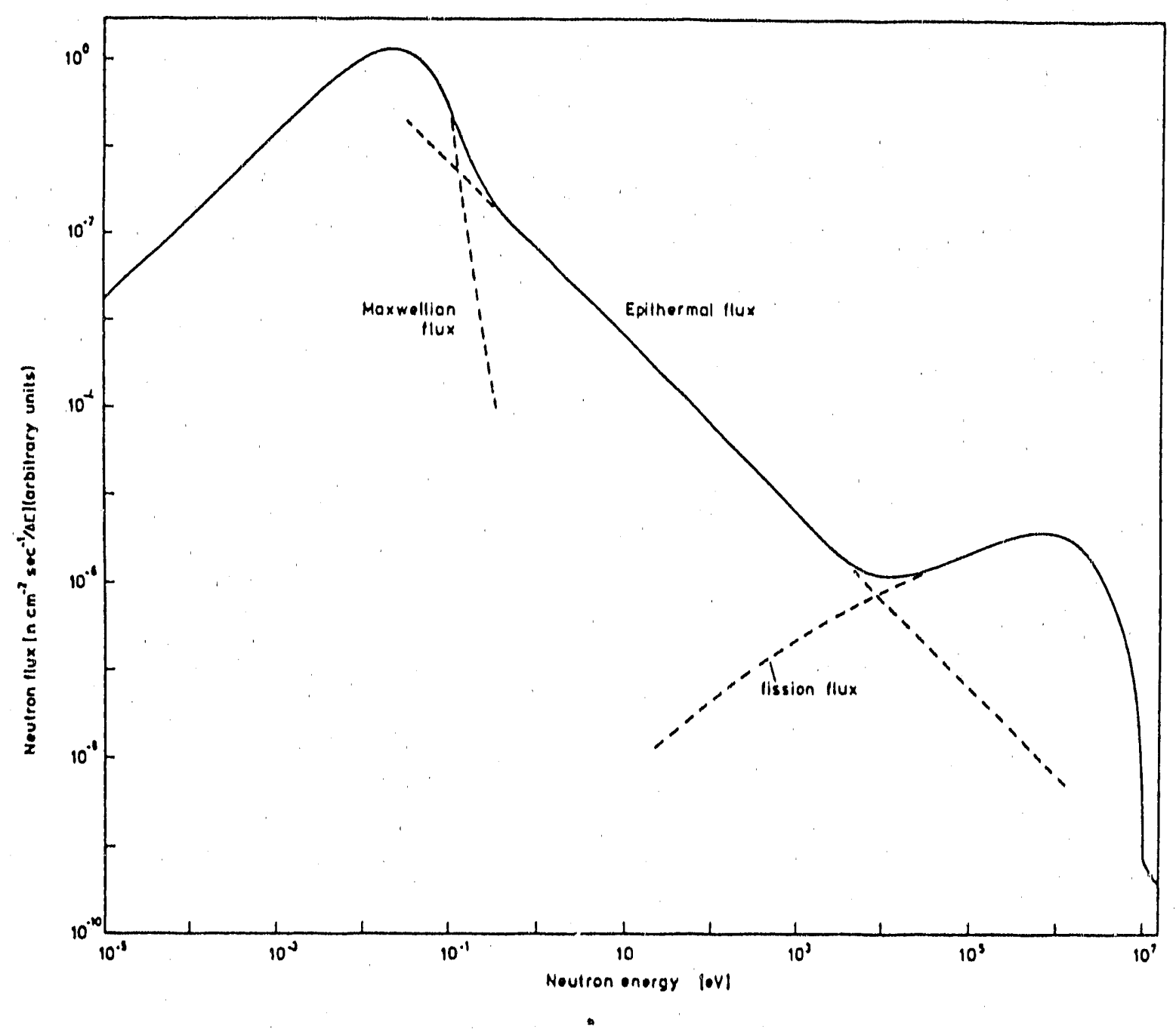

Figure 1. Typical Neutron Spectrum from a $U^{235}$ Nuclear Reactor. 


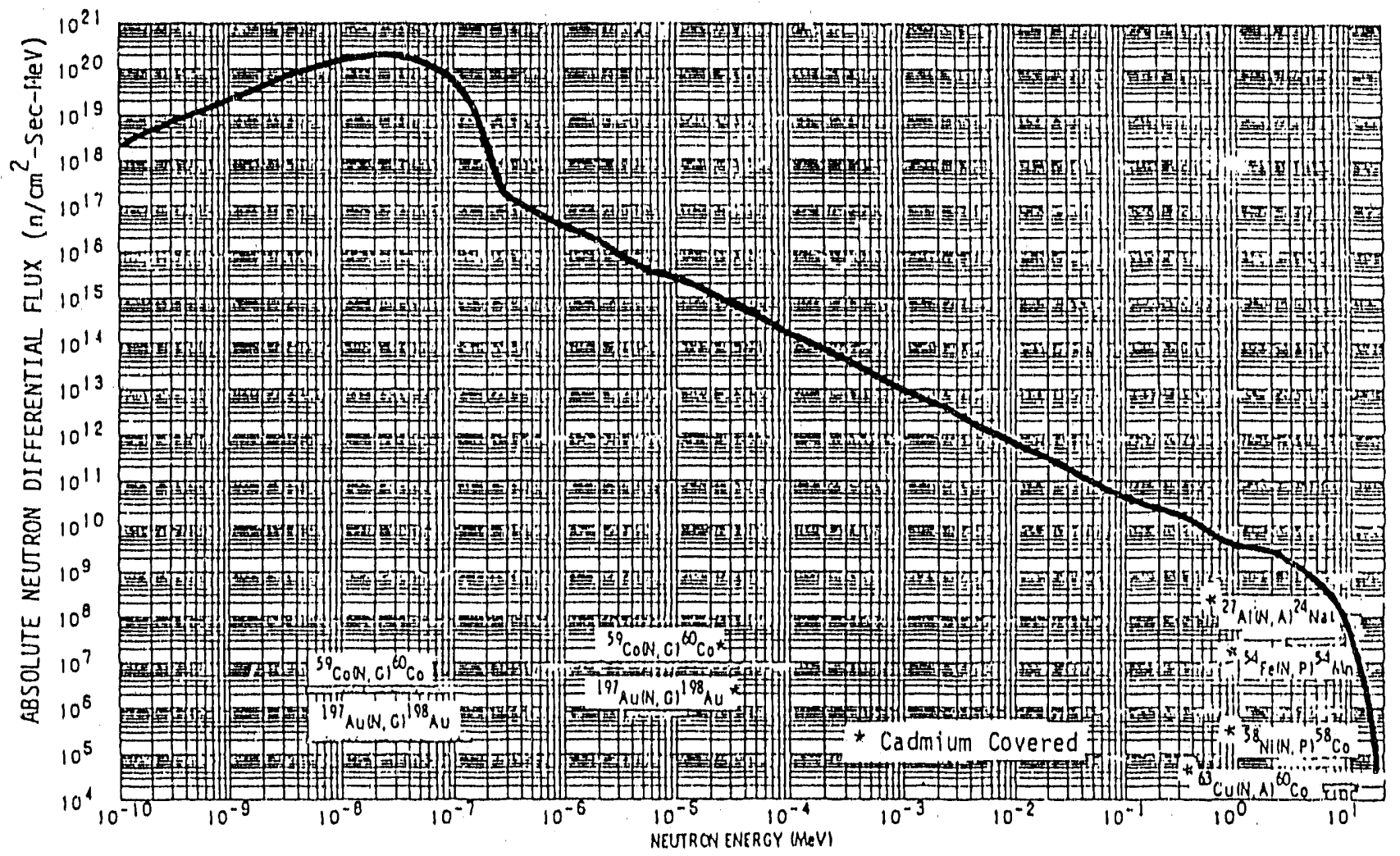

Figure 2. NIST Reactor RT-4 Position. Sand II $5^{\text {th }}$ Iteration Differential Flux Solution [4]. 


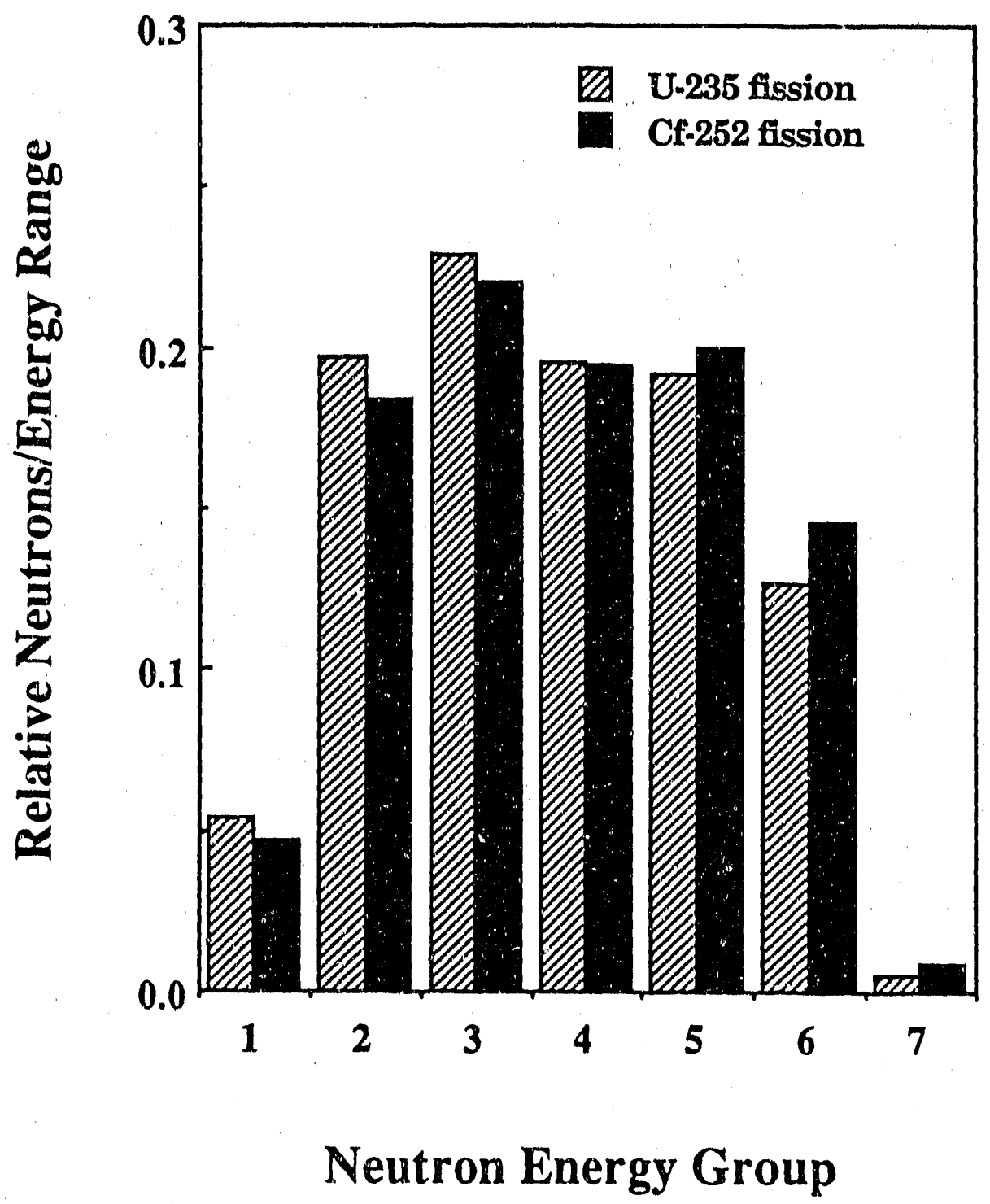

Figure 3. Course Seven Group Display of the Unmoderated Fission Neutron Spectra of Uranium-235 and Californium-252 [1]. (Note: Energy Groups are: 1) 0-0.25 MeV; 2) 0.25-0.8 MeV; 3) 0.8-1.5 MeV; 4) 1.5-2.3 MeV; 5) 2.3-3.7 MeV; 6) 3.7-8 MeV; and 7) 8-12MeV). 


\section{Top}

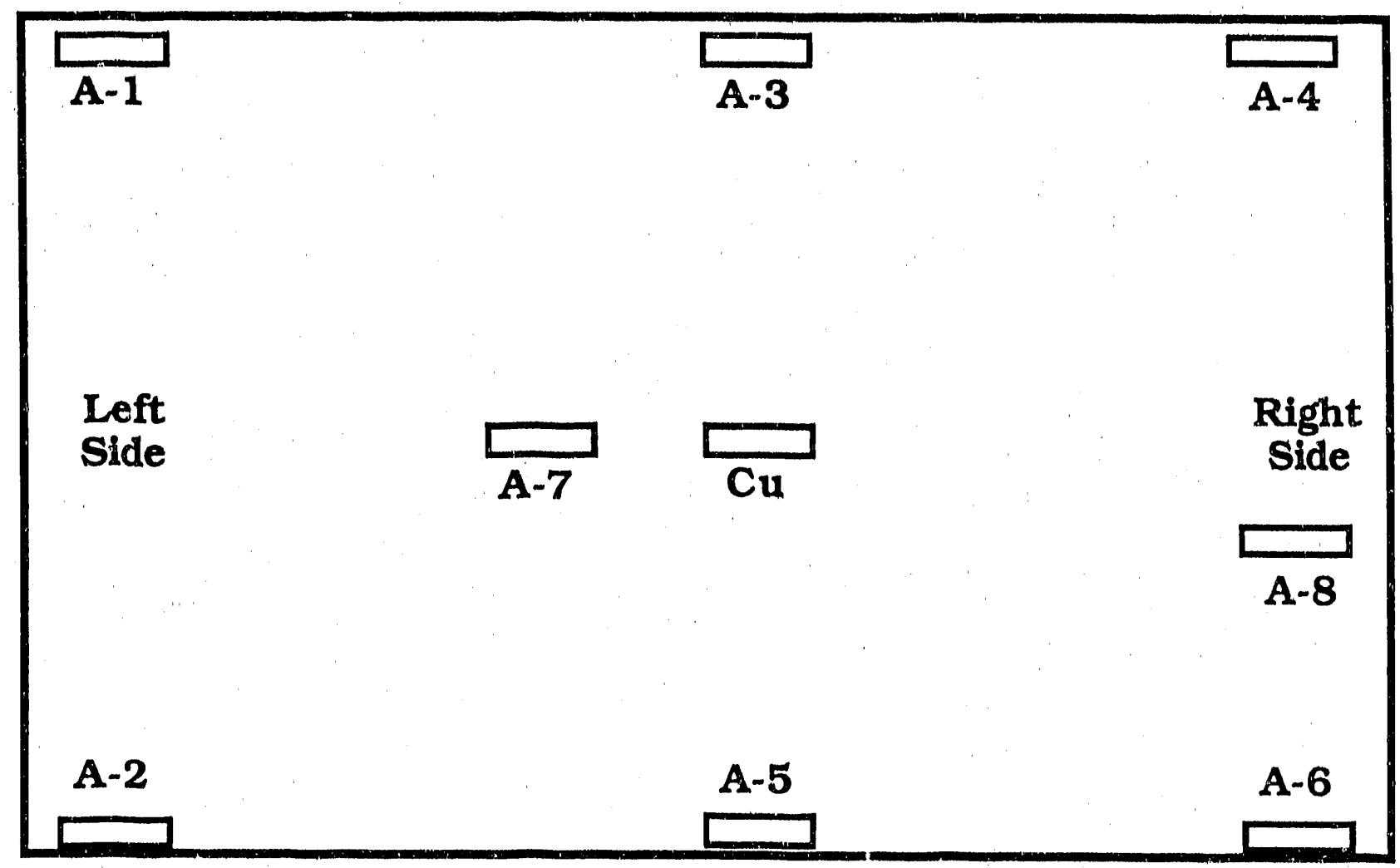

\section{Bottom}

Figure 4. Front View of Container for Irradlation No. 4, Fluence Mapping [Dimensions: $0.406 \mathrm{~m}$ (16 in) high; $0.660 \mathrm{~m}(26 \mathrm{ln}$ ) wide; approximately $0.762 \mathrm{~m}$ ( $30 \mathrm{ln}$ ) long]. (See Table 7 for fluence values). 


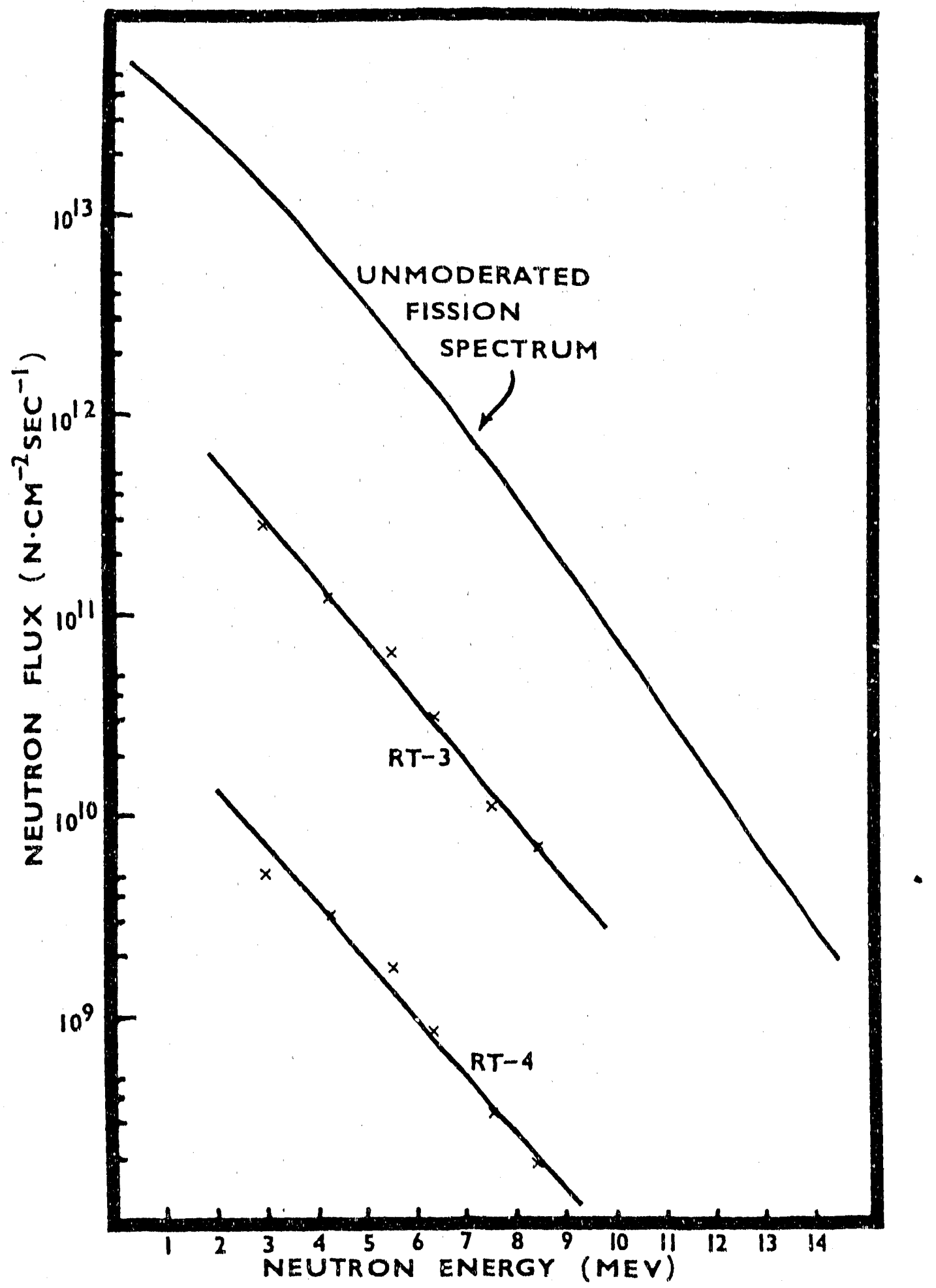

Figure 5. Integral Neutron Fluence Rate for the RT-3 and RT-4 Irradlation Positions in the NIST Nuclear Reactor [Note: Unmoderated Fission Spectrurn is that of Uranlum-235 (Hefernce 7)]. 
Table 1. Calculated Activities from One Yass

in a Neutron Interrogation System

\begin{tabular}{|c|c|c|c|c|c|c|c|}
\hline & Target & & & & (decay & $\begin{array}{r}\text { Activity } \\
\text { /s/sec/gram } 0\end{array}$ & of element) \\
\hline 2 & Isotope & Reaction & Product & Halflife & Initial & 1 min decay & 1 hour decay \\
\hline 1 & Hydrogen & & none & & * & $\star$ & * \\
\hline 2 & Helium & & none & & * & $\star$ & * \\
\hline 3 & Lithium- 6 & $n, \alpha$ & Hydrogen-3 & $12.35 \mathrm{y}$ & 0.011 & 0.011 & 0.011 \\
\hline 4 & Beryllium-9 & $\mathrm{n}, \alpha$ & Helium- 6 & $0.802 \mathrm{~s}$ & 1280 & i* & * \\
\hline 5 & Boron & & none & & * & * & $*$ \\
\hline 6 & Carbon & & none & & * & * & * \\
\hline 7 & Nitrogen-15 & $\mathrm{n}, \boldsymbol{\gamma}$ & Nitrogen-16 & $7.13 \mathrm{~s}$ & 0.0004 & * & $\star$ \\
\hline 7 & Nitrogen-14 & $n, 2 n$ & Nitrogen-13 & $9.96 \mathrm{~m}$ & 0.0001 & $\star$ & * \\
\hline 8 & Oxygen-18 & $n, \gamma$ & Oxygen-19 & $27.1 \mathrm{~s}$ & 0.0004 & * & * \\
\hline 8 & Oxygen-18 & $\mathrm{n}, \alpha$ & Carbon-15 & $2.46 \mathrm{~s}$ & 0.001 & $\star$ & * \\
\hline 9 & Fluorine-1s. & $n, \gamma$ & Fluorine -20 & $11.0 \mathrm{~s}$ & 19.7 & 0.449 & * \\
\hline 9 & Fluor Ine-19 & $n, p$ & Oxygen-19 & $27.1 \mathrm{~s}$ & 0.11 & 0.024 & * \\
\hline 9 & Fluorine 19 & $\mathrm{n}, \alpha$ & Nitrogen-16 & $7.13 \mathrm{~s}$ & 2.32 & 0.007 & $\star$ \\
\hline 10 & Neon- 22 & $\mathrm{n}, \boldsymbol{\gamma}$ & Neon-23 & $37.6 \mathrm{~s}$ & 2.43 & 0.804 & * \\
\hline 10 & Neon-20 & $n, p$ & Fluorine -20 & $11.0 \mathrm{~s}$ & 0.013 & * & * \\
\hline 11 & Sodium-23 & $n, \gamma$ & Sod1um- 24 & $15.02 \mathrm{~h}$ & 0.180 & 0.180 & 0.172 \\
\hline 11 & Sodium-23 & $n, p$ & Neon-23 & $37.6 \mathrm{~s}$ & 0.072 & 0.024 & * \\
\hline 11 & Sodium-23 & $n, \alpha$ & Fluor Ine-20 & $11.0 \mathrm{~s}$ & 0.121 & 0.003 & * \\
\hline 12 & Magnesium-26 & $\mathrm{n}, \boldsymbol{\gamma}$ & Magnesium-27 & $9.45 \mathrm{~m}$ & 0.129 & 0.120 & 0.002 \\
\hline 12 & Magnes Ium-25 & $n, p$ & Sod1um-25 & $60 \mathrm{~s}$ & 0.002 & 0.001 & * \\
\hline 12 & Magnes Ium-26 & $n, p$ & Sod1um-26 & $1.0 \mathrm{~s}$ & 0.001 & * & * \\
\hline
\end{tabular}

"None greater than 0.001 decays/sec/gram of element $(<0.001$ Becquerel/g)

*Less than 0.001 decays $/ \mathrm{sec} / \mathrm{gram}$ of element $(<0.001$ Becquerel/g) 
Table 1. Calculated Activities from One Pass in a Neutron Interrogation System (Cont.)

\begin{tabular}{|c|c|c|c|c|c|c|c|}
\hline \multicolumn{2}{|r|}{ Target } & \multirow[b]{2}{*}{ Reaction } & \multirow[b]{2}{*}{$\begin{array}{l}\text { Activation } \\
\text { Product }\end{array}$} & \multirow[b]{2}{*}{$\begin{array}{r}\text { Product } \\
\text { Halflife }\end{array}$} & \multicolumn{3}{|c|}{$\begin{array}{c}\text { Activity } \\
\text { (decays/sec/gram of element) }\end{array}$} \\
\hline$z$ & Isotope & & & & Inftial & $1 \mathrm{~m} I \mathrm{n}$ decay & 1 hour decay \\
\hline 13 & Aluminum-27 & $n, r$ & Aluminum-28 & $2.25 \mathrm{~m}$ & 27.2 & 20.0 & $\star$ \\
\hline 13 & Aluminum-27 & $n, p$ & Magnesium-27 & $9.45 \mathrm{~m}$ & 0.011 & 0.010 & * \\
\hline 14 & S111con -30 & $n, r$ & Silicon-31 & $2.62 \mathrm{~h}$ & 0.006 & 0.006 & 0.005 \\
\hline 14 & Silicon- 28 & $n, p$ & Aluminum-28 & $2.25 \mathrm{~m}$ & 0.065 & 0.048 & * \\
\hline 14 & Silicon-29 & $n, p$ & Aluminum-29 & $6.52 \mathrm{~m}$ & 0.100 & 0.090 & * \\
\hline 15 & Phosphorus - 31 & $n, r$ & Phosphorus - 32 & $14.28 \mathrm{~d}$ & 0.002 & 0.002 & 0.002 \\
\hline 15 & Phosphorus - 31 & $n, p$ & Silicon-31 & $2.62 \mathrm{~h}$ & 0.005 & 0.005 & 0.004 \\
\hline 15 & Phosphorus -31 & $n, \alpha$ & Aluminum-28 & $2.25 \mathrm{~m}$ & 0.019 & 0.014 & * \\
\hline 16 & Sulfur -36 & $n, \gamma$ & Sulfur -37 & $5.06 \mathrm{~m}$ & 0.001 & 0.001 & * \\
\hline 16 & Sulfur -34 & $n, p$ & Phosphorus - 34 & $12.4 \mathrm{~s}$ & 0.002 & * & * \\
\hline 16 & Sulfur -36 & $n, \alpha$ & Silicon-33 & $6.3 \mathrm{~s}$ & 0.001 & * & * \\
\hline 17 & Chlorine -37 & $n, \gamma$ & Chlorine-38 & $37.2 \mathrm{~m}$ & 0.555 & 0.545 & 0.181 \\
\hline 17 & Chlorine -37 & $n, \gamma$ & Chlorine-38m & $0.8 \mathrm{~s}$ & 12.0 & * & * \\
\hline 17 & Chlorine-37 & $\mathrm{n}, \alpha$ & Phosphorus - 34 & $12.4 \mathrm{~s}$ & 0.027 & 0.001 & * \\
\hline 17 & Chlorine-35 & $n, p$ & Sulfur -35 & $87.2 d$ & 0.001 & 0.001 & 0.001 \\
\hline 18 & Argon -40 & $n, \gamma$ & Argon-41 & $1.83 \mathrm{~h}$ & 1.06 & 1.05 & 0.726 \\
\hline 19 & Potassium -41 & $\mathrm{n}, \gamma$ & Potassium -42 & $12.36 \mathrm{~h}$ & 0.024 & 0.024 & 0.023 \\
\hline 20 & Calcium-48 & $n, \gamma$ & Calcium-49 & $8.72 \mathrm{~m}$ & 0.042 & 0.039 & * \\
\hline 21 & Scandium -45 & $n, \gamma$ & Scandium -46 & $83.8 \mathrm{~d}$ & 0.022 & 0.022 & 0.002 \\
\hline 21 & Scandium -4.5 & $n, \gamma$ & Scandium- $46 m$ & $18.7 \mathrm{~s}$ & 4825 & 522. & * \\
\hline 22 & Titanium-50 & $n, \gamma$ & Titanium -51 & $5.76 \mathrm{~m}$ & 0.357 & 0.317 & * \\
\hline
\end{tabular}

*Less than 0.001 decays $/ \mathrm{sec} / g$ ram of element $(<0.001$ Becquerel $/ g)$ 
Table 1. Calculated Activities from One Pass In a Neutron Interrogation System (Cont.)

\begin{tabular}{|c|c|c|c|c|c|c|c|}
\hline \multicolumn{2}{|r|}{ Target } & \multirow[b]{2}{*}{ Reaction } & \multirow{2}{*}{$\begin{array}{l}\text { Activation } \\
\text { Product }\end{array}$} & \multirow{2}{*}{$\begin{array}{l}\text { Product } \\
\text { Halflife }\end{array}$} & \multicolumn{3}{|c|}{$\begin{array}{c}\text { Activity } \\
\text { (decays/sec/gram of element) }\end{array}$} \\
\hline $\mathrm{Z}$ & Isotope & & & & In 1 tal & 1 min decay & 1 hour decay \\
\hline 23 & Vanadium- 51 & $n, \gamma$ & Vanadium-52 & $3.755 \mathrm{~m}$ & 179. & 149 & 0.003 \\
\hline 23 & Vanadium-51 & $n, p$ & Titanium-51 & $5.76 \mathrm{~m}$ & 0.002 & 0.002 & $\star$ \\
\hline 24 & Chromium-50 & $\pi, \gamma$ & Chromfum- 51 & $27.71 \mathrm{~d}$ & 0.002 & 0.002 & 0.002 \\
\hline 24 & Chromium- 54 & $n, \gamma$ & Chromium- 55 & $3.56 \mathrm{~m}$ & 0.322 & 0.265 & * \\
\hline 24 & Chromium- 52 & $n, p$ & Vanadium- 52 & $2.755 \mathrm{~m}$ & 0.003 & 0.002 & $\star$ \\
\hline 25 & Manganese- 55 & $n \cdot \gamma$ & Manganese-56 & $2.582 \mathrm{~h}$ & 11.1 & 11.1 & 8.49 \\
\hline 25 & Manganese -55 & $n, p$ & Chrom1um- 55 & $3.56 \mathrm{~m}$ & 0.001 & 0.001 & $\star$ \\
\hline 26 & Iron & & nonea & & * & * & $\star$ \\
\hline 27 & Cobalt-59 & $n, \gamma$ & Cobalt -60 & $5.272 \mathrm{y}$ & 0.002 & 0.002 & 0.002 \\
\hline 2.7 & Cobalt-59 & $\mathrm{n}, \gamma$ & Cobalt $-60 m$ & $10.48 \mathrm{~m}$ & 233. & 218 & 4.40 \\
\hline 28 & Nicke1-64 & $n, \gamma$ & N1ckel-65 & $2.520 \mathrm{~h}$ & 0.013 & 0.013 & 0.010 \\
\hline 28 & Nicke1-58 & $n, p$ & Cobalt-58m & $8.94 \mathrm{~h}$ & 0.001 & 0.001 & 0.001 \\
\hline 28 & Nicke1-60 & $n, p$ & Cobalt $-60 m$ & $10.48 \mathrm{~m}$ & 0.001 & 0.001 & * \\
\hline 29 & Copper -63 & $n, \gamma$ & Copper -64 & $12.74 \mathrm{~h}$ & 0.458 & 0.458 & 0.434 \\
\hline 29 & Copper -65 & $n, \gamma$ & Copper- 66 & $5.10 \mathrm{~m}$ & 14.7 & 12.8 & 0.004 \\
\hline 30 & Zinc- 68 & $n, \gamma$ & $21 n c-69$ & $57 \mathrm{~m}$ & 0.369 & 0.365 & 0.178 \\
\hline 30 & Zinc- 68 & $n, \gamma$ & Zinc-69m & $13.9 \mathrm{~h}$ & 0.002 & 0.002 & 0.002 \\
\hline 30 & Zinc- 70 & $n, y$ & $2 \ln c-71$ & $2.4 \mathrm{~m}$ & 0.028 & 0.021 & * \\
\hline 31 & Gallium-69 & $\mathrm{n}, \mathrm{r}$ & Gallium - 70 & $21.1 \mathrm{~m}$ & 5.43 & 5.25 & 0.756 \\
\hline 31 & Gall1um-71 & $n, \gamma$ & Gall1um- 72 & $14.10 \mathrm{~h}$ & 0.259 & 0.259 & 0.247 \\
\hline 31 & Gallium-69 & $n, \alpha$ & Copper -66 & $5.10 \mathrm{~m}$ & 0.001 & 0.001 & * \\
\hline
\end{tabular}

"None greater than 0.001 decays/sec/gram of element $(<0.001$ Becquere $1 / \mathrm{g})$

* Less than $0.001 \mathrm{decays} / \mathrm{sec} / \mathrm{gram}$ of element $(<0.001$ Becquere1/g) 
Table 1. Calculated Activities from One Pass in a Neutron Interrogation System (Cont.)

\begin{tabular}{|c|c|c|c|c|c|c|c|}
\hline \multicolumn{2}{|r|}{ Target } & \multirow[b]{2}{*}{ Reaction } & \multirow{2}{*}{$\begin{array}{l}\text { Activation } \\
\text { Product }\end{array}$} & \multirow{2}{*}{$\begin{array}{l}\text { Product } \\
\text { Halflife }\end{array}$} & \multicolumn{3}{|c|}{$\begin{array}{c}\text { Activity } \\
\text { (decays/sec/gram of element) }\end{array}$} \\
\hline $\mathrm{z}$ & Isotope & & & & Intetal & $1 \mathrm{~min}$ decay & 1 hour decay \\
\hline 32 & Germanfum -70 & $\mathrm{n}, \gamma$ & Germantum- 71 & $11.2 \mathrm{~d}$ & 0.004 & 0.004 & 0.004 \\
\hline 32 & Germantum- 74 & $n, \gamma$ & Germanfum-75 & $82.8 \mathrm{~m}$ & 0.105 & 0.104 & 0.064 \\
\hline 32. & Germarifum-74 & $n, \gamma$ & Germantum-75tn & $48.9 \mathrm{~s}$ & 6.38 & 2.73 & * \\
\hline 32 & Germanfum-76 & $n, r$ & Germanium- 77 & $11.30 \mathrm{~h}$ & 0.001 & 0.001 & 0.001 \\
\hline 32 & Germanium- 76 & $n, \gamma$ & Germanium-77m & $54.3 \mathrm{~s}$ & 0.871 & 0.405 & * \\
\hline 33 & Arsenic- 75 & $n, \gamma$ & Arsenic- $76^{\prime}$ & $26.3 \mathrm{~h}$ & 0.326 & 0.326 & 0.318 \\
\hline 34 & Selentum-76 & $n, \gamma$ & Selenium $-77 \mathrm{~m}$ & $17.5 \mathrm{~s}$ & 568 & 52.8 & $\star$ \\
\hline 34 & Selenfum-78 & $n, \gamma$ & Selenium-79m & $3.89 \mathrm{~m}$ & 2.15 & 1.80 & * \\
\hline 34 & Seleniun- 80 & $\mathrm{n}, \gamma$ & Selenfum- 81 & $18.5 \mathrm{~m}$ & 1.33 & 1.28 & 0.140 \\
\hline 34 & Selenium-80 & $n, \gamma$ & Selenium-81m & $57.3 \mathrm{~m}$ & 0.069 & 0.068 & 0.033 \\
\hline 34 & Selentum-82 & $n, \gamma$ & Selenium-83 & $22.5 \mathrm{~m}$ & 0.345 & 0.335 & 0.054 \\
\hline 34 & Selentum- 82 & $n, r$ & Selenium-83m & $70.0 \mathrm{~s}$ & 0.040 & 0.022 & * \\
\hline 34 & Selenfum-77 & $n, n^{\prime}$ & Selenium $-77 \mathrm{~m}$ & $17.5 \mathrm{~s}$ & 1.63 & 0.151 & * \\
\hline 35 & Bromine -79 & $n, \gamma$ & Bromine -80 & $17.4 \mathrm{~m}$ & 29.1 & 28.0 & 2.67 \\
\hline 35 & Bromine- 79 & $n, \gamma$ & Bromine-80m & $4.42 \mathrm{~h}$ & 0.548 & 0.547 & 0.468 \\
\hline 35 & Bromine -81 & $n, \gamma$ & Bromine -82 & $35.4 \mathrm{~h}$ & 0.007 & 0.007 & $0.00 \%$ \\
\hline 35 & Bromine- 81 & $n, r$ & Bromine $-82 m$ & $6.1 \mathrm{~m}$ & 23.1 & 20.6 & 0.025 \\
\hline
\end{tabular}

* Less than 0.001 decays/sec/gram of element. $(<0.001$ Becquerel/g) 
Table 1. Calculated Activities from One Pass in a Neutron Interrogation System (Cont.)

\begin{tabular}{|c|c|c|c|c|c|c|c|}
\hline \multicolumn{2}{|r|}{ Target } & \multirow{2}{*}{ Reaction } & \multirow{2}{*}{$\begin{array}{l}\text { Activation } \\
\text { Product }\end{array}$} & \multirow{2}{*}{$\begin{array}{r}\text { Product } \\
\text { Halfliffe }\end{array}$} & \multicolumn{3}{|c|}{$\begin{array}{c}\text { Activity } \\
\text { (decays/sec/gram of element) }\end{array}$} \\
\hline $\mathrm{z}$ & Isotope & & & & Inttial & $1 \mathrm{~min}$ decay & 1 hour decay \\
\hline 36 & Krypton-78 & $\pi, \gamma$ & Krypton-79 & $34.9 \mathrm{~h}$ & 0.001 & 0.001 & 0.001 \\
\hline 36 & Krypton-78 & $n, \gamma$ & Krypton-79m & $50 \mathrm{~s}$ & 0.074 & 0.032 & * \\
\hline $3 E$ & Krypton -80 & $n, \gamma$ & Krypton-81m & $13.3 \mathrm{~s}$ & 37.7 & 1.65 & * \\
\hline 36 & Krypton- 82 & $n, \gamma$ & Krypton-83m & $1.86 \mathrm{~h}$ & 1.74 & 1.73 & 1.20 \\
\hline 36 & Krypton -84 & $n, \gamma$ & Krypton-85m & $4.48 \mathrm{~h}$ & 0.023 & 0.023 & 0.020 \\
\hline 36 & Krypton -86 & $\mathrm{n}, \boldsymbol{\gamma}$ & Krypton -87 & $76 \mathrm{~m}$ & 0.012 & 0.012 & 0.007 \\
\hline 37 & Rubidium-85 & $n, \gamma$ & Rubidium-86 & $18.65 \mathrm{~d}$ & 0.001 & 0.001 & 0.001 \\
\hline 37 & Rubidium -85 & $n, \gamma$ & Rubidium-86m & $1.018 \mathrm{~m}$ & 4.20 & 2.13 & * \\
\hline 37. & Rubidium-87 & $n, \gamma$ & Rubidium- 88 & $17.7 \mathrm{~m}$ & 0.205 & 0.197 & 0.020 \\
\hline 38 & Strontium- 84 & $n, \gamma$ & strontiun- $85 m$ & $67.7 \mathrm{~m}$ & 0.004 & 0.004 & 0.002 \\
\hline 38 & Strontium- 86 & $n, \gamma$ & Strontium-87m & $2.81 \mathrm{~h}$ & 0.044 & 0.044 & 0.034 \\
\hline 39 & Yttrium-89 & $\mathrm{n}, \boldsymbol{\gamma}$ & Yttrium -90 & $64.0 \mathrm{~h}$ & 0.026 & 0.026 & 0.026 \\
\hline 39 & Yttrium-89 & $n, \gamma$ & Yttrium-90m & $3.19 \mathrm{~h}$ & 0.416 & 0.414 & 0.335 \\
\hline 39 & Yttrium -89 & $\mathrm{n}, \mathrm{n}^{\prime}$ & Yttrium-89m & $15.7 \mathrm{~s}$ & 3.75 & 0.265 & * \\
\hline 40 & Zirconium & & none & & * & * & * \\
\hline 41 & Niobium-93 & $n, \cdot y$ & Niobium-94m & $6.26 \mathrm{~m}$ & 3.80 & 3.40 & 0.005 \\
\hline 42 & Molybdenum-92 & $n, \gamma$ & Molybdenum-93m & $6.85 \mathrm{~h}$ & $<0.002$ & $<0.002$ & $<0.001$ \\
\hline+2 & Molybdenum- 98 & $n, \gamma$ & Molybdenum-99 & $66.02 \mathrm{~h}$ & 0.001 & 0.001 & 0.001 \\
\hline 42 & Molybdenum- 100 & $n, \gamma$ & Molybdenum-101 & $14.6 \mathrm{~m}$ & 0.135 & 0.129 & 0.008 \\
\hline 43 & Technetlum & & unstable/not $f$ & oind natur & rally & & \\
\hline 44 & Ruthenium-102 & $n, r$ & Ruthenium-103 & $39.6 \mathrm{~d}$ & 0.001 & 0.001 & 0.001 \\
\hline 44 & Ruthenium-104 & $\mathrm{n}, \gamma$ & Ruthenfum-105 & $4.44 \mathrm{~h}$ & 0.029 & 0.029 & 0.025 \\
\hline
\end{tabular}

*Less than 0.001 decays/sec/gram of element $(<0.001$ Becquerel/g) 
Table 1. Calculated Activities from One Pass

in a Neutron Interrogation System (Cont.)

\begin{tabular}{|c|c|c|c|c|c|c|c|}
\hline \multicolumn{2}{|r|}{ Target } & \multirow[b]{2}{*}{ Reaction } & \multirow{2}{*}{$\begin{array}{l}\text { Ac'ivation } \\
\text { Product }\end{array}$} & \multirow{2}{*}{$\begin{array}{r}\text { Product: } \\
\text { Halflife }\end{array}$} & \multicolumn{3}{|c|}{$\begin{array}{c}\text { Activity } \\
\text { (decays/sec/gram of element) }\end{array}$} \\
\hline$z$ & Isotope & & & & Initial & 1 min decay & 1 hour decay \\
\hline 45 & Rhodium-103 & $n, \gamma$ & Rhodium-104 & $42 s$ & 1543 & 573. & * \\
\hline 45 & Rhodium-103 & $\mathrm{n}, \boldsymbol{\gamma}$ & Rtrodiurn-104m & $4.35 \mathrm{~m}$ & 360. & 307 & 0.025 \\
\hline 45 & Rhodium-103 & $\mathrm{n}, \alpha$ & Technetium-100 & $16 \mathrm{~s}$ & 0.397 & 0.030 & * \\
\hline 45 & Rhodium-103 & $n, n^{\prime}$ & Rhodium-103m & $56 \mathrm{~m}$ & 0.064 & 0.063 & 0.030 \\
\hline 46 & Palladium-106 & $\mathrm{n}, \mathrm{r}$ & Palladium $-107 \mathrm{~m}$ & $21.3 \mathrm{~s}$ & 0.842 & 0.119 & * \\
\hline 46 & Paliadium-108 & $n, r$ & Palladium-109 & $13.46 \mathrm{~h}$ & 0.337 & 0.337 & 0.320 \\
\hline 46 & Palladium-108 & $n, \gamma$ & Palladium-109m & $4.69 \mathrm{~m}$ & 0.912 & 0.787 & * \\
\hline 46 & Palladium-110 & $n, \gamma$ & Palladium-111 & $22 \mathrm{~m}$ & 0.088 & 0.085 & 0.013 \\
\hline 46 & Palladium-110 & $n, r$ & Palladium-111m & $5.5 \mathrm{~h}$ & 0.001 & 0.001 & 0.001 \\
\hline 47 & Silver-107 & $n, r$ & Silver-108 & $2.41 \mathrm{~m}$ & 509. & 382. & * \\
\hline 47 & Silver-109 & $\mathrm{n}, \boldsymbol{\gamma}$ & Silver-110 & $24.6 \mathrm{~s}$ & 8310 & 1532 . & * \\
\hline 48 & Cadmium-106 & $\mathrm{n}, \boldsymbol{\gamma}$ & Cadmium-107 & $6.5 \mathrm{~h}$ & 0.002 & 0.002 & 0.002 \\
\hline 48 & Cadmium-110 & $n, r$ & Cadmium-111m & $48.7 \mathrm{~m}$ & 0.022 & 0.022 & 0.009 \\
\hline 48 & Cadmium $\cdot 114$ & $n, \gamma$ & Cadmium-115 & $53.5 \mathrm{~h}$ & 0.002 & 0.002 & 0.002 \\
\hline 48 & Cadmium-116 & $\mathrm{n}, \boldsymbol{\gamma}$ & Cadmium-117 & $2.6 \mathrm{~h}$ & 0.002 & 0.002 & 0.001 \\
\hline 48 & Cadmium-116 & $\mathrm{n}, \boldsymbol{\gamma}$ & Cadmium-117m & $3.4 \mathrm{~h}$ & 0.001 & 0.001 & 0.001 \\
\hline 48 & Cadmium-112 & $n, 2 n$ & Cadmium-111m & $48.7 \mathrm{~m}$ & 0.004 & 0.004 & 0.002 \\
\hline 49 & Indium-113 & $n, \gamma$ & Indium-114 & $71.9 \mathrm{~s}$ & 9.43 & 5.29 & * \\
\hline 49 & Indium-113 & $\mathrm{n}, \boldsymbol{\gamma}$ & Indium-114m & $49.51 \mathrm{~d}$ & 0.001 & 0.001 & 0.001 \\
\hline 49 & Indium-115 & $n, \gamma$ & Indium-116 & $14.2 \mathrm{~s}$ & 1360 & 72.7 & * \\
\hline 49 & Indium-115 & $\mathrm{n}, \boldsymbol{\gamma}$ & Indium-116m & $54.2 \mathrm{~m}$ & 129. & 127 & 59.9 \\
\hline 49 & Indium-115 & $\mathrm{n}, \boldsymbol{\gamma}$ & Indium-116m' & $2.16 \mathrm{~s}$ & 127000 & 0.001 & * \\
\hline 49 & Indium-115 & $\mathrm{n}, \mathrm{n}^{\prime}$ & Indium-115m & $4.50 \mathrm{~h}$ & 0.004 & 0.004 & 0.003 \\
\hline
\end{tabular}

*Less than 0.001 decays/sec/gram of element $(<0.001$ Becquerel/g) 
Table 1. Calculated Activities from One Pass

in a Neutron Interrogation System (Cont.)

\begin{tabular}{|c|c|c|c|c|c|c|c|}
\hline \multicolumn{2}{|r|}{ Target } & \multirow[b]{2}{*}{ Reaction } & \multirow{2}{*}{$\begin{array}{l}\text { Activation } \\
\text { Product }\end{array}$} & \multirow{2}{*}{$\begin{array}{l}\text { Product } \\
\text { Halflife }\end{array}$} & \multicolumn{3}{|c|}{$\begin{array}{c}\text { Activity } \\
\text { (decays/sec/gram of element) }\end{array}$} \\
\hline Z & Isotope & & & & Initial & 1 min decay & 1 hour decay \\
\hline 50 & $\operatorname{Tin}-112$ & $\mathrm{n}, \boldsymbol{\gamma}$ & $\operatorname{Tin}-113 \mathrm{~m}$ & $20 \mathrm{~m}$ & 0.018 & 0.017 & 0.002 \\
\hline 50 & $\operatorname{Tin}-120$ & $\mathrm{n}, \mathrm{\gamma}$ & $\operatorname{Tin}-121$ & $26.8 \mathrm{~h}$ & 0.002 & 0.002 & 0.002 \\
\hline 50 & $\operatorname{Tin}-122$ & $n, \gamma$ & Tin-123m & $40.1 \mathrm{~m}$ & 0.012 & 0.012 & 0.004 \\
\hline 50 & $\operatorname{Tin}-124$ & $\mathrm{n}, \boldsymbol{\gamma}$ & $\operatorname{Tin}-125 \mathrm{~m}$ & $9.2 \mathrm{~m}$ & 0.109 & 0.101 & 0.001 \\
\hline 51 & Antimony-121 & $\mathrm{n}, \boldsymbol{\gamma}$ & Antimony -122 & $2.72 \mathrm{~d}$ & 0.073 & 0.073 & 0.072 \\
\hline 51 & Antimony - 121 & $\mathrm{n}, \boldsymbol{\gamma}$ & Antimony $-122 \mathrm{~m}$ & $4.2 \mathrm{~m}$ & 0.708 & 0.600 & * \\
\hline 51 & Antimony -123 & $\mathrm{n}, \boldsymbol{\gamma}$ & Antimony-124 & $60.3 \mathrm{~d}$ & 0.003 & 0.003 & 0.003 \\
\hline 51 & Antimony -123 & $\mathrm{n}, \gamma$ & Antimony - $124 \mathrm{~m}$ & $93 \mathrm{~s}$ & 0.842 & 0.538 & * \\
\hline 51 & Antimony -123 & $\mathrm{n}, \gamma$ & Antimony - $124 \mathrm{~m}^{\prime}$ & $20.3 \mathrm{~m}$ & 0.013 & 0.013 & 0.002 \\
\hline 52 & Tellurium-126 & $\mathrm{n}, \gamma$ & Tellurium-127 & $9.4 \mathrm{~h}$ & 0.019 & 0.019 & 0.018 \\
\hline 52 & Tellurium-128 & $\mathrm{n}, \gamma$ & Tellurium-129. & $70 \mathrm{~m}$ & 0.057 & 0.056 & 0.031 \\
\hline 52 & Tellurium-130 & $\mathrm{n}, \gamma$ & Tellurium-131 & $25.0 \mathrm{~m}$ & 0.208 & 0.202 & 0.039 \\
\hline 53 & Iodine-127 & $\mathrm{n}, \boldsymbol{\gamma}$ & Iodine-128 & $25.00 \mathrm{~m}$ & 20.0 & 19.5 & 3.79 \\
\hline 54 & Xenon-124 & $\mathrm{n}, \gamma$ & Xenon-125 & $17.0 \mathrm{~h}$ & 0.008 & 0.008 & 0.008 \\
\hline 54 & Xenon-124 & $\mathrm{n}, \gamma$ & Xenon-125m & $57 \mathrm{~s}$ & 1.7 & 0.820 & * \\
\hline 54 & Xenon-126 & $n, \gamma$ & Xenon-127m & $72 \mathrm{~s}$ & 0.014 & 0.008 & * \\
\hline 54 & Xenon-130 & $\pi, \gamma$ & Xenon-131m & $11.99 \mathrm{~d}$ & 0.053 & 0.053 & 0.053 \\
\hline 54 & Xenon-132 & $\mathrm{n}, \gamma$ & Xenon-133 & $5.29 \mathrm{~d}$ & 0.001 & 0.001 & 0.001 \\
\hline 54 & Xenon-134 & $n, \gamma$ & Xenon-135 & $9.17 \mathrm{~h}$ & 0.003 & 0.003 & 0.003 \\
\hline 54 & Xenor -134 & $\mathrm{n}, \gamma$ & Xenon-135m & $15.3 \mathrm{~m}$ & 0.001 & 0.001 & * \\
\hline 54 & Xenon-136 & $\mathrm{n}, \boldsymbol{\gamma}$ & Xenon-137 & $3.84 \mathrm{~m}$ & 0.200 & 0.167 & $\star$ \\
\hline
\end{tabular}

*Less than 0.001 decays $/ \mathrm{sec} / \mathrm{gram}$ of element $(<0.001$ Becquerel $/ \mathrm{g})$ 
Table 1. Calculated Activities from One Pass

in a Neutron Interrogation System (Cont.)

\begin{tabular}{|c|c|c|c|c|c|c|c|}
\hline \multicolumn{2}{|r|}{ Target } & \multirow[b]{2}{*}{ Reaction } & \multirow{2}{*}{$\begin{array}{l}\text { Activation } \\
\text { Product }\end{array}$} & \multirow{2}{*}{$\begin{array}{r}\text { Product } \\
\text { Halflife }\end{array}$} & \multicolumn{3}{|c|}{$\begin{array}{c}\text { Activity } \\
\text { (decays/sec/gram of element) }\end{array}$} \\
\hline $\mathrm{Z}$ & Isotope & & & & Initial & 1 min decay & 1 hour decay \\
\hline 55 & Cesium-133 & $\mathrm{n}, \boldsymbol{\gamma}$ & Cesium-134 & $2.06 \mathrm{y}$ & 0.002 & 0.002 & 0.002 \\
\hline 55 & Cesium-133 & $\mathrm{n}, \boldsymbol{\gamma}$ & Cesium-134m & $2.9 \mathrm{~h}$ & 0.928 & 0.924 & 0.731 \\
\hline 56 & Barium-130 & $\mathrm{n}, \boldsymbol{\gamma}$ & Barium-131m & $14.6 \mathrm{~m}$ & 0.009 & 0.009 & 0.001 \\
\hline 56 & Barium-135 & $n, \gamma$ & Barium-136m & $0.31 \mathrm{~s}$ & 131. & * & * \\
\hline 56 & Barium-136 & $n, r$ & Barium-137m & $2.55 \mathrm{~m}$ & 0.039 & 0.030 & * \\
\hline 56 & Barium-138 & $\mathrm{n}, \boldsymbol{\gamma}$ & Barium-139 & $83.3 \mathrm{~m}$ & 0.155 & 0.154 & 0.094 \\
\hline 56 & Barium-137 & $n, n^{\prime}$ & Barium-137m & $2.55 \mathrm{~m}$ & 0.500 & 0.085 & * \\
\hline 57 & Lanthanum-139 & $\mathrm{n}, \mathrm{r}$ & Lanthanum-140 & $40.23 \mathrm{~h}$ & 0.190 & 0.190 & 0.187 \\
\hline 58 & Cerium-136 & $n, \gamma$ & Cerium-137. & $9.0 \mathrm{~h}$ & 0.014 & 0.014 & 0.013 \\
\hline 58 & Cerium-138 & $n, \gamma$ & Cerium-139m & $56 \mathrm{~s}$ & 0.054 & 0.026 & * \\
\hline 58 & Cerium-140 & $n, \gamma$ & Cerium-141 & $32.51 \mathrm{~d}$ & 0.005 & 0.005 & 0.005 \\
\hline 58 & Cerium-142 & $\mathrm{n}, \boldsymbol{\gamma}$ & Cerium-143 & $33.0 \mathrm{~h}$ & 0.027 & 0.027 & 0.026 \\
\hline 59 & Praseodymium-141 & $\mathrm{n}, \boldsymbol{\gamma}$ & Praseodymium -142 & $19.16 \mathrm{~h}$ & 0.343 & 0.343 & 0.331 \\
\hline 59 & Praseodymium-141 & $\mathrm{n}, \boldsymbol{\gamma}$ & Praseodymium $-142 m$ & $14.6 \mathrm{~m}$ & 13.3 & 12.7 & 0.770 \\
\hline 59 & Praseodymium-141 & $n, 2 n$ & Praseodymium-140 & $3.39 \mathrm{~m}$ & 0.012 & 0.010 & * \\
\hline 60 & Neodymium-146 & $\mathrm{n}, \boldsymbol{\gamma}$ & Neodymium-147 & $10.99 \mathrm{~d}$ & 0.007 & 0.007 & 0.007 \\
\hline 60 & Neodymium-148 & $\mathrm{n}, \gamma$ & Neodymium-149 & $1.73 \mathrm{~h}$ & 0.073 & 0.073 & 0.049 \\
\hline 60 & Neodymium-150 & $n, \gamma$ & Neodymium-151 & $12.4 \mathrm{~m}$ & 0.352 & 0.333 & 0.034 \\
\hline 61 & Promethium & & unstable/not fo & ound natur & cally & & \\
\hline 62 & Samarium-152 & $\mathrm{n}, \boldsymbol{\gamma}$ & Samarium-153 & $46.5 \mathrm{~h}$ & 1.19 & 1.19 & 1.17 \\
\hline 62 & Samarium- 154 & $\mathrm{n}, \boldsymbol{\gamma}$ & Samarium-155 & $22.2 \mathrm{~m}$ & 2.81 & 2.72 & 0.432 \\
\hline
\end{tabular}

*Less than 0.001 decays/sec/gram of element $(<0.001$ Becquerel/g) 
Table 1. Calculated Activities from One Pass in a Neutron Interrogation System (Cont.)

\begin{tabular}{|c|c|c|c|c|c|c|c|}
\hline & Target & & & & (decay & $\begin{array}{r}\text { Activity } \\
\mathrm{ys} / \mathrm{sec} / \mathrm{gram} 0\end{array}$ & of element) \\
\hline$z$ & Isotope & Reaction & Product & Halflife & Initial & 1 min decay & 1 hour decay \\
\hline 63 & Europium-151 & $\mathrm{n}, \boldsymbol{\gamma}$ & Europium-152 & $13.4 \mathrm{y}$ & 0.020 & 0.020 & 0.020 \\
\hline 63 & Europium-151 & $\mathrm{n}, \boldsymbol{\gamma}$ & Europium-152m & $9.3 \mathrm{~h}$ & 132. & 132. & 123. \\
\hline 63 & Europium-151 & $\mathrm{n}, \mathrm{\gamma}$ & Europium-152m' & $96 \mathrm{~m}$ & 0.921 & 0.914 & 0.597 \\
\hline 63 & Europium-153 & $\mathrm{n}, \mathrm{\gamma}$ & Europium-154 & $8.5 \mathrm{y}$ & 0.002 & 0.002 & 0.002 \\
\hline 64 & Gadolinium-158 & $n, \gamma$ & Gadolinium-159 & $18.6 \mathrm{~h}$ & 0.040 & 0.040 & 0.039 \\
\hline 64 & Gadolinium-160 & $n, \gamma$ & Gadolinium-161 & $3.7 \mathrm{~m}$ & 2.19 & 1.82 & * \\
\hline 65 & Terbium-1.59 & $\mathrm{n}, \gamma$ & Terbium-160 & $72.3 \mathrm{~d}$ & 0.014 & 0.014 & 0.014 \\
\hline 66 & Dysprosiun-156 & $\mathrm{n}, \boldsymbol{\gamma}$ & Dysprosium-157 & $8.1 \mathrm{~h}$ & 0.003 & 0.003 & 0.003 \\
\hline 66 & Dysprosium-164 & $n, \gamma$ & Dysprosium-165 & $2.35 \mathrm{~h}$ & 86.2 & 85.8 & 64.2 \\
\hline 66 & Dysprosium-164 & $n, y$ & Dysprosium-165m & $1.256 \mathrm{~m}$ & 16400 & 9420 & 6.81 \\
\hline 67 & Holmium-165 & $n, \gamma$ & Holmium-166 & $26.8 \mathrm{~h}$ & 1.98 & 1.98 & 1.93 \\
\hline 68 & Erbium-162 & $\mathrm{n}, \boldsymbol{\gamma}$ & Erbium-163 & $75 \mathrm{~m}$ & 0.022 & 0.022 & 0.013 \\
\hline 68 & Erbium-164 & $\mathrm{n}, \boldsymbol{\gamma}$ & Erbium-165 & $10.36 \mathrm{~h}$ & 0.016 & 0.016 & 0.015 \\
\hline 68 & Erbium-166 & $\mathrm{n}, \boldsymbol{\gamma}$ & Erbium-167m & $2.27 \mathrm{~s}$ & 4790 & * & * \\
\hline 68 & Erbium-168 & $\mathrm{n}, \gamma$ & Erbium-169 & $9.3 \mathrm{~d}$ & 0.002 & 0.002 & 0.002 \\
\hline 68 & Erbium-170 & $\mathrm{n}, \boldsymbol{\gamma}$ & Erbium-171 & $7.5 \mathrm{~h}$ & 0.085 & 0.085 & 0.077 \\
\hline 69 & Thulium-169 & $\mathrm{n}, \boldsymbol{\gamma}$ & Thulium-170 & $130 \mathrm{~d}$ & 0.030 & 0.030 & 0.030 \\
\hline 70 & Ytterbium-168 & $\mathrm{n}, \mathrm{\gamma}$ & Ytterbium-169 & $32.02 \mathrm{~d}$ & 0.005 & 0.005 & 0.005 \\
\hline 70 & Ytterbium-174 & $\mathrm{n}, \boldsymbol{\gamma}$ & Ytterbium-175 & $4.19 \mathrm{~d}$ & 0.139 & 0.139 & 0.138 \\
\hline 70 & Ytterbium-176 & $\mathrm{n}, \boldsymbol{\gamma}$ & Ytterbium- 177 & $1.9 \mathrm{~h}$ & 0.113 & 0.112 & 0.078 \\
\hline 71 & Lutecium-175 & $n, \gamma$ & Lutecium-176m & $3.69 \mathrm{~h}$ & 4.78 & 4.77 & 3.96 \\
\hline 71 & Lutecium-176 & $\mathrm{n}, \mathrm{\gamma}$ & Lutecium-177 & $6.71 \mathrm{~d}$ & 0.222 & 0.222 & 0.221 \\
\hline
\end{tabular}

*Less than 0.001 decays/sec/gram of element $(<0.001$ Becquerel/g) 
Table 1. Calculated Activities from One Pass in a Neutron Interrogation System (Cont.)

\begin{tabular}{|c|c|c|c|c|c|c|c|}
\hline \multicolumn{2}{|r|}{ Target } & \multirow[b]{2}{*}{ Reaction } & \multirow{2}{*}{$\begin{array}{l}\text { Activation } \\
\text { Product }\end{array}$} & \multirow{2}{*}{$\begin{array}{r}\text { Product } \\
\text { Halflife }\end{array}$} & \multicolumn{3}{|c|}{$\begin{array}{c}\text { Activity } \\
\text { (decays/sec/gram of element) }\end{array}$} \\
\hline $\mathrm{Z}$ & Isotope & & & & Initial & 1 min decay & 1 hour decay \\
\hline 72 & Hafnium- 177 & $\mathrm{n}, \gamma$ & Hafnium-178m & $4.3 \mathrm{~s}$ & 110 & 0.007 & * \\
\hline 72 & Hafnium -178 & $n, r$ & Hafnium $-179 m$ & $18.7 \mathrm{~s}$ & 2460 & 2.66 & $*$ \\
\hline 72 & Hafnium 179 & $n, \gamma$ & Hafnium-180m & $5.5 \mathrm{~h}$ & 0.007 & 0.007 & 0.006 \\
\hline 72 & Hafnium- 180 & $\mathrm{n}, \boldsymbol{\gamma}$ & Hafnium-181 & $42.4 \mathrm{~d}$ & 0.003 & 0.003 & 0.003 \\
\hline 73 & Tantalum-181 & $\mathrm{n}, \boldsymbol{\gamma}$ & Tantalum-182 & $115 \mathrm{~d}$ & 0.008 & 0.008 & 0.008 \\
\hline 73 & Tantalum-181 & $\mathrm{n}, \gamma$ & Tantalum-182m & $15.9 \mathrm{~m}$ & 0.038 & 0.036 & 0.003 \\
\hline 74 & Tungsten-184 & $\mathrm{n}, \gamma$ & Tungsten-185m & $1.64 \mathrm{~m}$ & 0.014 & 0.009 & * \\
\hline 74 & Tungsten-186 & $\mathrm{n}, \gamma$ & Tungsten-187 & $23.9 \mathrm{~h}$ & 0.347 & 0.347 & 0.337 \\
\hline 75 & Rhenium-185 & $n, \gamma$ & Rhenium-186 & $90.6 \mathrm{~h}$ & 0.362 & 0.362 & 0.359 \\
\hline 75 & Rhenium-187 & $\mathrm{n}, \mathrm{r}$ & Rhenium-188 & $16.7 \mathrm{~h}$ & 1.85 & 1.85 & 1.77 \\
\hline 75 & Rhenium- 187 & $n, \gamma$ & Rhenium-188m & $18.6 \mathrm{~m}$ & 2.18 & 2.10 & 0.233 \\
\hline 76 & Osmium-190 & $\mathrm{n}, \mathrm{\gamma}$ & Osimium - 191 & $15.3 \mathrm{~d}$ & 0.002 & 0.002 & 0.002 \\
\hline 76 & Osmium-190 & $n, y$ & Osmium-191m & $13.0 \mathrm{~h}$ & 0.119 & 0.119 & 0.113 \\
\hline 76 & Osmium-192 & $n, \gamma$ & Osimium-193 & $30.2 \mathrm{~h}$ & 0.017 & 0.017 & 0.017 \\
\hline 77 & Iridium-191 & $n, \gamma$ & Iridium-192 & $74.3 \mathrm{~d}$ & 0.090 & 0.090 & 0.090 \\
\hline 77 & Iridium-191 & $\mathrm{n}, \gamma$ & Iridium-192m & $1.4 \mathrm{~m}$ & 3120 & 1900 & * \\
\hline 77 & Iridiurn-193 & $\mathrm{n}, \mathrm{y}$ & Iridium- 194 & $19.38 \mathrm{~h}$ & 2.73 & 2.73 & 2.63 \\
\hline 78 & Platinum-196 & $n, \gamma$ & Platinum- 197 & $18.3 \mathrm{~h}$ & 0.006 & 0.006 & 0.006 \\
\hline 78 & Platinum-196 & $n, r$ & Platinum $-197 m$ & $81 \mathrm{~m}$ & 0.007 & 0.007 & 0.004 \\
\hline 78 & Platinum-198 & $n, \gamma$ & Platinum-199 & $30.8 \mathrm{~m}$ & 0.389 & 0.380 & 0.101 \\
\hline 78 & Platinum-198 & $n, y$ & Platinum-199m & $14.1 \mathrm{~s}$ & 0.383 & 0.020 & * \\
\hline 79 & Gold-197 & $n, y$ & Gold-198 & $2.695 \mathrm{~d}$ & 1.18 & 1.18 & 1.17 \\
\hline
\end{tabular}

*Less than 0.001 decays/sec/gram of element $(<0.001$ Becquerel/g) 
Table 1. Calculated Activities from One Pass in a Neutron Interrogation System (Cont.)

\begin{tabular}{|c|c|c|c|c|c|c|c|}
\hline \multicolumn{2}{|r|}{ Target } & \multirow[b]{2}{*}{ Reaction } & \multirow{2}{*}{$\begin{array}{l}\text { Activation } \\
\text { Product }\end{array}$} & \multirow{2}{*}{$\begin{array}{r}\text { Product } \\
\text { Halflife }\end{array}$} & \multicolumn{3}{|c|}{$\begin{array}{c}\text { Activity } \\
\text { (decays/sec/gram of element) }\end{array}$} \\
\hline$z$ & Isotope & & & & Indtial & $1 \mathrm{~min}$ decay & 1 hour decay \\
\hline 80 & Mercury-196 & $n, \gamma$ & Mercury -197 & $64.1 \mathrm{~d}$ & 0.042 & 0.042 & 0.042 \\
\hline 80 & Mercury-196 & $\mathrm{n}, \gamma$ & Mercury-197m & $23.8 \mathrm{~h}$ & 0.004 & 0.004 & 0.004 \\
\hline 80 & Mercury-198 & $\mathrm{n}, \boldsymbol{\gamma}$ & Mercury-199m & $42.6 \mathrm{~m}$ & 0.004 & 0.004 & 0.002 \\
\hline 80 & Mercury-202 & $\mathrm{n}, \boldsymbol{\gamma}$ & Mercury-203 & $46.60 \mathrm{~d}$ & 0.001 & 0.001 & 0.001 \\
\hline 80 & Mercury-204 & $\mathrm{n}, \boldsymbol{\gamma}$ & Mercury-205 & $5.2 \mathrm{~m}$ & 0.203 & 0.178 & * \\
\hline 81 & Thallium-205 & $\mathrm{n}, \boldsymbol{\gamma}$ & Thallium-206 & $4.2 \mathrm{~m}$ & 0.651 & 0.552 & * \\
\hline 82 & Lead & & none" & & * & * & * \\
\hline 83 & Bismuth & & none $e^{b}$ & & * & * & * \\
\hline 84 & Polontum & & \multicolumn{3}{|c|}{ unstable/not found naturally } & & \\
\hline 85 & Astatine & & \multicolumn{3}{|c|}{ unstable/not found naturally } & & \\
\hline 86 & Radon & & \multicolumn{3}{|c|}{ unstable/not found naturally } & & \\
\hline 87 & Francium & & \multicolumn{3}{|c|}{ unstable/not found naturally } & & \\
\hline 88 & Radium & & \multicolumn{3}{|c|}{ unstable/not found naturally } & & \\
\hline 89 & Actinium & & \multicolumn{3}{|c|}{ unstable/not found naturally } & & \\
\hline 90 & Thorium-232 & $\mathrm{n}, \mathrm{r}$ & Thorium - 233 & $22.2 \mathrm{rn}$ & 11.9 & 11.5 & 1.83 \\
\hline 91 & Protactinium & & \multicolumn{3}{|c|}{ unstable/not found naturally } & & \\
\hline 92 & Uranium-238 & $\mathrm{n}, \boldsymbol{\gamma}$ & Urantum- 239 & $23.5 \mathrm{~m}$ & 10.1 & 9.81 & 1.72 \\
\hline
\end{tabular}

- None greater than 0.001 decays $/ \mathrm{sec} /$ gram of element $(<0.001$ Becquerel $/ \mathrm{g})$

*Less than 0.001 decays $/ \mathrm{sec} / \mathrm{gram}$ of element $(<0.001$ Becquerel/g)

The special case of ${ }^{208} \mathrm{BI}(\mathrm{n}, \gamma){ }^{210} \mathrm{BI} \mathrm{B}^{-}{ }^{210} \mathrm{Po}$ is discussed in the text under Phase 3. 
Table 2. Listing of Calculated Activities from Table 1 Having the Highest Activities as Defined in the Text

\begin{tabular}{|c|c|c|c|c|c|c|}
\hline \multicolumn{2}{|r|}{ Target } & \multirow{2}{*}{$\begin{array}{l}\text { Activation } \\
\text { Product }\end{array}$} & \multirow{2}{*}{$\begin{array}{l}\text { Product } \\
\text { Halflife }\end{array}$} & \multicolumn{3}{|c|}{$\begin{array}{c}\text { Activity } \\
\text { (decays/sec/gram of element) }\end{array}$} \\
\hline$z$ & Isotope & & & Initial & 1 min docay & 1 hour decay \\
\hline 4 & Beryllium-9 & Helium- 6 & $0.802 \mathrm{~s}$ & 1280 & * & * \\
\hline 13 & Aluminum-27 & Aluminum-28 & $2.25 \mathrm{~m}$ & 27.2 & 20.0 & * \\
\hline 21 & Scandium -45 & Scandium-46m & $18.7 \mathrm{~s}$ & 4825 & 522 & $*$ \\
\hline 23 & Vanadium-51 & Vanadium-52 & $3.76 \mathrm{~m}$ & 179 & 149 & 0.003 \\
\hline 25 & Manganese- 55 & Manganese- 56 & $2.58 \mathrm{~h}$ & 11.1 & 11.1 & 8.49 \\
\hline 27 & Cobalt-59 & Cobalt-60m & $10.48 \mathrm{~m}$ & 2.33 & 218 & 4.40 \\
\hline 29. & Copper-65 & Copper-66 & $5.10 \mathrm{~m}$ & 14.7 & 12.8 & 0.004 \\
\hline 34 & Selenium. 76 & Selenium $-77 \mathrm{~m}$ & $17.5 \mathrm{~s}$ & 568 & 52.8 & * \\
\hline 35 & Bromine -79 & Bromine -80 & $17.4 \mathrm{~m}$ & 29.1 & 28.0 & 2.67 \\
\hline 35 & Bromine- 81 & Bromine $-82 m$ & $6.1 \mathrm{~m}$ & 23.1 & 20.6 & 0.025 \\
\hline 45 & Rhodium-103 & Rhodium-104 & $42 \mathrm{~s}$ & 1543 & 573 & * \\
\hline 45 & Rhodium-103 & Rhodium-104m & $4.35 \mathrm{~m}$ & 360 & 307 & 0.025 \\
\hline 47 & Silver -107 & Silver -108 & $2.41 \mathrm{~m}$ & 509 & 382 & * \\
\hline 47 & Silver -109 & Silver -110 & $24.6 \mathrm{~s}$ & 8310 & 1532 & * \\
\hline 49 & Indium-115 & Indium-116 & $14.2 \mathrm{~s}$ & 1360 & 72.7 & $\star$ \\
\hline 49 & Indium-115 & Indiurn-116m & $54.2 \mathrm{~m}$ & 129 & 127 & 59.9 \\
\hline 49 & Indium-115 & Indium-116m' & $2.16 \mathrm{~s}$ & 127000 & 0.001 & * \\
\hline 53 & Iodine-127 & Iodine -128 & $25.0 \mathrm{~m}$ & 20.0 & 19.5 & 3.79 \\
\hline 56 & Barium-135 & Barium-136m & $0.31 \mathrm{~s}$ & 132 & * & * \\
\hline 59 & $\mid$ Praseodymium-141| & Praseodymium-142m & $14.6 \mathrm{~m}$ & 13.3 & 12.7 & 0.770 \\
\hline
\end{tabular}

aFor Initial Activity, $>100 \mathrm{dps} / g$; for 1 minute decay, $>10 \mathrm{dps} / g$; for 1 hour decay, $>1 \mathrm{dps} / \mathrm{g}$.

*Less than 0.001 decays/sec/gram of element $(<0.001$ Becquerel/g) 
Table 2. Listing of Calculated Activities from Table 1 Having the Highest Activities as Defined in the Text (Cont.)

\begin{tabular}{|c|c|c|c|c|c|c|}
\hline \multicolumn{2}{|r|}{ Target } & \multirow{2}{*}{$\begin{array}{l}\text { Activation } \\
\text { Product }\end{array}$} & \multirow{2}{*}{$\begin{array}{r}\text { Product } \\
\text { Halfilfe }\end{array}$} & \multicolumn{3}{|c|}{$\begin{array}{c}\text { Activity } \\
\text { (decays/sec/gram of element) }\end{array}$} \\
\hline $\mathrm{z}$ & Isotope & & & Initial & 1 min decay & 1 hour decay \\
\hline 62 & Samarium-152 & Samarilum-153 & $46.5 \mathrm{~h}$ & 1.19 & 1.19 & 1.17 \\
\hline 63 & Europium-151 & Europium-152m & $9.3 \mathrm{~h}$ & 132 & 132 & 123 \\
\hline 66 & Dysprosium-164 & Dysprosium-165 & $2.35 \mathrm{~h}$ & 86.2 & 85.8 & 64.2 \\
\hline 66 & Dysprosium- 164 & Dysprosium-165m & $1.26 \mathrm{~m}$ & 16400 & 9420 & 6.81 \\
\hline 67 & Holmium-165 & Holmium-166 & $26.8 \mathrm{~h}$ & 1.98 & 1.98 & 1.93 \\
\hline 68 & Erbiurn-166 & Erbium-167m & $2.27 \mathrm{~s}$ & 4790 & * & * \\
\hline 71 & Lutecium-175 & Lutecium-176m & $3.69 \mathrm{~h}$ & 4.78 & 4.77 & 3.96 \\
\hline 72 & Hafnium -177 & Hafnium-178m & $4.3 \mathrm{~s}$ & 110 & 0.007 & * \\
\hline 72 & Hafrium -178 & Hafnium-179m & $18.7 \mathrm{~s}$ & 2460 & 2.66 & * \\
\hline 75 & Rhenium-187 & Rhenium-188 & $16.7 \mathrm{~h}$ & 1.85 & 1.85 & 1.77 \\
\hline 77 & Iridium-191 & Iridium-192m & $1.4 \mathrm{~m}$ & 3120 & 1900 & * \\
\hline 77 & Iridium-193 & Iridium-194 & $19.38 \mathrm{~h}$ & 2.73 & 2.73 & 2.63 \\
\hline 79 & Gold-197 & Gold-198 & $2.695 \mathrm{~d}$ & 1.18 & 1.18 & 1.17 \\
\hline 90 & Thorium-232 & Thorium-233 & $22.2 \mathrm{~m}$ & 11.9 & 11.5 & 1.83 \\
\hline 92 & Uranium-238 & Uranium-239 & $23.5 \mathrm{~m}$ & 10.1 & 9.81 & 1.72 \\
\hline
\end{tabular}

a For Initial Activity, $>100 \mathrm{dps} / \mathrm{g}$; for 1 minute decay, $>10 \mathrm{dps} / \mathrm{g}$; for 1 hour decay, $>1 \mathrm{dps} / \mathrm{g}$.

*Less than 0.001 decays $/ \mathrm{sec} / \mathrm{gram}$ of element $(<0.001$ Becquerel/g) 
Table 3. Neutron Fluence Results from Irradlation

No. $1\left({ }^{252} \mathrm{Cf}\right)$

\begin{tabular}{|c|c|c|c|c|}
\hline Element & $\begin{array}{l}\text { Actlvation } \\
\text { Product }\end{array}$ & $\begin{array}{c}\text { Foll } \\
\text { Welght }(g)\end{array}$ & $\begin{array}{l}\text { Gamma Ray } \\
\text { Energy (kev) }\end{array}$ & $\begin{array}{l}\text { Neutron Fluence } \\
\text { per pass }\left(\mathrm{n} / \mathrm{cm}^{2}\right)^{\mathrm{a}}\end{array}$ \\
\hline Gold & ${ }^{198} \mathrm{Au}$ & 0.7502 & 411 & $7.5 \times 10^{5}$ \\
\hline Tungsten & ${ }^{187} W$ & 2.9598 & 479 & $7,6 \times 10^{5}$ \\
\hline
\end{tabular}

\footnotetext{
Actual fluence values recalculated from first report using redetermined absolute efflclency values and using the procedure from ASTM Standard Method E262 for gold. This procedure could only be used after the gold-cadmlum ratlos had been measured. See text under Irradlatlon \#4.
}

Table 4. Neutron Fluence Results from Irradlation

No. 2 (D-D Generator)

\begin{tabular}{|c|c|c|c|c|}
\hline Element & $\begin{array}{c}\text { Activation } \\
\text { Product }\end{array}$ & $\begin{array}{c}\text { Foll } \\
\text { Weight (g) }\end{array}$ & $\begin{array}{l}\text { Gamma Ray } \\
\text { Energy (kev) }\end{array}$ & $\begin{array}{l}\text { Neutron Fluence } \\
\text { per pass }\left(\mathrm{n} / \mathrm{cm}^{2}\right)^{a}\end{array}$ \\
\hline Copper & $\begin{array}{l}{ }^{64} \mathrm{Cu} \\
{ }^{64} \mathrm{Cu}\end{array}$ & $\begin{array}{l}9.294 \\
9.294\end{array}$ & $\begin{array}{l}511 \\
511\end{array}$ & $\begin{array}{l}3.0 \times 10^{5} \\
2.9 \times 10^{5 b}\end{array}$ \\
\hline Gold & ${ }^{198} \mathrm{Au}$ & 0.7653 & 411 & $2.7 \times 10^{5}$ \\
\hline Tungsten & ${ }^{187} W$ & 3.332 & 1497 & $3.4 \times 10^{5}$ \\
\hline
\end{tabular}

\footnotetext{
Actual fluence values recalculated from first report using redetermined absolute efficlency values and using the procedure from ASTM Standard Method E262 for gold. This procedure could only be used after the gold-cadmium ratios had been measured. See text under Irradlation \#4.

bThis value calculated for a continuous 4 hour irradlation at lower fluence instead of a single higher fluence Irradiation (See text).
} 
Table 5. Neutron Fluence Results from Irradlation

No. 3 (D.D Generator)

\begin{tabular}{|c|c|c|c|c|}
\hline Element & $\begin{array}{l}\text { Activation } \\
\text { Product }\end{array}$ & $\begin{array}{c}\text { Foll } \\
\text { Welght (g) }\end{array}$ & $\begin{array}{l}\text { Gamma Ray } \\
\text { Energy (K@V) }\end{array}$ & $\begin{array}{l}\text { Neutron Fluenoe } \\
\text { per pass }\left(\mathrm{n} / \mathrm{cm}^{2}\right)^{\mathrm{a}}\end{array}$ \\
\hline Gold & ${ }^{188} \mathrm{Au}$ & 0.7503 & 411 & $1.9 \times 10^{5}$ \\
\hline Copper & ${ }^{64} \mathrm{Cu}$ & 11.14 & 511 & $2.7 \times 10^{5}$ \\
\hline Tungsten & ${ }^{187} W$ & 3.331 & 473 & $2.0 \times 10^{5}$ \\
\hline
\end{tabular}

Table 6. Neutron Fluence Fesults from Irradlation

No. $4\left({ }^{252} \mathrm{Cf}\right)$

\begin{tabular}{|c|c|c|c|c|}
\hline Element & $\begin{array}{l}\text { Activation } \\
\text { Product }\end{array}$ & $\begin{array}{c}\text { Foll } \\
\text { Welght }(\mathrm{g})\end{array}$ & $\begin{array}{l}\text { Gamma Ray } \\
\text { Energy (kev) }\end{array}$ & $\begin{array}{l}\text { Neutron Fluence } \\
\text { per pass }\left(\mathrm{n} / \mathrm{cm}^{2}\right)^{a}\end{array}$ \\
\hline Gold & ${ }^{198} \mathrm{Au}$ & 0.3148 & 411 & $7.9 \times 10^{5}$ \\
\hline Copper & ${ }^{64} \mathrm{Cu}$ & 7.417 & 511 & $7.7 \times 10^{5}$ \\
\hline
\end{tabular}


Table 7. Neutron Fluenoe vs. Position in ${ }^{252} \mathrm{Cf}$ EDS Using Gold Folls

\begin{tabular}{|c|c|c|c|}
\hline Foll I.D. & Position in Contalner ${ }^{a}$ & $\begin{array}{l}\text { Relative } \\
\text { Fluence }\end{array}$ & $\begin{array}{l}\text { Measure Fluence } \\
\text { per passs }\left(n / \mathrm{orn}^{2}\right)\end{array}$ \\
\hline A-1 & Top/Left & 0.87 & $6.9 \times 10^{5}$ \\
\hline A-2 & Bottom/Left & 0.86 & $6.8 \times 10^{5}$ \\
\hline$A-3$ & Top/Middle & 1.13 & $8.9 \times 10^{5}$ \\
\hline A-7 & Middle/Middle & 1.00 & $7.9 \times 10^{5}$ \\
\hline A.5 & Bottom/Mlddle $e^{b}$ & 1.31 & $10.3 \times 10^{5}$ \\
\hline$A-4$ & Top/Right & 0.89 & $7.0 \times 10^{5}$ \\
\hline A.8 & Lower Middle/Right & 0.85 & $6.7 \times 10^{5}$ \\
\hline \multirow[t]{3}{*}{ A.6 } & Bottom/Right & 0.85 & $6.7 \times 10^{5}$ \\
\hline & & Average & $7.6 \times 10^{5}( \pm 17 \%)^{0}$ \\
\hline & & Range & $6.7 \times 10^{5}$ to $10.3 \times 10^{5}$ \\
\hline
\end{tabular}

${ }^{a}$ See Flgure 4 for diagram of positions in container.

bThis folld had moved somewhat by the time it was recelved back at NIST. Exact positlon during irradlation sequence is thus unknown, but fluence value is consistent with the position given here and shown in Figure 4.

Oncertalnty value shown is the 10 standard deviation of all elght folls. 
Table 8. Results from Cadmlum Ratlo Measurements

\begin{tabular}{|c|c|c|c|c|}
\hline \multirow[b]{2}{*}{ Irradlation Facillty } & \multirow[b]{2}{*}{$\begin{array}{c}\text { Gold Cadmium Ratlos } \\
\text { (This Study) }\end{array}$} & \multicolumn{3}{|c|}{$\begin{array}{c}\text { Previously Measured Cadmlum } \\
\text { Ratlos (Ref, 7) }\end{array}$} \\
\hline & & Gold & Copper & Cobalt \\
\hline D-D EDS (Irrad. \#3) & 5.0 & $\cdots \cdots$ & $\cdots$ & $\cdots$ \\
\hline${ }^{252} \mathrm{Cf}$ EDS (Irrad. \#4) & 8.3 & -..-- & $\cdots$ & $-\cdots-\infty$ \\
\hline NBSR RT-3 & 9.2 & 10.3 & 65 & 42 \\
\hline NBSR RT-1 & 18.3 & -... & $\cdots$ & $\cdots$ \\
\hline NBSR RT-4 & 82.7 & 87 & 540 & 390 \\
\hline
\end{tabular}

\footnotetext{
a See text about using caution In comparing different foll element cadmlum ratlos and even measurements for the same elernent such as gold when small differences in thickness can produce significant differences in neutron self-shielding factors.
} 
Table 9. Comparison of Calculated and Measured Radioactivities from One Pass in the 232 CF EDS

[Irradlations No, 1 (Tungsten) and No, 4 (Gold and Copper)]

\begin{tabular}{|c|c|c|c|c|c|c|}
\hline \multicolumn{2}{|r|}{ Tanget } & \multirow{2}{*}{$\begin{array}{c}\text { Activation } \\
\text { Product }\end{array}$} & \multirow{2}{*}{$\begin{array}{l}\text { Product } \\
\text { Halflife }\end{array}$} & \multirow{2}{*}{$\begin{array}{c}\text { Calculated } \\
\text { Inftial Activity } \\
(\mathrm{d} / \mathrm{g} / \mathrm{s})\end{array}$} & \multicolumn{2}{|c|}{ Measured Activity } \\
\hline 2 & Isotope & & & & $(d / s / g)$ & Gamma Ray \\
\hline 29 & Copper:- 63 & Copper-64 & $12.74 \mathrm{~h}$ & 0.458 & 0.374 & $511 \mathrm{keV}$ \\
\hline 74 & Tungsten-186 & Tungsten-187 & $23.9 \mathrm{~h}$ & 0.347 & 0.217 & $479 \mathrm{keV}$ \\
\hline 79 & Gold-197 & Gold-198 & $2.695 \mathrm{~d}$ & 1.18 & 1.08 & $411 \mathrm{keV}$ \\
\hline
\end{tabular}

"Calculated Initial Activity is that fourd in Table 1 of this report, calculated for the conditions described (thermal fluence $=1 \times 10^{6} \mathrm{n} \cdot \mathrm{cm}^{2}$ per pass). [Note from Table 6 that the ${ }^{232}$ Cf EDS puts out about 0.8 of this fluence/pass.]

Table 10. Comparison of Calculated and Measured Radioactivities Orie Pass in the D-D EDS (Irradiation No. 3)

\begin{tabular}{|c|c|c|c|c|c|c|}
\hline \multicolumn{2}{|r|}{ Target } & \multirow{2}{*}{$\begin{array}{l}\text { Activation } \\
\text { Product }\end{array}$} & \multirow{2}{*}{$\begin{array}{l}\text { Product } \\
\text { Halflife }\end{array}$} & \multirow{2}{*}{$\begin{array}{c}\text { Calculateda } \\
\text { Initial Activity } \\
(\mathrm{d} / \mathrm{g} / \mathrm{s})\end{array}$} & \multicolumn{2}{|c|}{ Measured Activity } \\
\hline $\mathrm{Z}$ & Isotope & & & & $(d / s / g)$ & Gamma Ray \\
\hline 29 & Copper. -63 & Copper-64 & $12.74 \mathrm{~h}$ & 0.458 & 0.127 & $511 \mathrm{keV}$ \\
\hline 74 & Tungsten-186 & Tungsten-187 & $23.9 \mathrm{~h}$ & 0.347 & 0.077 & $479 \mathrm{keV}$ \\
\hline 79 & Gold-197 & Gold-198 & $2.695 \mathrm{~d}$ & 1.18 & 0.342 & $411 \mathrm{keV}$ \\
\hline
\end{tabular}

a Calculated Initial Activity is that found in Table 1 of this report, calculated for the conditions described (thermal fluence $=1 \times 10^{6} \mathrm{n} \cdot \mathrm{cm}^{2}$ per pass). (Note from Table 5 that the D-D EDS actually puts out only about $k$ of this fluence/pass.] 
Table 11. Comparison of Calculated and Measured Radioactivities from One Pass in a Simulated EDS

\begin{tabular}{|c|c|c|c|c|c|c|}
\hline \multicolumn{2}{|r|}{ Target } & \multirow[b]{2}{*}{$\begin{array}{l}\text { Activation } \\
\text { Product }\end{array}$} & \multirow[b]{2}{*}{$\begin{array}{l}\text { Product } \\
\text { ilalflife }\end{array}$} & \multirow{2}{*}{$\begin{array}{c}\text { Calculated } \\
\text { Intitial Activity } \\
(\mathrm{d} / \mathrm{g} / \mathrm{s})\end{array}$} & \multicolumn{2}{|c|}{ Measured Activityb } \\
\hline 2 & Isotope & & & & $\begin{array}{c}\text { Initial Activity } \\
(\mathrm{d} / \mathrm{s} / \mathrm{g})\end{array}$ & Gamma Ray \\
\hline 24 & Chromium- 50 & Chromfum- 51 & $27.71 \mathrm{~d}$ & 0.002 & 0.003 & $320 \mathrm{keV}$ \\
\hline 26 & Iron -58 & Iron -59 & $44.50 \mathrm{~d}$ & $<0.001^{\circ}$ & 0.0001 & $1099 \mathrm{keV}$ \\
\hline 27 & Cobalt -59 & Cobalt -60 & $5.272 \mathrm{y}$ & 0.002 & 0.002 & $1332 \mathrm{keV}$ \\
\hline 30 & $\operatorname{zinc}-64$ & $2 \operatorname{lnc}-65$ & $243.9 \mathrm{~d}$ & $<0.001$ & 0.0001 & $1115 \mathrm{keV}$ \\
\hline 37 & Rubidium-85 & Rubidium-86 & $18.65 \mathrm{~d}$ & 0.001 & 0.001 & $1076 \mathrm{keV}$ \\
\hline 38 & Strontium -84 & Strontium-85 & $64.84 \mathrm{~d}$ & $<0.001$ & 0.00004 & $514 \mathrm{keV}$ \\
\hline 51 & Antimony -123 & Antimony - 124 & $60.3 \mathrm{~d}$ & 0.003 & 0.002 & $1691 \mathrm{keV}$ \\
\hline 55 & Cesium-133 & Cesium-134 & $2.06 \mathrm{y}$ & 0.002 & 0.002 & $796 \mathrm{keV}$ \\
\hline 56 & Barfum-130 & Barium-131 & $11.8 \mathrm{~d}$ & $<0,001$ & 0.00004 & $496 \mathrm{keV}$ \\
\hline 63 & Europium-151 & Europium-152 & $13.4 \mathrm{y}$ & 0.020 & 0.018 & $964 \mathrm{keV}$ \\
\hline 63 & Europium-151 & Europium-152 & $13.4 \mathrm{y}$ & 0.020 & 0.017 & $1408 \mathrm{keV}$ \\
\hline 65 & Terbium- 159 & Terbium- 160 & $72.3 \mathrm{~d}$ & 0.014 & 0.011 & $879 \mathrm{keV}$ \\
\hline 72 & Hafnium- 180 & Hafnium-181 & $42.39 \mathrm{~d}$ & 0.003 & 0.003 & $482 \mathrm{keV}$ \\
\hline 73 & Tantalum-181 & Tantalum-182 & $114.5 \mathrm{~d}$ & 0.008 & 0.007 & $1221 \mathrm{keV}$ \\
\hline
\end{tabular}

- Calculated Initial Activity is that found in Table 1 of this report calculated for the conditions described (thermal fluence $=1 \times 10^{6} \mathrm{n} \cdot \mathrm{cm}^{2}$ per pass).

${ }^{b}$ In this Table, the measured activity was obtained using the NBSR RT-3 irradiation facility at. NIST, which was shown to be very similar to the $252 \mathrm{Cf}$ EDS facility (see text). The counting data this obtained was corrected to the experimentaily determined $252 \mathrm{Cf}$ EDS fluence of $8 \times 10^{5} \mathrm{n} \cdot \mathrm{cm}$ per pass.

- Isotopes having calculated initlal activities of less than 0.001 decays/gram/second were not included in Table 1 , as specified in the text. 


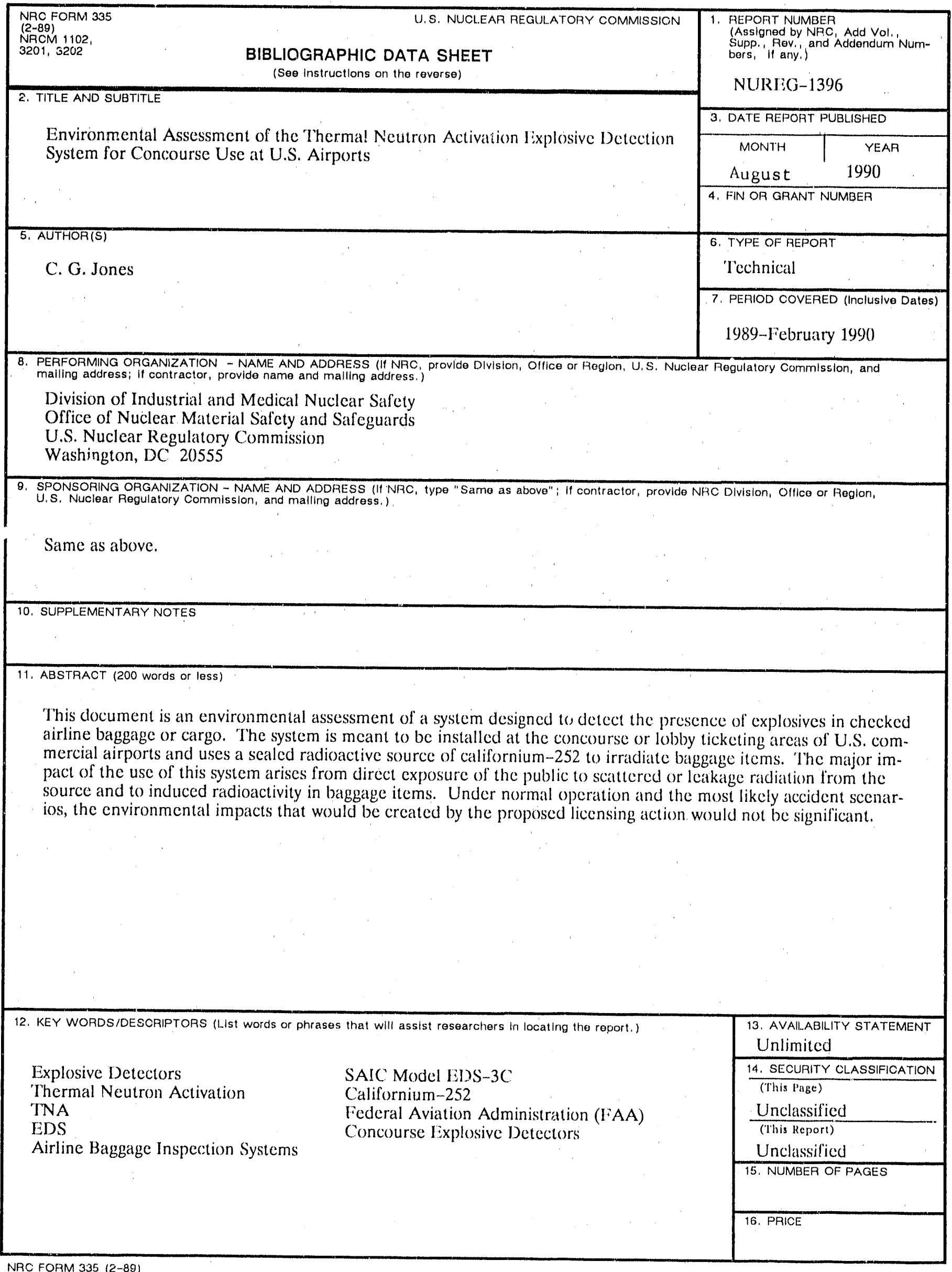



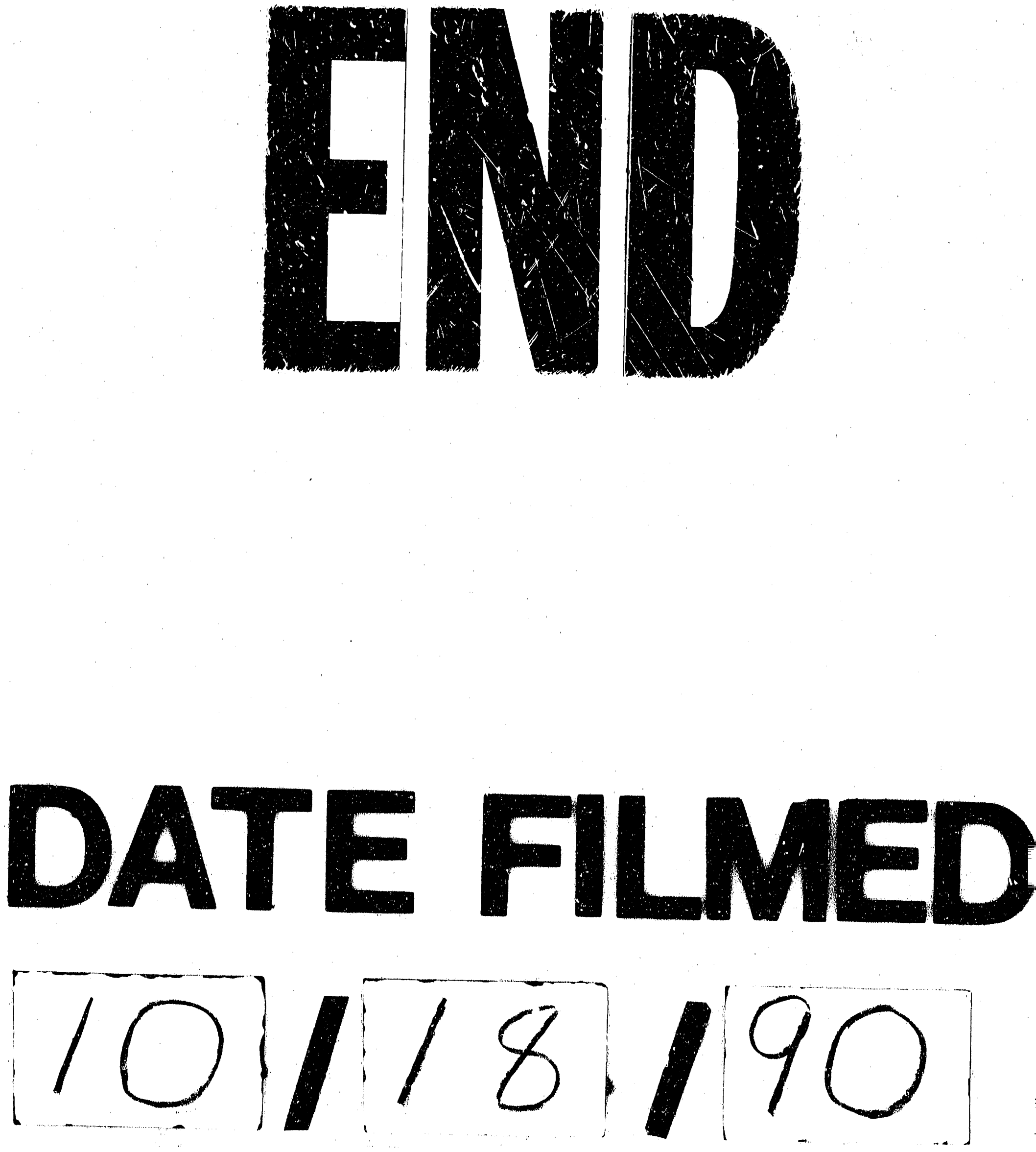
